\title{
Alfons Höcherl
}

\section{Zur Übersetzungstechnik des altrussischen \\ "Jüdischen Krieges" \\ des Josephus Flavius}

Verlag Otto Sagner München · Berlin · Washington D.C.

Digitalisiert im Rahmen der Kooperation mit dem DFG-Projekt „Digi20“

der Bayerischen Staatsbibliothek, München. OCR-Bearbeitung und Erstellung des eBooks durch den Verlag Otto Sagner:

http://verlag.kubon-sagner.de

(c) bei Verlag Otto Sagner. Eine Verwertung oder Weitergabe der Texte und Abbildungen, insbesondere durch Vervielfältigung, ist ohne vorherige schriftliche Genehmigung des Verlages unzulässig. 


\section{SLAVISTISCHE BEITRÄGE}

Unter Mitwirkung von M. Braun, Göttingen - †P. Diels, München - J. Holthusen, München - E. Koschmieder, München - W. Lettenbauer, Freiburg/Br. J J. Matl, Graz

F. W. Neumann, Mainz - K.-H. Pollok, Regensburg - L. Sadnik-Aitzetmüller, Graz $\cdot J$. Schütz, Erlangen

HERAUSGEGEBEN VON † A. SCHMAUS, MÜNCHEN

Technische Redaktion: P. Rehder, München

Band 46 


\section{ALFONS HÖCHERL}

\section{ZUR ÜBERSETZUNGSTECHNIK DES ALTRUSSISCHEN „ÜDISCHEN KRIEGES" DES JOSEPHUS FLAVIUS}

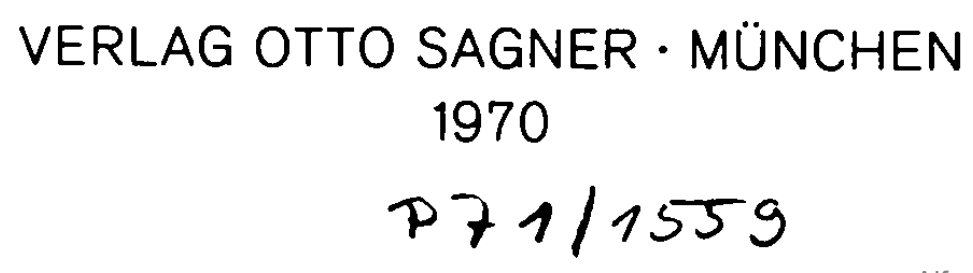


Copyright: Verlag Otto Sagner, München 1970 Abteilung der Fa. Kubon \& Sagner, München Druck: Fa. W.u.I.M. Salzer

8 München 2, Schleißheimerstr. 20 


\section{INHALTSVERZEICHNIS}

Seite

Literaturverzeichnis

Abkurzungen

15

Einleitung

1. Kapitel: BESONDERE STILISTISCHE TENDENZEN

2. Kapitel: LEXIK UND WORTBILDUNG

1. Die Behandlung der Termini aus dem politischadministrativen und kriegstechnischen Bereich 31

11. Die Wiedergabe und Verwendung zusammengesetzter wörter

3. Kapitel: AUS DER SYNTAX

A. Kasuelehre

1. Akkusativ

II. Dativ

111. Genitiv

B. Prapositionen

1. Prapositionen mit einem Kasus

II. Präpositionen mit zwei Kasus

111. Prapositionen mit drei Kasus

C. Bypotaxe

1. Relativsatze 101

II. Objektsätze 105

III. Finale Adverbialsätze

IV. Konsekutivsatze

v. Konditionalsatze

VI. Konzessivsätze

VII. Kausalsätze

VIII. Temporalsatze 
Seite

D. Modi im unabhängigen Satz $\quad 124$

1. Realis 124

11. Irrealis 125

III. Potentialls 125

IV. Imperativ 127

E. Partizipialkonstruktionen $\quad 128$

1. Das Partizip als Ergänzung eines Verbalbegrifts

11. Das Partizip als năhere Bestimmung eines substantivs

111. Das Partizip zum Ausdruck adverbieller Beziehungen

IV. Das Partizip des Futurs zum Ausdruck finaler Beziehungen

V. Das absolute Partizip (Accusativus abso(utus)

F. Verbaladjektive

1. Verbaladjektiv auf - reos

11. Verbaladjektiv auf - tos

G. Infinitivkonstruktionen

1. Der finale objektsinfinitiv

11. Der Akkusativ mit dem Infinitiv (AcI)

111. Der substantivierte oder artikulierte Intinitiv

H. Artikel 


\section{BENUTZTE LITERATUR}

1. Quellenwerke

FLAVII IOSEPHI OPERA edidit et apparatu critico instruxit BENEDICTUS NIESE. Vol. VI. De bello Iudaico Libri VII. Berlin 1894. (=N)

FLAVIUS IOSEPHUS De bello iudaico - Der jủdische Krieg. Zweisprachige Ausgabe der sieben Bücher. Herausgegeben und mit einer Einleitung sowie mit Anmerkungen versehen von OTTO MICHEL und OTTO BAUERNFEIND. Darmstadt. Band 1. 1951. Band 2,1. 1963.

LA PRISE DE JERUSALEM de Josèphe le Juif. Text vieux-russe publié intégralement par V. ISTRIN. Imprimé sous la direction de ANDRE VAILLANT. Traduit en francais par PIERRE PASCAL. Tome 1-2. Paris 1934-1938. (= I)

MESCERSKIJ N.A. Istorija Iudejskoj vojny Iosifa Flavija v drevnerusskom perevode. Moskva-Leningrad 1958. (= M)

2. worterbücher

ACHMANOVA O.S. Slovaŕ lingvistiCeskich terminov. Moskva 1966. AN SSSR Slovaŕ drevnerusskogo jazyka 11-14 vv. Vvedenie, instrukcija, spisok istornikov, probnye stat`i. Pod redakciej rlena-korrespondenta AN SSSR R.I. AVANESOVA. Moskva 1966. Drevnegre Cesko-russkij slovaŕ. Sostavil I.CH. DVORECKIJ. Pod redakciej Clena-korrespondenta Akademi $i$ Nauk SSSR prof. S.I. SOBOLEVSKOGO. TOm 1-2. Moskva 1958.

FASMER M. /VASMER/ EtimologiCeskij slovar russkogo jazyka. Perevod s nemeckogo i dopolnenija J.N. TRUBACEVA. Tom 1. Moskva 1964. Tom 2. 1967.

MIKLOSICH F. Lexicon palaeoslovenico-graeco-latinum. Wien 1862-1865 (Reprint Aalen 1963).

OZEgov S.I. Slovaŕ russkoqo jazyka. 7 Moskva 1959.

PAPE W. Griechisch-deutsches Handwörterbuch. Band 1-2. Braunschweig 1914. 
SREZNEVSKIJ I:I. Materialy dlja slovarja drevne-russkogo jazyka po pismennym pamjatnikam. Tom 1-3. Sankt-Peterburg 18931903. Dopolnenija 1912 (Reprint Moskva 1958).

VASMER M. Russisches etymologisches Wörterbuch. Band 1-3. Heidelberg 1953-1958.

VINOGRADOVA V;L. Slovaŕ-spravoZnik 'slova o polku Igoreve'. Vypusk 1. Moskva-Leningrad 1965. Vypusk 2. Leningrad 1967.

\section{Sekundärliteratur}

ADRIANOVA-PERETC V.P. "Slovo o polku Igoreve" 1 pamjatniki russkoj literatury $11-13$ vekov. Leningrad 1968 .

AN SSSR Grammatika russkogo jazyka. Tom 1-2. Moskva 1960. ANGEIOV B. Iosif Flavij v južnoslavjanskich literaturach, in TODRL TOM 19, S. 255-261.

ANGELOVA Die Partizipialkonstruktionen in den altbulgarischen Sprachdenkmälern. Sofia 1929.

BARSOV E.V. Slovo o polku Igoreve kak chudožestvennyj pamjatnik Kievskoj družinnoj Rusi. Tom 1, Moskva 1887.

BARTULA CZ. Skladnia zdania pojedynczego w języku starocerkiewno-slowiahskim. Kraków 1969 = Zeszyty Naukowe Uniwersytetu Jagiellońskiego CLXXXV. Prace językoznawcze. Zeszyt 22.

BAUER J. Vliv Fettiny a latiny na vívoj syntaktické stavby slovenských jazyku, in: Ceskoslovenské płednaśki pro IV. mezinárodný sjezd slavistú v Moskve. Praha 1958.

BAUEROVI J. a M. Staroslovernské aste, in: Slavia 26 (1957), S. 157-179.

BEHRENDTS A. Die Zeugnisse vom Christentum im slavischen "De bel10 Iudaico" des Josephus. Leipzig 1906 = Texte und Untersuchungen zur Geschichte der altchristl. Literatur. NF Band 14, Heft 3 .

BEHRENDTS A. - GRASS K. Flavius Josephus "Vom Jüdischen Kriege" . Buch 1-4. Nach der slavischen Ubersetzung deutsch herausgegeben und mit dem griechischen Text verglichen. Tartu 1924-1927= Acta et Commentationes Universitatis Dorpatiensis. Vol. 5. Fasc. 9-10. Serie B: Humaniora. 
BENESEVIC V.N. Iz istoril perevodnoj literatury $v$ Novgorode v konce 15 stoletija, in: Sbornik statej $v$ cest' A.I. Sobolevskogo. Leningrad 1928 , s. 378-380.

BERNSTEJN S.B. (red.) Tvoritel 'nyj padě̃ v slavjanskich jazykach. Moskva 1958.

BICKERMANN E. Sur la version vieux-russe de Flavius-Josèphe, in: Annuaire de l'Institut de Philologie et d'Histoire orientales et slaves. Tome 4.1. Bruxelles 1936, S.53-84.

BIRNBAUM H. Zur Aussonderung der syntaktischen Gräzismen im Altkirchenslavischen, in: Scando-Slavia 4, Kopenhagen 1958, S.239257 .

BIRNBAUM H. Untersuchungen $z u$ den zukunftsumschreibungen mit dem Infinitiv im Altkirchenslavischen. Stockholm 1958.

BLASS F. - DEBRUNNER A. Gramatik des neutestamentlichen Griechisch. ${ }^{12}$ Gottingen 1965.

BORKOVSKIJ V.I. Sintaksis drevnerusskich gramot (Sloznoe predloženie). Moskva 1958.

BORKOVSKIJ V.I. Sintaksis drevnerusskich gramot (Prostoe predloŽenie). L' vov 1949.

BORKOVSKIJ V.I. - KUZNECOV P.S. IstoriČskaja grammatika russkogo jazyka. Moskva 1963.

BRÄUER H. Der persönliche Agens beim Passiv im Altbulgarischen. Wiesbaden 1952 .

BRAUUER H. Zur Entwicklung der ursprünglichen Abwehrsätze im Altkirchenslavischen und Altrussischen, in: Festschrift für Max Vasmer, Wiesbaden 1956 , S. 74-82.-

BRAUER H. Untersuchungen zum Konjunktiv im Altkirchenslavischen und Altrussischen. Teil 1. Die Final- und abhängigen Helschesätze. Wiesbaden 1957.

BRAUUER H. Zur Frage der altrussischen Ubersetzungsliteratur. Der Wert syntaktischer Beobachtungen fur die Bestimmung der altrussischen Ubersetzungsliteratur, in: ZfSIPh 27, 1940, S.322-347. BULACHOVSKIJ L.A. Istoričeskij kommentarij k russkomu literaturnomu jazyku. ${ }^{5}$ Kiev 1958. 
BUSLAEV F.I. IstoriCeskaja grammatika russkogo jazyka. ${ }^{3}$ Moskva 1959.

CHODOVA K.I. Sistema padežej starosląjanskogo jazyka. Moskva 1963.

DOSTÁ A. Slovanský płeklad byzantské kroniky Georgia Hamartola, in: Slavia 32 (1963), S. 375-384).

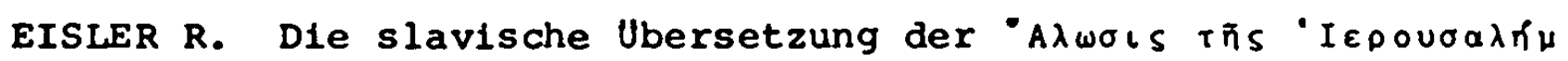
des Josephus Flavius, in: BS 2 (1930), S. 305-373.

EISLER R. IHEOYE BAEIAEYE OY BAEIAEYIAL. Die messianische Unabhängigkeitsbewegung vom Auftreten Johannes des Tăufers bis 2 um Untergang Jakobs des Gerechten nach der neu erschlossenen "Eroberung von Jerusalem" des Josephus Flavius und den christlichen Quellen. Band 1-2. Heidelberg 1929-1930.

FORSSMANN TH. Die Ubertragung der griechischen Partizipialkonstruktionen in dem Ostromirschen Evangelium. Straßburg 1877. FRUCHTEL L. Griechische Grammatik. ${ }^{4}$ Munchen 1955. GERKULES ST. Staroslavjanskie predlogi, in: Issledovanija po sintaksisu staroslavjanskogo jazyka. Praga 1963, S. 313-368. GRUNENTHAL O. Die Ubersetzungstechnik der altkirchenslavischen Evangelienubersetzung, in: AfslPh Band 31, 1910, S. 321-366, Band 32,1911, S. 1-48.

HORAIEK K. Evangeliár̆e a Ctveroevangelia. Přispěvky $k$ textové kritice a $k$ dẽjinám staroslovẽnského prékladu evangelia. Praha 1954.

ISTRIN V.M. "Iudejsłaja vojna" Iosifa Flavija v drevnem slavjano-russkom perevode, in: Ucenve zapiski vysక̌j skoly goroda Odessy. Tom 2. Odessa 1922.

ISTRINA E.S. SintaksiČeskie javlenija Sinodal 'nogo spiska I Novgorodskoj letopisi = Izvestija Otdelenija russkogo jazyka 1 slovesnosti Rossijskoj Akademil Nauk. Petrograd 1920. Tom 24. Kniga 2.

IVANOVA V.A. Padežnye konstrukcil bez predlogov, vyražavšle pričinnoe značenie $v$ drevnerusskom jazyke, in: voprosy istoril russkogo jazyka. Moskva 1959, S. 276-302. 
JAGIC̄ V. Beiträge zur slavischen Syntax. Wien 1899.

JAKUBINSKIJ L.P. Istorija drevnerusskogo jazyka. Moskva 1953. JANKE G. Der Ausdruck des Passivs im Altrussischen. Berlin 1960.

KOPYLENKO M.M. Gipotaktičeskie konstrukcil slavjano-russkogo perevoda "Chroniki" Georgija Amartola, in: Vizantijskij vremenik. Tom 12. Moskva 1957, S. 232-241.

KOPYLENKO M.M. O jazyke drevne-russkogo perevoda "Istorii Iudejskoj vojny" Iosifa Flavija (Glagol'no-imennye frazeologizmy) in: Vizantijskij vremennik. Tom 20. Moskva 1961, S. 168-183. KOTLJAREVS'KYJ I.P. Eneïa. Kyïv 1963.

KRULL E. Zur Bildsprache des altrussischen Josephus Flavius. Bonn 1959. (Diss).

KUHNER R. - GERTH B. Ausfürliche Grammatik der griechischen Sprache. Teil 1-2. ${ }^{3}$ Hannover-Leipzig 1890 (Reprint Darmstadt 1966).

KURZ J. K otázce Clenu v jazycích slovánských se zvlástním zetelem $k$ staroslovenstine, in: BS 7 (1937/38), S. 212-340; $8(1939 / 46)$, S. 172-288.

KURZOVA H. Zur syntaktiscinen Struktur des Griechischen/Infinitiv und Nebensatz/. Amsterdam-Prag 1968.

KURZOVA H. Zum Charakter des griechischen Artikels, in: Listy filologické. 92,3. Praha 1969, S. 198-205.

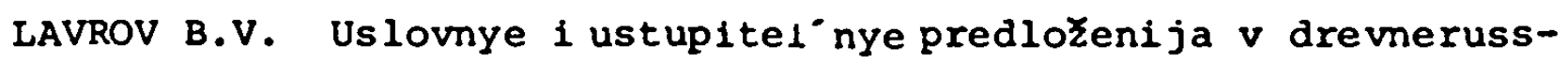
kom jazyke. Moskva-Leningrad 1941.

LEBEDEVA I.N. Pozdnie greteskie chroniki 1 ich russkie 1 vostotnye perevody. Leningrad 1968 = Palestinskij sbornik. Vypusk 18 (81).

IESKIEN A. Die Ubersetzungskunst des Exarchen Johannes, in: AfSIPh 25, 1903, S. 48-60.

LESKIEN A. Handbuch der altbulgarischen Sprache. ${ }^{8}$ Heidelberg 1962 .

LESKIEN A. Zum Sestodnev des Exarchen Johannes, in: AfSIPh 26,1904, S. $1-70$. 
IICHACEV D.S. (Hrsg.) Slovo o polku Igoreve. Leningrad 1967. LOMTEV T.P. OCerki po istoriCeskomu sintaksisu russkogo jazyka. Moskva 1956.

MESCERSKIJ N.A. Iskusstvo perevoda Kievskoj Rusi, in: TODRL. Tom 15. Moskva-Leningrad 1958, S. 54-72.

MESCERSKIJ N.A. K voprosu ob 1 zučenil perevodnoj pismennosti Kievskogo perioda, in: Učenye zapiski Karelo-Finskogo pedinstituta. Tom 2. Vypusk 2. Petrozavodsk 1956, S. 198-219.

MESCERSKIJ N.A. $\mathrm{K}$ voprosu o datirovke Vilenskogo chronografa, in: TODRL. Tom 13. Moskva-Leningrad 1957, S. 57-65.

MESCERSKIJ N.A. O sintaksise slavjanorusskich perevodnych proizvedenif, in: Teorija 1 kritika perevoda. Leningrad 1962,5:83-103. MESCERSKIJ N.A. Problemy izučenija slavjano-russkoj perevodnoj literatury 11-15 vv., in: TODRL. Tom 20. Moskva-Leningrad 1964, S. 180-231.

MESCERSKIJ N.A. Značenie drevneslavjanskich perevodov dija vosstanovlenija ich archetipov. Moskva 1958.

MIKLOSICH F. Vergleichende Grammatik der slavischen Sprachen. Band 4. Syntax. Heidelberg 1926.

NEXASEK L. Staroslovẽnské dativni vazby participiální a jejlch předlohy $v$ reckém textu evangelif, in: Slavia 24 (1955), S. 1320.

POSPELOV N.S. Izmenenija v stroe složnopodčinennogo predloženija. Moskva 1964 - AN SSSR రcerki po istoričeskoj grammatike russkogo literaturnogo jazyka $19 \mathrm{v}$. Tom 5 .

POTEBNJA A.A. Iz zapisok po russkoj grammatike. Tom 1-2. Moskva 1958. Tom 3. 1968.

RUZICKA R. Das syntaktische system der altslavischen Partizipien und sein Verhăltnis zum Griechischen. Berlin 1963.

RUZICKA R. Griechische Lehnsyntax im Altslavischen, in: ZfSl

3. Heft 2-4, (1958) S.173-185.

కACHMATOV A.A. Sintaksis russkogo jazyka. Leningrad 1925. 
SCHMID H.F. Die Sprache der kirchenslavischen Ubersetzung der Synagoge des Joh. Scholasticus. Leipzig 1922.

SCHUMANN K. Die griechischen Lehnbildungen und Lehnbedeutungen im Altbulgarischen. Berlin 1958.

SCHWYZER E. Griechische Gramatik. Band 2. Syntax und syntaktische Stilistik. München 1950.

SŁONSKI ST. Die Ubertragung der griechischen Nebensatzkonstruktionen in den altbulgarischen Sprachdenkmälern. Kirchhain N. $-L$. 1908.

Slovo o polku Igoreve. PoetiZeskie perevody 1 pereloženija. Pod obščej redakciej V. RZIGI, V. KUZ'MINOJ 1 V. STELLECKOGO. MoskVa 1961 .

SOBOLEVSKIJ A.I. Lekcil po istorii russkogo jazyka. ${ }^{4}$ Moskva 1907.

SOBOLEVSKIJ A.I. Materialy $i$ issledovanija $v$ oblasti slavjanskoj filologii 1 archeologil, in: Sbornik otd. russkogo jazyka 1 slovesnosti AN, Tom 88, Nr. 3, S. 1-286.

SPERANSKIJ M.M. Zu den slavischen Ubersetzungen der griechischen Florilegien, in: AfS1Ph 15, 1893, S. 545-555.

SPRINCAK J.A. Očerk russkogo istoričeskogo sintaksisa. Prostoe predloženie. Kiev 1960. Složnoe predloženie. 1964.

TAUSCHER-KIRSCHBAUM Grammatik der russischen Sprache. Berlin 1958.

TOPOROV V.N. Lokativ v slavjanskich jazykach. Moskva 1961.

VJALKINA L.V. Grečeskie paralleli složnych slov v dreverusskom jazyke 11-14 vv. , in: Leksikologija i slovoobrazovanie drevnerusskogo jazyka. Moskva 1966, S. 154-188.

VONDRAK W. Vergleichende slavische Grammatik. Band 2. Formenlehre und syntax. ${ }^{2}$ Göttingen 1928.

WEINREICH U. Languages in Contact. New York 1953.

Dank des Entgegenkommens des 'Institut d'Etudes Slaves' in Paris wurde mir außerdem die Auswertung unveröffentlichter Fragmente von V.M.ISTRINs geplantem "Issledovanie" zu seiner Textausgabe ermöglicht. Es handelt sich dabel um Schreibmaschinendurchschläge 
eines Teils des im Leningrader Archiv der Akademie der Wissenschaften der UdSSR (fond 332, opis 1, Nr.7) aufbewahrten ISTRINNachlasses. 


\section{ABKURZUNGEN}
AfSlPh = Archiv für Slavische Philologie
BS = Byzantinoslavica
ZfSl = Zeitschrift für slawistik
ZfSlPh = Zeitschrift für Slavische Philologie 


\section{EINLEITUNG}

Die vorliegende Arbeit will versuchen aufzuzeigen, welche sprachlichen Mittel der Ubersetzer des $\Pi \delta \lambda \varepsilon \mu \circ S^{\prime} I 0 u \delta a i x \delta s$ verwandte und wie er sie einsetzte, um in der jungen, noch nicht festgefügten Sprache des Altrussischen wiederzugeben, was der jüdische Geschichtsschreiber in einem unter Anlehnung an klassische Vorbilder höchst ausgefellten Griechisch verfasst hatte.

Dabei soll zunächst die der Ubersetzung zugrundeliegende Vorlage ermittelt werden, um dann der altrussischen Fassung gegenubergestellt und mit ihr verglichen $z u$ werden. Vergleichspunkte sind (neben einem allgemeinen Vergleich in inhaltlicher und stilistischer Hinsicht) die Lexik und einzelne syntaktische Probleme. Bel der Gegenuberstellung der beiden Texte wird in der Regel vom Griechischen ausgegangen, wie auch bei der Behandlung und Einteilung der einzelnen Abschnitte die Terminologie der klassischen Schulgrammatik Verwendung findet. Aufgrund der unten näher erlăuterten Besonderheiten der Ubersetzung ist bei den angefuhrten Textbeispielen nicht immer eine volle Ubereinstimung festzustellen, doch wurde darauf geachtet, das die beiden Texte zumindest in der Darstellung des gerade behandelten Problems kongruieren.

Der griechische Text wird zitiert nach der Ausgabe von BENEDIKT NIESE 1), der altrussische nach der von N.A. MESCERSKIJ ${ }^{2}$. Dabei findet die vereinfachte schreibung MESCERSKIJs aus drucktechnischen Gründen auch dann Anwendung, wenn eine Stelle ausnahmswe1se nach der Ausgabe von ISTRIN 3) zitiert wird. Nach den einzelnen Textbeispielen folgt jeweils in runden Klammern der Kennbuchstabe der betreffenden Ausgabe ( $I=$ ISTRIN, $M=$ MESCERSKIJ, $N=N I E S E)$, dahinter die Seiten- und zeilenangabe. Diese zitierweise wurde der sonst ublichen (Einteilung nach Buch, Kapitel, Abschnitt) vorgezogen, da elnerseits auf diese Weise ein schnelleres Auffinden einer Stelle in den oft uberlangen Abschnitten gesichert 1st, andererseits aber auch die Kapiteleinteilung MESCERSKIJs von der der grlechischen (und ISTRINschen) Ausgabe mitunter erheblich abweicht. 
1. Handschriften und Ausgaben

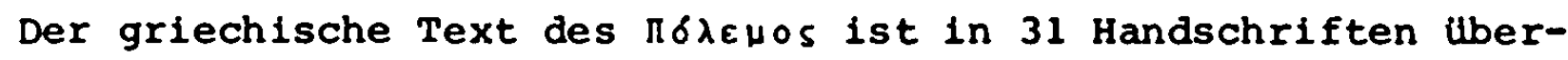
liefert. NIESE benützt als Grundlage seiner Ausgabe vor allem die sieben folgenden Codices: Parisinus (P), Ambrosianus (A), Marcianus (M), Laurentianus (L), Vaticanus (V), Romanus (R) und Codex Urbinas (C) 4). Davon bilden in textkritischer Hinsicht $P$ und $A$ sowle $V$ und $R$ je eine Einhelt, MLC neigen teilweise zur einen, tellweise zur anderen Gruppe. Allgemein sind jedoch die Abweichungen der griechischen Lesarten voneinander nicht sehr bedeutend.

Im Altrussischen sind uns 30 Handschriften der Ubersetzung bekannt, davon drel nicht erhalten. Die übrigen befinden sich in Leningrad (14), Moskau (12) und Wilna (1) 5). Die erste Ausgabe des altrussischen Textes, die in den Jahren 1934-38 von ISTRIN besorgt und vom Institut d'Etudes Slaves in Paris publiziert wurde ${ }^{6)}$, basiert vor allem auf der Handschrift des Archivs des AuBenministeriums (Archivskij spisok $=A$ ) und der des Klosters Volokolamsk (Volokolamskij = Vol.); abweichende Lesarten sind nach folgenden Handschriften gegeben: Akademiceskij ( = Ak.), Barsovskij (= BARSOV), Kirillo-Belozerskij, Makarovskij und Rumjanceva, insgesamt sind also 9 Manuskripte berücksichtigt. MESCERSKIJ legt seiner Ausgabe den Text des 'Vilenskij chronograf' zugrunde, behauptet aber auch, alle restlichen Handschriften $z u$ berücksichtigen. 7)

11. Kurzer Uberblick uber die Forschungsgeschichte

8)

Seit der deutschen Ubersetzung der ersten vier Bücher der altrussischen 'Iudeiskaja vojna' durch BEHRENDTS und GRASS im Jahre $1924^{9)}$ bzw. schon seit der Veröffentlichung eines Artikels des ersteren im Jahre 1906 unter dem Titel "Die Zeugnisse vom Christentum im slavischen 'De bello Iudaico' des Josephus" 10) entbrannte vor allem unter den Religionshistorikern ein reges Interesse für die Frage, wo die Quellen zur altrussischen Ubersetzung zu suchen seien. AnlaB dafür waren einige nur in dieser Version enthaltene Berichte über das Auftreten Christi und Johannes des Täufers. BEHRENDTS schrieb sie der Feder des Jose- 
phus selbst $z u$ und setzte dementsprechend als Vorlage für die slavische Ubersetzung einen von der bekannten griechischen Version abweichenden Text voraus, als welchen er eine in der aramäischen Muttersprache des Josephus verfaßte Urfassung postulierte. In seinem Artikel "Iudeiskaja vojna Iosifa Flavija $v$ drevnem slavjanorusskom perevode" 11) schloB sich ISTRIN dieser Ansicht von BEHRENDTS weitgehend an, doch distanzierte er sich später von seiner damaligen Auffassung. 12)

Einige Jahre später griff ROBERT EISLER in seinem zweibăndigen Werk IHIOY BAEIAEYI OY BAIIAEYIAL 13) die Hypothese von einer verschollenen aramäischen Urfassung von neuem auf. Er verfocht die Meinung, die Ubersetzung ins Altrussische sei von einer griechischen Redaktion dieses aramäischen Prototyps erfolgt und zwar wort für wort, so daß durch eine wortwörtliche Rulckubersetzung des altrussischen Textes ins Griechische die genaue Vorlage mühelos rekonstruiert werden könne. Er schlägt denn auch selbst eine Reihe rekonstruierter "Originalausdrukke" vor, die philologisch jedoch unhaltbar sind 14).

ISTRIN, der inzwischen seine Textedition vorbereitet und sich besser als irgendein anderer in die Materie eingearbeitet hatte, reagierte scharf auf die Spekulationen EISLERs und stellte im Entwurf der geplanten Einführung zu seiner Ausgabe seinen gegensätzlichen Standpunkt deutlich heraus: "...l) Avtor/ d.1.EISLER/ priznaet sustestvovanie dvuch redakcij ('izdanij', po ego terminologii) 'Istorii' Iosifa-odnoj, napisannoj $v$ 71-m godu 1 byvకej perevodom s redakcii aramejskoj, 1 drugoj, peredelannoj iz pervoj Iosifom posle 75 goda dlja rimskich Citatelej: ja Ze priznaju suščstvovanie tol'ko odnoj redakcii (izdanija), napisannoj v 75-79 godach. 2) Avtor priznaet, Cto slavjanskij perevod 'Istorii' byl sdelan imenno s pervoj redakcil: ja priznaju, razumeetsja, čto perevod byl sdelan $s$ redakcii 75-79 gg., byvsej edinstvennoj redakciej 1 sochranivSejsja vo vsech greðeskich spiskach, no s osobennogo spiska, dopolnennogo samim Iosifom nekotorymi épizodami. 3) Avtor priznaet, Cto perevod byl sdelan po dvum grečeskim spiskam (načalo - po neispravnomu): ja priznaju, čto veś perevod s načala 
do konca byl sdelan po odnoj rukopisi. 4) Avtor priznaet, čto slavjanskij perevod byl sdelan s bukval' noj točnost'ju 1 Cto, poétomu, on vosproizvodit točno grečeskij original: ja priznaju, čto perevod byl sdelan s redkoj svobodoj: greðeskij tekst byl peredan $v$ svobodnom izloženii, s bol'šim količestvom propuskov bol'šich $i \mathrm{malych,} i$ s stilističeskim rasprostraneniem v vide otdel'nych slov i celych predloženij." 15) Die Autorschaft an den christologischen Interpolationen im slavischen Text schreibt ISTRIN jedoch gleich BEHRENDTS und EISLER Josephus selbst $z u^{16)}$. Als zeit der Ubersetzung nennt er spätestens das Ende des 12. Jahrhunderts, als den Raum, in dem sie entstand, den Süden oder Südwesten der Kiever Rús ${ }^{17)}$. Der Ubersetzer war ihm zufolge ein dem Družinamilieu entstammender Russe, der "... obnaružil otličnoe znanie grě́eskogo jazyka, davaja nepravil'nyj perevod $v$ očen redkich sluxajach; on svobodno vladel russkoj literaturnoj rečju, Casto perevodja original bol'šimi periodami, kotorye, pri svobode postroenija, sochranili, odnako, vernost' podlinnika" 18)

MEŠCERSKIJ stimmt in seiner detaillierten Einführung $z$ ur Textausgabe hinsichtlich der Vorlage der Ubersetzung mit ISTRIN überein, schreibt die Interpolationen (auch die christologischer Art) jedoch dem Ubersetzer zu. 19) Als Raum der Ubersetzung nimmt er den südöstlichen Teil der Rús an, zeitlich reiht er sie unter die ersten russischen Ubersetzungen uberhaupt ein und datiert sie ins 11. Jahrhundert, die Regierungszeit Jaroslavs des Weisen 201 .

Wie sieht nun das Verhältnis von original und Ubersetzung bei einem Vergleich beider Texte aus? Sicherlich hat der Ubersetzer eine beträchtliche Freizügigkeit gegenüber dem Urtext an den Tag gelegt. ISTRIN gibt dafur folgende, allerdings etwas übertriebene Chrakteristik: "... perevodxik ... delal bol'కie i malye propuski, rasprostranjal tekst otdel'nymi slovami $i$ peredaval greceskij tekst $v$ bol' Kinstve slučaev $v$ svobodnom pereskaze" 21). MESCERSKIJ betont ebenfalls die außergewöhnliche Freiheit der Ubersetzung und in seinem Aufsatz "O sintaksise drevnich slavjano-russkich perevodnych proizvedenij" 22) 
geht er sogar so weit, die Möglichkeit eines Vergleichs mit dem Original in syntaktischer Hinsicht in Frage $z u$ stellen. Dagegen wendet sich jedoch allgemein RUZICKA, der den Vergleich einzelner syntaktischer Einheiten eines Denkmals der Ubersetzungsliteratur selbst unter der Voraussetzung fordert, "... daß die griechischen Textvorlagen nicht ganz sicher bekannt sind". 23)

Da gerade bei freien Ubersetzungen ein Vergleich mit dem Original die syntaktische Struktur der Ubersetzungssprache besonders deutlich zum Ausdruck kommt - eine Beeinflussung durch die Vorlage ist ja auf das MindestmaB reduziert -, erscheint die Gegenuberstellung des griechischen und des altrussischen Textes des "Judischen Krieges" gerechtfertigt.

Was die zufügungen des Ubersetzers betrifft, die ziemlich vollständig bei MESCERSKIJ angefüht sind 24), so lassen sie sich in verschledene Gruppen einteilen. Die umfangmăBig stărkste davon (etwa insgesamt 50 Prozent) stelien die sogenannten "christologischen", die Erzăhlungen uber die Weisen aus dem Morgenlande, Johannes den Täufer, den Tod Christi, die Apostel und zahlreiche der christlichen Ideologie entspringende Hinweise und Interpretationen verschiedener Ereignisse beinhalten. Trotz der gegenteiligen Auffassung ISTRINs 25) sind sie wohl zweifellos dem Ubersetzer zuzuschreiben, da Einzelheiten wie die Erwăhnung der 30 silberlinge, um die Jesus verraten wurde (M 260,13) oder die Legende von der Heilung der Frau des Pilatus wohl eher auf den EinfluB der Evangelien bzw. christlicher Apokryphenliteratur als auf den Bericht des Josephus zurickzufuhren sind. Zudem wurde nach MESCERSKIJ gerade die Stelle uber den Tod Jesu von christlichen Herausgebern fruhzeitig in den griechischen Text der "Antiquitates" interpoliert und erscheint auch in der Chronik des Hamartolos 26), so daB auch von hier aus an eine Aufnahme der stelle in den "Jüischen Krieg" gedacht werden könnte. Dieselbe Herkunft dürften auch die zusätze haben, die sich gegen die Römer, die "Lateiner" richten (M 233,10-16 und 234, 5-15). Wendungen wie "... obace inoplemennici sutb, a nase uCenie prikasaetsja imb" 
(M 233,15-16) weisen deutlich auf einen Vertreter der Orthodoxie als Verfasser hin.

Eine dritte Gruppe bringt zusatzliche Episoden aus dem Kriegsgeschehen, erzăhlt von den Kriegslisten einzelner Soldaten und Heerfuhrer. Diese Interpolationen konnten zum Teil der vom Ubersetzer benutzten Vorlage entstammen, zum andern aber auch der Phantasie des letzteren entsprungen sein. MESCERSKIJ weist z.B. mit Recht darauf hin, daB Josephus selbst kaum wohl offen zugegeben hätte, er habe bei der Auslosung daruber, wer von den eingeschlossenen Juden zuerst sterben solle, die $\mathrm{Z}$ ahl vorherberechnet und auf diese Weise die übrigen betrogen:"...poðte čisla mudrostiju $i$ tem prĕbljadi vsja" (M 310, 4-5) - vgl.Istorija s. 58).

Der letzte Teil der Einfügungen schlieblich besteht aus Erlăuterungen $z u$ Begriffen des übersetzten Textes, die dem altrussischen Leser Schwierigkeiten berelten mochten. Hier bestehen keinerlei Zweifel an der Autorschaft des Ubersetzers, der dadurch seine Belesenheit und Gelehrsambeit zur Genüge kundtun konnte. Beispielhaft ist etwa der Bericht uber den Kampf des Herakles gegen die Hydra, der durch die Metapher "Hydraköpfe" im Text (N $134,7 / M 230,30$ ) bedingt ist.

Weit zahlreicher als die Interpolationen, die insgesamt etwa 15 Textseiten ergeben, sind die Auslassungen gegenuber dem griechischen Text, denen zum Teil ganze Kapitel des Originals zum Opfer fallen 27). Vergleicht man den Inhalt der in der Ubersetzung fehlenden Stellen, der entweder aus geographischen und ethnologischen Beschreibungen oder Schilderungen von Randereignissen des Krieges besteht (z.B. N 466,5-20 die Beschreibung der liturgischen Gewänder des jüdischen Hohenpriesters oder $N$ 308, 22-312,8 die Schilderung der AbwehrmaBnahmen des Josephus bei der Belagerung von Jotapata), so ist man geneigt, sich der Ansicht MESCERSKIJs anzuschlieBen, daB "...on/d.i.der Ubersetzer/... osnovnoe vnimanie udeljal sobytijam, neposredstvenno svjazannym s osadoj 1 vzjatiem Ierusalima... Obostal'nych sobytijach, kotorye dlja nego ne kazalis stol' central'nymi, on ne sčital nužnym rasprostranjat'sja podrobno, a inogda $i$ sovsem opuskal ich ..." 28). 
Kürzungen wurden auBerdem an stellen vorgenommen, wo einerseits die volle Ubertragung des griechischen Textes aufgrund der darin enthaltenen grammatikalischen Besonderheiten Schwierigkeiten bereitet häte, andererseits aber eine kürzung das Verstänanis des Kontextes nicht beeinträchtigte, z.B.:

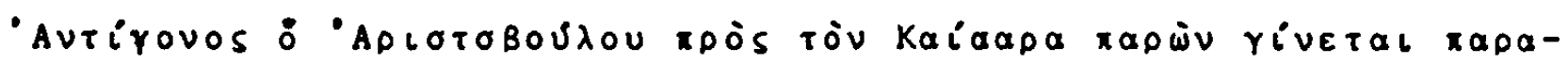

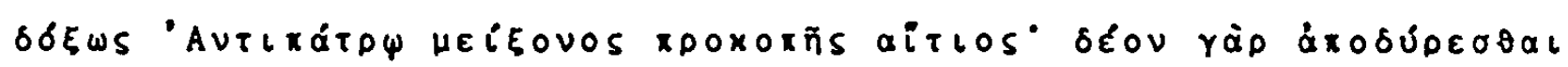

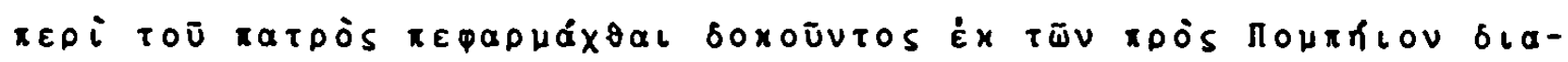

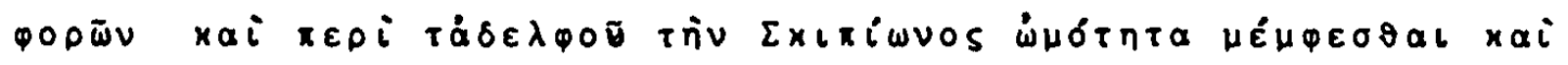

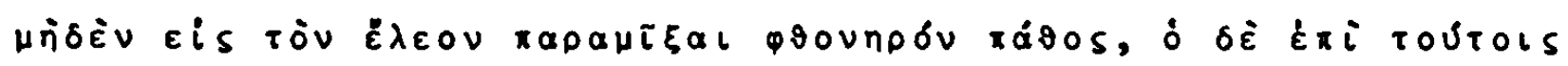
$x \alpha i$ 'Yoxavoठ xai 'Avilxátpou xarnyópel... (N 44,16-22). In der Ubersetzung heibt es an der entsprechenden stelle nur: Antigonb, synb Aristoulovb, prišed kb cesarevi, vopijaše na Urkana 1 na Antipatra (M 183, 19-20). Das fehlende stück enthält im original folgende typisch griechischen und daher schwer wiederzugebenden Konstruktionen:

1. ein absolutes Partizip im Akkusativ

2. einen Infinitiv Perfecti Passivi

3. eine Artikelkonstruktion.

Die Vermeidung einer Ubersetzung dieser und ahnlicher stellen aufgrund ihres komplizierten Aufbaues zeugt keineswegs von mangelandem können, sondern eher von einer gewissen Routine, die es dem Ubersetzer erlaubt zu entscheiden, welche Stellen er unberulcksichtigt lassen konnte, ohne den Sinn des Abschnittes $z u$ storren. 


\section{Kapitel: BESONDERE STILISTISCHE TENDENZEN}

Im übrigen Text, wo der Ubersetzer den Ausfuhrungen des Originals folgt, gibt er diese, wenn auch nicht "bol'seju cast' ju", wie ISTRIN behauptet ${ }^{1)}$, so doch ziemlich häufig in einem "svobodnyj pereskaz" wieder. Bei einem Vergleich mit dem original lassen sich folgende Besonderheiten herausstellen:

1) Ein wichtiges Anliegen war dem Ubersetzer die Ubersichtlichkeit und Prägnanz der Darstellung, die auch im Verlauf des ganzen altrussischen Textes gewahrt wird. Dabei wird bezüglich der Vorlage nur auf die Beibehaltung des Sinnes geachtet, der Satzbau folgt den eigensprachlichen Gesetzen des Altrussischen. So können griechische Perioden in einzelne Hauptsätze aufgegliedert werden, wenn thre Nachvollziehung in der Ubersetzung schwerfälig wirken würde, z.B.:

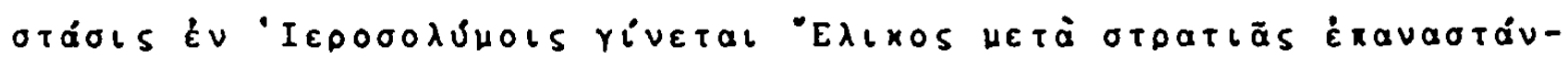

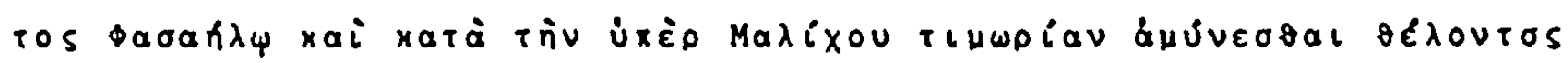

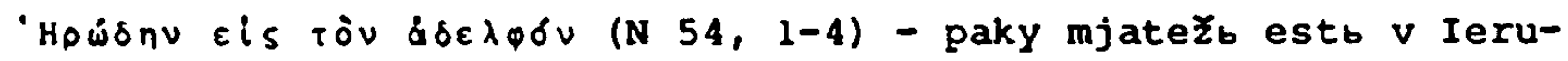
salime. Malichovb bo brat Elegb, poem voja,ide na Irodova brata Fasaila, chotja mostiti Malicha (M 188, 11-14):

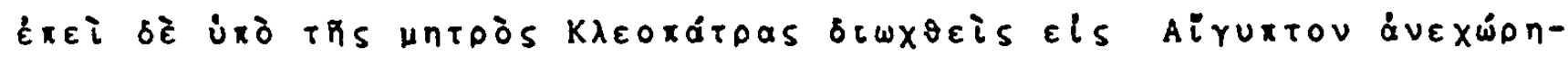

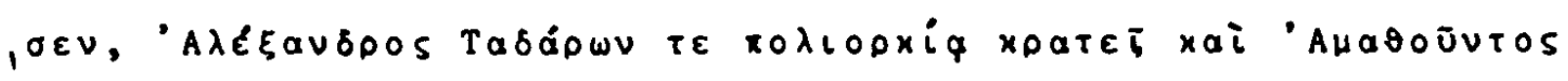
(N 21, 5-7) - no mati ego Kleopatra progna ego v Egupetb. Aleksandrb ze očjutisja $i$ vzja gorody ego: Gadarb $i$ Mafusb (M 173, 15-16).

Andererseits wird eine griechische Satzreihe durch hypotaktische Konstruktionen wiedergegeben, um den Inhalt straffer zum Ausdruck zu bringen:

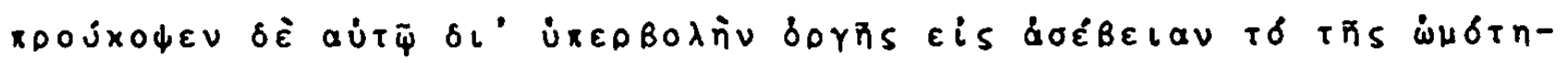

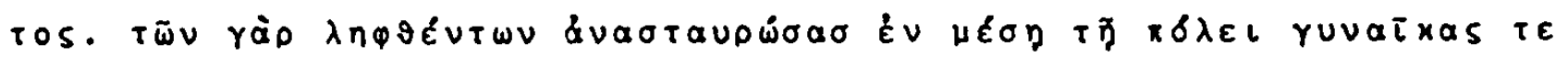

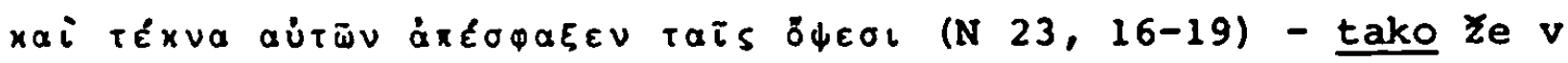
nemb jarostı bjaకe neceloveceskaja, jako odinemb dbnem posredi grada 8 sot ot nich raspja, a Zeny ich 1 deti ich pred oxima ich izbi (M 174, 21-23);

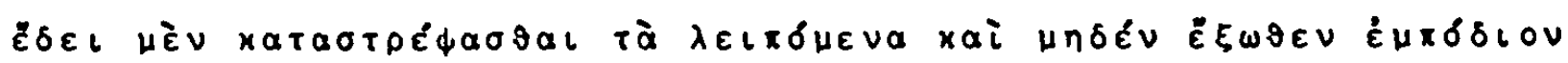

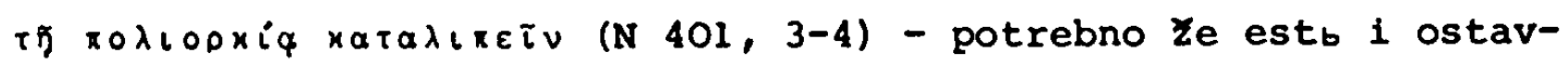
Saja grady rusiti, da ne ostanutsja (em.n.Mak.) emu 1 nazade protivnii (M 342, 28-30). 
2) Der Ubersetzer liebt es, die manchmal etwas trockene und abstrakte Darstellung des Griechischen durch eine direkte, konkrete zu ersetzen. Hierbel greift er einerselts in der Wortwahl gegenuber dem original zu determinierteren Ausdrücken, fügt aber auch zusätzliche Details, die zur Veranschaulichung des Geschehens beitragen, in die Handlung ein:

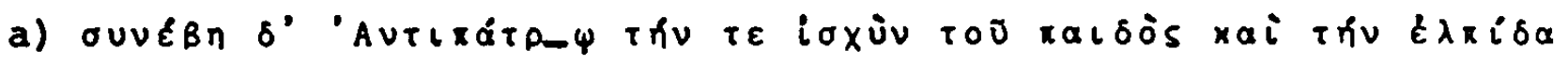

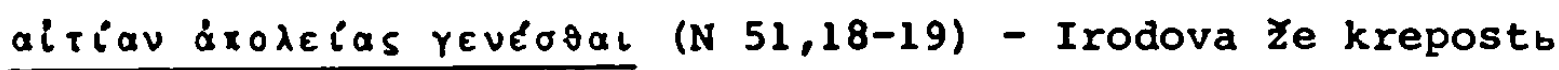
1 vaznb 1 sanb pogubi otbca ego (M 187,11):

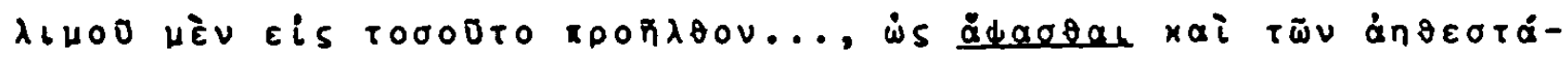
TwV (N 15, 22 - 16,1) - gladb bystb.... jako 1 neobyCnaja est1 (M 170, 34-35):

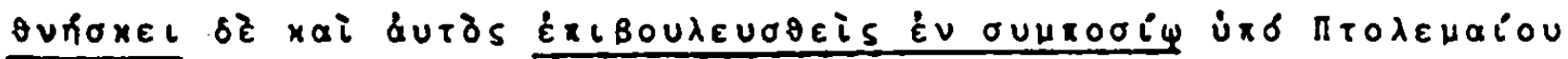
TOD YaUBDOD (N 13, 24-25) - zjatb Ze ego Potolomei vda emu otrava na obede 1 umori 1 (M 170, 1-2):

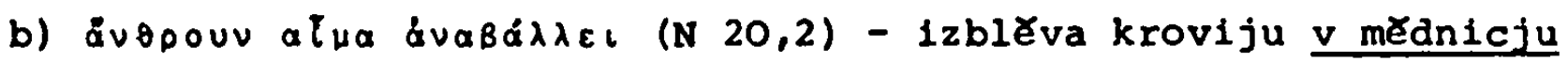
(M 172, 33-34),

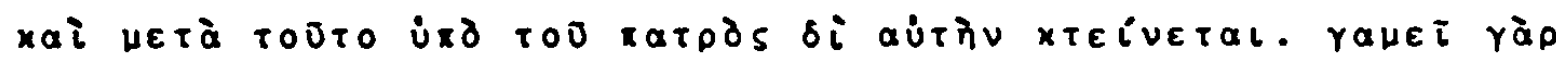

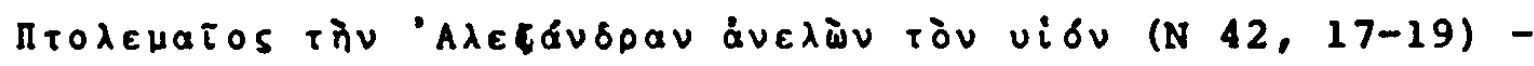
otbcb Ze ego Ptolomel, vbzrêvb na nju 1 viděvb ju krasnu sušju, 1 voschotervo ju, 1 ubi syna svoego 1 pojatb ju za sebe (M 183, 11-13):

Oft tritt dabei eine Interpretation des Geschehens aus der Sicht des Ubersetzers ein und es werden Tendenzen spurbar, die der Vorlage gänzlich fehlen:

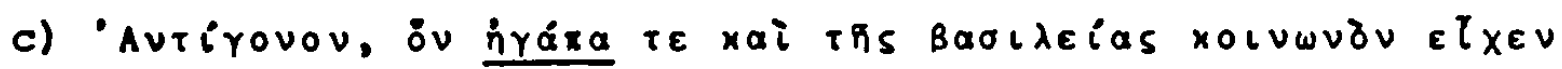
(N 17, 15) - Antigona, ego Ze sja tvorjašt ljubja, priCastnika imeja cesarbstvija svoego (M 171, 23-24):

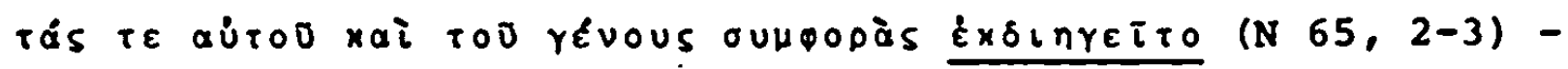
rydjase $k$ nemu o svoich napastech 1 o rode ego (M 191,11-12),

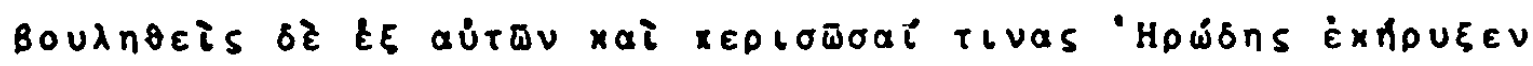

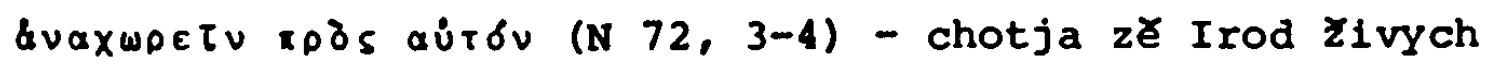
1zimati nekoliko ich slavy radi, dajase im ruku (M 174, 3-4;diese Einfügung dürfte aus der Druzina-Ideologie heraus entstanden sein; vgl.im Igorlied 'Iఈとa sebe (ti,a knjazju slavy'). 
3) Häufig ist das Bemuhhen um eine konkretere Darstellung verbunden mit einer Dramatisierung der Handlung, wobei durch die Einführung wörtlicher Rede bzw. von Dialogen eine szenische wirkung erreicht wird:

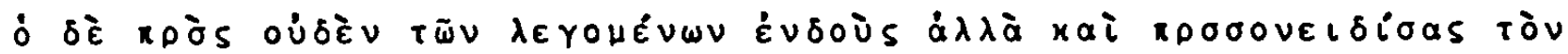

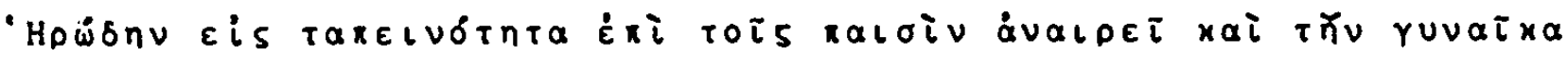

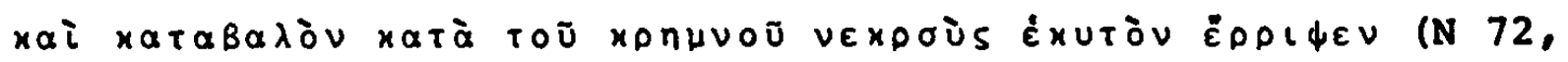
11-14) - starecb Ze, razsmejavsja velmi, emb Zenu za vlasy, 1 posece ju, $i$ syny po edinomu. I poslexdi vbzdvigb ruku s međemb i rek: "Smbrtb svobodna estb luzbsi mi tvoego cesarbstva", i ta rek vogruzi mex $v$ utrobu svoju (I1 194, 10-13):

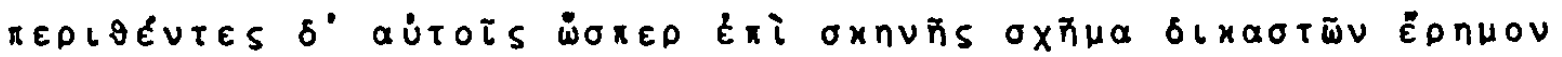

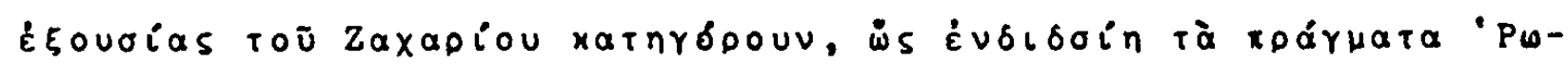

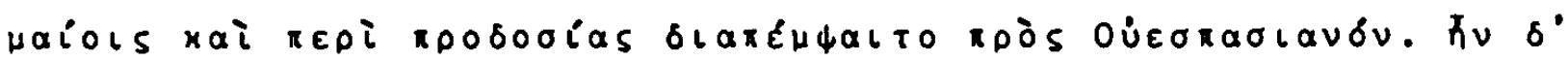

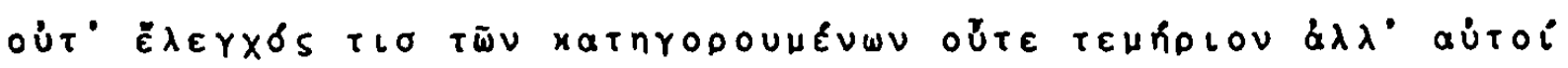

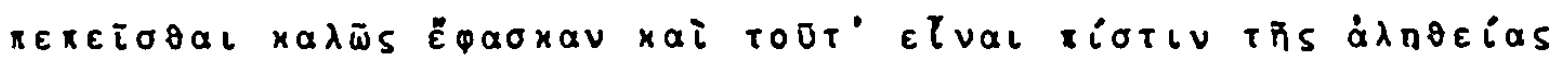
h́fiouv (N 391, 6-11) - postavisa sudisca $i$ sobrasa 70 muz ot starec, i vdasa imb vlastb suditi, porugajušesja imb. I sami oni, stavకe pred 70 sb Zacharieju, prjachusja s nimb glagoljuše, jako tь predaetь grad rimljanom. Sudija Že rekosa: Kto oblixitelo ili kotoroe znamenie? I revniteli otvešavకe: My vædoci tomu, my že poslusi, i nam vêru imête. Sudii že rekoక̌a: Ne imemı verry vamb, zane protivnii este ( $11338,1-8$ ).

Im letzten Beispiel wird dadurch, daB die Richter als sprechende Personen auftreten, der Handlungsablauf nicht wie im Griechischen nur berichtet, sondern er spielt sich gleichsam vor dem Leser $a b$.

Neben diesen Kennzeichen einer freien Wiedergabe finden wir andererseits eine Reihe von stellen, die sich äuBerst eng an das Original anlehnen. Sie mögen den $A n l a B$ für nachstehende, freilich keineswegs für den ganzen Text zutreffende Charakterisierung der Ubersetzung durch E. BICKERMANN gegeben haben:"... le caractère de la version russe ne paraitra pas douteux. Faite sur le grec, elle est très exacte/Hervorhebung von $\mathrm{mir} / . .$. Elle ne se écarte du grec que sur de details, ajoute ca et là, tel ou tel mot, telle ou telle phrase." ${ }^{2}$ ) Die folgenden Beispiele 
sollen diese Abhängigkeit von der Vorlage illustrieren:

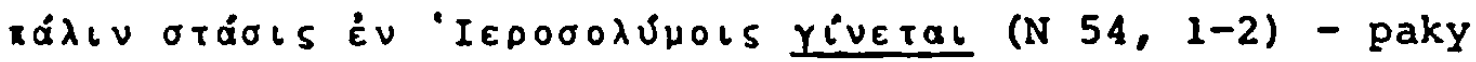
mjatezb estb $V_{b}$ Ierusalime (11 188, 11-12; - das historische Präsens kommt sonst im altrussischen Text nicht vor);

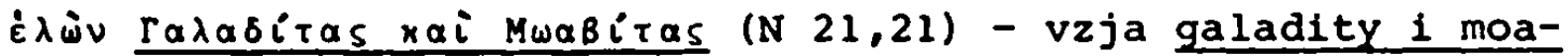
vitiy (M 173,25; - 'vzjati' hat als kriegstechnischer Terminus sonst nur geographische Bezeichnungen als Objekt bei sich 3).

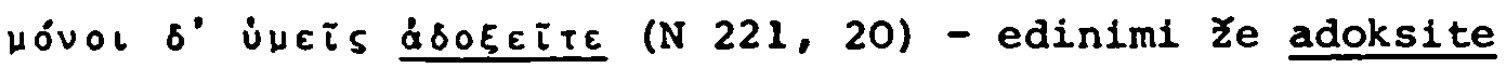
(M 276, 3: - dieses unübersetzte Verbum wird von MESCERSKIJ mit als ein wichtiges Argument fur das zugrundeliegen des allgemein bekannten griechischen Textes gewertet ${ }^{4)}$ );

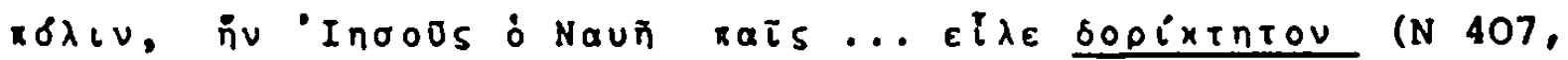
7-9) - tb Ze gradb Isusb, Navvinb synb, doby koplemb (M 345 , 21-22).

Mitunter geht dabei die Anlehnung an das Original so weit, daB sich daraus ein MiBverstehen des Textes ergibt, wie etwa in folgendem Beispiel:

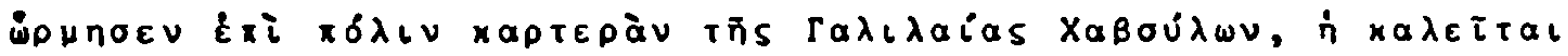
$\dot{\alpha} \cup \delta \rho \bar{\omega} v$ (N 269, 7) - strêmisja na grad galileisky, narekomyi Zaulonb, nareCemii Andronb (M 283, 15-17). Hier wurde das griechische Epitheton 'andrón' (also stadt "der Männer") fälschlicherweise als Eigenname betrachtet und blieb als solcher unubersetzt.

Schlieblich seien noch einige Beispiele angeführt für die nach ISTRIN "oteń redkie slucai" einer Fehlübersetzung bzw. Fehlinterpretation der Vorlage. In den meisten Fällen ist hier die sonstige Ubereinstimmung der beiden Texte so offensichtlich, dab sich die Fehler nicht durch eine von der bekannten abweichende Vorlage erklären lassen. Dabei handelt es sich sowohl um Verwechslungen von Namen und Verwandtschaftsverhältnissen als auch um Sinnverdrehungen bei der Schilderung eines Handlungsablaufs :

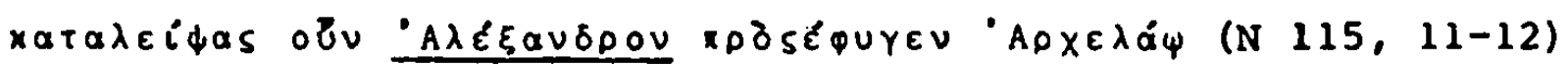


1 ostavivb Iroda, bě̌a kb Archelaevi (M 217, 23-23; - in den Handschriften ist an dieser Stelle weder für das Griechische noch für das Altrussische eine andere Lesart der Namen zu finden).

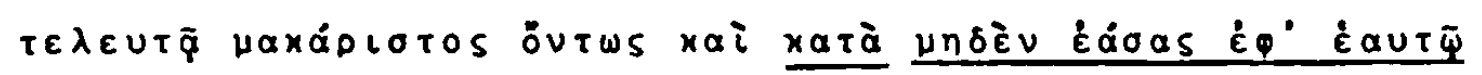

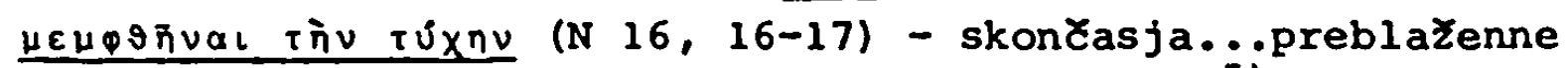
vo istinnu $i$ bezb ponosa pozivb (M 171, 9-10) 5$)$,

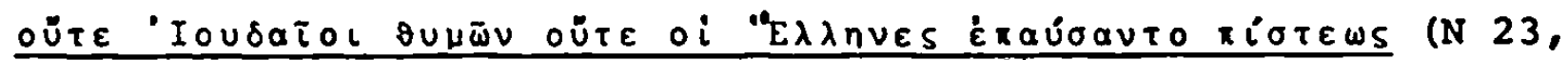
2-3) - 1 mnoziprelbstisasja (M 174,11) 6).

Nach diesen stilistischen Eigenheiten der Ubersetzung sei noch hingewiesen auf einige grammatische Besonderheiten, die sich durch den ganzen Text ziehen.

1) Der Gebrauch des Duals

Die durchgehende Verwendung des altrussischen Duals in der Ubersetzung (in insgesamt uber 100 Fälien) zeugt von ihrem Alter und reiht sie mit in die ersten Werke der altrussischen Schriftsprache ein. Dieses Kriterium ist umso zuverlässiger, als hier eine Beeinflussung durch die Vorlage völilg ausgeschaltet ist. Der griechische Text zeigt nämlich den Dual nur bei einem einzigen Wort $(\tau \dot{\omega} x \in i p \varepsilon)$ in einigen wenigen Beispielen, sonst steht zur Bezeichnung der $\mathrm{zweizahl}$ konsequent der Plural:

Ti் Xeipe XLvoũolv (N 284,18) - ruce vozdvigajutb (M 296,15):

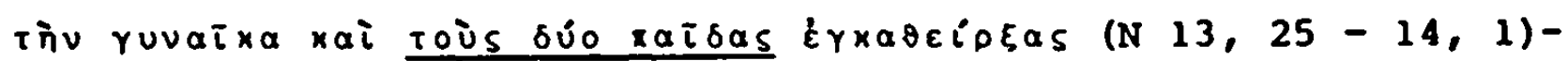
Zenu ego $i$ dva syna ego dêrzase okovavb $(M 170,2)$;

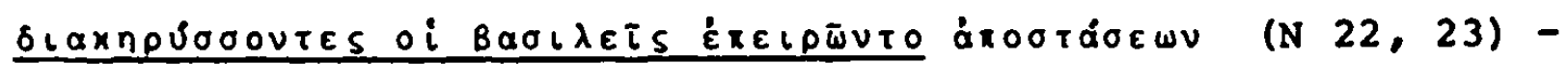
poslasta oba cesarja $\mathrm{kb}$ voemb, vabjasta (M 174, 10-11):

So konsequent der Ubersetzer jedes Auftreten einer Zweiheit durch den Dual bezeichnet, kommt es doch vor, daB er im verlauf der weiteren Schilderung einfach zum plural uberwechselt, obwohl es sich weiterhin un dieselben zwei Personen oder Gegenstände handelt. Das Bewußtsein der Zweiheit bleibt also nur solange erhalten, als das zahlwort, das dabei im Vergleich zum Griechischen oft ergänzt wird (vgl. das obige Beispiel), 
oder die beiden Namen noch in nächster Năhe stehen; nach einem Einschubsatz oder auch nur elner Bestimmung wird für dieselbe Zweiheit bereits der Plural gebraucht:

Eleazarb, Simonovb synb, 1 zacharia Falekovb, rodom 1ereja, susca s ljudmi, 1 dumasta, tto dostoino tvoriti, ostru vrêmeni prispevsju na nja, zane 1 sami zatvoren 1 sutb, 1 po vnénjjuju

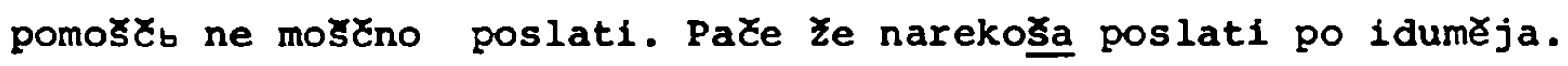
I ispisavకe epistoliju skore, i poslaşa ko idumæ̇i rekşe ... (M 333, 24-29).

In weiteren Text erscheint nur mehr der Plural. Dasselbe gilt für M 338, 18-22: dva Ze bestudnika napadosta na Zachariju i

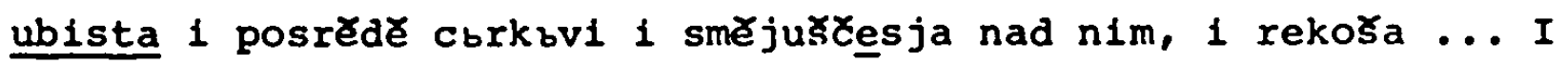
abie vyvergosa ot corkbve ...

2) Die Behandlung der griechischen indirekten Rede

Hier geht der Ubersetzer ziemlich konsequent vor und gibt die Oratio obliqua des Originals im Altrussischen fast immer durch direkte Rede wieder ${ }^{7)}$ :

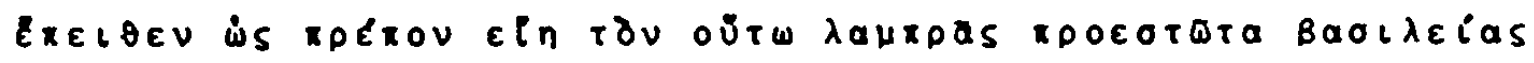

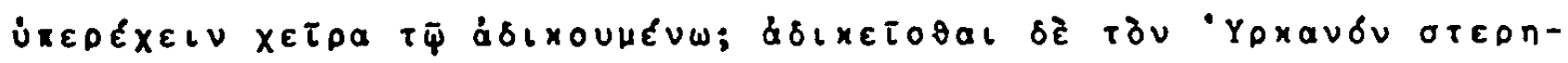

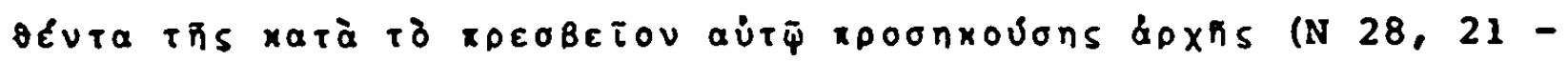
29,1) - glagolja: slavnyi cesarb (em.n.I) syi, podoben esi obidimymb ruku podavati, a Irkanb obidim k tobe beritb. Podai emu otbCeskoe vlasti (em.n.I) svoeju siloju (M 176, 36-177,2):

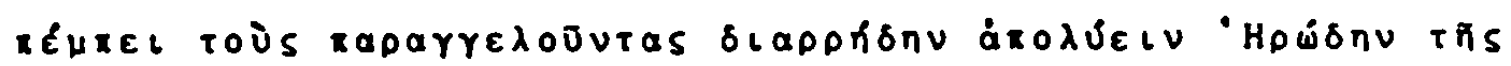
Dolvixñs $8 i x n s$ (N 48, 6-7) - napisa ... glagolja: Otpusti Irodovi vsjaku tjazju (M 185, 30-31).

Hăufig erfolgt die Uberleitung zur altrussischen direkten Rede mittels der Konjunktion 'jako', die, im Griechischen oft ein als Einleitung eines Deklarativsatzes stehendes or vertretend, im Altrussischen nur mehr die Funktion eines Satzzelchens hat, namlich auf einen neuen Textabschnitt und Einschnitt in der Darstellung hinzuweisen ${ }^{8)}$ :

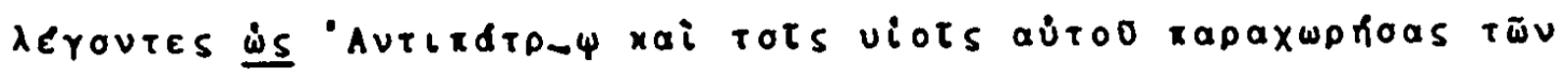

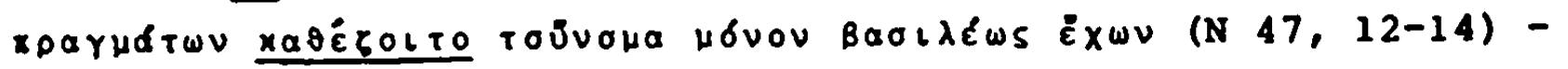


glagoljusti, jako ty sedisi tokmo imenujasja archiereomb, cesaremb bez vlasti... (M 185, 14-15).

Steht dabei das subjekt der direkten Rede in der dritten Person, so könnte diese Konstruktion rein formal auch im Altrussischen mit einem Deklarativsatz verwechselt werden. Klarheit schaffen nur Anreden oder Hinweise auf den Gesprächspartner, die in der zweiten Person ausgedrückt sind:

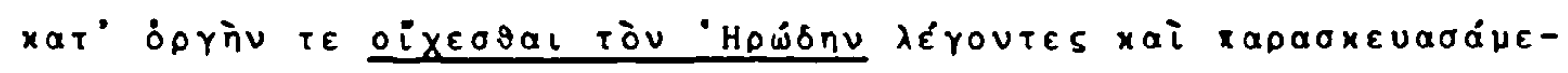
vov $x \alpha \tau^{\circ} \alpha u ̛ \delta$ (N 48, 12-13) - glagoljusce, jako sb jarostiju otide Irod pristroitsja (unglückliche Konjektur MESCERSKIJs statt des $z$ u erwartenden 'pristroitisja') na tja (M 185, 38);

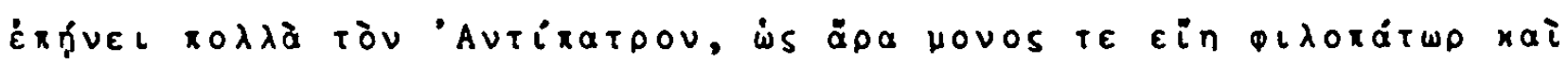

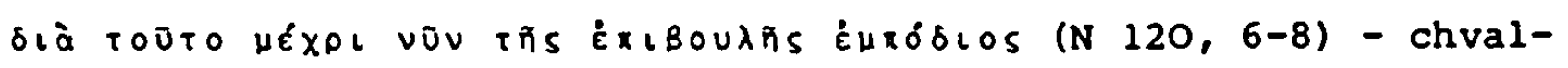
jaseto Antipatra, jako tb edinb estb otbcbljubecb. I témb sochranenb esi ot zlodumania (M 22, 11-13) 9).

Uber die Wertung dieses 'jako' als Grăzismus schreibt RUZICKA folgendes: "... Im allgemeinen wird 'jako' zur Einleitung der direkten Rede ... als Grăzismus bezeichnet; es kann jedoch nur mit Einschränkung als solcher gelten. Es handelt sich hier um eine syntaktisch kaum charakterisierte Fuge, eine Leerstelle, an der die Einfügung einer Konjunktion, auch wenn sie durch das griechische Vorbild angeregt worden war, kaum als sehr fremd oder störend empfunden werden konnte." 10) Diese Meinung findet eine Unterstützung in der Verwendung der Konjunktion ' 5 'O' in derselben Funktion in KOTLJAREVS"KYJs "Eneida", einem Werk, das ja hauptsächlich die ukrainische Volkssprache widerspiegelt:

"... Enej kryðyt', šo: 'ja Neptunu

Pivkopy hrosej $v$ ruku sunu,

Aby na mori sturm utych" "11).

3) Die Vermeidung des Passivs

Das im Original bei der Schilderung der einzelnen Ereignisse sehr häufig verwendete Passiv versucht der Ubersetzer $z u$ vermeiden, wo immer es nur geht. In uber 50 fällen wird bei sonst ubereinstimmenden Texten in der altrussischen Fassung das Aktiv 
gewählt:

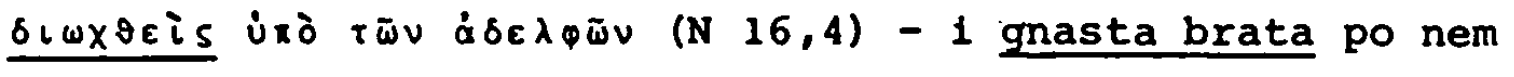
$(\mathrm{M} 185,1)$ :

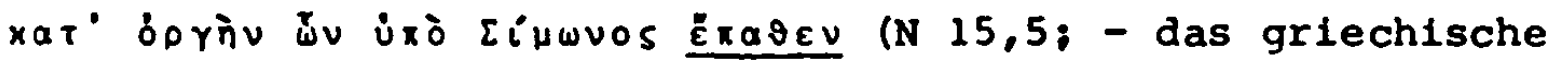
Verbum ist hier trotz seiner aktiven Form eindeutig in passivischer Funktion gebraucht) - pomjanuv, jaže emu sotvori simon (M 170, 24).

Dabel wird bel fehlendem Agens im Griechischen entweder die subjektlose, "Indefinlert-persönliche" 12) Konstruktion der 3 . Person Pluralis gewählt oder ein Agens ergänzt:

úuveito roōv... Howions (N 46,16) - pesni pojachu emu (M 185,1):

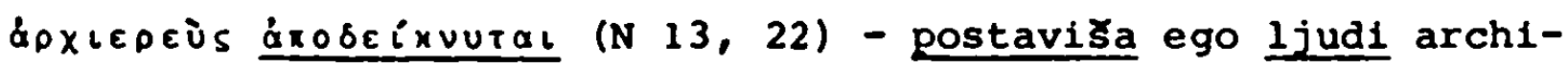
ereemb (M 169, 32-33).

Andererselts wird die Wiedergabe des Agens, wenn er in der Vorlage bezeichnet ist und ausnahmsweise auch im Altrussischen das Passiv erscheint, umgangen. 13)

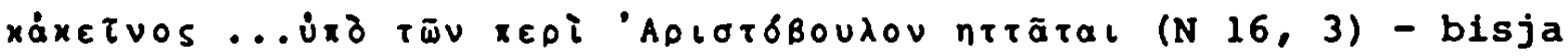
$s_{b}$ Aristovulomb 1 pobezenb bystb $(M 170,37)$ :

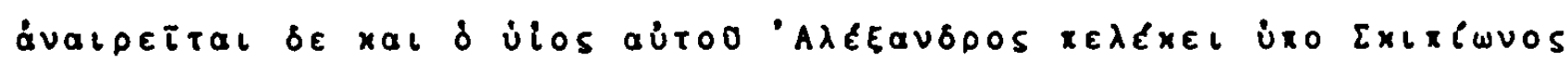

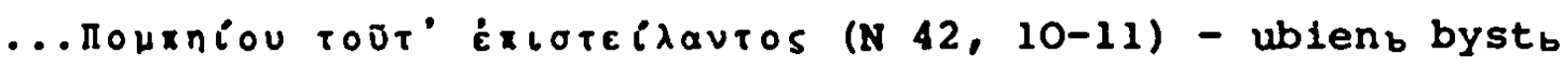

1 synb ego Aleksandrb okbSevbju, poveleniemb Pompievymb (M 183, 7-8).

Der passive Infinitiv des Griechischen schlieblich wird durchwegs durch den aktiven wiedergegeben, der dann auch ein Akkusativobjekt bel sich haben kann:

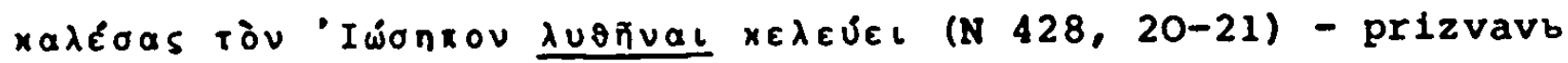
Iosifa puele razdresiti 1 (M 355, 31);

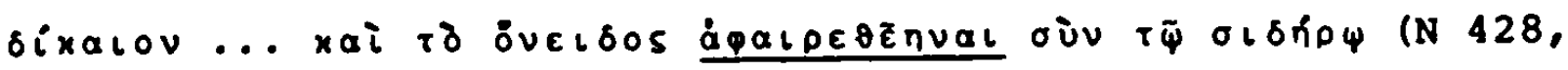
23 -24) - podobaetb... 1 ponosenie otjati ot Iosifa (M 355, 32). 


\section{Kapitel: IEXIK UND WORTBILDUNG}

Mangels eines vollständigen vergleichenden wörterbuches beider Texte des "Jüdischen Krieges" - die Verzeichnisse von VAILLANT und MESCERSKIJ ${ }^{1)}$ unfassen nur einen Teil des altrussischen Wortschatzes, die griechischen Parallelen sind nur vereinzelt gegeben 2) - muB ein Vergleich der altrussischen Fassung mit dom Original auf dem Gebiet der Lexik und wortbildung notgedrungen unvollstăndig bleiben.

Anhand des dieser Arbeit zugrundeliegenden Materials ließen sich lediglich in folgenden Punkten vergleichende Beobachtungen anstellen.

1. Die Behandlung der Termini aus dem politisch-administrativen und kriegstechnischen Bereich

Ein historisches Werk, das schon seinem Titel nach die Beschreibung eines Krieges zum Inhalt hat, muB eo ipso ein reichhaltiges Inventar an militärischen (fur die Beschreibung des äuBeren Ablaufs) und politischen (zur Illustration der Ursachen und Auswirkungen) Termini technici aufweisen. So finden wir denn auch im $\pi \delta \lambda \varepsilon \mu \circ$ eine ziemlich vollständige Liste von Spezialausdrücken des Waffenhandwerks und des staatlichen Lebens vor.

Einerseits halt sich der Ubersetzer bei der Ubertragung dieser Termini ziemlich genau an die Vorlage und läBt sich hier von dieser wesentlich mehr beeinflussen als etwa auf dem Gebiet der einzelnen syntaktischen Konstruktionen.

So wird z.B. die Semantik allgemein bekannter und vielfach gebrauchter slavisch-altrussischer worter um Lehnbedeutungen erweitert, die sie bis zum zeitpunkt der Ubersetzung nicht besassen ${ }^{3)}$. So erhalten etwa die substantiva 'ruka' und 'slurba' als Entsprechungen für $x \in i \rho$ und $\theta \varepsilon \rho \alpha \pi \varepsilon i \alpha$ in kriegstechnischem und höfisch zerimoniellem zusammenhang die zusätzlichen Bedeutungen von "Abteilung, Kriegsschar" (vgl. das lat. 'manus") und "Ehre, Huldigung", die beide bei SREZNEVSKIJ nicht registriert sind ${ }^{4)}$ :

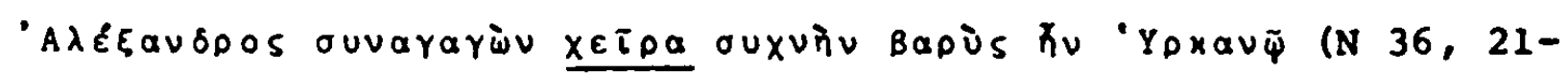


23) - Aleksandrb... silnu ruku skupivb, strach bystb Urkanovi (M 181, 6-7);

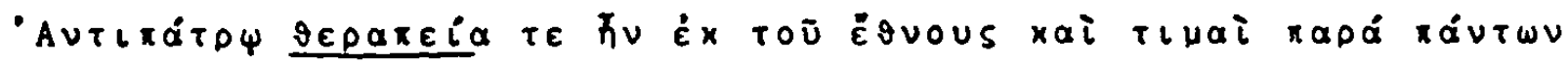
(N 47, 4-5) - bystb Antipatrovi služba cesarbskaja i $\tau_{b} s t_{b}$ otb vsêch (M 185, 5-6):

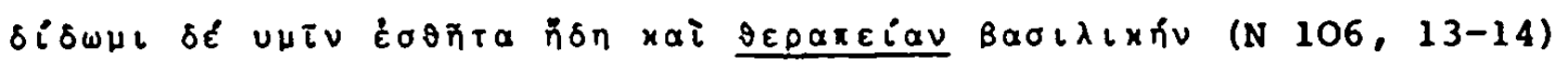
- podavaju Ze vam nyne rizy 1 službu cesarskuju (M 213, 2-3).

Beim letzteren Wort 'služba' kommt in der zusätzlichen Bedeutung das passive Genus verbi zum Ausdruck: Es bezeichnet nicht mehr die eigene Dienst"leistung", sondern steht im sinne von "bedient werden".

Zu den Lehnbedeutungen gehört auch die Bezeichnung für eine Belagerungsmaschine, den "Widder". Das altrussische 'ovbnb' bezeichnet ursprünglich nur den "Schafbock, Widder" als Tier, später auch als Tierkreiszeichen. Die zusätzliche Bedeutung "Rammbock" ist bei SREZNEVSKIJ nur für unser Denkmal registriert" ${ }^{5)}$. Anhand dieses Wortes läBt sich anschaulich die Einführung einer Lehnbedeutung studieren. Der Terminus "Widder" wird nämlich in Original und Ubersetzung an einer stelle ausdrücklich motiviert, obgleich er im Griechischen seit Xenophon üblich war ${ }^{6)}$ :

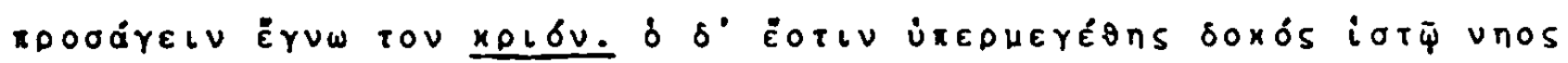

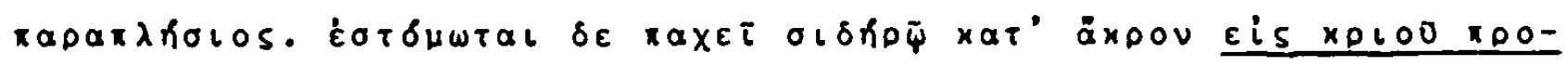

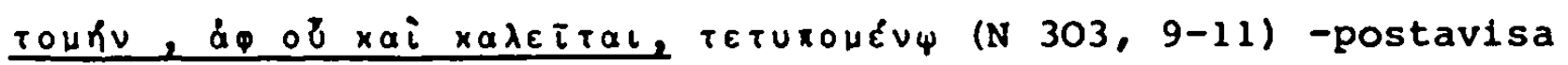
ovenb, eze estb drevo veliko $i$ tolbsto, podobno Segle korablonoi, a v konecr Że ego vsaženo Zelezo veliko, rogato, im Że i ovenb naretetsja (M 303, 4-7).

Im folgenden wird der Terminus im Altrussischen bereits als bekannt vorausgesetzt und zur wiedergabe verschiedener synonymer Bezeichnungen für Belagerungsmaschinen gebraucht:

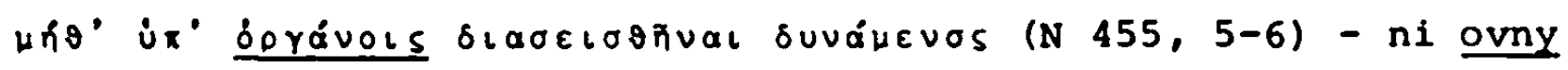
podvigaemo (M 368, 3):

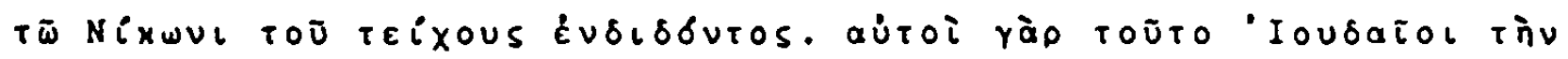

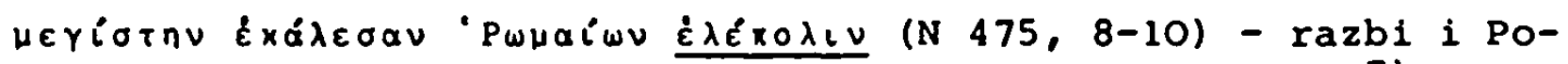
beđanikb. Tako bo naricachu velikago ovna (M $377,3-4)$ 7). 
Lehnübersetzungen liegen vor in Ausdrücken wie 'dale pušaemaja' für griechisch $\dot{\varepsilon} \times \dot{n}-B \circ \lambda a(M 300,24 / N 295,4)$, und wenn man darunter wie SCHUMANN in weiterem Sinne auch Ableitungen rechnet ${ }^{8)}$, gehören hierher auch Nomina agentis wie oфevooun-

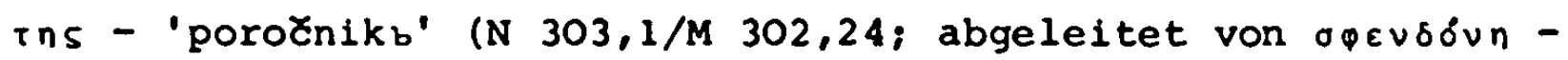

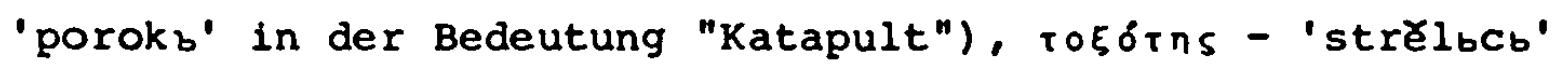
(N 295,4/M 300,24) und $i \times x \varepsilon U_{s}$ 'konbnikb (passim).

Termini, die wegen ihrer speziellen, auf typisch römische Verhältnisse zugeschnittenen Bedeutung eine Ubertragung allzu problematisch erscheinen lassen, da in der Ubersetzungssprache der entsprechende Begriff und damit auch seine Benennung fehlt, übernimmt der Ubersetzer als Fremdwörter und paBt sie lediglich an die Phonetik und Flexion des Altrussischen an. Es handelt sich dabei vor allem um die Begriffe der oneipa, die dem lat. 'manipulus' entspricht und im Heer der Kaiserzeit eine Abteilung von etwa 100 Mann bezelchnet, des nireusu, der sowohl für'imperator' wie auch für 'legatus' steht, des ixatos('consul') und ähnliche:

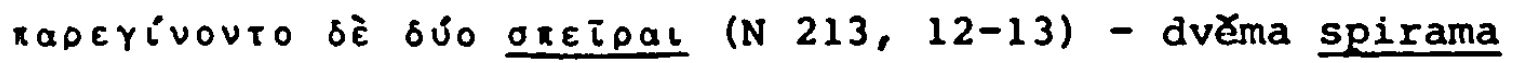
idustimb (M 271, 32-33):

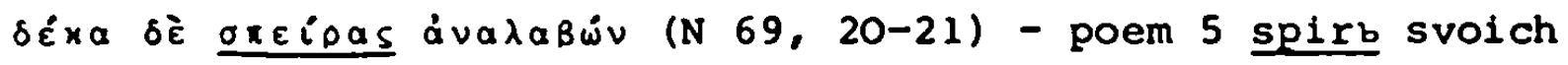
(M 193, 20):

rapà $\tau \tilde{\psi}$ 'Punaíw ịyeuóvl $(N 45,8)$ - pred rimbskym gemonomb (M 223, 2);

rpoñrov oi üratol (N 66, 1-2) - idosta... upaty (M 191, 30-31):

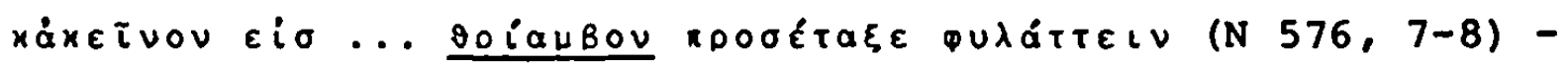
povele suchraniti i na Eriamva ( 438,1$)$ :

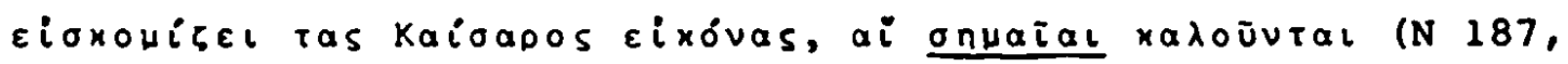
6-7) - prinese $v b$ Ierusalimb cesarevb obraz, nareCemyi silmeja (M 258, 23-24) ${ }^{9}$.

Dieses enge Festhalten an der Vorlage praktiziert der Ubersetzer aber nur in den Fällen, wo in seiner sprache und in den ihn umgebendenverhaltnissen keine vergleichbaren Begriffe vorhanden sind. Wenn er dagegen Parallelen zu den im Ió $\lambda \varepsilon \mu \circ s$ ge- 
schilderten Einrichtungen in seiner eigenen Heimat $z u$ sehen glaubt, zögert er nicht, die Terminologie des staatlichen und militărischen Lebens der Kiever Rus zu verwenden, was seiner Darstellungsweise Farbe und Lebendigkeit verleiht, wenn er auch dadurch miunter erheblich vom original abweicht.

In der folgenden (keineswegs vollständigen) Aufstellung wird zuerst der altrussische Terminus, dann seine griechische(n) Entsprechung(en) im Text, schließlich, soweit vorhanden, die Entsprechungen in anderen Werken der altrussischen und kirchenslavischen Ubersetzungsliteratur anhand der Wörterbücher von SREZNEVSKIJ und MIKLOSICH gegeben:

Belege bei

Aruss. Term. Griech. Term. SREZNEVSKIJ MIKLOSICH

\begin{tabular}{|c|c|}
\hline 'Zelbvb' & (N 296, \\
\hline $\begin{array}{l}\text { (eigentlich } \\
\text { "Schildkröte", }\end{array}$ & $16 / \mathrm{M} 301,9)$ \\
\hline hier: "Schutz- & $\sigma \times \varepsilon \times n$ \\
\hline dach") & $11 / M 301,181$ \\
\hline
\end{tabular}

kopie

xovTós (N 288,

$3 / M 298,6)$

दuotos (N 287 .

$21 / M 298,2)$

-Vorkommen in Originallit.: Russkaja Pravda, Povest' vremennych let, Slovo o polku Igoreve.

bronja

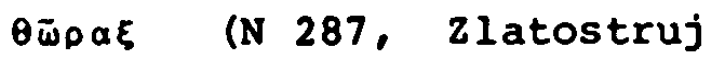

Chrys . Hom.,

$17 / M 297,30)$

Ap.v.Sisatovac

Vorkommen in Originallit.:- Pov. vr. let, Ipat., Lavr., Novg., Troick. letopis, Urkundenliteratur. 


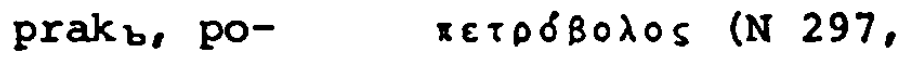
rokb 4-5/M 301, 14-15)

Vorkommen in Originallit.: Ipat., Lavr., Novg. I, Pskov. I letopiśs.

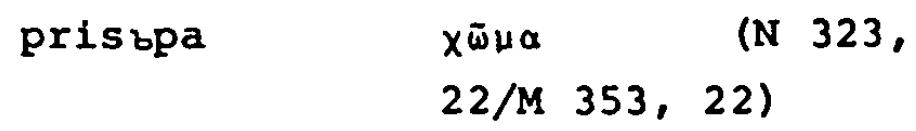

Vorkommen in Originallit.: Pov. vr. let, Ipat. letopiś.

\begin{tabular}{|c|c|c|c|c|}
\hline \multirow[t]{3}{*}{ sulica } & $\dot{\alpha} \times \dot{w} v$ & (N 288, & & \multirow[t]{2}{*}{ Hamartolos } \\
\hline & $5 / M 2 S$ & & & \\
\hline & $\lambda \circ x^{n}$ & (N 287, & Hamartolos & Pentateuc \\
\hline & $20 / M$ & & & Mihanović \\
\hline
\end{tabular}

Vorkommen in Originallit.: Chronikliteratur, slovo o polku Igoreve, Afanasij Nikitin.

Selomb xpávos (N 287,

$17 / M 297,31)$

Vorkommen in Originallit,: Chronikliteratur,slovo o polku Igoreve, $\mathrm{z}$ adonకtina.

\begin{tabular}{|c|c|c|c|c|}
\hline \multirow[t]{3}{*}{ scits } & (kruglb) & $\dot{\alpha} \sigma x i s$ & (N 287, & zlatostruj \\
\hline & & $20 / M 298$ & 2) & \\
\hline & $(d o l g b)$ & OUpeós & (N 287, & \\
\hline & & $21 / M 298$ & 3) & \\
\hline
\end{tabular}

Vorkommen in Originallit.: Chronikliteratur, Russk. Pravda, sl. o polku Ig., Afanasij Nikitin.

tovarblimpedi- arooxevai (N 291, menta) $2 / M 299,25)$

Vorkommen in Originallit.: Chronikliteratur. 
tulb ywoutos (N 288,

$4 / M 298,7)$

Vorkommen in Originallit.: Chronikliteratur, slovo o polku Igoreve.

\begin{tabular}{|c|c|c|c|c|}
\hline \multirow[t]{3}{*}{ zabralo } & $\tau \in \tau \times \circ S$ & 449. & Upyír Lichoj, & Ezechiel \\
\hline & $12 / M \quad 365,25)$ & & $\begin{array}{l}\text { Greg. v. Naz., } \\
\text { Hamartolos }\end{array}$ & \\
\hline & $\pi \varepsilon \rho i B O \lambda \circ S \quad$ (N & 304, & & \\
\hline
\end{tabular}

Vorkommen in Originaliit.: Chronikliteratur, slovo o polku Ig.

detinbcb Tó $\dot{\phi n \lambda \sigma \tau \varepsilon p o v}$

$$
\begin{aligned}
& \text { PDOUDiOV (N 413, } \\
& 8 / M 348,25)
\end{aligned}
$$

Vorkommen in Originali1t.: Chronikliteratur.

$$
\begin{aligned}
& \text { Ostrogb Tò natoTEOW DDOU- } \\
& \text { Diov (N 413, } \\
& 7-8 / M 348,24-25)
\end{aligned}
$$

Vorkommen in Originallit.: Chronikliteratur, Pouc. Vl. Monomacha, Ilarion.

$\begin{array}{lll}\text { tbma Húplo } & (\mathrm{N} 264, & \text { Upy Lichoj, Clozianus } \\ 8-9 / M 289,22-23) & \text { Ostrom. ev., } \\ & \text { Malalas }\end{array}$

Vorkommen in Originallit.: Chronikliteratur, Slovo o polku Ig., Afanasif Nikitin. 
vorsta
oTáslov
(N 307,
Zitie Andreja
Prolog Mihano-
$11 / M 304,28)$
Jurodivogo
vié, Sbornik
Kirillo-Belo-
zerskij

Vorkommen in Originallit.: Chronikliteratur, Urkundenliteratur, ChoŽenie igumena Daniila.

\begin{tabular}{|c|c|c|c|c|}
\hline \multirow[t]{3}{*}{ kbnjazb } & $\dot{\alpha} p \times \omega v$ & (N 56 . & Ostrom. ev., & Cod.Suprasl. \\
\hline & $6 / M \quad 189,9)$ & & Genes. $14 \mathrm{v}$. , & Menăen (Vuk) \\
\hline & & & Greg.v.Naz., & \\
\hline & & & Efr.kormZaja & \\
\hline
\end{tabular}

Vorkommen in Originallit.: Russkaja Pravda, PouX. Vl. Monomacha, Slovo o polku Ig., Mol. Dan. Zatoßn.

bojare

$$
\text { oi suvaroi (N } 55 \text {, }
$$

$10-11 / M 188,24)$

oúrxintos (N 41 ,

Efr. kormCaja Ioannes Climacus,

$21 / M 186,28)$

Kormc.Mihanovic

vorkommen in Originallit.: Chronik- und Urkundenliteratur.

dumbci Uंyxintos (N 39,
$24 / M 182,8)$
Boùn (N 65,
$21 / M 191,29)$

Vorkommen in Originallit.: Chronikliteratur.

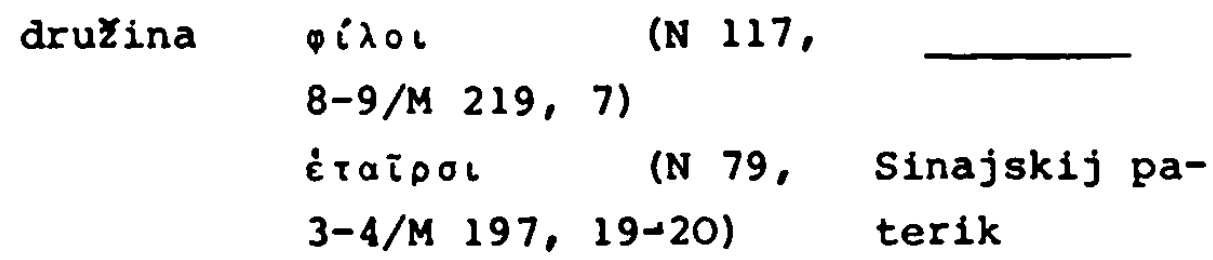

Vorkommen in Originalilteratur: Chronik- und Urkundenliteratur, Russk. Pravda, Vl. Monomach, Slovo o polku Igoreve. 
sotbnikb غ̇xatoutápxns (N 308, Ostrom. ev., Savvina kniga 9-10/M 306,16) Greg.v.Naz. Menäen (Vuk)

Vorkommen in Originallit.: Chronik- und Urkundenliteratur.

$\begin{aligned} & \text { tysjackyi } x i \lambda i \alpha p x \circ 5 \\ &5 / M 306,6)\end{aligned} \quad(N 317$,

Vorkommen in Originallit.: Russk. Pravda, Chronik- und Urkundenliteratur.

\begin{tabular}{|c|c|c|}
\hline prlkb & Tárua & $(N$ \\
\hline & $19 / \mathrm{M} 303,32)$ & \\
\hline & $T \dot{\alpha} \xi \varepsilon \imath S$ & (N \\
\hline & $20 / M \quad 304,1)$ & \\
\hline
\end{tabular}

Vorkommen in Originallit.: slovo o polku Igoreve, Pout. Vl. Monomacha, Chronikliteratur.

sténobi- áథetrólol un-

¿্nyja sb- xavai (N 297.

sudy $1 / M 301,13)$.

Sonstiges Vorkommen: Prologus mensium: März (MIKLOSICH), August (SREZNEVSKIJ) .

Wie aus obiger Tabelle hervorgeht, hat der Ubersetzer viele dieser Termini, die im Altrussischen allgemein bekannt waren, erstmals zur Wiedergabe entsprechender griechischer verwendet.

Neben diesen Termini technici ist auch noch die Verwendung der (uneigentlichen) Präposition 'obapoly' fur das griechische Orts-

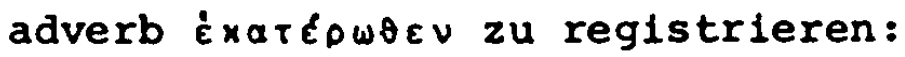

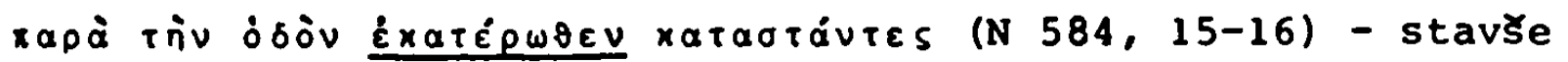
obapoly put1 (M 443, 16).

Für diese Entsprechung bringt SREZNEVSKIJ noch ein Beispiel aus 
den Cet'1-Mine1; das altrussische Wort ist ausserdem belegt in der Povest " vremennych let, der Novgorodskaja letopis und dem Igorlied 10).

An phraseologischen Ausdrücken aus dem Berelch von Krieg und Staatsleben finden sich neben anderen, öfter gebrauchten wie 'vbzloziti danb' (éxıтátreıv pópov: N 21, 22-23/M 173, 25-26) vor allem die beiden Wendungen 'vdati na కritb' (M 193, 22-23; ohne genaue griechische Entsprechung) in der Bedeutung "zur plünderung, als Beute freigeben" 11 ) und 'Ziti sb bojary' im sinne von "sich vom Hof- und staatsleben fernhalten:

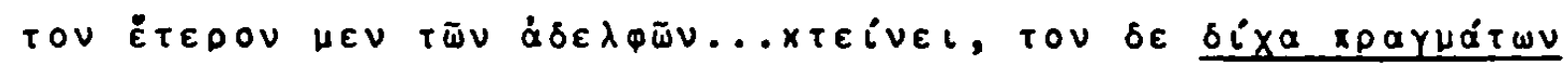
$\underline{\varepsilon} I_{X \in V}(\mathrm{~N} 20,20-21,1)$ - vtorago brata pod nim ubi, a tretbemu povele ziti s bojary (M 173, 13).

11. Die Wiedergabe und Verwendung zusammengesetiter worter

Unter zusammengesetzten wörtem seien hier Komposita verstanden, deren beide Bestandtelle entweder Substantiva, Adverbia oder Verba sind; Verbalkomposita, die durch das Vorsetzen von Präpositional- und anderen Präfixen entstanden sind, bleiben auber Betracht, ebenso wie die zusamensetzungen mit a privativum bzw. 'ne-'('bez-').

Bei einer Ubersetzung wie der unseren, die ihre Vorlage relativ frei wiedergibt, sind die altrussischen Entsprechungen für griechische Komposita nicht allein auf zusamengesetzte worter beschränkt. So werden zusammengesetzte substantiva durch Simplicia oder durch Genitivverbindungen, Verba durch Verba mit Akkusativobjekt und Adjektiva und Adverbia durch Modalbestimmungen ersetzt, z.B.:

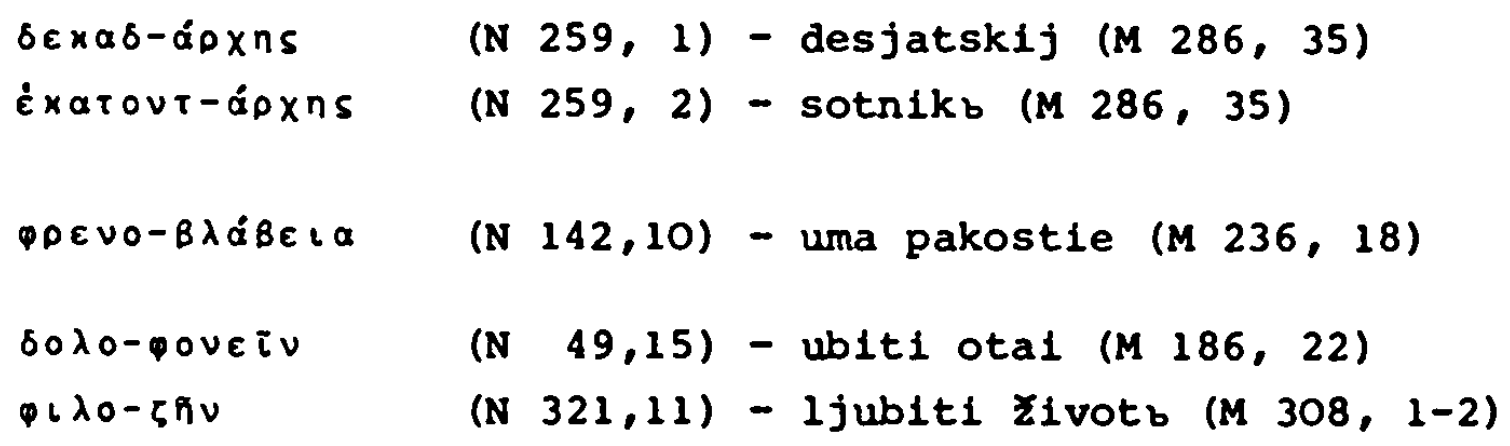


ávopo-urixns (N 463, 8) - vozvyక̌e mužska vozrasta $(M 370,1)$

ódo-xpuoos (N 34,23) - Cistymb zlatomb ustroenb (M 180,6-7)

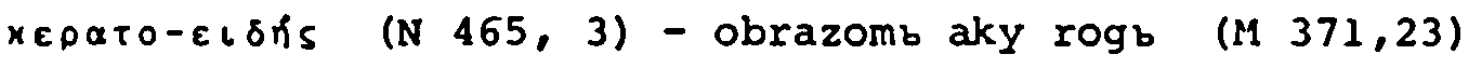

Eเ申-ñons (N 34,10) - s mexi (M 179,33)

Elф-fiphs (N 425,11) - s nagymi meti (M 354,20)

Andererseits stehen von den über 250 altrussischen Komposita nur etwa 130 für griechische zusammengesetzte wörter. Darunter stellen die von VJALKINA als "kal'ki" bezeichneten 12), also diejenigen, bei denen das altrussische wort mit dem griechischen hinsichtlich beider Bestandteile übereinstimmt, nur 60 prozent. Es handelt sich dabei um folgende Komposita:

\begin{tabular}{|c|c|c|c|}
\hline$\alpha \delta \varepsilon \lambda \varphi O-x \tau O V \varepsilon \tau \nu$ & $(\mathbf{N}$ & $195,17-18)$ & - brato-ubiistvo (M 263,25) \\
\hline$\dot{a} \delta \varepsilon \lambda \phi \delta-x \tau 0$ vos & $(\mathrm{N}$ & $145,19)$ & - brato-ubienie (M 238,14) \\
\hline$\dot{\alpha} \lambda \lambda \sigma-\phi \cup \lambda \circ s$ & $(\mathrm{~N}$ & $11,4)$ & - ino-plémennikb (M 168,4$)$ \\
\hline$\lambda \lambda \sigma-\varphi \cup \lambda \circ s$ & $(N$ & $231,1)$ & - ino-plexmenbnb (M 279,28) \\
\hline$\dot{\alpha} \lambda \lambda \delta-\varphi \cup \lambda \circ s$ & $(\mathrm{~N}$ & $170,6)$ & - ino-plémennilb (M 248, 4) \\
\hline$\dot{U T}-\varepsilon \xi \circ \dot{O} \sigma$ LS & $(\mathbf{N}$ & $554,9)$ & - samo-volbnb (M 421,35) \\
\hline$\alpha \dot{U} \tau 0-x \rho \alpha \dot{\tau} \omega p$ & $(\mathrm{~N}$ & $427,18)$ & - samo-derŽcb (M 355,12$)$ \\
\hline 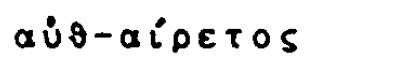 & $(\mathbf{N}$ & $286,12)$ & - samo-vlastbnb (M 297,11) \\
\hline$\delta \cup \sigma-x \omega p i \alpha$ & $(N$ & 352,18 & - Ijuto-mestie (M 323,2$)$ \\
\hline$\varepsilon \dot{u}-\dot{\alpha} \gamma \gamma \varepsilon \lambda i \alpha$ & $(\mathrm{N}$ & $427,18-19$ & - blago-věsCenie (M 355,13 ) \\
\hline$\varepsilon \dot{U}-\dot{\alpha} \gamma \gamma \in \lambda i \xi \varepsilon \sigma \theta \alpha \iota$ & $(\mathbf{N}$ & 340,81 & - blago-věstvovati (M 316,13$)$ \\
\hline$\varepsilon \ddot{U}-B \circ \tau O S$ & $(\mathrm{~N}$ & $279,14)$ & - blago-zélonb (M 294,29) \\
\hline$\varepsilon \dot{U}-x \propto \rho\llcorner\sigma \tau \varepsilon \tau \tilde{\tau}$ & $(\mathbf{N}$ & $49,4)$ & - blago-darenie (M 186,13 ) \\
\hline$\varepsilon \dot{u}-\delta \alpha \iota$ uovia & $(N$ & 170,81 & - blago-vaznivb (M 248,6) \\
\hline$\varepsilon \dot{u}-\dot{\varepsilon} p \gamma \varepsilon \sigma i \alpha$ & $(N$ & 119,31 & - blago-datb (M 220,15) \\
\hline$\varepsilon \dot{U}-\dot{\varepsilon} \rho \gamma \varepsilon \sigma i \alpha$ & $(\mathbf{N}$ & $144,8)$ & - blago-darenie (M 237,23) \\
\hline$\varepsilon \dot{U}-\dot{\varepsilon} \rho \gamma \in \tau \varepsilon \tau \iota$ & $(\mathrm{N}$ & 142,131 & - blago-tvoriti (M 186,17) \\
\hline$\varepsilon \dot{U}-\varepsilon \dot{p} \gamma \varepsilon \mathcal{\tau} \cap S$ & $(\mathrm{~N}$ & $164,4)$ & - blago-davbcb (M 289,19) \\
\hline$\varepsilon \delta$ - है $\rho Y \varepsilon \tau T S$ & $(\mathbb{N}$ & $580,26)$ & - blago-datelonikb (M 441, 8) \\
\hline 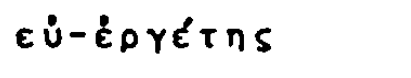 & $(N$ & $507,17)$ & - blago-děicь (M 393,11-12) \\
\hline Ėं-ย́pYétกS & $(N$ & $361,16)$ & - blago-dettelonikb (M 326,17 ) \\
\hline$\varepsilon \dot{u}-\gamma \varepsilon \mathfrak{v e} \iota \alpha$ & $(\mathbf{N}$ & $105,6)$ & - blago-rodbstvo (M 212,10$)$ \\
\hline$\varepsilon \dot{u}-\gamma \varepsilon \hat{v} \operatorname{c} \iota \alpha$ & $(N$ & $389,1)$ & - blago-rodie (M 337,15) \\
\hline$\varepsilon 0$ - YeURS & $(\mathbf{N}$ & $613, \cdot 7)$ & - blago-rodniCbskb (M 459,30) \\
\hline yevis & $(\mathrm{N}$ & $202,9)$ & - blago-rodbnb (M 267,11) \\
\hline
\end{tabular}




\begin{tabular}{|c|c|c|c|}
\hline$\varepsilon \dot{U}-\lambda \circ \gamma \varepsilon \tau \nu$ & $(\mathrm{N}$ & $489,18)$ & - blago-sloviti (M 385,13) \\
\hline$\varepsilon \dot{u}-\omega \times i a$ & $(\mathbf{N}$ & $117,5-6)$ & - blago-pistie (M 219, 2) \\
\hline$\varepsilon \dot{u}-x \rho \alpha \gamma i \alpha$ & $(\mathrm{N}$ & $99,11)$ & - dobro-vaznie (M 208,27) \\
\hline$\varepsilon \dot{U}-\sigma \varepsilon \hat{\varepsilon} B \varepsilon \downarrow \alpha$ & $(\mathrm{N}$ & $114,14)$ & - blago-Žstie (M 237,30) \\
\hline$\varepsilon \dot{U}-\sigma \varepsilon \beta E\llcorner\alpha$ & $(\mathrm{N}$ & 105,231 & - blago-rodbstvo (M 212,24) \\
\hline$\varepsilon \dot{U}-\sigma \varepsilon \beta \varepsilon\llcorner\alpha$ & $(\mathbf{N}$ & $143,20)$ & - dobro-dejjanie (M 237,10) \\
\hline$\varepsilon \dot{U}-0 \varepsilon B$ Ŕs & $\ln$ & $540,15)$ & - blago-Cbstivb (M 413,22) \\
\hline$\varepsilon \tilde{U}-\sigma \tau 0 \times 05$ & $(\mathrm{~N}$ & $585,13)$ & - blago-polučnb (M 443,30) \\
\hline$\varepsilon \ddot{U}-\tau \alpha \times \tau \circ s$ & $(\mathrm{~N}$ & $531,4)$ & - dobro-Cinie (M 407,34) \\
\hline$\varepsilon \dot{u}-\tau \cup \times \hat{r} s$ & $(\mathrm{~N}$ & $90,1)$ & - blago-vaznivb (M 203,25) \\
\hline$\dot{\varepsilon} \theta v-\alpha \dot{p} \times n s$ & $(\mathbf{N}$ & $175,14-15)$ & - jazyko-deržbcb (M 251,28) \\
\hline$\dot{\varepsilon} \theta v-\alpha p \times i \alpha$ & $(\mathrm{N}$ & $174,14)$ & - jazyko-vlastostvo (M 251,9) \\
\hline$\gamma \in \nu \in \alpha-\lambda$ ore $\tau \nu$ & $(N$ & $109,2)$ & - rodo-slovit1 (M 214,12) \\
\hline$\gamma \rho \alpha \mu \mu \alpha \tau o-\varphi \cup \lambda \alpha \dot{\alpha}<\llcorner\nu$ & $(\mathbf{N}$ & $578,20)$ & - knigo-chranilanica (M 439,24-25) \\
\hline$\dot{n} \mu \dot{\imath}-\theta \varepsilon \circ s$ & $(\mathrm{~N}$ & $184,11)$ & - polo-bogb (M 256, 6) \\
\hline$i \times x \delta-\delta 00 \mu \circ 5$ & $(\mathrm{~N}$ & $150,18)$ & - koné-ristanie (M 240,32) \\
\hline $0 \delta 0-\pi 0 \iota 6 s$ & $(\mathrm{~N}$ & $290,23)$ & - pute-dXlbct (M 299,23) \\
\hline 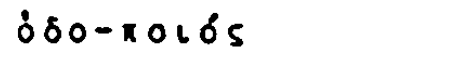 & $(N$ & $440,22)$ & - put-stroicb (M 361,10$)$ \\
\hline$\dot{o H o-v o \varepsilon \tau \nu}$ & $(\mathbf{N}$ & $106,15)$ & - edino-umiti (M 213,4) \\
\hline$\delta \mu \delta-v o l \alpha$ & $(\mathrm{N}$ & $541,8)$ & - edino-umie (M 413,36) \\
\hline$\dot{\delta} \mu \delta-v o l \alpha$ & $(\mathrm{N}$ & $105,14)$ & - kupno-umie (M 212,16) \\
\hline$\delta \mu \delta-\Phi \cup \lambda \circ s$ & $(\mathrm{~N}$ & 195,141 & - edino-piermenbniks (M 263,22) \\
\hline 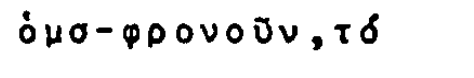 & $(\mathbb{N}$ & $185,6)$ & - odinb-glasie (M 256,22) \\
\hline$x \alpha \times \delta-\varphi$ nu०v & $(\mathrm{N}$ & $553,6)$ & - zlo-recie (M 421,9) \\
\hline$\lambda \iota \theta \delta-\tau \circ \mu \circ S$ & $(\mathbf{N}$ & $575,1)$ & - kameno-seとbcb (M 437,1) \\
\hline 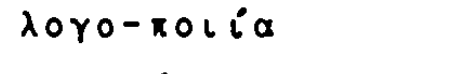 & $(\mathrm{N}$ & 110,111 & - slovo-tvorenie (M 214,35) \\
\hline$\mu \varepsilon \gamma \alpha \lambda \delta-\phi \cup \times \circ \nu$ & (II & $126,7)$ & - vele-dusie (M 225,20) \\
\hline 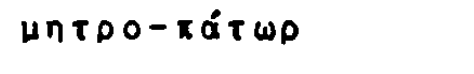 & $(\mathbf{N}$ & $125,14)$ & - matere-1jubьcь (M 224,31) \\
\hline$\mu \varepsilon \sigma-n u \beta \rho i \alpha$ & $(\mathrm{N}$ & $278,19)$ & - polu-dons (M 294,17) \\
\hline$\mu \varepsilon \sigma-n \mu \beta \rho \tau \nu O S$ & $(\mathrm{~N}$ & $550,6)$ & - polu-dbnbnb (M 419,15) \\
\hline 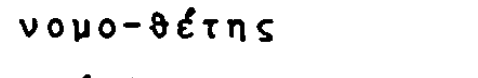 & $(\mathrm{N}$ & 183,101 & - zakono-davbcb (M 255,21) \\
\hline$v \varepsilon \delta-\delta \circ p \circ s$ & $(\mathrm{~N}$ & $298,1)$ & - novo-dran b (M 301,23-24) \\
\hline 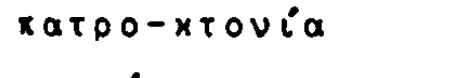 & $(N$ & $142,7)$ & - otbcb-ubiistvo (M 236,15) \\
\hline$x \alpha \tau p \delta-x \tau O \vee \circ S$ & $(\mathrm{~N}$ & $142,21)$ & - otbcb-ubiecs (M 236,27) \\
\hline$\pi \circ \lambda_{L}-0 p \times i \alpha$ & $(\mathrm{N}$ & 306,101 & - grado-vzjatie (M 304,15) \\
\hline$\pi \circ \lambda \iota-0 p \times i \alpha$ & $(N$ & $484,2)$ & - grado-vzimanie (N 381,31$)$ \\
\hline$\pi \circ \lambda U-\tau \varepsilon \lambda \dot{r} S$ & $(\mathrm{~N}$ & $262,4)$ & - mnogo-cĕnbns (M 288,18) \\
\hline
\end{tabular}




\begin{tabular}{|c|c|c|c|}
\hline$\sigma \iota \tau-n \gamma \delta s$ & $(\mathbf{N}$ & $69,12)$ & - kormble-nosbcb (M 193,19-20) \\
\hline$\sigma \times \varepsilon \cup 0-\phi \delta \rho \circ s$ & $(\mathrm{~N}$ & $440,23)$ & - sbsudo-nosbcb (M 361,11$)$ \\
\hline 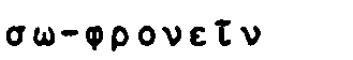 & $(\mathbf{N}$ & $492,3)$ & - cerlo-mudrit1 (M 386,24$)$ \\
\hline$\sigma \omega \mu \alpha \tau 0-\emptyset \mathcal{U \lambda a \xi}$ & $(\mathrm{N}$ & $263,1)$ & - têlo-chranbcb (M 288,34) \\
\hline$\sigma \omega \mu \alpha \tau \sigma-\phi \cup \lambda \alpha \xi$ & $(\mathbf{N}$ & $143,6)$ & - têle-chranitelb (M 236,33-34) \\
\hline$\tau \varepsilon \iota \times \circ-\mu a \times \imath a$ & $(N$ & 476,151 & - stêno-bitie (M 377,20$)$ \\
\hline$\tau \in x \cup o-x \operatorname{Tovi\alpha }$ & $(n$ & $123,23)$ & - Cado-ubienie (M 223,27) \\
\hline$\tau \in \times v o-p a r i \alpha$ & $(\mathbf{N}$ & $541,11)$ & - Cado-jadĕnie (M 414, 4) \\
\hline TETDá-Yovos & $(\mathrm{N}$ & $578,19)$ & - Cetvero-ugolbnb (M 439,24) \\
\hline$\tau \varepsilon \tau \rho-a p \times n$ & $(\mathrm{~N}$ & $152,2)$ & - Cetvero-vlastostvo (M 241,22) \\
\hline$\tau \in \tau \rho-\alpha \dot{\rho} \times n s$ & $(\mathbf{N}$ & 110,201 & - Cetvero-vlastonikb (M 215, 6) \\
\hline$\tau \in \tau \rho-\alpha \rho \times i \alpha$ & $(\mathbf{N}$ & $186,16)$ & - Cetvero-vlastostvo (M 257,16) \\
\hline$\tau \in \tau p-\alpha p \times i \alpha$ & $(\mathbf{N}$ & $132,7)$ & - Cetvero-vlastie (11 229,15) \\
\hline$\tau \in T \rho-\alpha \rho \times \omega v$ & $(N$ & $341,10)$ & - Cetvero-vlastonikb (M 317,1$)$ \\
\hline$T E T \rho \delta$ TQWФOS & $(\mathrm{N}$ & $589,10)$ & - Cetvero-verchonb (M 446,16) \\
\hline$\tau \rho i-\rho \omega \phi O S$ & $(\mathbf{N}$ & $589,10)$ & - tro-verchbnb (M 446,16) \\
\hline roi-oteros & $(\mathrm{N}$ & $464,12-13)$ & - tro-verchbnb (M 371, 8) \\
\hline$\theta \varepsilon 0-\phi \iota \lambda h s$ & $(\mathbf{N}$ & $487,4)$ & - bogo-ljubivb (M 383,27$)$ \\
\hline$\xi \cup \lambda o-\Phi \sigma \rho \iota \alpha, \tau \dot{\alpha}$ & $(N$ & $233,3)$ & - drêvo-nesenie (M 280,15) \\
\hline
\end{tabular}

Wenn auch der GroBteil der oben angefuhrten altrussischen Komposita zweifellos aus Lehnubersetzungen besteht, die zum Teil auf kirchenslavische Tradition zurückgreifen, was schon die festen Entsprechungen einiger Bestandtelle (etwa cu-und 'blago-', 'juo- und 'edino-') zeigen, so beweist doch die verschiedenartige wiedergabe gleicher griechischer wörter (z.B. die Behandlung von $\varepsilon \dot{u}-\varepsilon p \gamma \varepsilon \tau_{n}$ das Bemihen des Ubersetzers um $A b-$ wechslung und Eigenständigkeit. Auch die Schaffung bisher nicht vorhandener Lehnübersetzungen, wie z.B. 'Ijuto-méstie' (svo$x \omega \rho i \alpha)$, 'şsudo-nosbcb' (oxevo-popos) und 'kbrmle-nosbcb' $(\sigma\llcorner\tau-n \gamma \delta s)$ 13), die nach dem Vorbild ahnlicher calques erfolgt sein durfte ${ }^{14)}$, berucksichtigt die Eigenart des slavischen und bemulht sich trotzdem, nicht allzu sehr von der vorlage abzuweichen.

Würde eine Wort-für-Wort-Ubersetzung den Wortbildungsgesetzen des Altrussischen zuwiderlaufen, so zögert der Ubersetzer nicht, durch frele wiedergabe entweder eines oder beider Glie- 
der des Kompositums eine Vergewaltigung seiner Muttersprache $2 u$ vermeiden; manchmal bildet er auf diese Weise auch nur Varianten $\mathrm{zu}$ bereits wörtlich wiedergegebenen Komposita:

a) $\underline{\dot{\alpha} \cup \tau o}-x p \alpha \dot{\tau} \tau \rho$

$\underline{\varepsilon \dot{u}}-x \dot{\alpha} \rho \delta\llcorner O S$

$\pi \circ \lambda u-\tau \dot{\alpha} \lambda \alpha \cup \tau O S$

$\mu \alpha \times p o-\vartheta \cup \mu i \alpha$

$x a \times 0-\delta 0 \xi i \alpha$

$\varepsilon \dot{u}-\underline{\tau \varepsilon \times v i a}$

$\zeta \omega-\gamma D \alpha \varphi i \alpha$

aúto-xelpia

b) doc

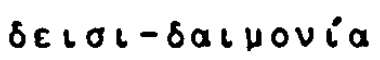

$\varepsilon \dot{u}-\tau \varepsilon \times v i \alpha$

iEp-ouproov, $\delta$

loo-urins

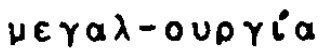

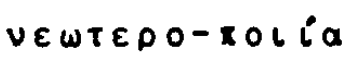

$\pi \lambda \varepsilon \circ \nu-\varepsilon \xi i \alpha$

$x \lambda \varepsilon O V-\varepsilon \xi i \alpha$

$x \lambda \varepsilon \circ U-\varepsilon \xi i a$

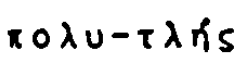

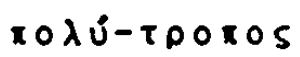

(N 195,19$)$

- e vgl. oben 'samo-')

(N 616, 6)

- Eisto-sbrdbCbnb (M 461,15)

(N 590,10

(N 518,5 )

- mnogo-cênonb (M 447,4-5)

(N 510,11 )

- dblgo-torpenie (M 399,32)

- zlo-imanie (M 394,28)

(N 508,19$)$

- blago-slovenie (M 394,4; "Kindersegen")

(N 460,6) - ruko-plsanbnb (M 368,25-26; vgl. 'zivo-pis')

(N 332,24) - samo-rězanie (M 308,30)

(N 224,13) - krovo-piicb (M 277,12)

(N 188,21) - blago-Cbstie (M 265,30)

(N 408, 4) - mnogo-plodbstvo (M 346, 9)

(N 436,11) - Zertvo-nosbcb (M 359,15)

(N 98,6) - mnogo-cênbnb (M 208,6)

(N 590, 5) - dêlo-muarie (M 446,32)

(N 623,21) - mjatež-ljubbstvo (M 465,16)

(N 603,14) - grable-ljubie (M 455, 8)

(N 216,16) - mnogo-imanie (M 273, 1)

(N 568,17) - srebro-ljubie (M 432,12)

(N 583,24$)$ - razno-liCbnb (M 443,3)

(N 605,19) - razno-iitunb (M 456,10)

Eine besondere Bèhandlung erfahren diejenigen griechischen Komposita, deren erstes Glied von einem Verbum abgeleitet ist und deren Auflösung eine Verbindung von Verbum und Akkusativ-

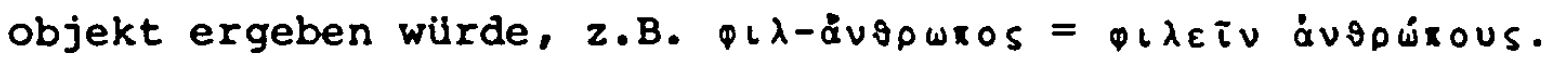
Die Mehrzahl dieser Wörter ist mit der Wurzel $\varphi \iota \lambda$-zusammengesetzt, doch finden auch noch einige andere Wurzeln Verwendung. Nach der Feststellung von VJALKINA herrscht in anderen Denkmälern bei der Wiedergabe dieser Komposita keine Einheitlich- 
keit, z.B. in der Efremovskaja Kormčaja und der Chronik des Hamartolos, sondern sie werden wiedergegeben "... to tocnoj $\mathrm{kal}^{\circ} \mathrm{koj}$, to kal'koj perevernutoj, to slovosoKetaniem" 16). In unserem Denkmal haben wir es hier ausnahmslos mit "perevernutye kal'ki' zu tun, es erfolgt also eine Umstellung der beiden Bestandteile des Kompositums wie auch bei den eigenständigen altrussischen Komposita "...v slovach, sootvetstvujuscich dannoj modeli, komponent, $v$ kotorom zakljuCeno dejstvie, vsegda zanimaet vtoroe mesto" 17). Wir haben also ein weiteres Merkmal der souverănen Sprachbeherrschung des Ubersetzers vor uns:

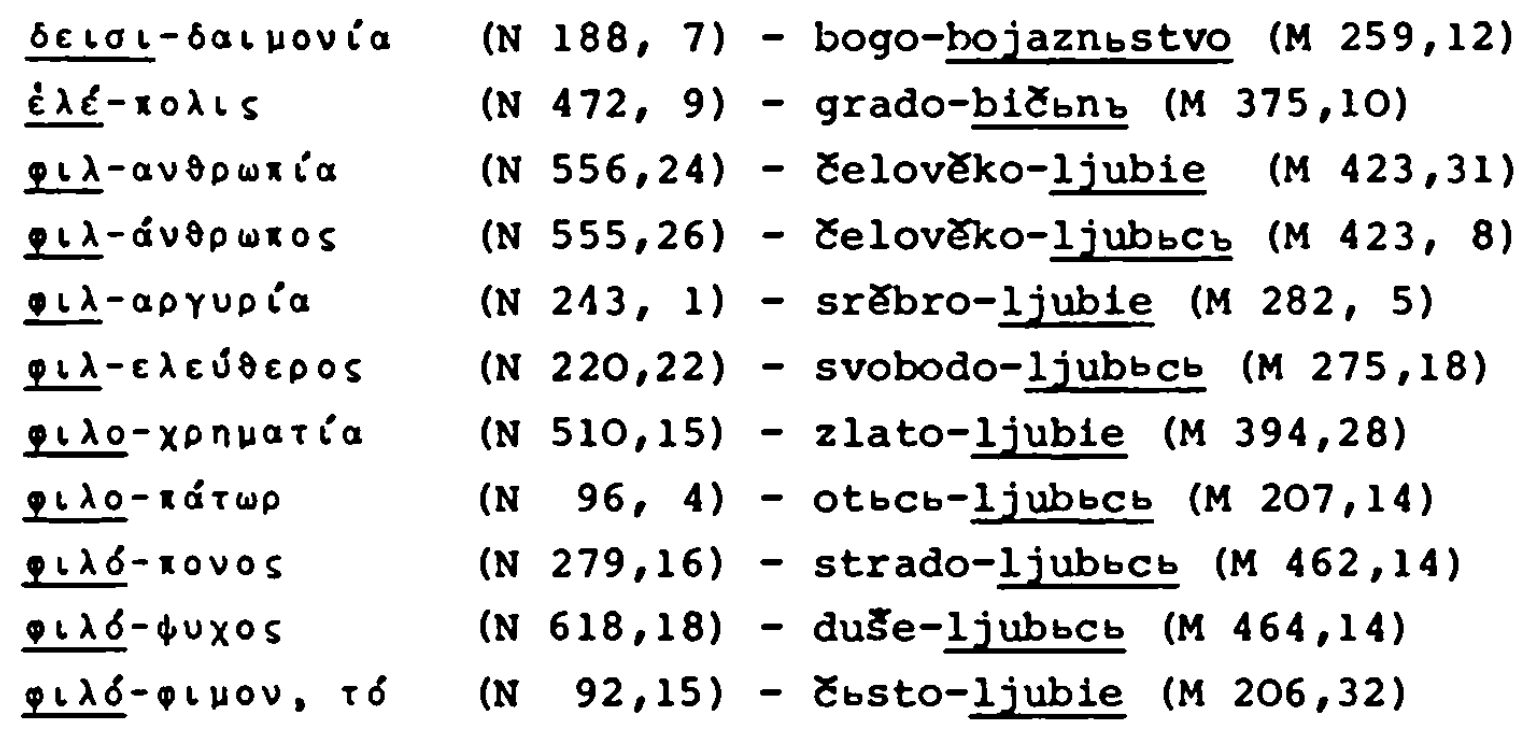

Etwa 60 altrussischen Komposita entsprechen im Original Substantiva simplicia oder simplicia mit Adjektiv. Es folgen einige ausgewăhlte Beispiele:

\begin{tabular}{|c|c|c|}
\hline cerlo-umie (M 466,11$)$ & - ن́rıins ruwiun & $(N 625,4)$ \\
\hline dobro-dxtelb (M 341, 1) & 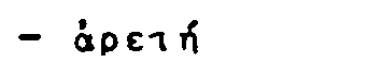 & $(\mathrm{N} 3,92,21)$ \\
\hline kone-ristanie (II 443,27 ) & 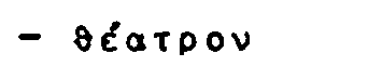 & (N $585,10^{\prime} j$ \\
\hline krae-kamenie (M 178,17) & $-\lambda \iota \vartheta O \iota \delta \xi E \tau \zeta$ & $31,17)$ \\
\hline mnogo-létьstvo (M 433,10$)$ & - $\dot{\alpha} p \times a \iota \delta \tau n s$ & $(\mathrm{~N} 570,1)$ \\
\hline ruko-deistvo (M 253,11) & $-\tau \varepsilon \times \cup n$ & (N 178 , \\
\hline tranno-ljubie (M 220,16) & $-\xi \varepsilon v i a$ & (N 119 , \\
\hline
\end{tabular}

Altrussische Komposita treten auch fur griechische Genitivkonstruktionen (vor allem Gen. obi.) ein:

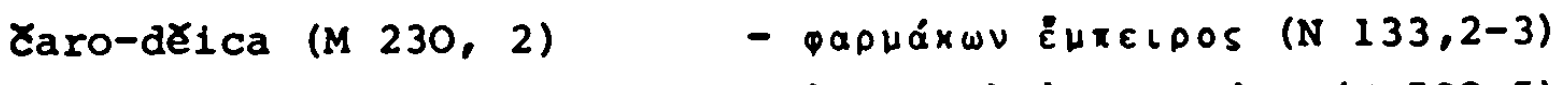

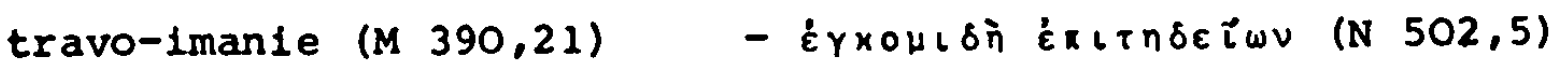


vse-vidbcb (M 350,28)

zlato-imanie (M 219,14)

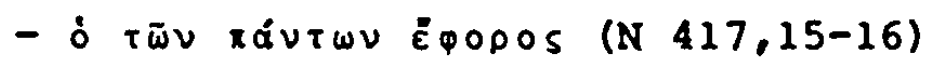

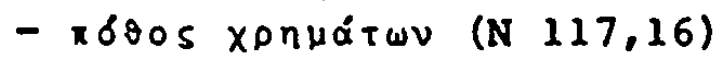

Daneben weist die altrussische Fassung des "Jüdischen Krieges" noch eine Reihe von Komposita auf, die im griechischen Text uberhaupt keine Entsprechung besitzen. Fast die Hälfte davon ist weder bei SREZNEVSKIJ noch bei MIKLOSICH registriert; diese Wörter dürften zum Teil Neologismen des Ubersetzers darstellen. Es handelt sich dabei um folgende Komposita:

\begin{tabular}{|c|c|c|}
\hline brani-starbcb & $1299,22)$ & prjamo-కevbcb \\
\hline Zjudo-sudbcb & $1196,19)$ & prosto-serdie \\
\hline dobro-poltie & $1191,24)$ & ravno-glasbnb \\
\hline dobro-smę̧ınb (M & 1317,111 & rjabo-vidimb \\
\hline dobro-travbnb & $1295,11)$ & vele-durbstvovati (M 262, 9) \\
\hline dvo-razumbnb & $422,6)$ & verch-gradbnb \\
\hline gorno-gradbnb (M & $1280,21)$ & zakono-mudrbcb (M 244,5) \\
\hline kruglo-stranbnb (M & $1368,26-27)$ & zlo-glagolbnikb (M 222,12 ) \\
\hline ljuto-nravie & 1226,311 & zlo-smbrtbnb \\
\hline \multirow[t]{2}{*}{ mnogo-stonanınb (M } & $(444,19)$ & zmie-nogb \\
\hline & & Zesto-slavie \\
\hline
\end{tabular}


3. Kapitel: AUS DER SYNTAX

\section{A. Kasuslehre}

Unter dem Begriff der Kasuslehre versteht die'Schulgramatik der klassischen Sprachen die Lehre von der Verwendung der casus obliqui zum Ausdruck "objektiver" (Genitiv, Dativ, Akkusativ) sowie "rein grammatischer" (Ablatvi, Lokativ, Instrumental, Komitativ) Beziehungen innerhalb eines Satzes ${ }^{1)}$. Für das Griechische haben die erstgenannten drei Kasus die Funktionen der geschwundenen übrigen mitübernommen. ${ }^{2)}$ Im folgenden soll nun dargelegt werden, wie die vielfältigen Funktionen dieser Kasus vom Ubersetzer im Altrussischen ausgedrückt wurden.

\section{Akkusativ}

\section{1) Der Akkusativ bei Verben}

Die Hauptfunktion des Akkusátivs besteht in der Bezeichnung des Objekts transitiver Verba. Dieser Gebrauch "...stimmt mit dem in anderen sprachen uberein und unterscheldet sich nur dadurch, dab die griechische Sprache viele Verbalbegriffe transitiv auffabt, die in anderen Sprachen intransitive sind und mit dem Dative oder mit einer Präposition verbunden werdenn ${ }^{3)}$. Infolgedessen deckt sich auch der Kasusgebrauch nach Verba im Griechischen und Altrussischen nur teliweise, wobel sich jedoch Ubereinstimmungen ergeben können, die beim Vergleich mit einer dritten Sprache fehlen. So handelt es sich $z . B$. bei den Verben - áve $v$ und variti, die belde mit dem Akkusativ stehen, um eine echte Entsprechung:

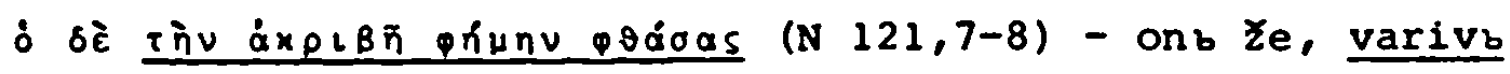
pravuju véstb (M 221, 31-32);

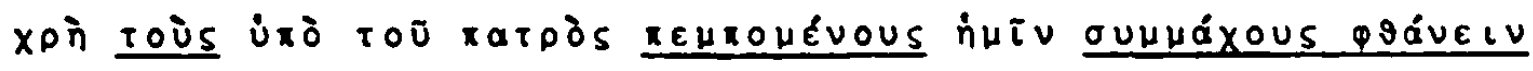
(N 337, 16-17) - 1 lepo namb na slavu variti pomošniky, 1chb Ze chošetb poslati otbcb (M 314,26-27).

Dasselbe gilt auch fur Komposita wie $\delta$ Laßaivelv - preiti, wo Im Griechischen die Präposition $\delta \iota \dot{a}$ ins Verbum gezogen wurde; das 
nunmehr entstandene transitive Verbum regiert denselben Kasus, mit dem die Präposition verbunden wurde. Das slavische Präfix 'prě-' ist zwar von keiner Präposition abgeleitet, doch stünde die entsprechende Präposition 'Ceresb' ebenfalls mit dem Akkusativ; somit ergeben sich auch hier bei der Ubersetzung keine Schwierigkeiten:

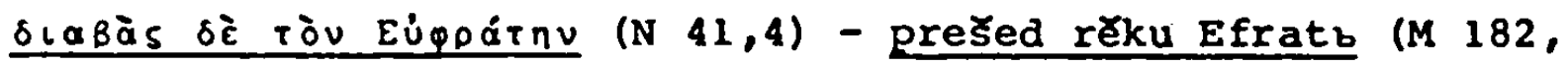
22).

Anders dürfte jedoch der Fall bel 'vladeti' liegen, das sich in unserem Denkmal auch in Verbindung mit dem Akkusativ findet :

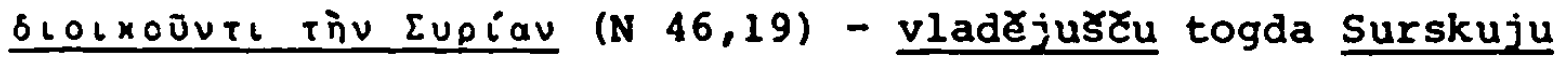
zemlju (M 185,3$)$.

Da dieses Verbum sonst nur mit dem Instrumental oder einer Prăposition vorkommt 4), handelt es sich hier wohl um einen syntaktischen Gräzismus, der durch ein zu enges Festhalten an der Vorlage bedingt ist.

$\mathrm{Zahlrelch}$ sind andrerseits die Fălle, wo das Griechische und das Altrussische voneinander differieren. So haben in der Ubersetzung die Verba des Entfliehens, Sich-Hütens und Fürchtens, die im klassischen und neutestamentlichen Griechisch in der Regel den Akkusativ regieren 5), entweder den bloken Genitiv oder die Präposition 'otb' + Genitiv (Verba des Fliehens) nach sich. Bei dem Genitiv düfte sich es dabei um eine Art separativus handeln: 6)

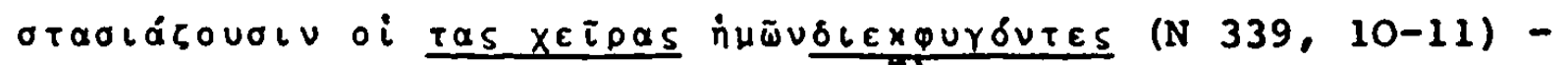
smjatutsja, iže utekse ruk nasich 7$)$ (M 315, 26-27),

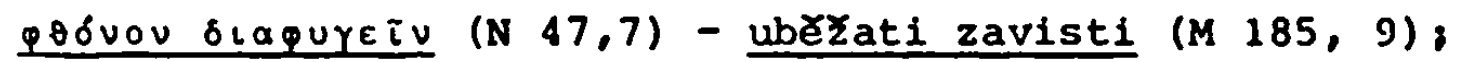

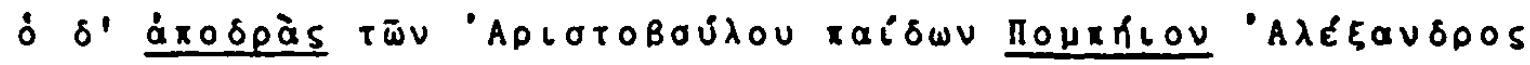
(N 36, 21-22) - Aleksandrb Ze, Aristoulovb synb, iZe ubeZ̃e ot Pompija $(M 181,6)$,

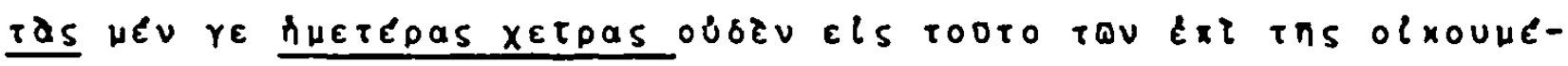

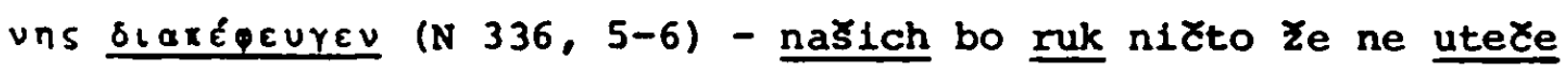
ot vseja vselenyja (M $314,1-2)$; 


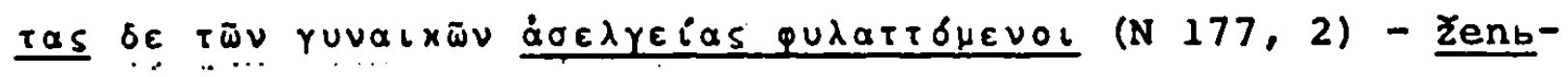
skago stremlenia chranjašesja (M 252, 22-23);

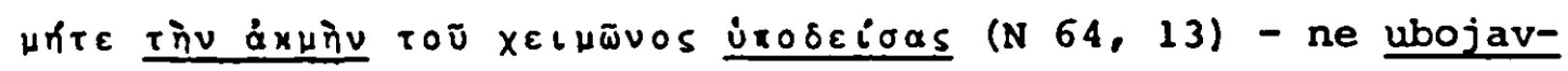
sja zimnjago vrement $(M 191,10)$.

Das letzte Beispiel könnte, ebenso wie das drittletzte, den Gedanken aufkommen lassen, der altrussische Genitiv sei hier durch die Verneinung bedingt. Diese Auslegung muB jedoch zurückgewiesen werden, da sich an anderer stelle (ohne griechische Entsprechung) derselbe Genitiv in einem positiven Satz findet: ubojav Ze sja (Aristoulb) vnezapnago priSestvija (M 178,20).

Freilich treten auch Fălle auf, wo im Altrussischen die Verneinung den Ersatz des direkten Akkusativobjekts durch den Genitiv hervorruft. So kann hel dem ersten der nachstehend zitierten Beispiele der Genitiv sowohl von der Verbalrektion - 'Zbdati' regiert in allen bei SREZNEVSKIJ angefürten stellen den Genitiv 8) - wie auch von der Vernelnung herrühren, in den anderen beiden aber hängt der Genitiv einwandfrei von der Negation ab. Grammatisch ist dieser Genitiv unter dem partitivus einzuordnen 9):

oủsè duahévovolv toús xalpoùs (N 284,20) - 1 ne Zdutb vremene (M 296,17):

oi xeplsqoual thiv UBpLv (N 175, 21) - to ne prezrju obidy

(M 252, 5):

oú Yào évoisou xoóvov (N 31,14) - ni dadjałe vremeni (M 178, 13).

Hierher gehört auch die Rektion von 'nenavidðti', bei dem augenscheinlich das Präfix 'ne-' noch als echte Negation empfunden wurde:

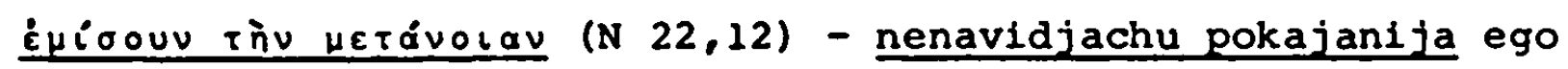
1 neutvěržnago norova ( $1173,34-35$ ).

Mit dem Dativ stehen abweichend von der Konstruktion des Grie-

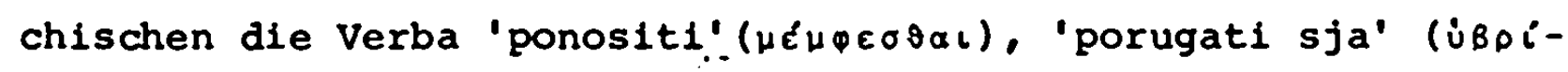
$\zeta \varepsilon(v)$ und 'diviti sja' (oauhárelv): 


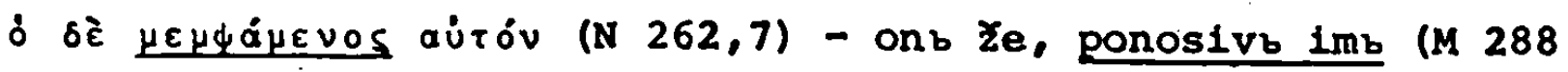
21: imb 1st hier Dativ Plural);

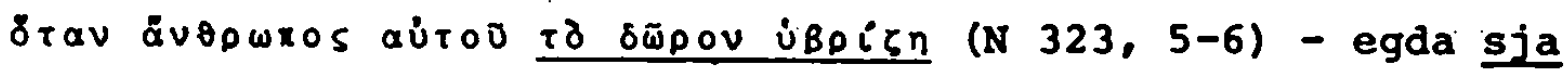
daru ego porugajutb (M 309,1$)$;

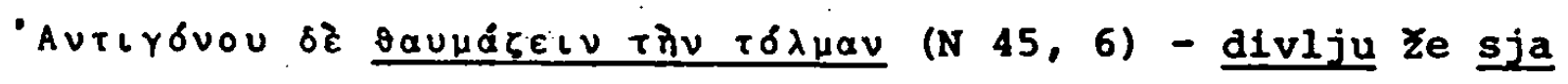
Antigonovu bezstudstvu (M 183,29);

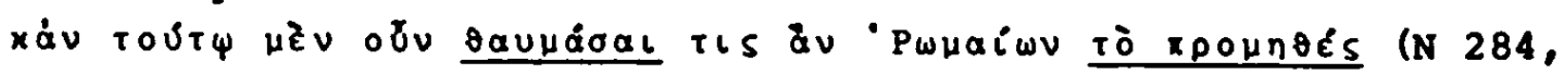
12) - tĕmb Ze uaivitsja kto rimskoma promyslu (M 296,10):

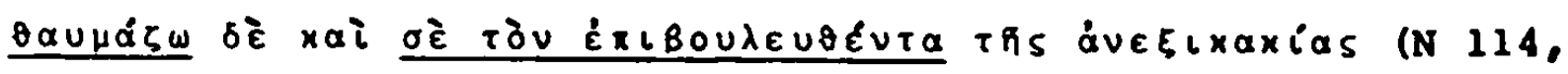
8-9) - divljusja 1 tober o trbpenil (M 217, 2):

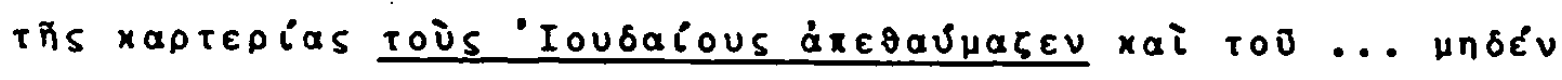

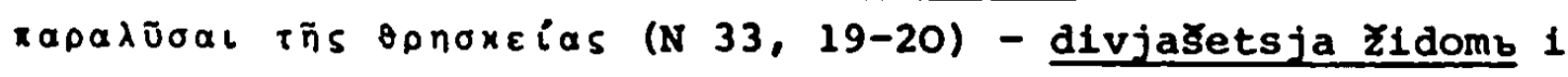
tbrpenija radi 1 zakona chranenija (M 179, 23-24).

Der griechische Genitiv der Sache, der den Grund der Bewunderung anzeigt, ist in den beiden letzten obigen Beispielen durch kausale Präpositionalwendungen wiedergegeben. Auch das griechische Akkusativobjekt nach den Verben des Trauerns und Beklagens wird in der Ubersetzung durch Prăpositionalausdruck vertreten:

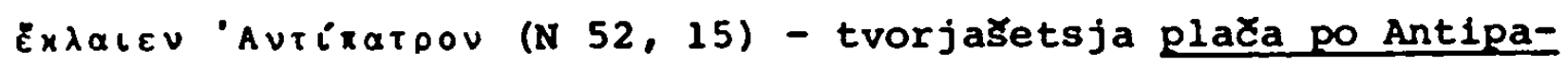
te (M 187, 28-29).

Bei einer Reihe transitiver Verba. (meist der Bewegung) steht Im Altrussischen das objekt im "tvoritel'nyj padez ob'ekta". welcher "... oboznacaet predmet, polnost' ju ochvacennyj dejstviem sub'ekta" 10). Den Unterschied zwischen dieser Konstruktion und der des Akkusativobjekts definiert POTEBNJA folgendermaßen:

"...meždu glagolom s tvoritel’nym 1 glagolom s vinitel‘nym voznikaet ta raznica, Cto $v$ pervom slucae vnimanie sosredotoceno na samom dejstvil, kotoroe možet byt' bescel'no, a vo vtorom - na dopolnenil, $v$ kotorom vyrazena blizajłaja, vpolne opredelennajá cel'avizenijan: 11)

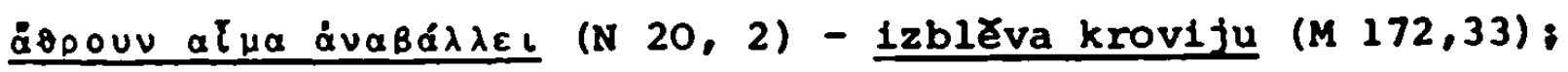

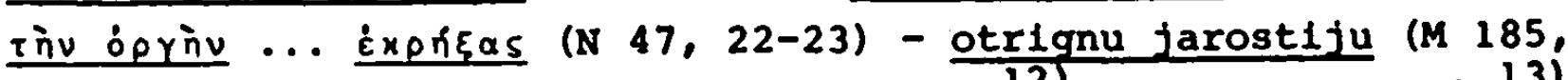
24). Bei SREZNEVSKIJ kommen 'izblovati' 12) und 'otrignuti' 13) nur mit dem Akkusativ vor. 
2) Der doppelte Akkusativ

Der doppelte Akkusativ steht im Griechischen als objektsakkusativ nach den Verben des Lehrens und Erinnerns. Dabei wird neben der Person (dem unmittelbaren objekt) auch die Sache, die gelehrt oder an die erinnert wird, in den Akkusativ ge-

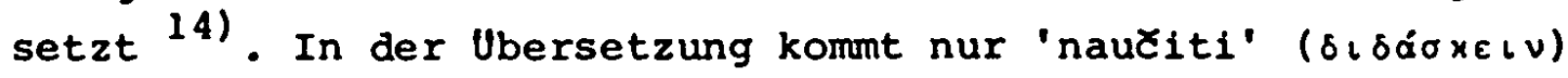
in Verbindung mit dem doppelten objekt vor, wobei das Sachobjekt, der Vorliebe des Slavischen für den Dativ entsprechend, in diesem Kasuś steht:

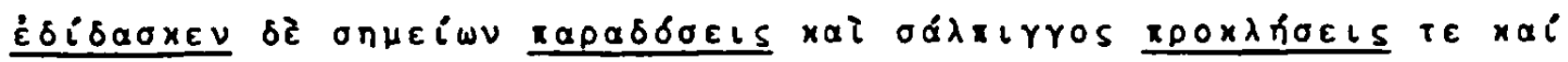

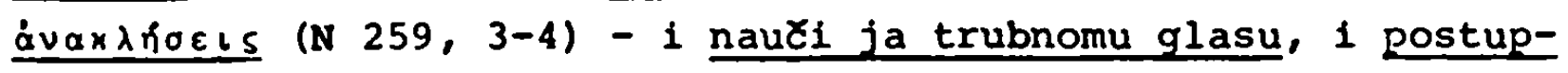
leniju $i$ otstupleniju (M 287, 1-2)

Als "...ein Akkusativ des Objekts und ein Akkusativ des Prädikats" 15) steht der doppelte Akkusativ nach den Verba des Ernennens und Machens 'zu etwas'. Der Ubersetzer folgt hier zum Teil dem Original und setzt ebenfalls einen zweiten Akkusativ:

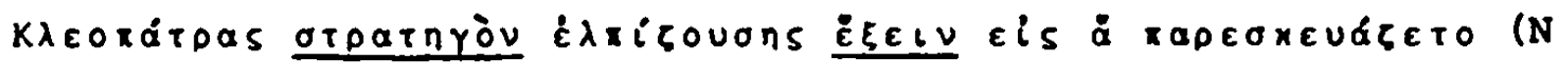
64, 11-12) - Kleopatra...chotjasti ego postaviti voevodu u sebe (M 191, 8-9);

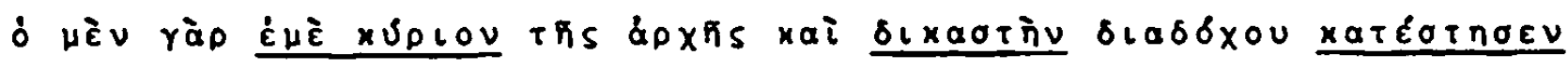
(N 105, 4-5) - cesarb mene postavil gospodina esarstvu $i$ sudiju dostoina (M 212, 25-26):

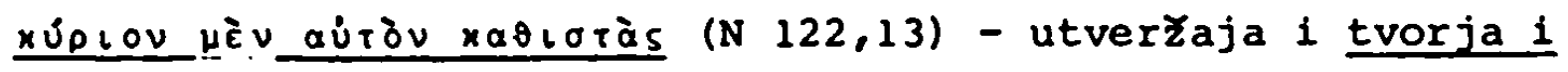
gospodina (M 22,29).

Zahlenmäвig stärker vertreten ist jedoch die Konstruktion mit dem Akkusativ des objekts und dem prädikativen Instrumental:

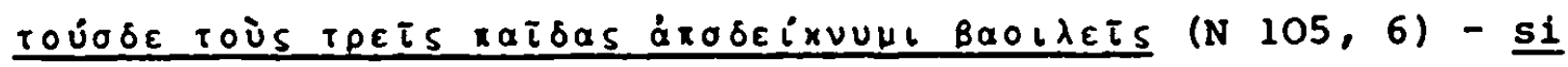
Ze tri syny postavlju cesarbmi (M 212, 7);

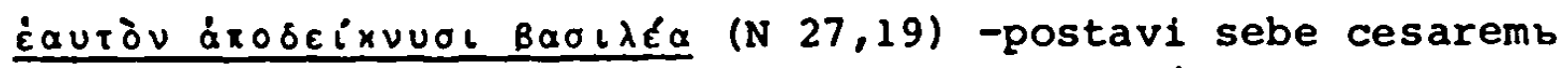
(M 176, 13). Weitere Beispiele siehe N 20,18-19/M 172,10-11; N $51,18-19 / \mathrm{M} 187,10$; N $65,7 / \mathrm{M} 191,15-16$; N 170,14-16/M 248,1213 und passim.

Nach LOMTEV ist der prädikative Instrumental bereits in der 
ältesten zeit häufiger vertreten als der Akkusativ: "Pri glagolach so znaCeniem naznaCenija, izbranija, 'delanija kogolibo Cem-libo' vtoroj vinitel'nyj upotrebljalsja v drevnejకich pamjatnikach menee intensivno, Cem tvoritel'nyj predikativnyj" 16)

In unserem Denkmal hält sich jedoch der Ubersetzer nicht immer an die grammatischen Entsprechungen und bringt neben dem prädikativen Akkusativ und Instrumental auch freiere Ubersetzungen, etwa durch die Verwendung transitiver, phraseologisch produktiver Verbalgruppen wie z.B. 'dati' mit seinen Komposita: ${ }^{17}$ )

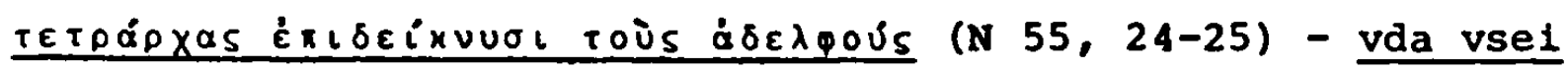
bratil Cetverovlastnoe (M 189, 4).

Im Passiv wird der griechische doppelte Akkusativ zum doppelten Nominativ 18). Diese Konstruktion ist dem Altrussischen wie dem Slavischen uberhaupt fremd; sie wird daher in freierer Ubersetzung wiedergegeben:

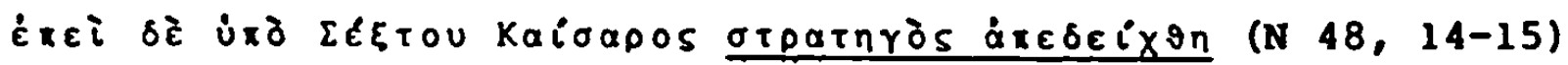
- 1 potomb Sekstb Cesarb via Irodovi voevodstvo (11 186, 2-3):

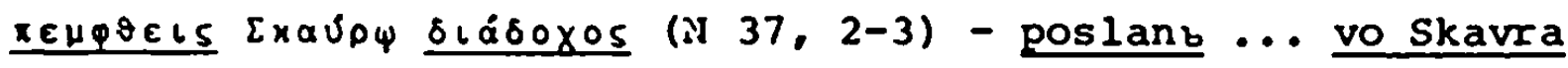
mêsto $(M 181,10)$.

Dasselbe gilt für das persönliche Passiv (aus aktivem AcP), das in der Ubersetzung meist in ein unpersönliches umgewandelt wird, und den Prädikatsnominativ bei kopulativen Verba:

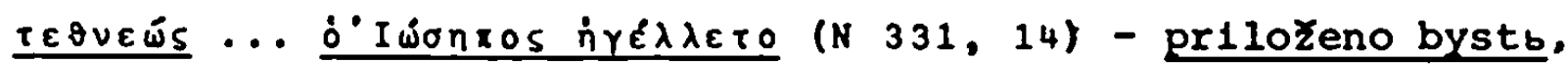
jako Iosif ubienb bystb $(M 312,14)$;

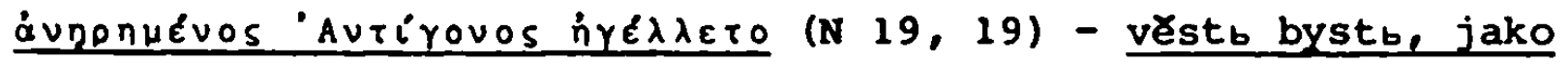
Antigon ubbenb bystb (M 172, 30):

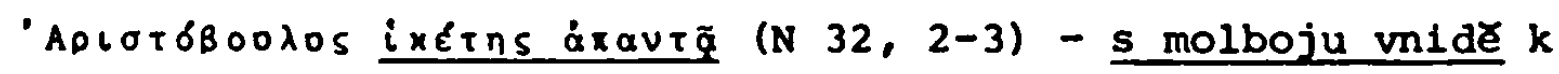
nemu (M 178, 20-21):

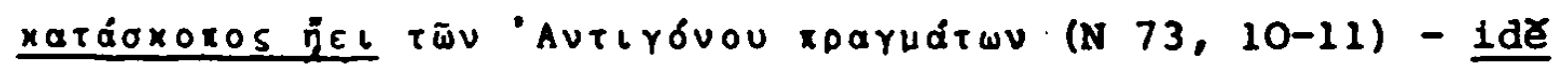
$k$ gradu razgljadati Antigonovu silu (M 194, 27). 
Besonders die belden letzten Beispiele, wo der prädikative Nominativ einmal durch einen Präpositionalausdruck (modal), das andere Mal durch einen finalen Infinitiv wiedergegeben ist, zelgen deutlich, das hier nicht mechanisch ibersetzt wurde, sondern daB der Ubersetzer nach der Erfassung des Sinnes diejenigen sprachlichen Mittel wălte, die dem Altrussischen am ehesten entsprachen.

Sollte aber der doppelte Nominativ doch einmal möglichst wortgetreu ubersetzt werden, dann erscheint auch im Altrussischen der Prädikatsnominativ, aber immer in der Verbindung mit 'jako', was auch der deutschen Ubersetzung mit 'als' entspricht:

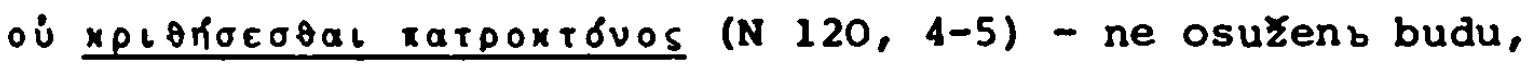
jako otbca ubiecb (M 221,10).

3) Der adnominale Akkusativ

Beim Nomen kommt der Akkusativ im Griechischen in zwei Funktionen vor, als Akkusativ der Zeitangabe (Accusativus temporis) und als Akkusativ der Beziehung (Accusativus limitationis, Accusativis graecus).

a) Der Akkusativus temporis, der ubrigens weit seltener auftritt als der Dativus temporis 19), gibt in Verbindung mit einem Ordinale an, wann eine Handlung stattgefunden hat. $\mathrm{zu}$ seiner Wiedergabe verweńdet der Ubersetzer die Präposition $v_{b}+$ Akkusativ:

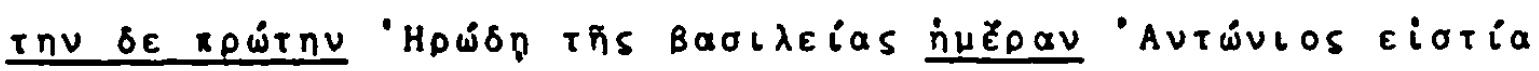
(N 66, 3-4) - $\mathrm{vb}_{\mathrm{b}}$ pervyi Ze donb cesarbstvija ... Antonil Ze obed emu ustroi (M 192, 1-2).

b) Der Akkusativ der Beziehung ist einem Wesen nach ein Akkusativ des Inhalts 20). Er bezelchnet den Gesichtspunkt, von dem aus über eine Person oder einen Gegenstand etwas ausgesagt wird, das Kriterium, in Hinblick auf welches eine Wertung erfolgt. Er ist demgemäB abhängig von Wortarten, die eine Eigenschaft bezeichnen, also in erster Iinie von 
Substantiv und Adjektiv, von einem Verbum dagegen nur dann, wenn dieses seiner Semantik nach auch durch ein Adjektiv + sein ersetzt werden kann. Am häufigsten findet er Verwendung bei Angabe einer Volkszugehörigkeit oder eines Namens. In diesem zusammenhang ist er in der Ubersetzung stets durch den Instrumental wiedergegeben:

- Iousaios uèv to révos (N 172, 17) - rodom luderi (M 279, 14):

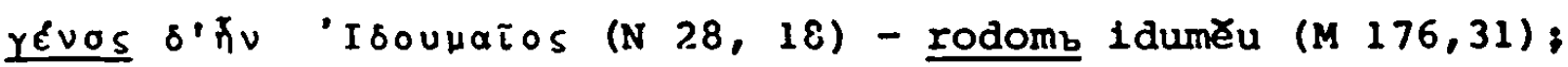
otpatıítns, övoha Tipwu (N 124, I) - volnb někto, imenem Titb (M 223, 29):

Kúxpov toüvoua, (N 41, 12) - imenemb Kuprosb (M 182, 24): EaBivos toũvora, yévos áxó Eupias (N 520, 4-5) - muz nékyi imenemb Savinb, rodom sirianinb (M 401, 17-18).

Bezüglich der Wortstellung ist hier bemerkenswert, daB im Griechischen der Akkusativ sowohl (ohne Artikel) vor als auch (mit Artikel) nach seinem Beziehungswort stehen kann, wăhrend im Altrussischen der Instrumental stets an erster stelle steht.

Auch der von einem Adjektiv abhängige Accusativus limitationis wird in der Regel wiedergegeben durch den limitativen Instrumental (tvoritel'nyj ogranicenija), der auch im modernen Russisch verbreitet ist ${ }^{21}$ ):

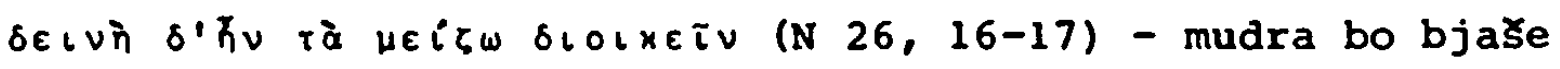
rasmotreniemb (M 175, 31)

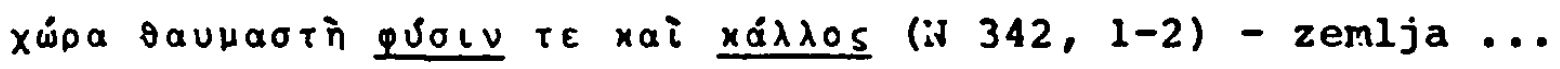
Cjudna estostvom 1 krasotoju (M 317, 8-9):

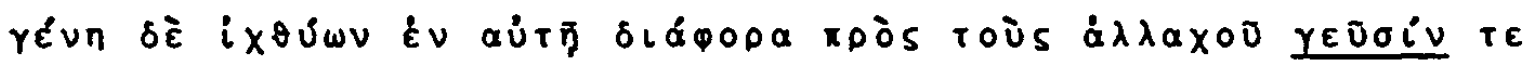

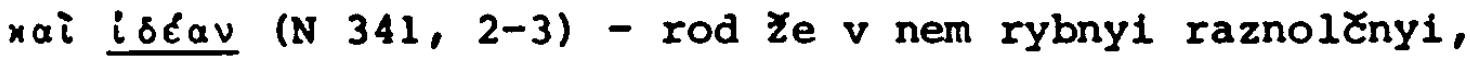
krome inêch rybb vidêniemb i jadeniemb (M 316, 23-25):

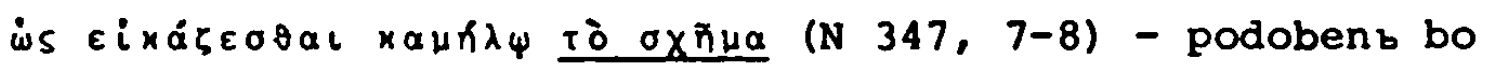
estb obrazom vel bbudu ( $M 319,15)$.

Uber die adjektivische Wertung von $\varepsilon i x a j \zeta \varepsilon \sigma \theta \alpha \iota$ im letzten 
Beispiel vgl. oben 22). Im Altrussischen ist es dementsprechend durch Adjektiv + 'byti' wiedergegeben.

Der im klassischen Griechisch äußerst produktive Accusativus limitationis erfährt in der Sprache des Neuen Testamentes, die ja dem griechischen Original des "Jüdischen Krieges" zeitgenössich war, nur mehr "... einen sehr beschränkten Gebrauch, da seine Funktion fast ganz auf den Dativ ubergegangen ist" ${ }^{23)}$. Bei Iosephus, der "... überhaupt seinen stil gern mit Reminiszenzen aus der altesten Literaturepoche ausschmulckt" 24), ist der Akkusativ noch ziemlich häufig vertreten. Doch kommt es vor, daB bel einer Aneinanderreihung zweier Limitative der eine im Akkusativ, der andere dagegen im Dativ steht. Für die Ubersetzung hat diese Inkonsequenz keinerlei Bedeutung, da auch der limitative Dativ in der Regel durch den altrussischen Instrumental wiedergegeben wird 25):

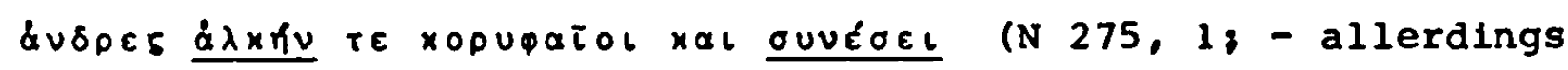
liefern die codices MLVRC, die nach MESCERSKIJ hauptsächlich die Vorlage für die (b)ersetzung stellten 26), hier die Lesart ojveolv) - muzi vrbchovnii siloju $i$ mudrostiju (M 293, 2-3)

Der Ubersetzer beschränkt sich aber nicht auf die Wiedergabe des Accusativus limitationis durch den Instrumental. Als weitere Ubersetzungsmöglichkeiten nüzt er die Verwendung von

a) Prăpositionalausdrilcken:

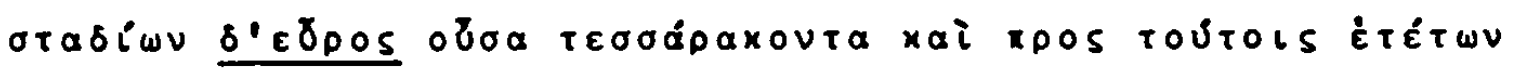
Exatov to $\mu$ గxos $(N 340,17-18)$ - estb Ze usire (Vol. vSiré) 40 verstb, a $\underline{v}$ dolgotu 100 (M 316, 21),

B) Partizipformen eines transitiven Verbums:

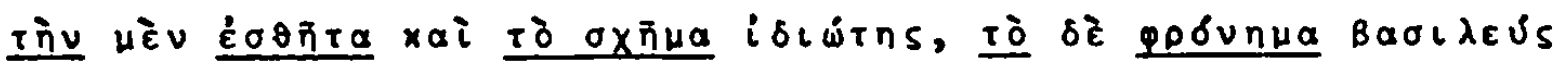
(N 89, 4-5) - rizy 1 obrazb prosto nosja, umb Ze cesarbskyi Imeja (M 203, 3-4):

r) Partizipialkonstruktionen mit absolutem Akkusativ:

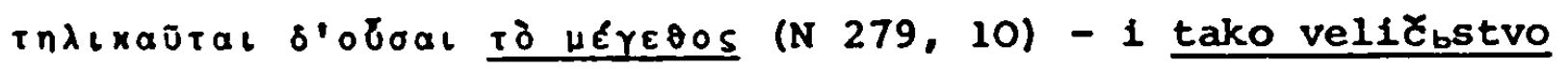
suste ima (M 294, 25); 
8) Adjektiva

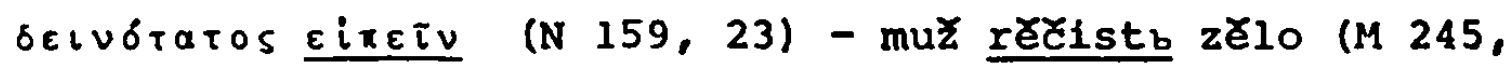
21-22).

Der Accusativus limiationis tritt auch auf beim persönlichen Passiv und reflexiven Medium mancher Verba; das altrussische Reflexivum regiert aber in diesem Fall denselben Kasus wie das Aktiv (hier den Genitivus separationis ${ }^{27}$ ):

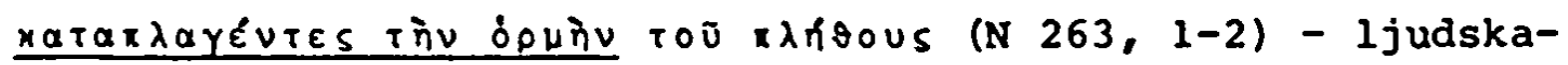
go stremlenia užaš̃esja (M289, 34-35);

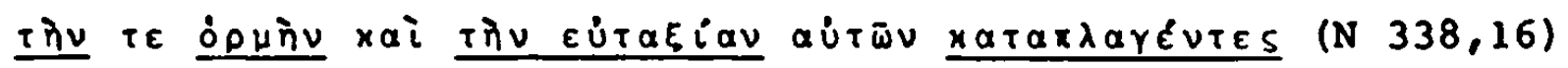
- iuderi užasołasja ustrêmlenia ich i ispolerenia (M 315, 12).

Eine Sonderform des Akkusativs der Beziehung stellt der adverbielle Akkusativ dar. Eine Reihe von Akkusativen (meist Neutra von Adjektiva und Pronomina) ist zu Adverbia erstarrt. In der tbersetzung sind sie entweder wörtlich wiedergegeben oder durch ein Adverb oder den modalen Instrumental vertreten, wobei letzterer vornehmlich für einen mehrgliedrigen Advertialakkusativ des Originals eintritt:

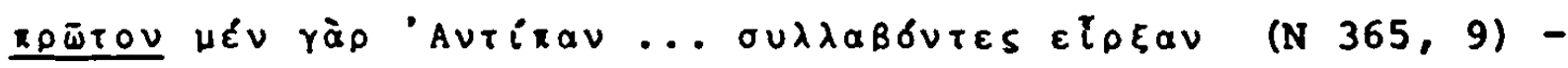
pervoe bo ubisa Antipu (M 328, 19);

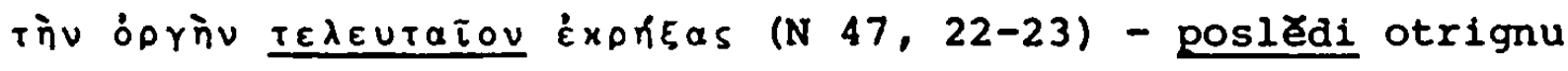
jarostiju (M 185, 23);

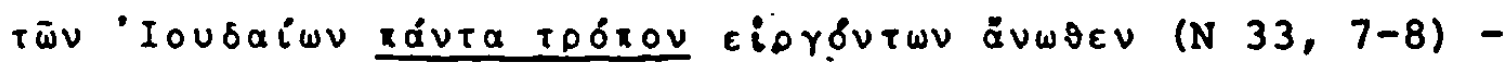
Zidomı borjusðimb svyకe vsjakoju pristroeju (M 179, 14-15).

Allgemein läßt sich also feststellen, daB die genau Entsprechung des griechischen Akkusativs der Beziehung durch den altrussischen Instrumentalis limitationis gegeben ist, der hier, wie im Griechischen der Akkusativ, eine Funktion des ursprünglichen Ablativs übernommen hat ${ }^{28)}$. Die Wiedergabe des Accusativus limitationis durch den Instrumental ist 
also die dem Original am năchsten kommende Ubersetzungsweise und daher auch an hăufigsten anzutreffen; die ubbrigen oben aufgezeigten Möglichkeiten stellen stilistische Varianten und freiere Ubersetzungen dar.

11. Dativ

Der Dativ ist im Griechischen ein "Mischkasus", der "... neben seinen ursprlinglichen Funktionen zugleich den Instrumentalis ... und den Lokativ" vertritt 29).

Der eigentliche Dativ kann "... Im Gegensatze zu dem Akkusative, dem Kasus des unmittelbaren Objektes, ... der Kasus des entfernteren oder des mittelbaren objektes genannt werden, denn während der Akkusativ den Gegenstand ausdrückt, der in unmittelbarer Beziehung $z u$ dem Prädikate steht und dasselbe ergänzt, bezeichnet der Dativ den Gegenstand, der zu der im Satze ausgedrickten Handlung nur eine mittelbare Beziehung hat" 30). Diese Dativfunktion des indirekten Objekts hat das Griechische als indogermanische Sprache mit dem slavischen gemeinsam, und wir finden dementsprechend auch in unserem Denkmal keine grundsatzlichen Abweichungen:

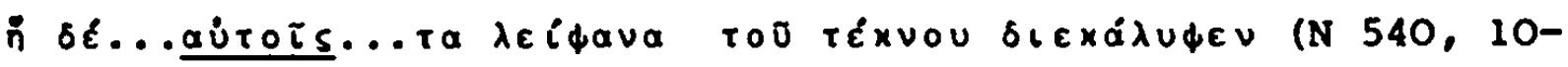
11) - 1 otkry imb ostanok Cada (M 413, 18).

\section{1) Der ablativische Dativ bei Verben}

In Vertretung des Ablativs steht nach Verba im Griechischen der Dativus sociativus (oder comitativus). Er *... bezeichnet in komitativem sinne die person oder sache, mit der zusamen (unter deren Mitwirkung oder Gegenwirkung) eine Handlung vor sich geht" 31). Dabei handelt es sich vor allem um "....Verben der Gemeinschaft, der Vereinigung, des Verkehrs" ${ }^{32}$ ) sowie um solche "... des streitens und Wetteiferns", 33), die in der Regel als Komposita auftreten. In unserer Ubersetzung ist dieser Dativ fast ausschlieblich durch Präpositionalwendungen wiedergegeben. Eine der wenigen Ausnahmen bildet áviḱxєv, dessen alt- 
russische Entsprechung, nämlich 'protiviti sja', selbst den Dativ regiert ${ }^{34)}$ :

$\tau \tilde{\varphi} \dot{\varphi} \vartheta \omega \cup \tilde{Q} \dot{\alpha} \nu \tau \dot{\varepsilon} x \varepsilon \iota$ - protivitisja zavistiju $\left.{ }^{35}\right)(M 172,20)$.

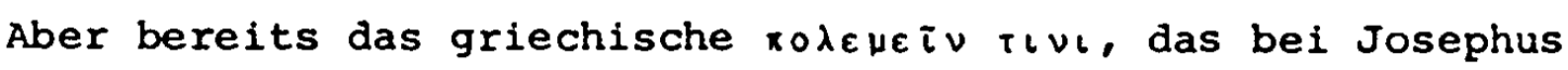
eine Anlehnung an die Sprache der klassischen zeit ist, weil es im NT nur mehr in der Konstruktion $\mu \varepsilon \tau \alpha^{\circ}$ T ( vos vorkommt 36 ) wird übersetzt durch 'zaratiti sja + sb':

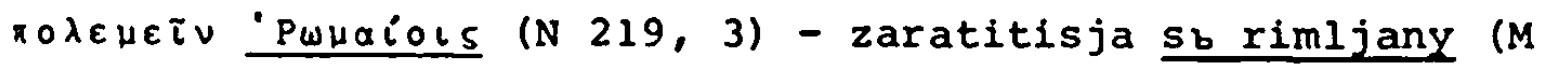
$274,15-16)$.

Bei den präfigierten Verba des Griechischen läßt sich feststellen, daß in der Ubersetzung dem Präfix ouv- die Präposition 'sb' + Instrumental, xpos- in der Bedeutung "hinzu" $\mathrm{kb}$ + Dativ (mitbedingt durch das altrussische Präfix 'pri-' der betreffenden Verba), $\dot{\varepsilon} \times l-' n a '+$ Akkusativ (altrussisches Präfix 'vbz-') und '́v- 'vb' + Lokativ entspricht:

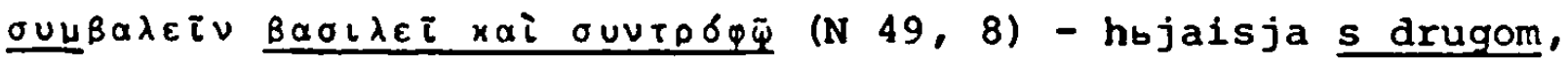
i s gospodinom (M 186, 17);

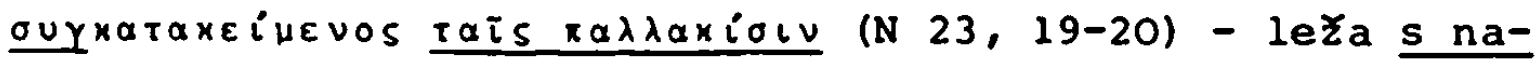
loznicami (M 174, 23-24);

Tais dugperivals ounpopais noogoeival thu eis tov xitoavta

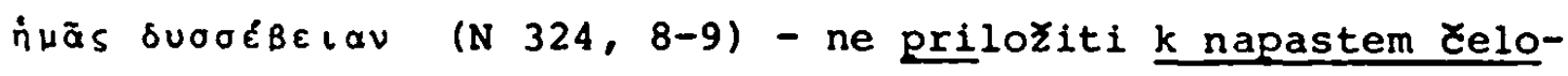
vę̌skim gněva zižditeleva (M 309, 22-23);

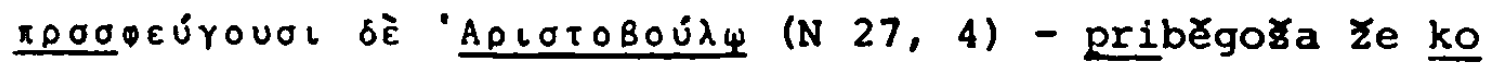
Aristoulu (M 176, 4);

RpoO

- prilozja k dobromu zjatju dకCerb (M 216, 38);

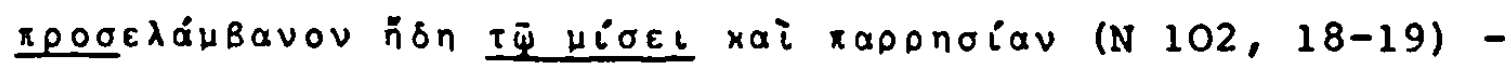
$i$ primaseta Ze $k$ nenavisti derznovenie (M 210, 32-33);

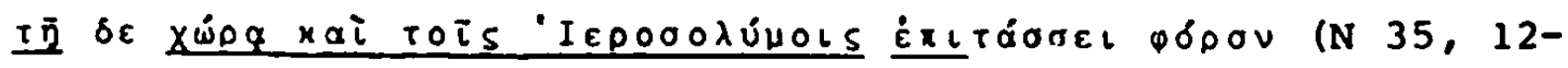
13) - vozloði dannaja Cisla na vsju TjudXisku zemlju i na 
Ierusalimb (11 180, 20-21):

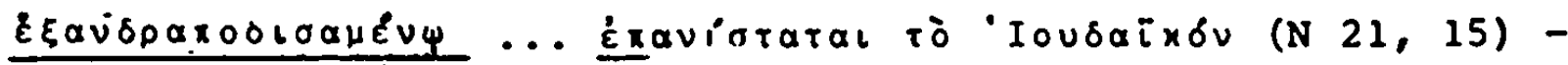
Zidove ... vbstasa na cesarja (M 173, 21);

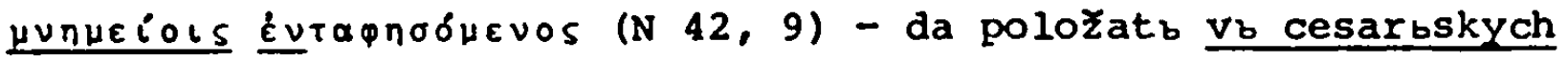
grobechb (M 183, 6).

2) Der adnominale ablativische Dativ

a) Der Dativus instrumenti

Der griechische Dativ bezeichnet ferner in Vertretung des Ablativus instrument1 "... als Instrumentalis im eigentlichen Sinne das Mittel und Nerkzeug" 37) "mit dessen Hilfe eine Handlung durchgefuhrt wird. Da das Altrussische für diese Funktion einen eigenen Kasus, eben den Instrumental, besitzt, ergibt sich hier eine eindeutige Ubersetzung:

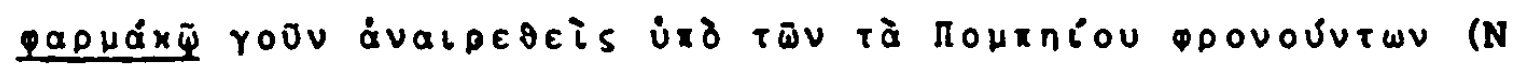
42, 5-6) - otravisa bo ego zeliemb Pompievi prijateli (M $183,3)$ :

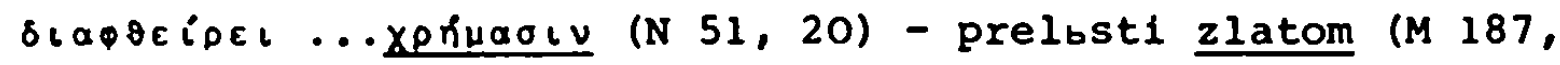
12-13):

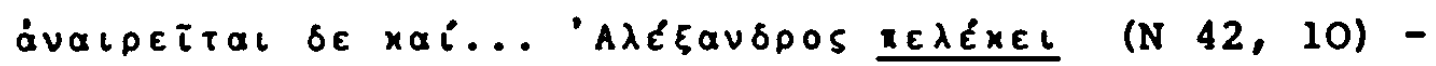
ublens bystb 1 ... Aleksandrb okbsevbju $(M 183,7)$.

Weitere Beispiele siehe $\mathrm{Nr} .27,12 / \mathrm{M} 176,8-9, \mathrm{~N} 32,3-4 /$ $M 178,21 ; \mathrm{N} 33,2 / \mathrm{M} \mathrm{179,8;N} 35,11-12 / \mathrm{M} 180,18-19 ; \mathrm{N} 47,22 /$ $M 185,23 ; N 53,13-14 / M 188,27-28$ und passim.

Eine Abart des instrumentalen Dativs ist der Dativus causae, der Im Griechischen Verwendung findet, "... um einen Grund oder Beweggrund, eine Ursache zu bezeichnen" 38) . Obwohl "...dlja oboznaCenija priciny ili osnovanija tvoritel 'nyj padez కiroko upotrebljalsja 1 v drevnerusskom jazyke" 39). wird der Dativus causae in unserem Denkmal nur zum Teil durch diesen wiedergegeben. Der Ubersetzer läBt ihn abwechseln mit kausalen Präpositionalwendungen: 


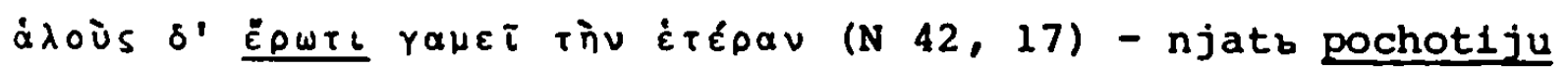
1 poja mentsuju (M 183, 10-11):

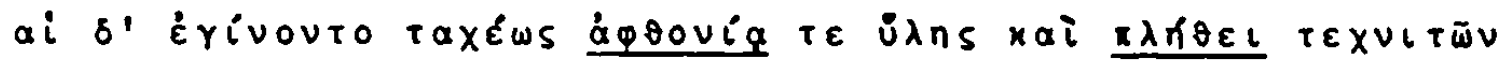
(N 340, 14-15) - 1 skoro ustroisa obiliemb dreva 1 mnoŽestvom dêlatelb (M 316, 18): .

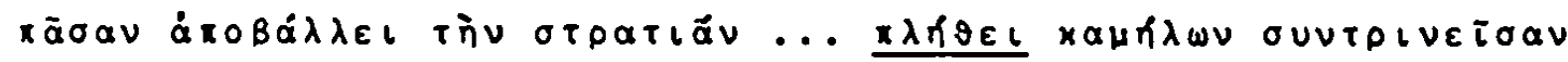
(N 22, 4-6) - vsju silu svoju pogubi ... ot množstva velbbud $(M 173,29)$ 39a):

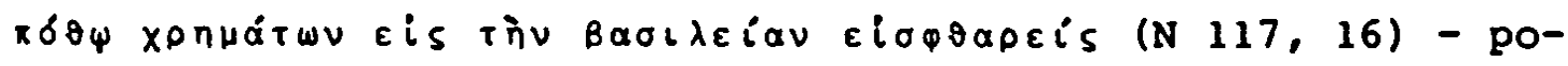
gubi zlatoimania radi (M 219, 14).

Eine weitere Untergliederung des Dativus instrumenti haben wir im Dativus modi vor uns, der die Art und Weise bezeichnet, auf die eine Handlung durchgefuhrt wird ${ }^{40)}$. Wiedergegeben wird er in der Ubersetzung durch den Instrumental:

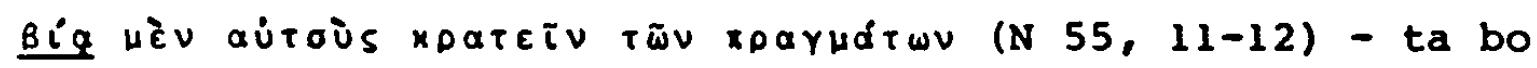
brata otjasta vse $k b$ sobe nasiliemb (M 188, 27-28).

Als instrumental empfindet das Griechische auch den Dativ bei Ortsbezeichnung nach Verben des Aufnehmens und Unterbringens 41). Das Altrussische betrachtet ebenso wie das Deutsche diese Beziehung als rein lokal und gibt den Dativ durch Präpositionen mit räumlicher Funktion wieder:

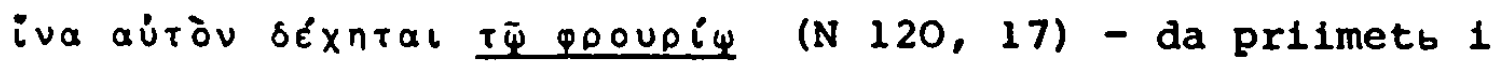
vb grad ( 221,20$)$.

b) Der Dativus limitationis

Der limitative Dativ, der, wie bereits oben erwăhnt 42), in nachklassischer zeit den Akkusativ der Beziehung immer mehr verdrängt, tritt auch in unserem Denkmal ziemlich häufig auf. Ubersetzt wird er wie jener durch den Instrumental:

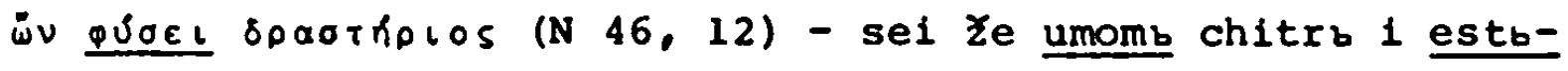
stvom (M 184, 30), 


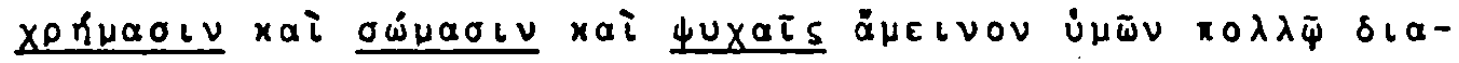
xeinevol (N 221, 2-3) - luesi nas susci dusami 1 texiomb 1 imeniemb (M 275, 21);

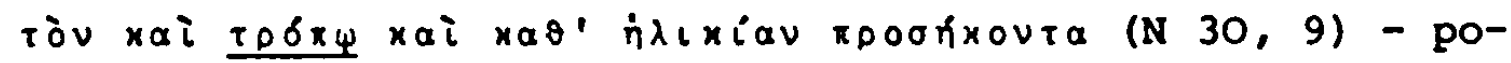
dobnago nravomb $i$ vozrastomb(M 177, 27-28).

c) Der Dativus commodi

Im Dativ erscheint im Griechischen ferner "... die Person oder persönlich gedachte Sache, zu deren Vorteil oder Nachteil eine Handlung vollzogen wird, wie uberhaupt die an der Handlung interessierte Person" 43). Dieser Dativus commodi taucht in der Ubersetzung entweder als objektsgenitiv oder als Präpositionalausdruck auf, wobei die Präposition die Einbezogenheit der betreffenden Person in die Handlung ausdrückt :

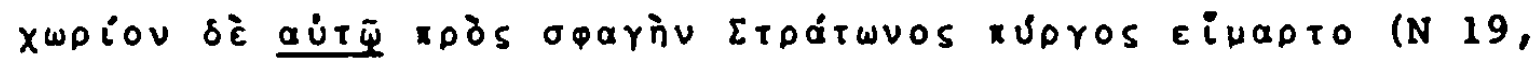
15) - mésto (em.n.A) そe ugotovano na ubilstvo ego (M 172, 16 :

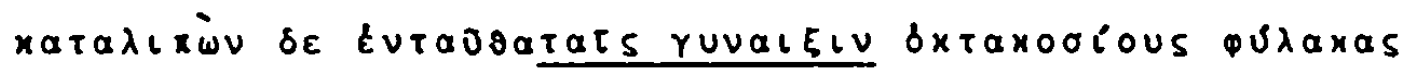
(M 61, 9-10) - ostavi 으 (em.n.I) ̌eni storozev 8 sot (M 172, 26).

Die Wahl des Terminus 'datel'nyj zainteresovannogo lica' in Hinblick auf den Dativus ethicus, wie sie LOMTEV handhabt 44), kann kaum akzeptiert werden, da dieser Terminus fur den D. commodi reserviert werden sollte.

d) Der Dativus temporis

Er bezeichnet den Zeitpunkt einer Handlung (auch das Datum) und tritt meist in Verbindung mit ordinalia auf. Ebenso wie der Accusativus temporis wird er im Altrussischen durch die Präposition ' $v b^{\prime}+$ Akkusativ ubersetzt ${ }^{45}$ ):

IpiTu rap unui (N 34, 4) - vb 3 mésjacb $(M 179,28)$. Weitere Beispiele sind zahlreich über den ganzen Text hin verstreut. 
III. Genitiv

Der Genitiv ist im Griechischen ebenfalls ein Mischkasus und übernimmt neben seinen ursprünglichen Funktionen auch Teilfunktion von Ablativ und Lokativ.

1) Der eigentliche Genitiv

Er findet vor allem Verwendung, "... um den Begriff eines Substantivs näher (qualitativ oder vesentlich) zu bestimmen... ...Wie aber der Gebrauch des Akkusativs sich erweiterte, und auch intransitive Verben und Adjektive inr unmittelbares objekt im Akkusative $z u$ sich nehmen, so geschah dies auch bei dem Genetive, und er wurde auch gebraucht, um ein intransitives Verb und ein Adjektiv năher zu bestimmen. 46). Einteilen läBt sich der eigentliche Genitiv in vier Untergruppen:

a) Der Genitivus subiectivus

Hier haben wir im Griechischen eine Konstruktion vor uns, in der "... der Genetivbegriff sich als Subjekt der im regierenden Nomen liegenden Handlung betrachten läBt: ФठB०S

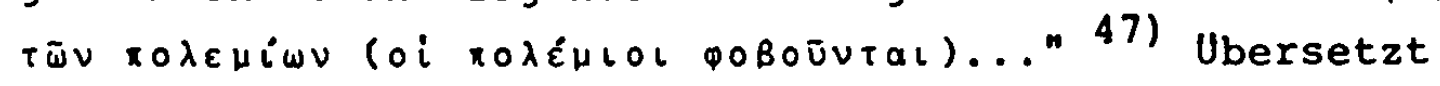
wird der Subjektsgenitiv in unserem Denkmal stets durch eine adjektivische Bestimmung; besonders zahlreich sind dabei Possessivadjektive vertreten:

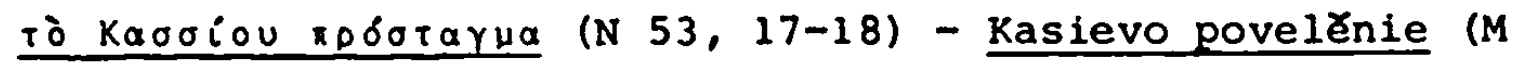
$188,5)$;

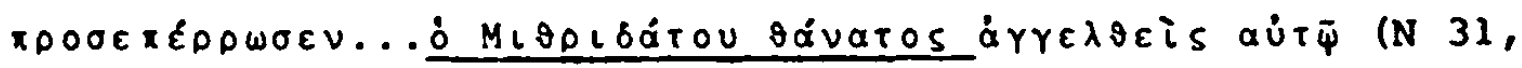
15-16) - slyకavb Ze Mifriidatovo skon Zanie (M 178, 14-15);

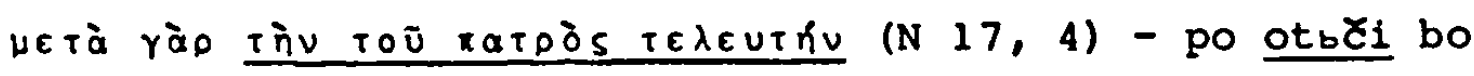
skoncanii (M 178, 14-15):

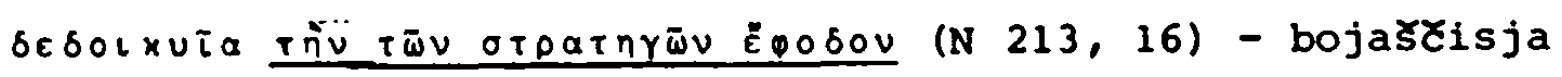
ustremlenia voiskago (M 271, 14):

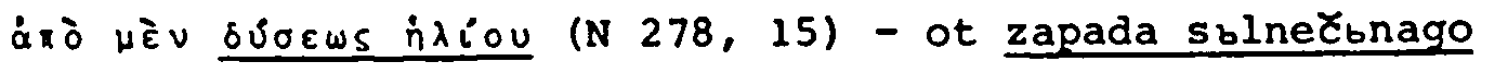
(M 294,13). 
Weitere Beispiele sind in äuBerst groBer Anzahl passim im Text zu finden.

b) Der Genitivus obiectivus

Das Gegenstück zum Subjektsgenitiv, der Genitivus obiectivus, bei dem "...der Genetiv das objekt (im weitesten Sinne) der im regierenden Verbum liegenden Handlung darstellt: $\varphi$ óB OS

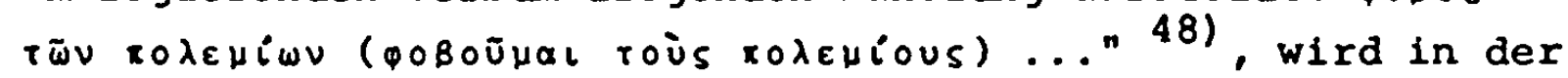
Ubersetzung nicht so einheitlich wie ersterer behandelt.

Vereinzelt tritt auch im Altrussischen der Objektsgenitiv auf:

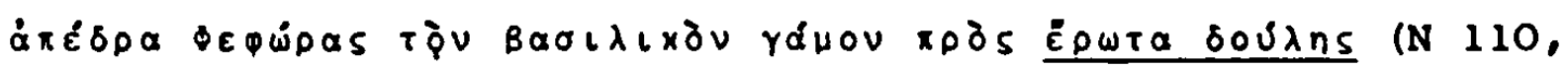
23-111,1) - Ferora uklonisja ot cesarskogo braka na pochotb rabynja (M 215,10).

Manchmal wird der Genitivus sublectivus wie der Subjektsgenitiv durch ein Possessivadjektiv wiedergegeben:

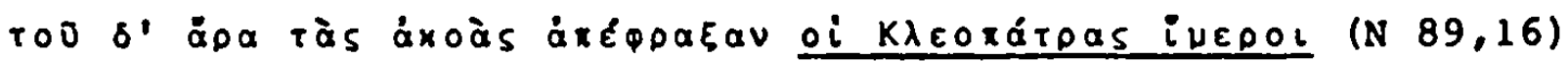

- Klęopatrina pochotь zatとe emu uక1 (M 203, 15-16);

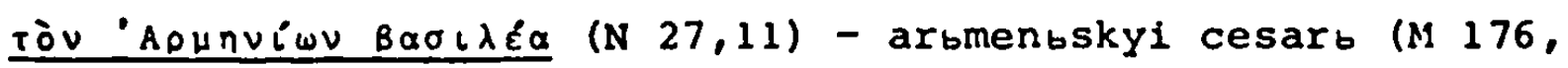
7-8)

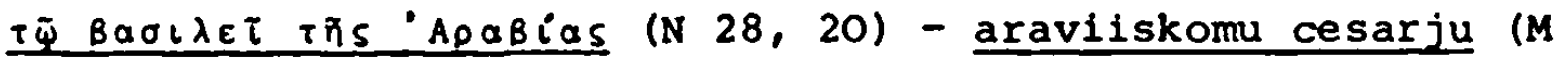
$176,34-35)$ )

In der erarückenden Mehrzahl der Fälle steht jedoch in der Ubersetzung der im Slavischen äuBerst beliebte Dativ des Objekts :

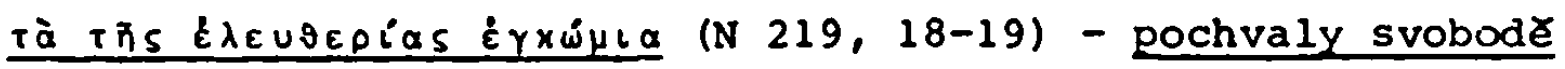
(M 274, 32) :

riotews xpootátal, eiphuns uxouproi (N 179, 16-17) - vĕrĕ zastupnici i sluziteli miru (M 253, 31),

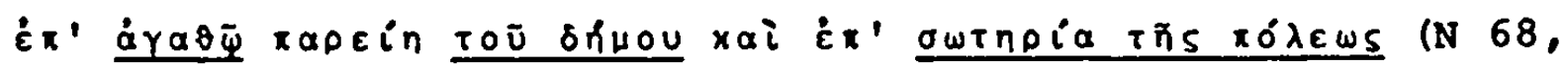


10-11) - na polzu gradu prildoch 1 na spasenie ljudem (M $192,31-32)$;

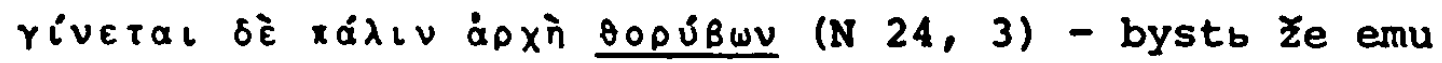
paky nazatokb zlu (M 174, 30):

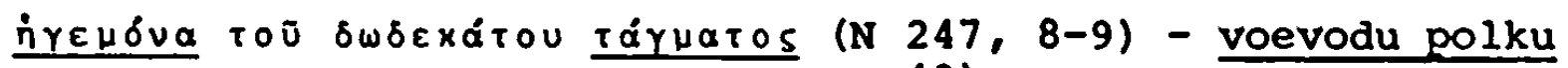
vtoromu na desjatb (M 283, 30-31) 49),

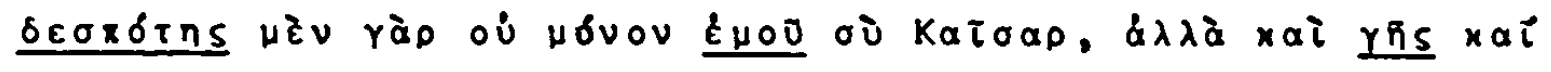

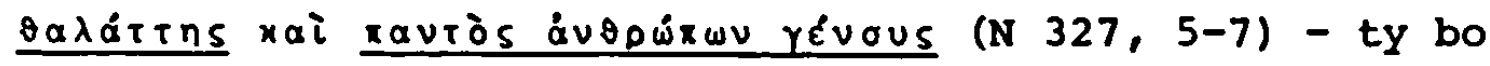
esi vladyka ne tokmo 1 zde, no 1 vsel zemli, 1 morju 1 vsemu rodu Celovectoskomu (M 310, 22-23):

xaxias wuothpiov (N 107, 13) - zlobe taina (M 213, 29).

Weitere Beispiele siehe $N 26,13 / M 175,28, N 28,19 / M 176,31$; $N 105,4-5 / M 212,5 ; N 155,13-14 / M 243,14 ; N 157,10 / M 244$, 25; $N$ 193,18/M 262, 22-23; N 270,3-4/M 291,4-5; N 291, 8/ $M 299,28 ; N 291,10-11 / M 299,29-30$ und passim 50$)$.

c) Der Genitivus possessivus

In den Bereich des eigentlichen Genitivs gehört ferner der "...Genetiv des Besitzers, d.h. im weitesten sinne: dem etwas angehört ..." 51 Dieser Genitiv bezeichnet neben dem elgentlichen Besitzverhältnis vor allem Verwandtschaftsbeziehungen und Charaktereigenschaften. $\overline{\mathrm{Da}}$ es sich hier innerhalb des Griechischen nur um feine Bedeutungsnuancen handelt, nimmt der Ubersetzer keine Rücksicht auf diese Unterteilung und gibt den gesamten Genitivus possessionis durch das Possessivadjektiv wieder:

Eis tinv Aplotoboúdou oixiav (N 28, 15) - vo Aristoulovb domb (M 116, 28):

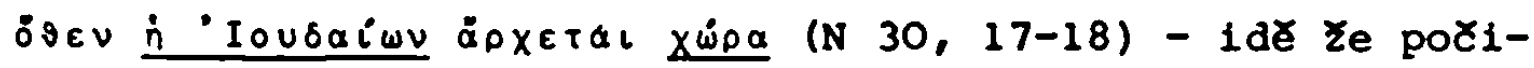
naetsja Zidovbskaja zemlja (M 177, 33):

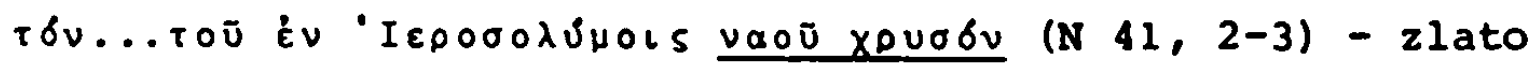
cbrkbvbnoe (M 182, 21): 


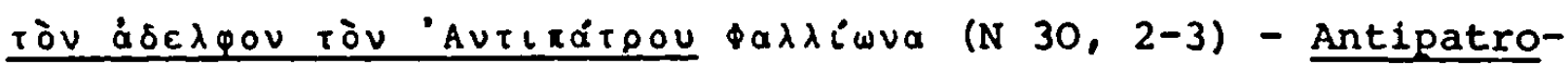
va brata Filiona ( $177,21-22)$;

d Aplotoboujou revoepós (N 35, 9) - Aristoulovb testb (M 180, 17):

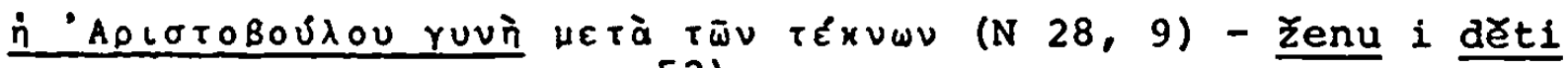
Aristuole (M 176, 21-22) 52):

Tñv Aplotoboujou Bíav (N 30, 8) - Aristoulbskoe bezumie (M 177,26$)$ :

Der Genitiv des Besitzers nach kopulativen Verben (elval 'byti', ein adverbaler Pertinentiv 52a), wird im Altrussischen wiedergegeben durch den Dativ:

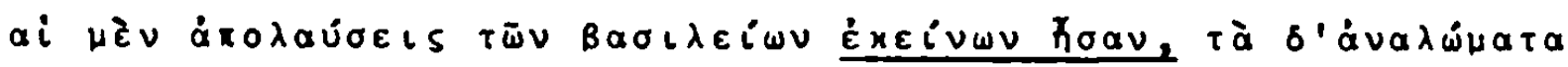

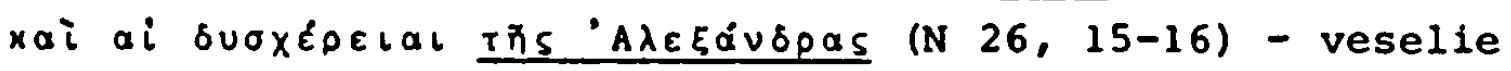
cesarbskoe têmb bjase, a pexalb $i$ raspoltenie Aleksandrii (M 175, 29-31; - em.n.I).

Ein Genitiv der Zugehörigkeit ist auch der Genitivus copiae, der im Griechischen nach Verba und Adjektiva des Anfüllens und Vollseins steht ${ }^{53}$. Ubersetzt wird er entweder durch den altrussischen Genitiv oder den Instrumental:

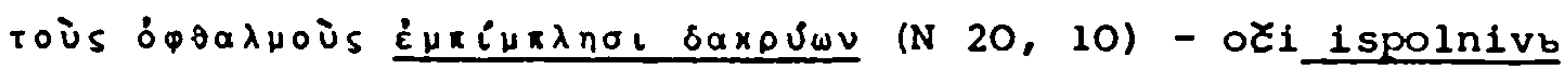
slezzb $(M 173,1)$ :

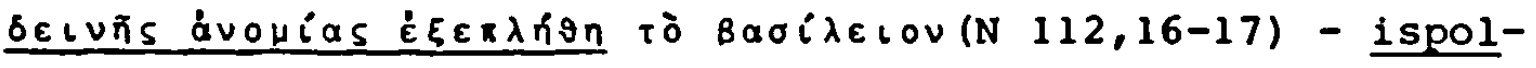
nbSesja cesarevb dvorb bezakonija ljutago (M 216, 6):

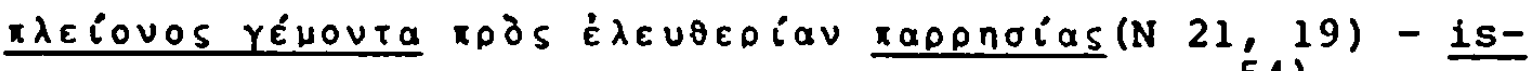
polnbsesja na svobodu drbznoveniemb (M 276, 2) 54).

d) Der Genitivus partitivus

Dieser äußerst produktive griechische Genitiv, der im weitesten Sinne das Ganze bezeichnet, von dessen Teil eine Aussage gemacht wird, hat in der Ubersetzung nur selten eine genaue Entsprechung, z.B.: 


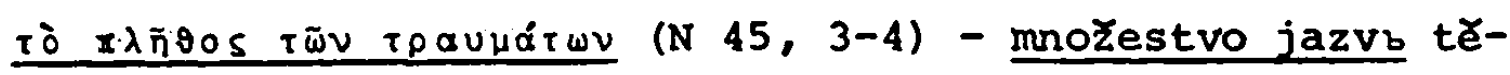
lesnych (M 183, 26-27).

In der Regel wird er vielmehr wiedergegeben durch die Präposition 'otb' + Genitiv:

TẼ x ci otb ubivaemychb ( 176,4$)$ :

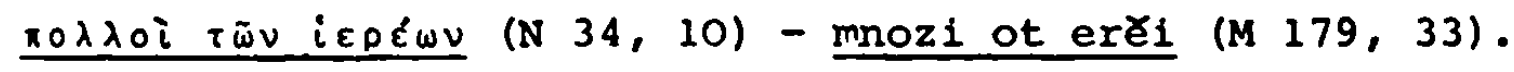

Weitere Beispiele siehe $N$ 23,21/M 174,26: $N$ 32,22/M 179,6: N 124,15/M 224,12-13: N 217,11-12/M 273,20 und passim.

Bisweilen tritt in der Jbersetzung für den griechischen Genitiv auch der Nominativ bzw. Akkusativ auf, d.h. die kongruierte Form der Bezeichnungen von Teil (Adjektiv) und Ganzem (Substantiv):

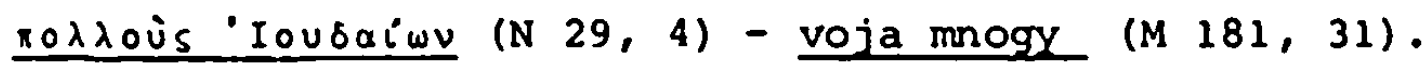

Die für das Griechische so typischen Wendungen mit den Neu-

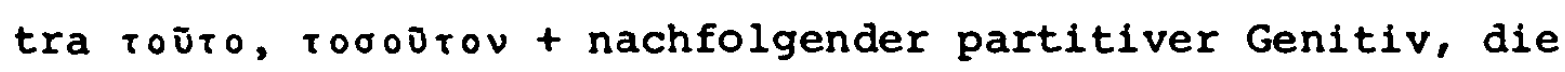
meist, durch $\varepsilon i s$ eingeleitet, als Hauptsatzkorrelativa konsekutiver Nebensätze (Gradsätze) fungieren 55), finden im Altrussischen keine wörtliche Ubersetzung. In den wenigen Fällen, wo hier die beiden Texte übereinstimmen, wird das im Neutrum stehende Pronomen des Griechischen wiedergegeben durch ein Adjektiv, das mit dem darauffolgenden Substantiv kongruiert und dadurch die Voraussetzung für den Genitiv wegnimmt:

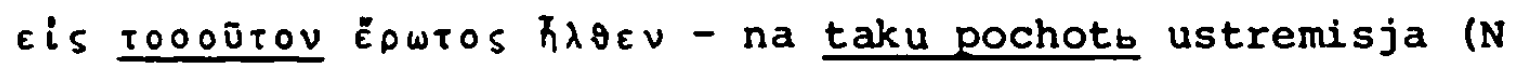
$175,15-16-M 251,28-29)$.

Der ebenfalls zum partitiven Genitiv gehörende Genitiv des Bereiches 56) nach den Verben des Strebens und Erreichens, des Sorgens, der Berührung und des Anfangens sowie der sinnlichen Wahrnehmung, wird in unserem Denkmal nicht einheitlich uibersetzt.

Lediglich die Konstruktion von $\dot{\varepsilon} \approx \vartheta \cup \mu \varepsilon \tau \nu$, dem das altrussische 
'choteti' entspricht, zeigt eine Parallele zu der Ubersetzung:

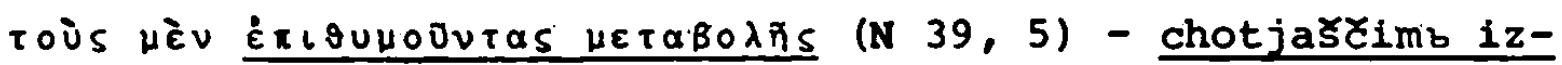
menenija (M 181, 31).

Vergleiche dagegen:

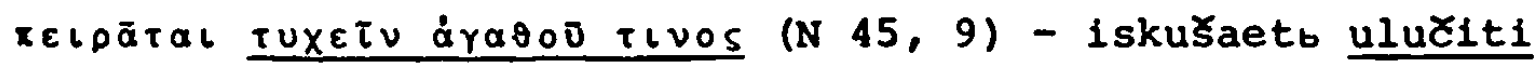
někuju vlasto (M 184, 1);

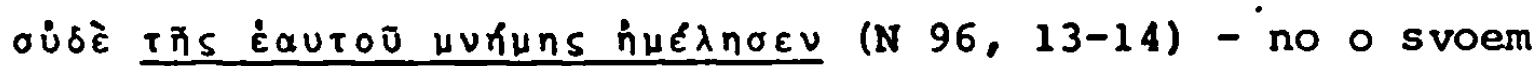
[sic!] pamjati oblenisja (M 207, 21-22).

Nach den Verba des Anfangens steht in der thersetzung die Präposition 'otb'+ Genitiv:

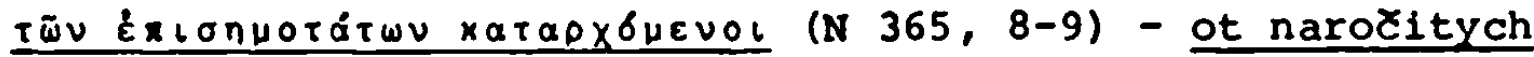
porinajusce (M 328,18$)$.

Im modernen Russisch hat die Präposition ' $s$ ', ebenfalls mit dem Genitiv, diese Funktion ubernommen $56 \lambda$ ).

Die Verba der Berührung und der Anteilnahme werden im Altrussischen mit dem Dativ verbunden:

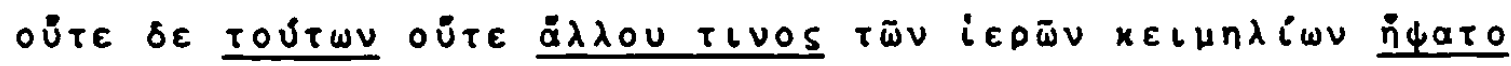
(N 35, 1-2) - no ne prikosnusja ni temu Ze otb tæch svjašennych sosudechb [sic!] (M 180, 8-9);

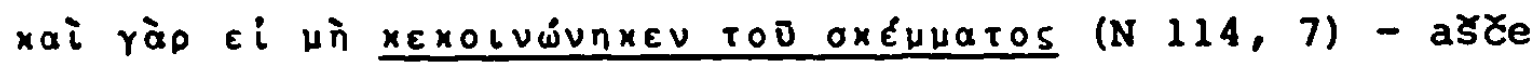
bo $i$ ne pritastnica bystb dume (I1 216, 38-217,1).

Im heutigen Russisch haben beide Ausdrücke die Konstruktion ' $k$ ' + Dativ 57), bei SREZNEvskiJ stehen 'pricastonikb' und 'pricastbnica' zur Hälfte mit dem Dativ, zur anderen mit dem Genitiv 58), wahrend 'prikasati sja' und 'prikosnuti sja' mit dem Lokativ verbunden werden 59 ).

Bei den mit $\alpha$ ia- zusammengesetzten Verba steht im Griechischen ebenfalls der Genitiv. In der Ubersetzung wird xatnropeiv $\tau$ ivos durch verschiedene sinnverwandte Verba, aber 
stets in der Konstruktion 'na' + Akkusativ wiedergegeben:

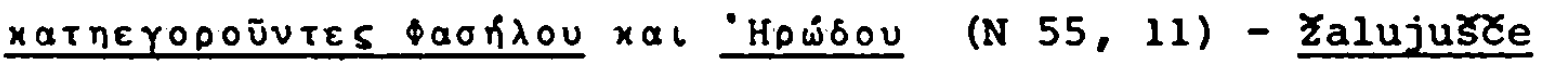
na Iroda i na Fasaila (M 188, 24-25);

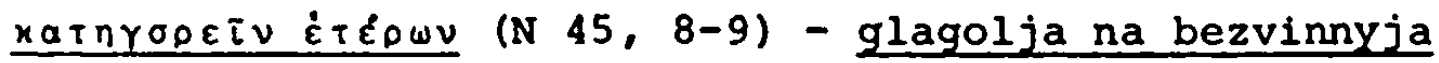
(M 183, 32).

Den Verba des Herrschens, die, im Griechischen den Genitiv regieren, entspricht 'vladéti' + Instrumental:

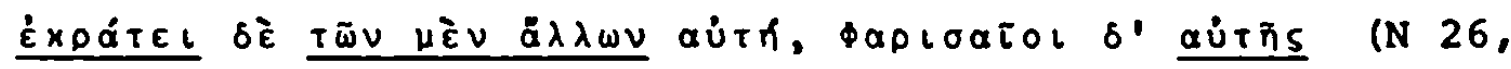
19-20) - vladejase ta vsĕmb, a fariseri toju (M 175, 34).

2) Der Genitiv als Vertreter des Ablativs

a) Der Genitivus comparationis

Als Vertreter des Ablativs bezeichnet der griechische Genitiv "... bei komparativischen Begriffen den Gegenstand, von dem aus ein anderer gemessen, mit dem er verglichen wird" 60). Er steht beim Komparativ von Adjektiva und Adverbia sowie bei Verba mit komparativischem Sinn. Die Ubersetzung folgt hier genau der griechischen Konstruktion; doch durfen wir hier trotzdem keinen syntaktischen EinfluB der Vorlage annehmen, denn der Genitivus comparationis "... ist [im slavischen] ursprachlich "60a):

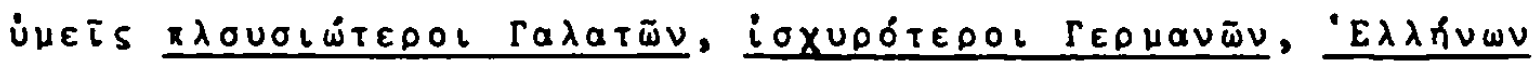

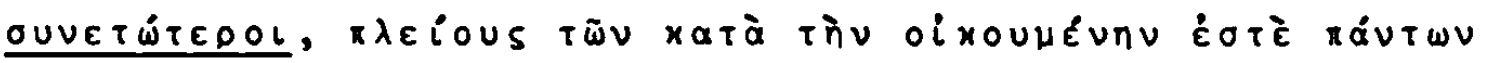
(N 222, 11-13) - bogatéisi li este galatb, ili kréplëiši germanb, ili mudreisi ellinb (M 276, 15-16).

Weitere Beispiele siehe $N$ 108,10/M 214,5; N 112,20-21/M 216, $8-9 ; \mathrm{N} \mathrm{180,1-2/M} \mathrm{253,33-34;} \mathrm{N} \mathrm{183,10-11/M} \mathrm{255,18;} \mathrm{N} \mathrm{302,21-}$ 22/M 302,22-23 und pasisim.

Bei den Verba der Bevorzugung und Komposita mit dem Präfix xpo-steht im Griechischen ebenfalls der komparative Genitiv, ebenso in der Ubersetzung: 


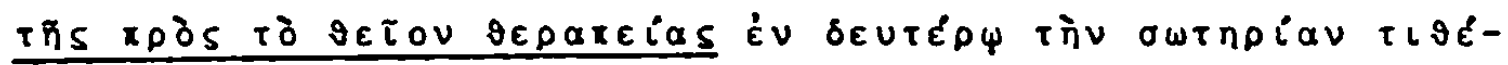
Hevol (N 34, 12-13) - ne pomnjaร̌e そivota pałe ugozenija bozija (M 179, 34-35):

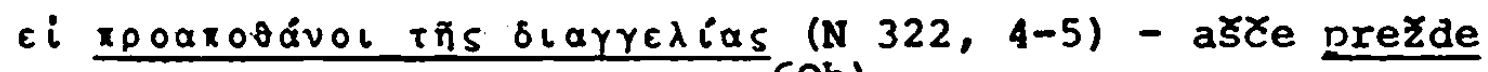
povelenia umretb (M 308,13$) 60 b)$.

Die Konjunktion 'negli' anstelle des separativen Genitivs findet in der Ubersetzung nur dann Verwendung, wenn das Vergleichswort ein Indeklinabile (z.B. Infinitiv) ist oder aufgrund anderer grammatischer Abhängigkeiten bereits in einem obliquen Kasus steht:

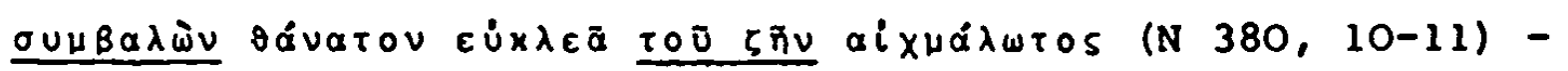
léplę smbrtb slavnu vzjati negli ¿iti plëneni (M 335, 5-6);

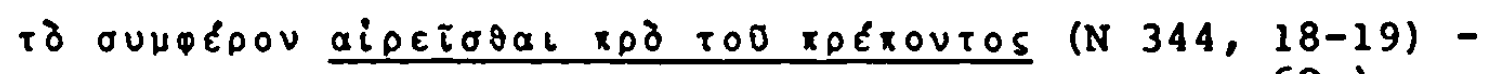
vbziskati poleznago, negli podobnago (M 318,4$) 60 \mathrm{C})$.

b) Der Genitivus separationis

Er bezeichnet "... den Gegenstand, von dem ein anderer entfernt wird oder fern ist" 61) und steht nach den Verba "... der Trennung, des Ablassens und Abhaltens von etwas, des Lobsens und Befreiens, des Beraubens und Entbehrens, des Verfehlens, des Verschiedenseins ..." 62). Mit einer einzigen Ausnahme, wo auch im Altrussischen der bloBe Genitiv steht 63) wahlt der Ubersetzer zu seiner Wiedergabe stets die Präposition 'otb' + Genitiv, wie auch im Griechischen die entsprechenden Verba oft mit áxo- und $\dot{\varepsilon} x$-präfigiert sind 63a):

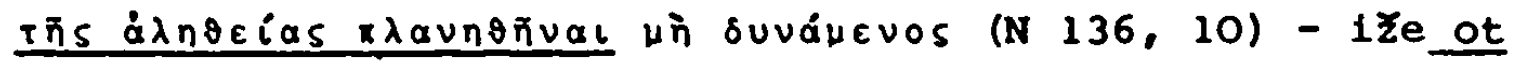
istinny priklōitisja ne mozetb (M 232, 11-12);

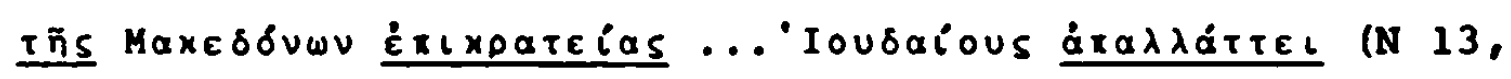
23) - toi bo svobodi Zidy ot makedonskyja derrzavy (M 169,33);

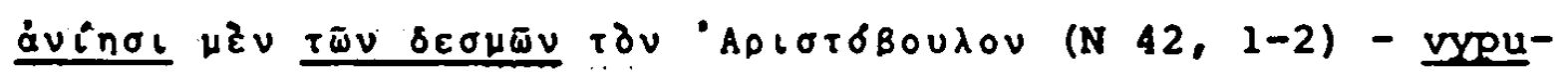
sti ... Aristoula ot uzb (M 182, 29-30): 


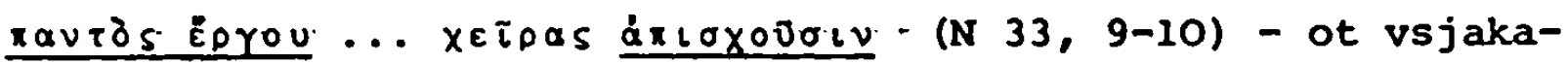
go déla prazdnovati (M 179, 17):

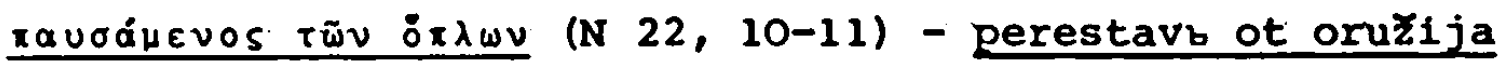
(M 173, 33):

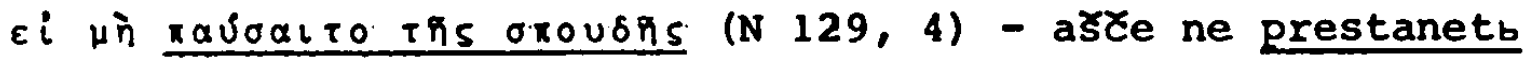
ot togo tstanija (M 227, 6).

Das griechische Adjektiv E̊nuos, das auch den separativen Genitiv nach sich hat, wird durch die Präposition 'bezb' ubersetzt:

Eonuov ikovoias (N 47, 14) - bez vlasti (M 185, 15-16)

3) Der Genitiv als Vertreter des Lokativs

a) Der Genitivus temporis

Er steht im Griechischen "... zur Angabe des Zeitraumes, wăhrend dessen etwas geschieht" 64) und zwar "... am haufigsten adverbial zur Bezeichnung von Tages- und Jahreszeiten, in die ein Ereignis fällt * 65). Der Ubersetzer gibt inn wieder durch den Instrumental ${ }^{66)}$ :

vuxiós (N 360, 15) - nostiju (M 326, 13).

Im Text finden sich noch zahlreiche weitere Beispiele.

b) Der Genitivus locativus

Obgleich schon im klassischen Griechisch "... bei Ortsbestimmungen fast nur in der Dichtersprache" vorkommend 67), erscheint dieser Genitiv in unserem Denkmal an einer Stelle und wird übersetzt durch ' $v b$ ' + Lokativ: 68)

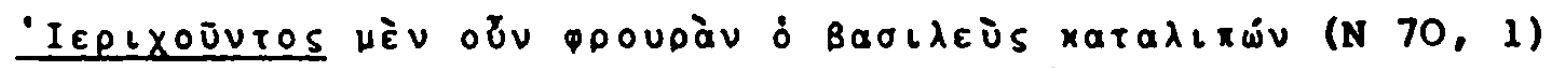
- ostaviv Ze straža vb Erichone (M 193, 23).

Im ganzen betrachtet, haben die altrussischen casus obliqui im Vergleich zu den griechischen einen Grobteil ihrer Funktionen 


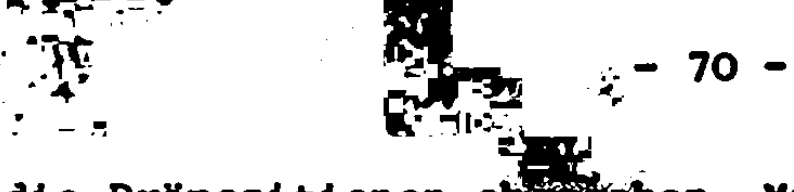

an die Präpositionen an kann also von einer ge- «. wissen Tendenz zu einer analytischen Ausdrucksweise spre- op chen 69).

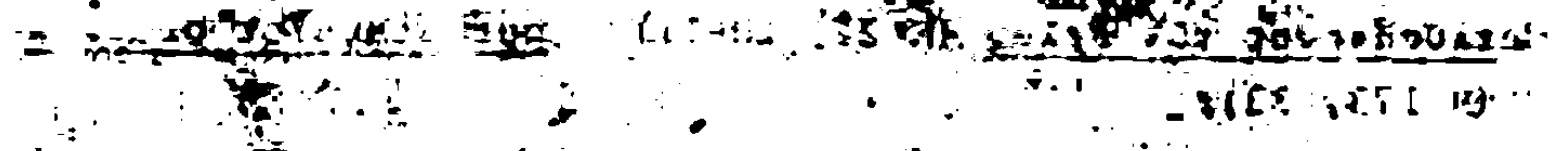

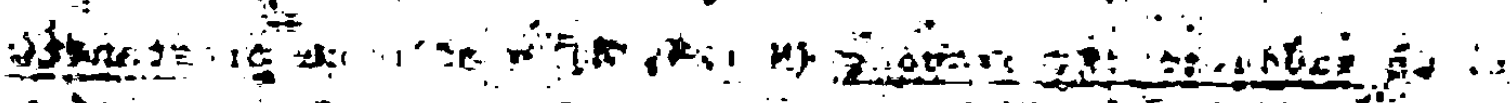

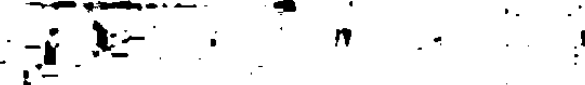

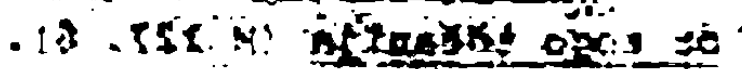

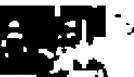

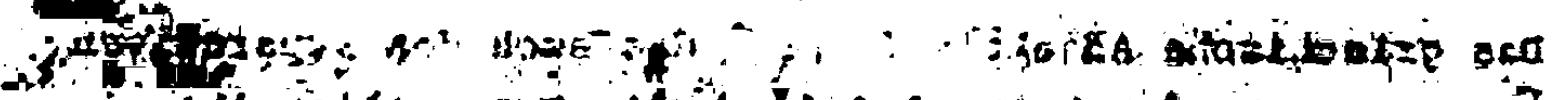

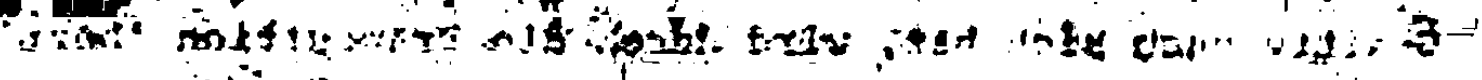

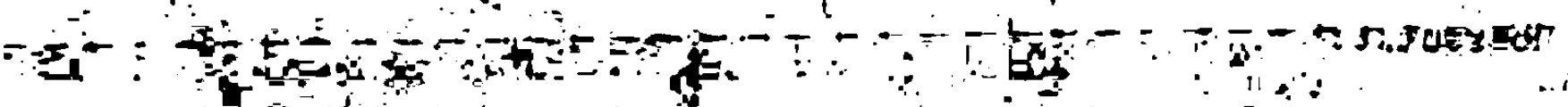

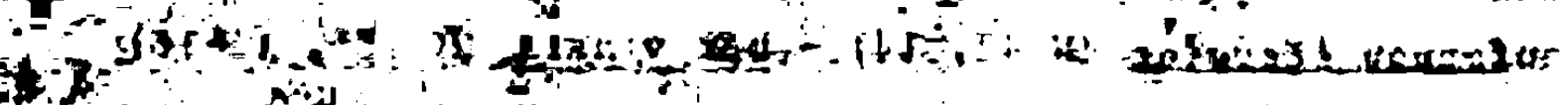
sip a

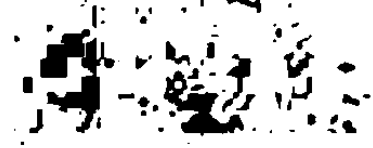
7y $\therefore$ ho

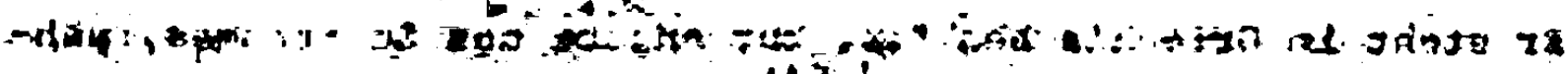

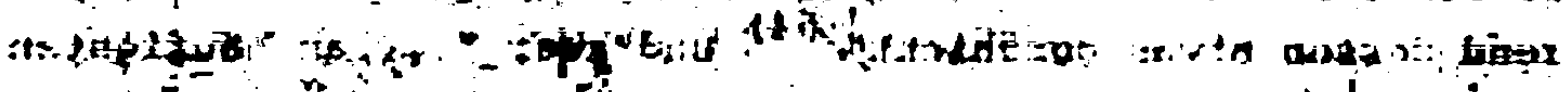

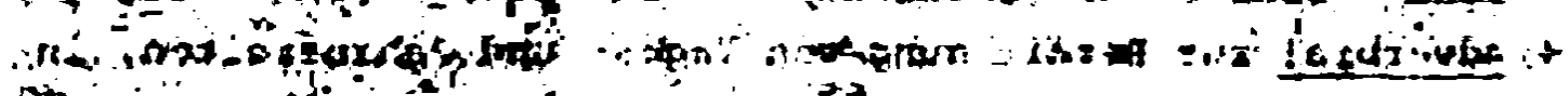
-

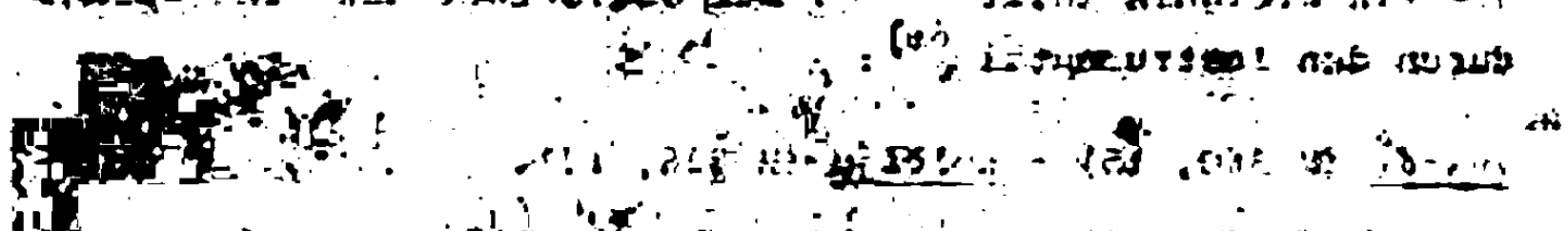

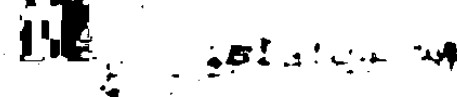

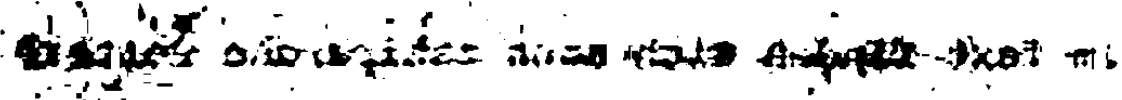
$\because=$

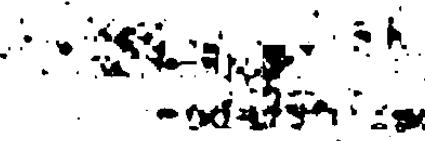

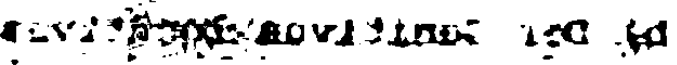

oxity : 6\%

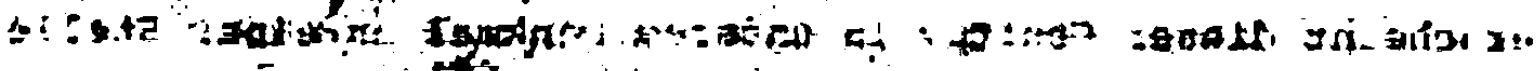

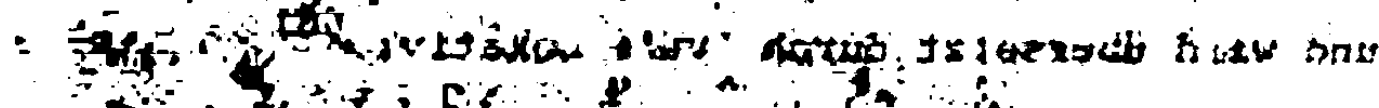

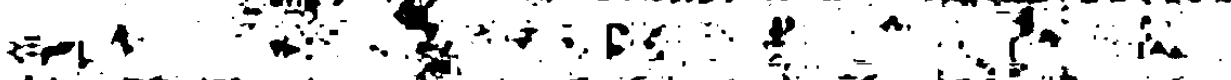

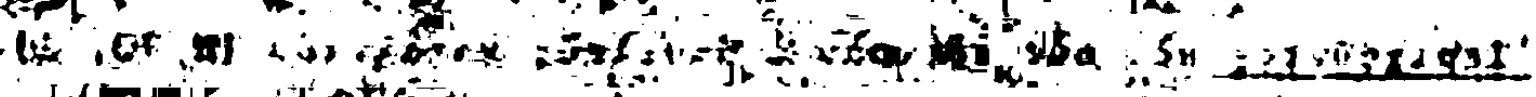

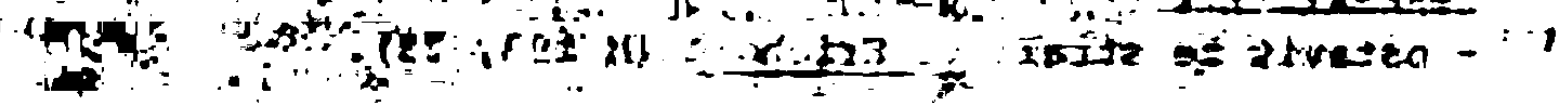

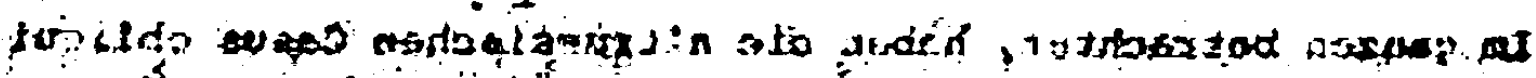

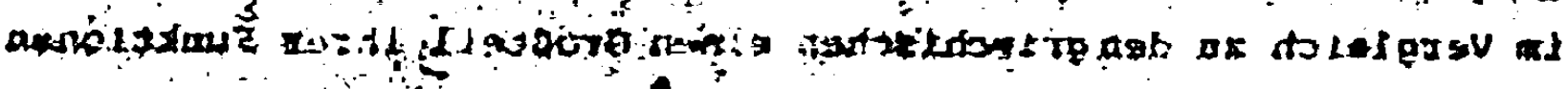

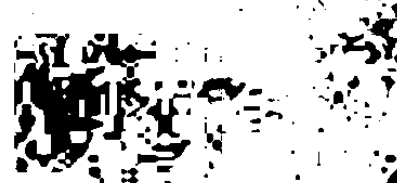




\section{B. Präpositionen}

In engem Zusammenhang mit der Kasuslehre einer Sprache steht der Gebrauch der Präpositionen. Haben doch "... die Kasus und die Präpositionen ... das miteinander gemein, daß sie Verhältnisse eines Substantivbegriffes zu dem Prädikate des Satzes ausdrücken, weichen aber darin voneinander $a b$, daß jene nur ganz allgemeine, diese hingegen bestimmtere Verhältnisse bezeichnen, und zwar die Verhältnisse des Raumes, der zeit, der Kausalitat und der Art und Weise" 70). Dabei ist wohl davon auszugehen, daß die Präpositionen ursprünglich nur das räumliche Verhältnis ausdrückten, und dieses dann zunächst auf die zeitlichen Beziehungen ubertragen wurde. Daher werden vielfach räumliche und zeitliche Verhältnisse durch ein und dieselbe Präposition bezeichnet 71). Später erst durften kausale und modale Beziehungen mit hereingenommen worden sein, bis schlieblich einzelne Präpositionen in Abhängigkeit von bestimmten Verba zur Bezelchnung eines bloBen Objektsverhältnisses dienen und nahezu vollständig entsemantisiert werden ${ }^{72}$ ).

Morphologisch gesehen, bildet die Präposition mit dem zugehörigen Nomen eine durch zwei Morpheme gekennzeichnete Verbindung, nămlich durch die Präposition selbst und die entsprechende Kasusendung des Nomens 73). Dabei kann man jedoch, wie es in populärwissenschaftlichen Werken noch immer der Fall ist, keineswegs davon sprechen, daB die Präposition einen bestimmten Kasus "regiert". Die historische Entwicklung zeigt genau das Gegenteil: Die Präpositionen, entstanden aus Orts- und zeitadverbien, wurden zunächst lediglich zur näheren Bestimmung und Verdeutlichung der Kasusfunktionen verwendet, ein bestimmter Kasus nahm also in einer bestimmten Funktion eine bestimmte Präposition zu sich. Heute kann man indes nur mehr von einer engen Zusammengehörigkeit von Präposition und Nominalkasus sprechen, ohne daß eine Dominanz des einen oder anderen Gliedes vorläge 74). Diese Gleichberechtigung beider Teile kommt deutlich zum Ausdruck, wenn einerseits eine Präposition mit zwei verschiedenen Kasus verbunden wird und diese Verbindung jedes Mal ein an- 
deres Verhältnis ausdrückt, und andrerseits diese Bedeutungsunterscheidung ebenso eintritt, nachdem unter Beibehaltung der Kasusendung eine andere Präposition gewăhlt wurde.

Im folgenden wird nun die wiedergabe der griechischen Präpositionalausdrücke des $\pi \delta \lambda \varepsilon \mu \circ 5$ in der altrussischen Ubersetzung untersucht. Meist wird auch hier als Entsprechung wieder eine Präpositionalwendung stehen, doch ergeben sich auch andere Ubersetzungsweisen, da es oft nicht einfach ist, "... die Grundbedeutung einer Präposition durch eine gänzlich entsprechende Präposition einer anderen Sprache auszudrücken" 75). Dabei werden die ursprünglichen räumlich und zeitlichen Funktionen der Präpositionen leichter durch altrussische Präpositionalwendungen wiederzugeben sein als die vielfachen sekundären, deren treffende thersetzung sowohl ein genaues Sinnverstänanis der Vorlage wie auch eine souverăne Beherrschung der Ubersetzungssprache voraussetzt.

\section{Präpositionen mit einem Kasus}

1) Präpositionen, die mit dem Genitiv verbunden werden

In der Sprache der xolvh ist ein Zurückgehen der Häufigkeit bestimmter, mit dem Genitiv gebrauchter Präpositionen festzustellen. So werden $\dot{a} \varphi l$, ává, aveu, ávi immer seltener verwendet und treten auch in unserem Denkmal in relativ geringer Anzahl auf ${ }^{76)}$. Da auch bei den wenigen stellen ihres Vorkommens nur höchst selten eine vergleichbare Ubersetzung vorliegt, mulssen wir sie aus unserer Betrachtung ausschlieBen. Die übrigen Präposotionen mit dem Genitiv finden jedoch nach wie vor Verwendung; $z u$ ihnen gesellen sich seit dem Ende der klassischen Zeit immer mehr "uneigentliche Präpositionen" oder "Präpositionadverbien", die "... erst in jüngerer zeit den Charakter von Präpositionen erhalten haben, aber nun gleich den eigentlichen Präp. nie oder fast nie ohne ihren Kasus (Gen.) stehen" 77 ).

\section{a) $\dot{a} \times \delta$}

Diese griechische Präposition bezeichnet zunächst die "..Entfernung von einem Orte oder Gegenstande weg bei Verben der 
Bewegung" 78); hier entspricht ihr in der Ubersetzung 'otb' das ebenfalls mit dem Genitiv verbunden wird und sowohl im Altkirchenslavischen ${ }^{79}$ ) wie im Altrussischen ${ }^{80}$ ) dieselbe Funktion innehat:

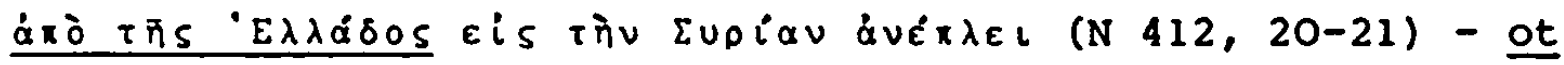
Elady priplu k Surii (M 348, 13);

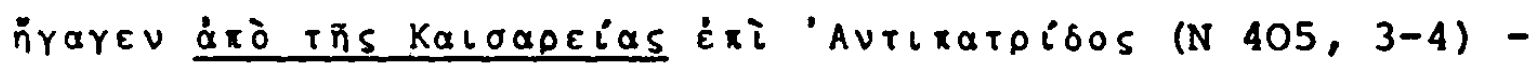
poide ot Kesarija na Antipatridu (M 344, 16-17);

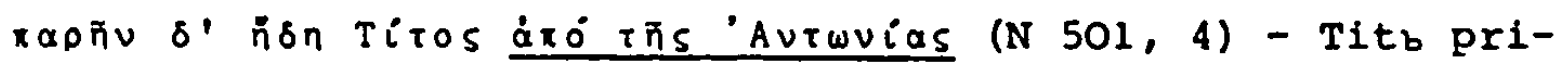
Sed ot Antonia (M 389,33$)$.

Die Auffassung eines räumlichen Verhältnisses dürfte auch bei dem folgenden übertragenen Gebrauch von \&xo zugrundeliegen:

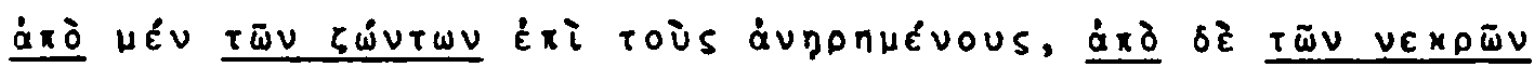

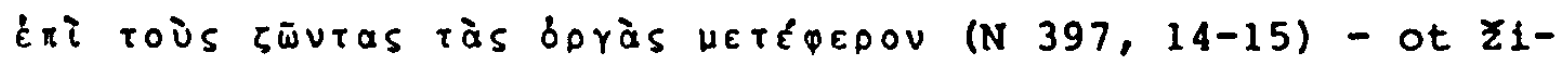
vych na umerక̌ja prinosjachu gnevb, a umerక̌ch na żivyja (M 340, 29-30).

Bezeichnet axó den Ausgangspunkt einer Handlung, die (räumlich) von oben nach unten gerichtet ist, so entspricht ihm das altrussische 'sb' + Genitiv 80a):

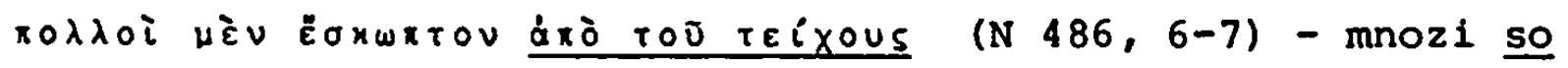
zabral porugachusja ( $M 383,3)$;

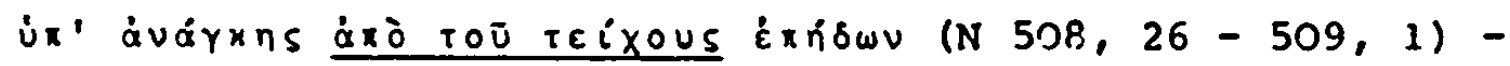
skakachu so zabral nužeju (!1 394, 12).

Temporal drückt $\dot{\alpha} \times \delta$ das "... Ausgehen von einem zeitpunkte" 81), also den Anfangspunkt eines Zeitraumes aus. Auch hier wird es übersetzt durch 'otb' + Genitiv, das im Altkirchenslavischen wie im Griechischen "... oboznacaet naral'nyj moment dejstvija vo vremeni" 82), während es im Altrussischen darüber hinaus noch "... dlja oboznaלenija vsego vremeni" 83) diente: 


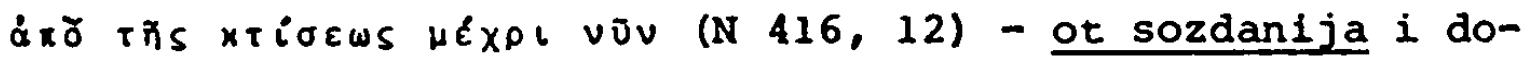
sele (M 356,7$)$.

b) $\dot{\varepsilon} x$

Es entspricht dem slavischen ' $1 z_{b}$ ' 84) und wird in seiner ursprünglichen Funktion, in der es "... die Entfernung entweder aus dem Innern eines Ortes oder Gegenstandes bei Verben der Bewegung" 85 ) bezeichnet, auch durch dieses wiedergegeben:

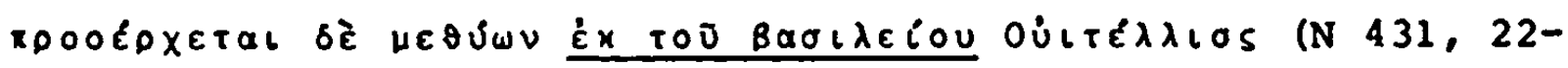
$432,1)$ - Utilii vynide is polati pojanb (M 357, 19-20);

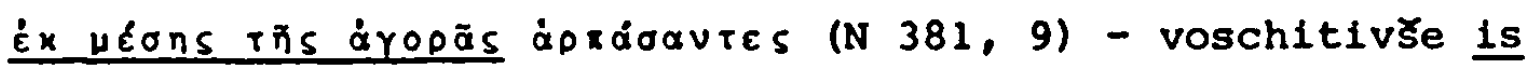
srêdy grada (M 335,16$)$.

Manchmal betont jedoch der Ubersetzer mehr die äußere Entfernung, wie sie å $\delta$ ausdrúckt ${ }^{86)}$, als die Bewegung aus einem Inneren heraus und setzt statt des erwarteten 'izb' die Präposition 'otb', z.B.:

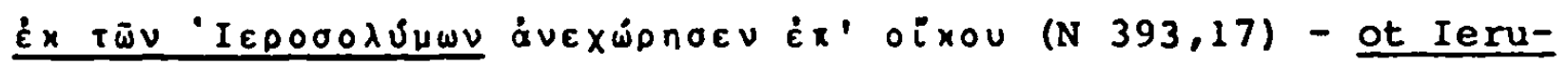
salima idosa $k b$ svoim ( $M 33,2-3$ )

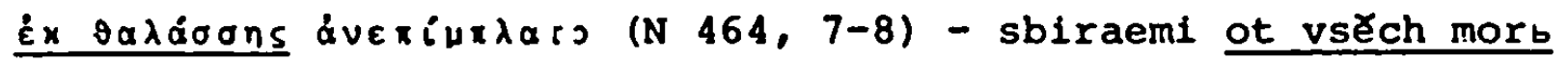
(M 371, 2-3).

Bezeichnet $\dot{x} x$ die Abstammung, so wird es bei Angabe der Eltern durch 'otb', bel der der geographischen Herkunft durch ein (Possesiv-) Adjektiv ubersetzt:

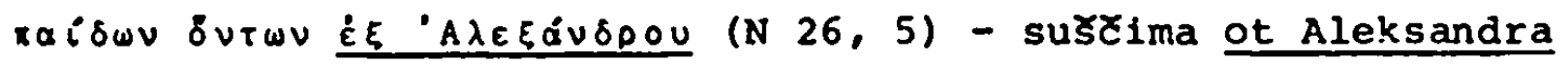
(M 175, 23);

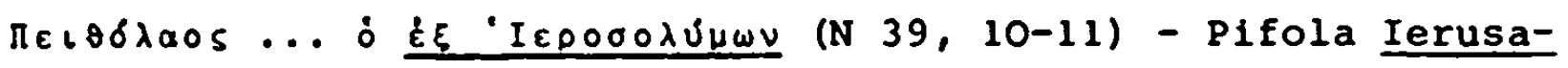
limbskyi (M 181, 36).

Desgleichen wird der durch $\dot{\varepsilon} x$ ausgedrückte ursächliche Ausgangs punkt einer Handlung oder eines Tatbestandes durch ein Adjektiv wiedergegeben. Wăhrend hier das Griechische eine mehr dynamisch. Betrachtungsweise zeigt ${ }^{87}$, betont das Altrussische vor allem 
die zusammengehörigkeit des Geschehens und dessen Urheber (und bringt sie durch die Kongruenz von Substantiv und Adjektiv zum Ausdruck), ohne năher auf die Art dieser Verbindung einzugehen:

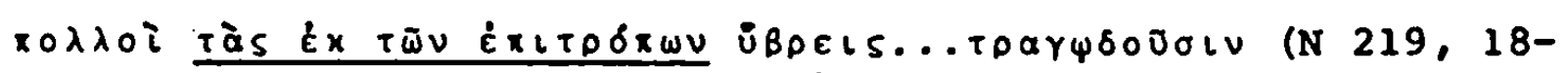
19) - mnozi vb ustêch nesutb nepravdy gemonbsky (M 274, 31).

Die durch $\dot{k} x$ ausgedrickte Ursache oder Veranlassung einer Handlung wird in der Ubersetzung ebenso wie der Dativus causae durch den kausalen Instrumental ersetzt:

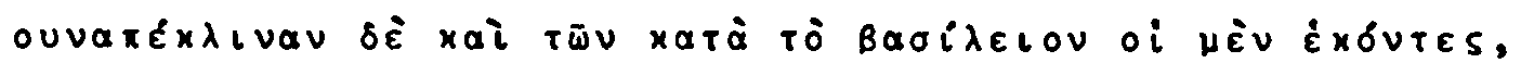

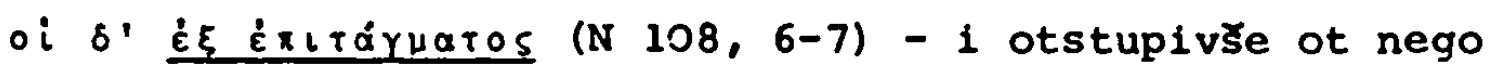
slugy, ovi voleju, ovi ze povelentemb (M 213, 39-214, 1).

íx kann in Verbindung mit einem substantiv auch die Art und Weise bezeichnen, in der eine Handlung vor sich geht ${ }^{88}$ ); im Altrussischen steht dann dafür eine modale Bestimmung:

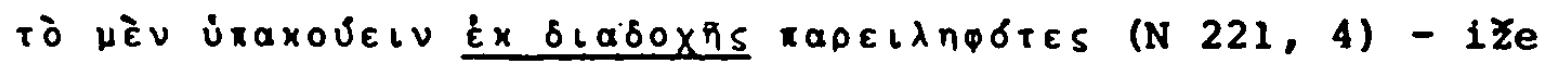
priali este aky otbroskoe (em.n.Vol.) nasledovanie rabotu (M 275, 22-23).

Auf ähnlich freie Weise wird auch eine temporale Funktion von $\dot{x}$, die Bezeichnung des "položenie vo vremeni" 89) wiedergegeben, und zwar durch einen temporalen Nebensatz:

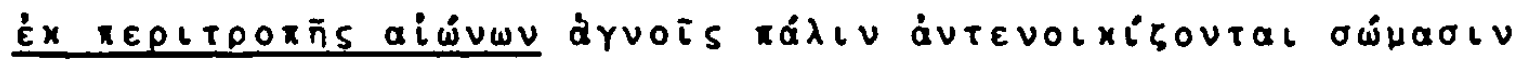
(N 323, 20-21) - vospjat vselitisja imb vb svoja telesa, egda vozvratjatsja vêci (M 309, 15-16).

c) $x p 8$

Auch hier ist die Grundfunktion die Darstellung eines răumlichen Verhältnisses; in Verbindung mit dem Genitiv eines Nomens bezeichnet xo 6 die Position eines Gegenstands oder einer Person vor einem anderen Gegenstand, bzw. den Ablauf einer Handlung vor einem bestimmten Hintergrund. In der Ubersetzung entspricht ihm 'peredb, prědb' + Instrumental, 
das im Altrussischen gleichfalls ein "... prebyvanie na perednem plane predmeta" 90) ausdrückte:

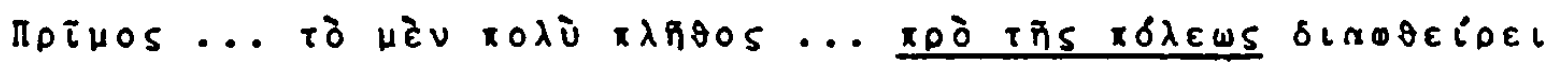

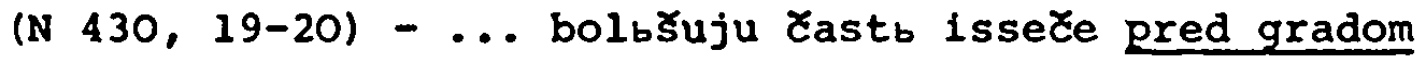
(M 356, 29-30):

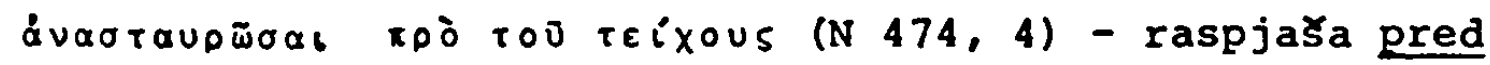
stênami (M 376,15$)$;

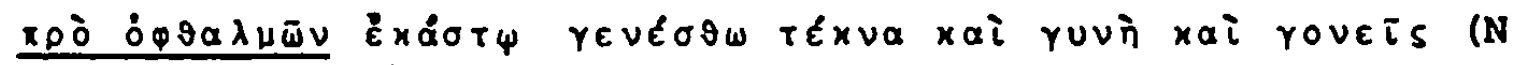
491, 21-22) - polozite Cada vasa pred oxima, Zeny, roditelja (M 386, 19-20).

In temporaler Funktion entspricht dem griechischen noठ meist das altrussische 'prë̌e', das eigentlich ein Komparativ ist und mit dem Genitivus comparationis verbunden wurde,spater aber als Präposition aufgefaBt wurde. Auch SREZNEVSKIJ gibt es als Entsprechung fur xo6 an 91):

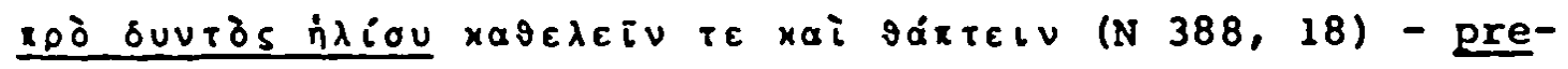
Ze zachoda sblnblnago [pogrebsti] (11 337, 11-12):

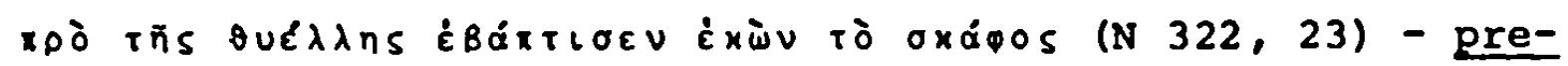
Ze bure (em.n.Vol.) potopitb korablb (M 308, 29);

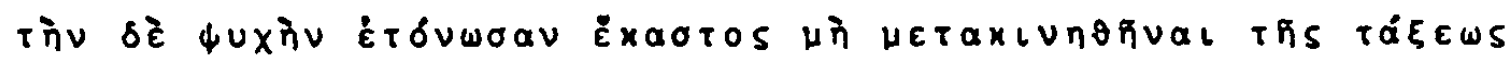
xpo taváiou (N 515, 16-17) - ukrêpisasja duకami koždo ichb, ne podvizatisja ot polka preżde smerti (M 398, 24-25). 92).

Die griechische Præ̈position kann aber auch durch einen Temporalsatz, eingeleitet durch die konjunktion 'prěže (daže ne)'. wiedergegeben werden:

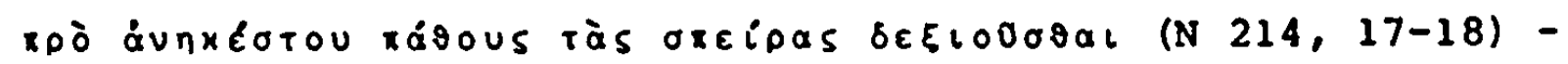
da ... pocêlujutb spire (em.n.Vol.), prež ne prilmuto strasti bezlecebnyja (em.n.Vol.) (M 272, 1-2);

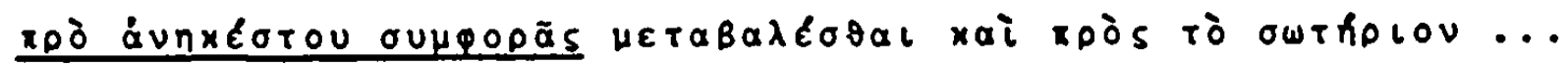

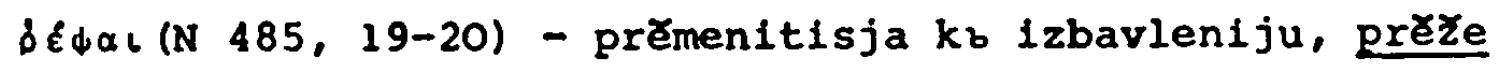
daze ne postignet vas zlo neiscelimoe (M $382,30-31)$. 
Neben den bisher behandelten urpsprünglichen griechischen Präpositionen, bei denen der Genitiv als Vertreter des $\mathrm{Ab}$ lativs steht 93), treten im $\pi \delta \lambda \varepsilon \mu \circ$ auch uneigentliche Prăpositionen auf, die zum Teil ursprüngliche Adverbia, zum Teil erstarrte Nominalformen sind 94) und als solche den eigentlichen Genitiv bei sich haben.

d) $\dot{\alpha} v \tau\llcorner\times p \jmath$

Das im klassischen Griechisch selten gebrauchte, mit dem Genitiv des zieles verbundene $94 \mathrm{a}$ ) und in der sprache des NT gănzlich fehlende $94 \mathrm{~b})$ áviıxoú, das verwendet wurde zur Bezeichnung der Lage eines Ortes oder Gegenstandes gegenuber einem anderen, wird in der Uhersetzung wiedergegeben durch 'protivu' + Dativ, das nach LOMTEV ein "... nachozdenie oko10 predmeta ili dvizenie navstrecu predmetu" ausdruckt 94c):

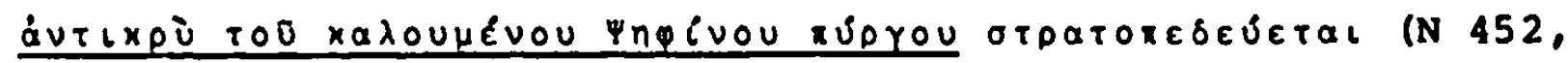
7-8) - stasa protiva synu konnomu (M 367,3$)$ :

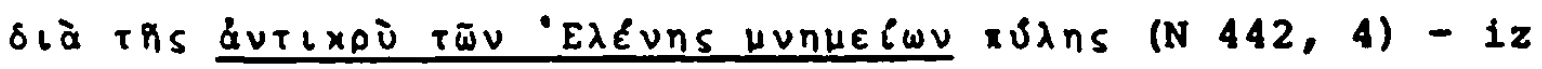
vratb, iZe sutb protiva Elininomb (em.n.I) grobom (M 361,3031).

e) $\mu E ́ \times 0 เ 5$

Dieses Präpositionsadverb zeigt im Griechischen die răumliche oder zeitliche Grenze an, bis zu der sich eine Handlung oder ein Tatbestand erstreckt. Im Altrussischen steht dafür 'do' + Genitiv, das unterschiedslos răumlich und zeitlich gebraucht wird:

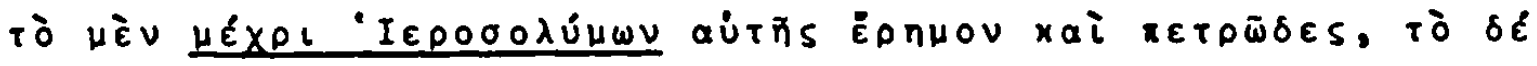

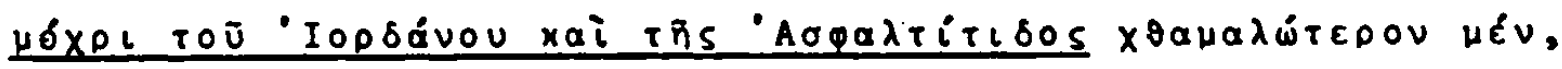
Épnuov $\delta \dot{\varepsilon}$ òuoíws åxaprov (N 409, 10-12)! - do Ierusalima vse pusto 1 kameno, do Ierdana že 1 do Alflatita, podobno 1 neplodino (M 346, 28-29):

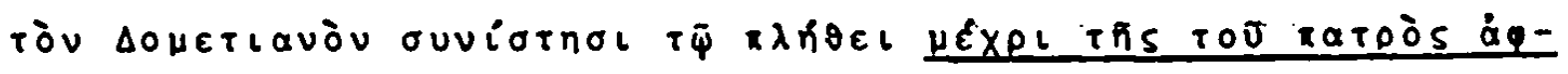

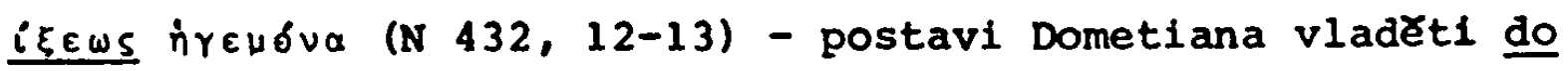
prisestria otbea (M 357, 27-28). 
f) $\times \lambda \Re v$

Es bezelchnet die Ausnahme einer Person oder einer Sache von der im Prädikat des Satzes enthaltenen Aussage. Der Genitiv, mit dem es verbunden wird, ist separativen Ursprungs 95). In der Ubersetzung ist es vertreten durch 'razve' + Genitiv, das im Altrussischen dieselbe Funktion wahrnahm 96):

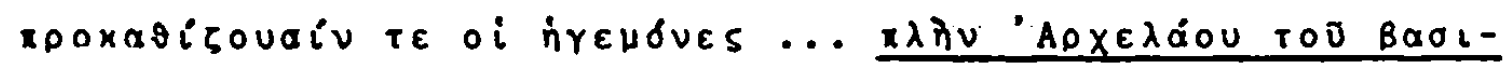

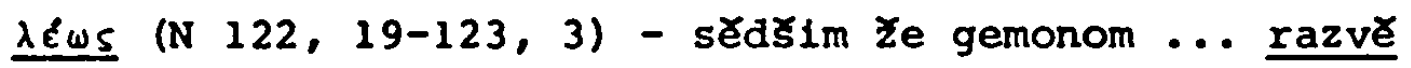
Archelaja cesarja (M 223, 2-5);

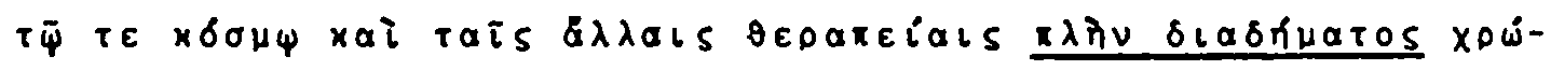
uevos (N 103, 14-15) - vb cesarskych rizach, 1 vb službe, 1 vb sosuděch, jako cesarb, razvẽ vênca (M 211, 13-15).

g) $\delta i x a$ und $x w p i s$

Diese beiden Prăpositionsadverbien stehen ebenfalls mit dem separativen Genitiv 97). Bel Josephus vertreten sie das kaum noch vorkommende avev und werden im Altrussischen durch 'bezb' + Genitiv ubersetzt ${ }^{98)}$ :

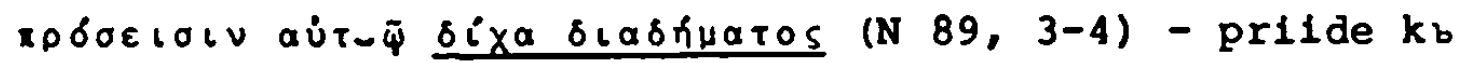
cesarevi bez vênca (M 203, 3):

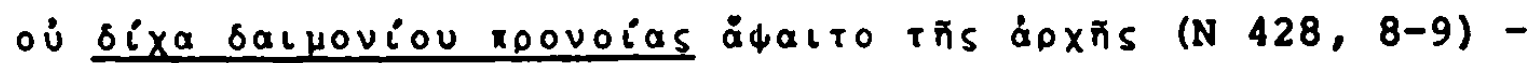
ne bez bożia promusla priklonilisja $k$ nemu vlasti (M 355 . 19-20);

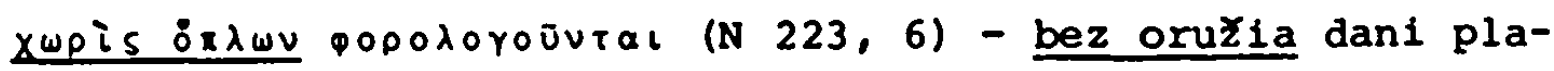
tjatb (M 276, 25).

h) Eัvexa

Diese ursprüngliche Akkusativform bezelchnet in Verbindung mit dem Genitiv wie das lateinische 'causā' einen "... Bestimmungsgrund, der als Absicht aufgefaBt werden kann" 99). 
Die altrussische Entsprechung dafür stellt 'radi' + Genitiv dar, das auch in erster Linie eine Absicht, ein ziel ausdrickt ${ }^{100)}$ :

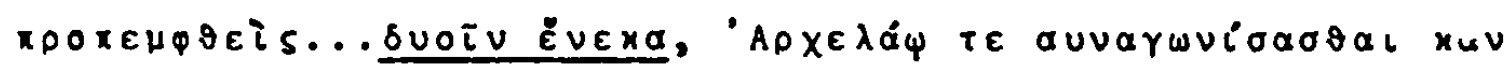

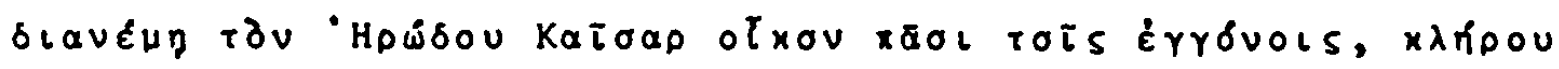

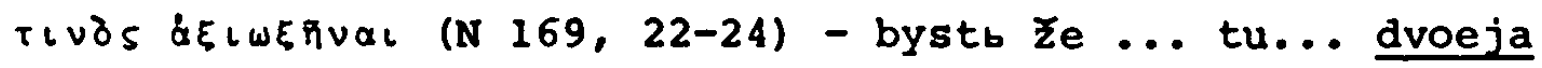
radi viny: 111 Archelaevi pomagat 1 $\tau_{b} s t_{b}$ ot nego priati, 11i, ałte cesarb razdělitb vsemu rodu dom Irodovb, da 1 sego prilastjats ko imeniju ego (M 247, 27-31).

Gibt Ěvexa dagegen einen wirklichen Grund, die Ursache oder Voraussetzung eines bereits bestehenden Tatbestandes oder einer geschehenen Handlung an 101), so erscheint in der Ubersetzung dafur der kausale Instrumental, obwohl 'radi' im Altrussischen auch den tatsächlichen Grund angeben konnte 102) :

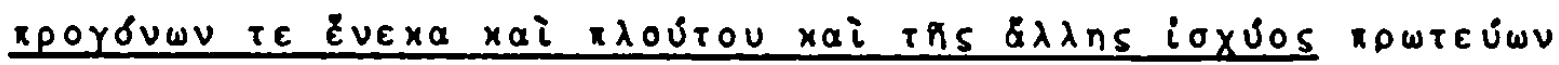

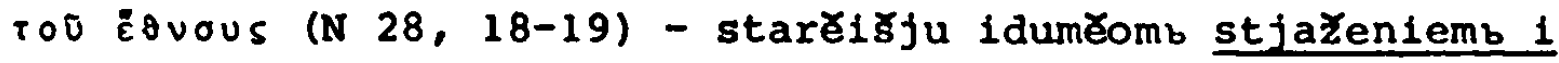
siloju (M 176, 31-32):

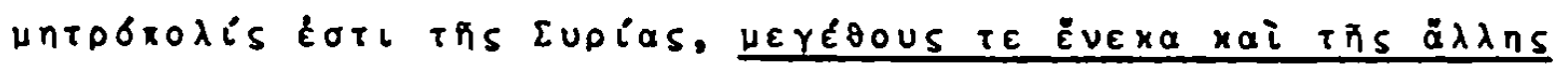
Eusaluovias (N 277, 20-21) - estb mitropolia vsea surii veliZbstvom i bogatbstvom (M 293, 32).

2) Präpositionen, die mit dem Dativ verbunden werden

a) $\dot{\varepsilon} v$

Der ursprünglichen räumlichen Funktion des $\dot{\varepsilon} v$, das den ort angibt, an dem oder innerhalb dessen sich etwas befindet und statisch verharrt, entspricht das altrussische ' $v_{b}$ ' + Lokativ:

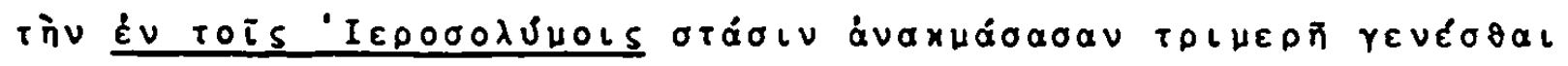
(N 434, 5-6) - vbzraste mjateź vb Ierusalime (11 359, 3-4).

Erstreckt sich aber die Handlung mehr oder weniger gleichmäBig uber einen größeren Raum hin, vor allem, wenn das mit der Präposition verbundene Nomen im Plural steht oder einen stoffbegriff ausdrückt, kann auch 'po' + Dativ stehen 103) : 


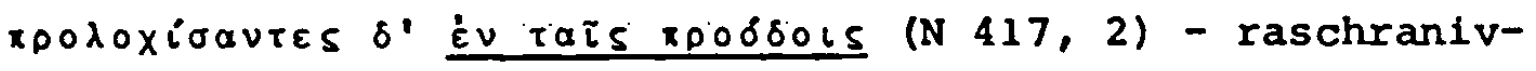
Sesja po rasputiemb (M 350, 18).

Ein durch $\dot{\varepsilon} v$ gekennzeichnetes modales Verhältnis wird durch ' $v_{b}$ ' + Lokativ wiedergegeben; hier läbt sich im weitesten Sinne eine Beziehung $z$ u räumlichen Kategorien herstellen; GERKULES bezieht daher auch einen Teil der modalen Funktionen von 'vb' mit in die räumlichen ein 104):

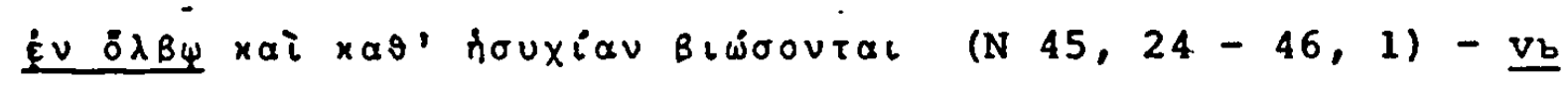
obilii 1 tisine poživete (M 184, 21-22).

Die modale Färbung des $\dot{\varepsilon} v$ in obigem Beispiel kommt auch dadurch zum Ausdruck, daB das zweite Glied der Wendung durch die Präposition xará eingeleitet wird, von deren modaler Funktion unten die Rede sein wird.

Wird év zur Bezeichnung einer gewissen Einschränkung vor allem nach Superlativen, verwendet, so wählt der Ubersetzer dafür stets den Instrumental der Beziehung, obwohl zumindest im Altkirchenslavischen auch ein Ausdruck mit ' $v b$ ' + Lokativ dieses Verhältnis bezeichnen konnte ${ }^{105)}$ :

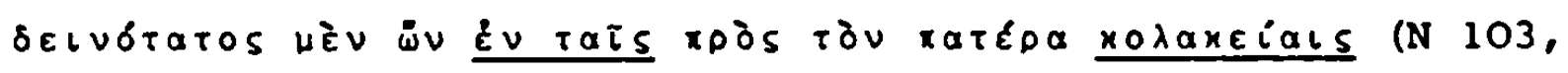
8-9) - bystb bo chitrb laskaniemi kb otbcju (M 211, 9-10).

3) Präpositionen, die mit dem Akkusativ verbunden werden

a) Eis

Ursprünglich keine eigene Präposition, sondern nur "... eine abgeänderte Form von $\left.\dot{\varepsilon} v^{\prime \prime} 106\right)$, welch letzteres früher auch mit dem Akkusativ des zieles verbunden wurde, hat sich $\varepsilon i s$ im Lauf der Entwicklung verselbständigt und auf die Bezeichnung der dynamischen Funktionen des alten $\dot{\varepsilon} v$ spezialisiert, die statischen weiterhin der alten Form überlassend. Wenn also im Altkirchenslavischen und Altrussischen die Entsprechung für \&̇v (d.h. dessen ursprüngliche Funktionen) ' $v b$ ' + Lokativ war, ist es für $\varepsilon$ is dieselbe Präposition, aber in verbindung mit dem Akkusativ 107). Auch in unserem Denkmal 
erscheint für $\varepsilon i$ s die Präposition ' $v b$ ' + Akkusativ:

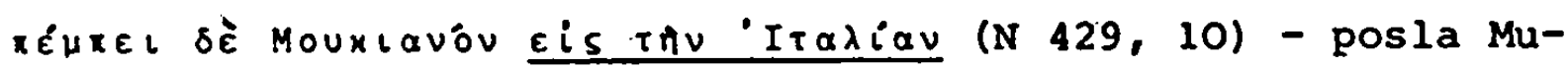
kiana (em.n.Vol) vb Italiju (M 356, 4):

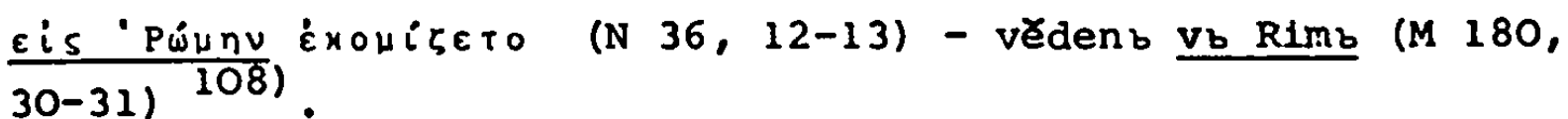

Das im Griechischen ebenfalls durch $\varepsilon i s$ ausgedrückte "...napravlenie 1 pronikanie $v$ sredu mezdu bol' Se predmetov, Iic i t.p." 109), wofür im Altkirchenslavischen gleichfalls 'vb' + Akkusativ erscheint, wird in der 'Iudejskaja vojna' durch die mehr die Richtung als das ziel betonende Präposition ' $k b$ ' + Dativ wiedergegeben 110):

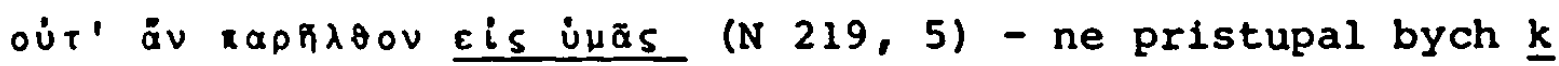
vam (M 274, 17-18).

In den von SREZNEVSKIJ zitierten Beispielen aus anderen Denkmälern findet sich diese Entsprechung nicht lil).

Dagegen geht die Iiledergabe des $\varepsilon i s$, das (nach den Verba des Machens oder Veränderns) das erwartete Resultat einer Handlung ausdrückt, durch 'na' + Akkusativ konform mit der Ubersetzungspraxis des Altkirchenslavischen 112):

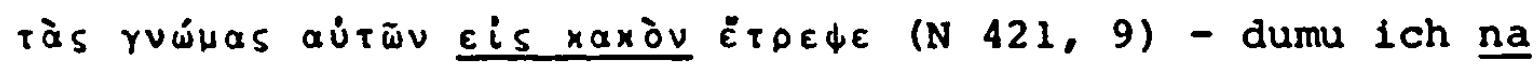
zlo utverdi (M 352, 19).

Dasselbe gilt für die verwandte Funktion der "...Angabe des geistigen Zieles, des Zwecks, der Absicht 1131" :

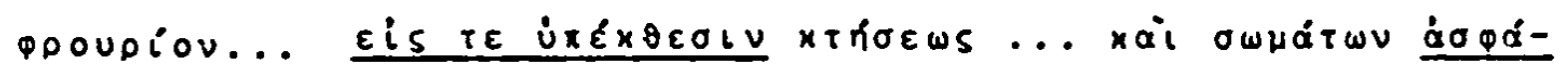

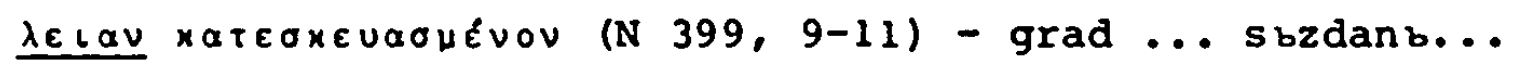
na sochranenie imeñija 1 orużija (M 341, 22-23);

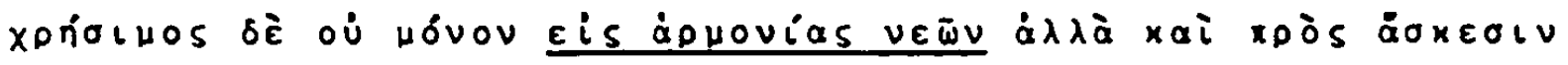

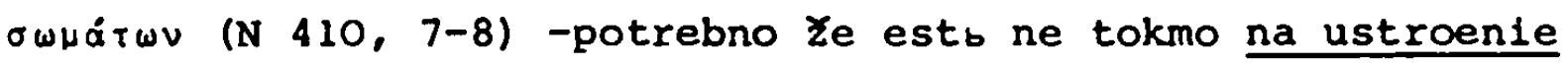
korablju, no $i$ na iscelenie telest ( (M 347, 9-10).

Mitunter wird allerdings hier $\varepsilon i s$ in freier tbersetzung durch eine Partizipialkonstruktion wiedergegeben: 


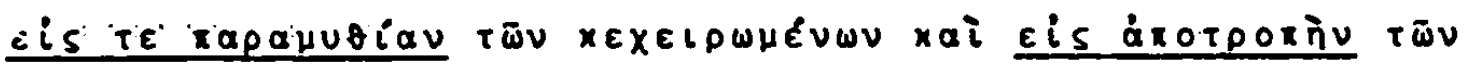

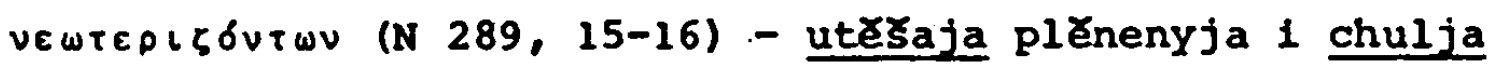
mjateźniky (M 299, 3-4).

b) $x \circ \delta 5$

Diese Präposition wurde im klassischen Griechisch mit allen drei obliquen Kasus verbunden 114). Da aber der Genitiv bei ross im hellenistischen Griechisch kaum mehr auftaucht und der Datıv ohnehin "... bel allen Präp. außer év im Abnehmen begriffen ist" 115). finden wir im $\Pi \delta \lambda \in u$ os (zumindest an den mit der Ubersetzung vergleichbaren stellen) eigentlich nur mehr die Verbindung mit dem Akkusativ.

Zeigt roós in räumlicher Funktion nach neutralen Verben der Bewegung die Richtung auf eine Person hin an, so steht im Altrussischen dafür meist ' $k b^{\prime}$ + Dativ; ist das Objekt der Bewegung eine Sache (in der Regel geographische Bezeichnungen), wird 'na' + Akkusativ gebraucht 116) :

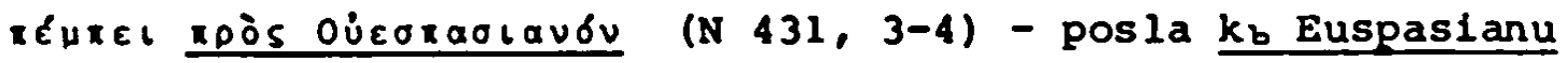
(M 357, 1):

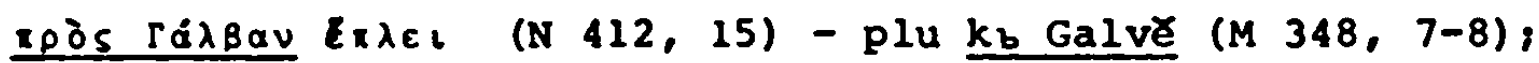

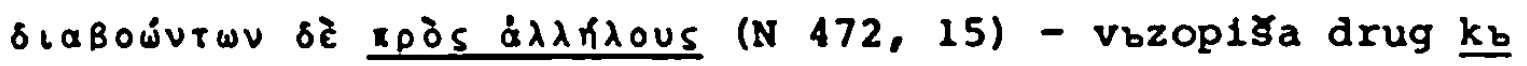
drugu (M 375, 16):

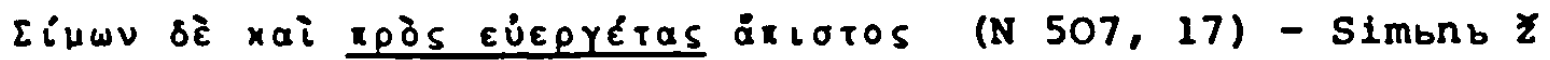
$1 \mathrm{~kb}$ blagodelcemb ne verrenb (II 393, 11-12);

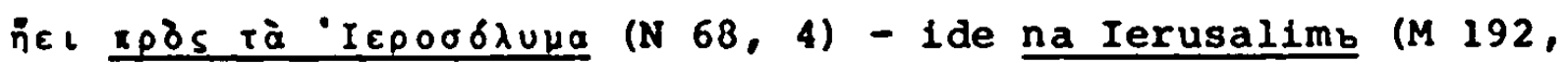
28-29),

Éyxiivas rojs 8jolv (N 503, 19) - uklinisja na zapad (M 391, 74).

Auch bei der Angabe des zieles und zweckes wird rods durch 'na' + Akkusativ ubersetzt:

xwpiov... rpòs opayru (N 19, 15) - mésto...na ubilstvo (M 172, 
26);

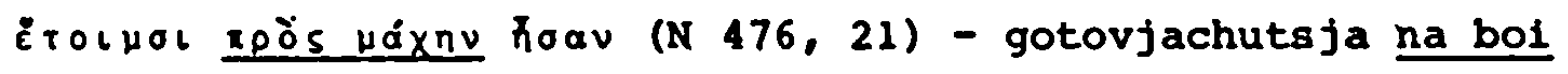
(M 377,28$)$.

Wenn jedoch beim Nomen noch weitere Bestimmungen stehen, die eine wortliche Ubersetzung erschweren, wird die griechische Präpositionalwendung im altrussischen Text oft durch einen finalen Nebensatz wiedergegeben:

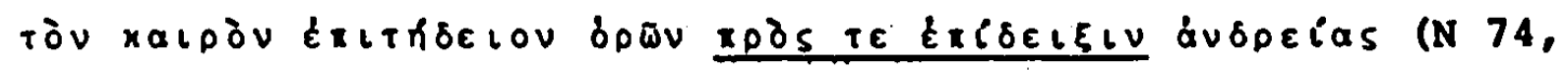
3-4) - vide vremja ugodno, da pokažetb pred Antoniemb svoe muzestvo (M 195, 3-4),

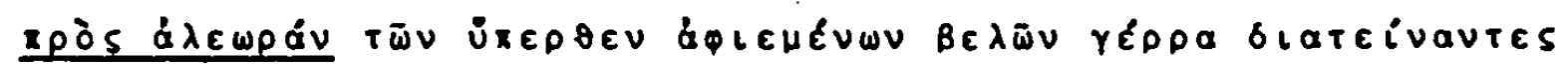
(N 296, 15-16) - ustroivse Zelovb da bysa ne pakostili iz grada (M 301, 9-10).

11. Prypositionen mit zwel Kasus

1) Präpositionen, die mit dem Genitiv und dem Akkusativ verbunden werden

a) $\delta\left\llcorner\alpha^{\circ}\right.$

In Verbindung mit dem Genitiv wird $\delta \iota a^{\prime}$ gebraucht "... zur Angabe einer durch einen Raum oder Gegenstand sich erstrekkenden und aus demselben wieder heraus- oder hervortretenden Bewegung" 117). In der Ubersetzung entspricht ihm hier 'skvozb, skvože' + Akkusativ, das im Altrussischen verwendung findet "... dija oboznaCenija predmeta 111 sredy, Cerez kotorye prochodit to 111 inoe dejstvie" 118):

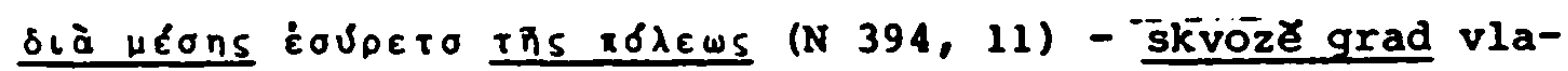
Cim bystb (M 339, 8) i.

Tñv otpatıàv hre sıà Kaxraboxías xai ppurias (N 429, 12) vede voja skvoze Kapadokiju i Frigiju (M 356, 6-7). 
Dient $\delta\llcorner\alpha+$ Genitiv lediglich zur Angabe "... eines räumlichen Erstreckens ... ohne die Nebenbedeutung des Wiederhervortretens" 119), so wird es durch 'po' + Dativ oder eine abgeleitete, aus einer Verbindung mit letzterem entstandene Präposition wiedergegeben:

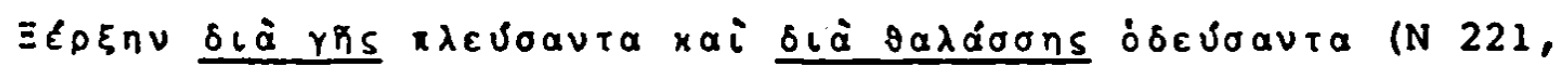
8-9) - Kserksa, po zemli plavavకa 1 po morju chodivకa (M $275,26)$ :

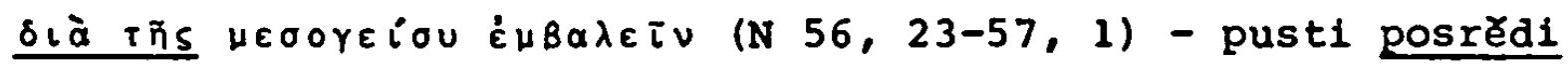
zemlja (M 189, 27).

$\delta \iota \dot{\alpha}+$ Genitiv in temporaler Funktion zur "... Angabe des zeitlichen Erstreckens" 120) wird ebenso wie der Genitivus und Dativus temporis durch den altrussischen Instrumental der Zeitangabe - hauptsächlich handelt es sich um Bezeichnungen derTages - und Jahreszeiten wie im modernen Russisch ubersetzt:

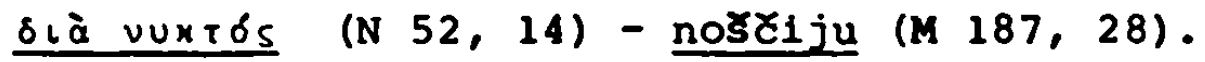

$\delta \iota \dot{a}+$ Akkusativ, das im Griechischen die Ursache oder den AnlaB einer Handlung bezeichnet, findet keine einheitliche Ubersetzung.

In vielen Fällen wird es, in einem gewissen Widerspruch $z u$ der bei Evexa gehandhabten Praxis 121), durch 'radi' oder 'dělja' + Genitiv wiedergegeben, obwohl es elndeutig einen Grund und nicht eine Absicht angibt:

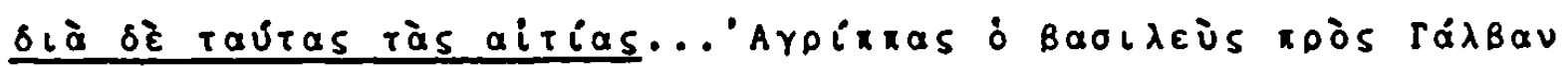
$\varepsilon \pi \lambda \varepsilon\llcorner(N 412,14-15)$ - toja Ze radi viny 1 Agripa cesarb plu... kr Galve (M 348, 7-8);

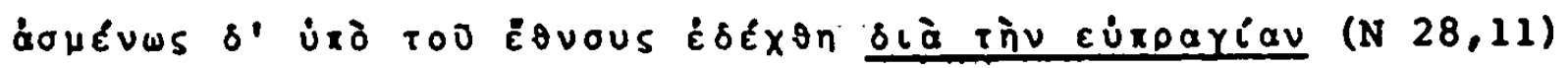
- prijasa ego s radostiju ljudie pobedy radi (M 175, 13-14):

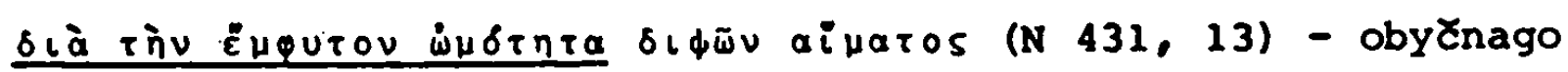
Zestoserdia radi Zadase $\operatorname{krovi}(M 357,9-10)$; 


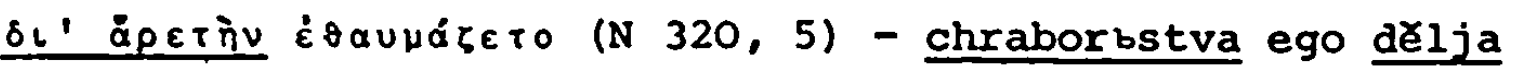
1 mudrosti ... divjatsja (M 307, 8).

Daneben tritt für $\delta\llcorner\alpha+$ Akkusativ in derselben Funktion auch der aitrussische Instrumentalis causae ein, ohne daB sich gegenüber der ersten Ubersetzungsweise ein bedeutungsmäßiger Unterschied feststellen ließe:

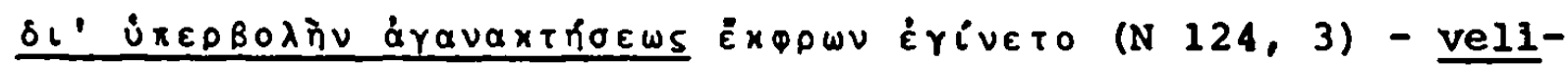
Costvom peCali uzasesja 1 umb svoi pogubi (M 223, 30-31):

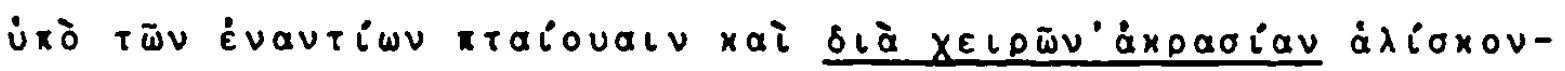
Tal (N 450, 23-24) - pobezaetesja ot protivnych nesytostiju svoeju (M 366,13$)$ :

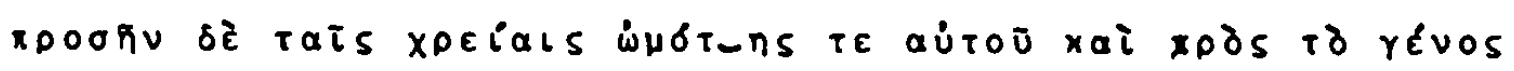

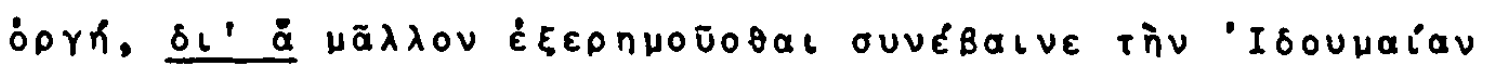
(N 416, 16-18) - Žestokb Ze by 1 jarb.... Im Ze 1 gubjase vsju zemlju (M 350, 12-13).

Schlieblich wird die Wendung mit olá auch durch einen Kausalsatz, eingeleitet durch 'zane' oder 'poneže', wiedergegeben. Diese Konstruktion bevorzugt der Ubersetzer besonders dann, wenn im Griechischen das mit $\delta \imath a ́$ verbundene Nomen noch eine nicht mit ihm kongruierende Bestimmung bei sich hat, so daB die wörtliche Ubertragung ins Altrussische - bedingt unter anderem durch das Fehlen einer genauen Entsprechung für den griechischen Artikel - erhebliche Schwierigkeiten bereiten wirde. In der Folge wird aber der Kausalsatz im Altrussischen gleichsam automatisiert als Entsprechung fur den griechischen Präpositionalausdruck mit $\delta\llcorner\dot{a}$ und vom Ubersetzer auch dort angewandt, wo ubersetzungstechnisch dazu keine Notwendigkeit besteht:

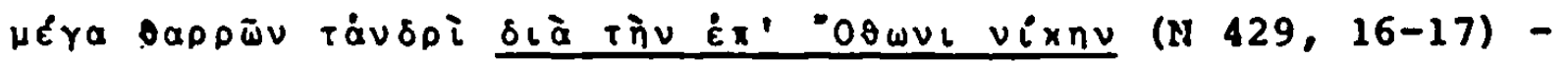
upova na $n b$, zane pobedi.Aftona (M 356,10$)$;

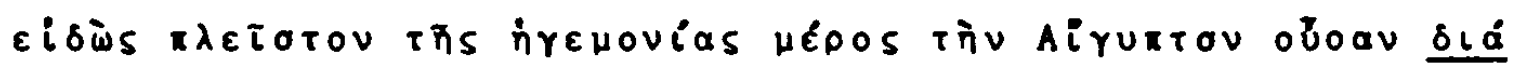
tĥv roũ oirou xopnyiav (N 425, 17-18) - jako bolsaja Castb vseja estb (em.n.Behr.) Igĕmonija Egipetb. Zane psenicju vozjachu ottudu k Rimu (M 354, 25-26) 122), 


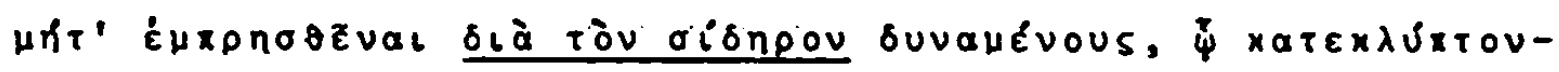
to (N 475, 5-6) - nemozxno bystb... nI zazesti, zane okovana byša Zelezomb (M 376, 29-31):

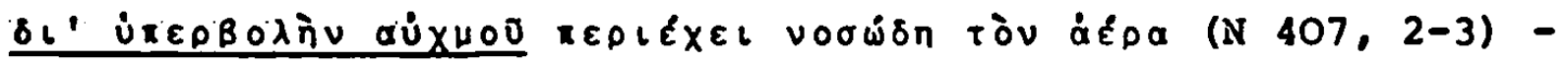
aerb na nem nedužen, zane ne odozdaetsja mesto to ( $M 345$, 16-17):

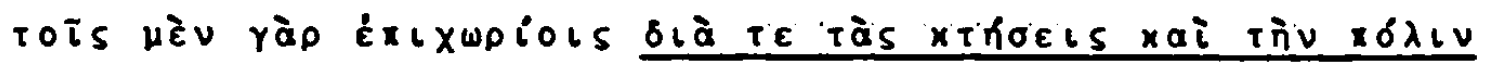

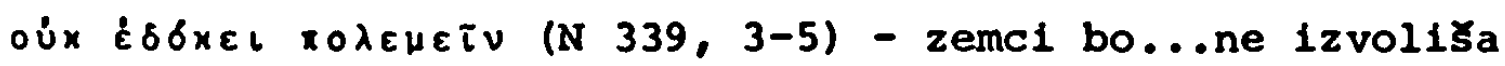
zaratitisja, zane bogatstvo 1 imenia moga imjachu vb grade (M 315, 18-20):

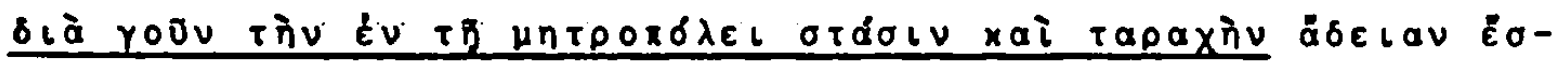
xov oi xatà tìv xwipav xounpoi tw̃u ápxarūu (N 400, 9-11) pone Ze mitropolia obderżma bystb mjatežms 1 razboiniky. temm 1 zlodei ... svoju volju 1spolnisa (M 341, $32-342,2)$,

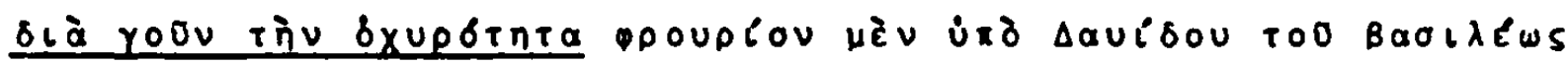
Exaגeito (N 452, 18-19) - narecenb Davidom cesaremb Chranitelb, zane bystb utverženb $(M 367,11)$.

Anstelle des Nebensatzes kann auch eine Partizipialkonstruktion (absoluter Dativ oder Participium coniunctum) mit kausalem Sinn stehen:

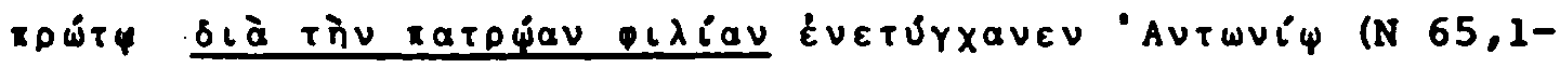
2) - prised kb Antonievi, drugu emu otbeju sustju (M 191 , 10-11):

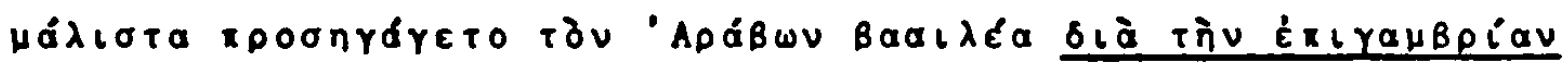
(N 41, 15-16) - porutil svoja Cada aravskomu cesarevi,tbstju emu suscju (M 182, 27-28):

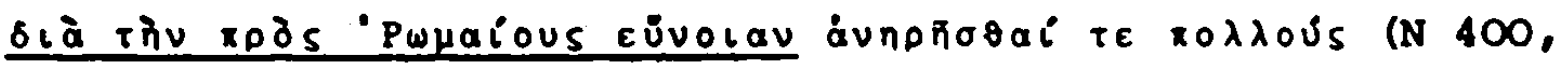
22-23) - mnozi bo, mirno mysljałłe $k$ nemu, padoła ot svoich (M 342, 22-23).

b) $x a r a$

Fipr die ursprünglichen răumlichen Funktionen von xatá + Geni- 
tiv, wo es zur Bezelchnung einer von oben nach unten verlaufenden Handlung gebraucht wurde 123), liegt bel den wenigen betreffenden Stellen des Originals keine vergleichbare Ubersetzung vor. In seiner ubertragenen Funktion, in der es nach Verben der Bewegung oder Veranlassung einer Bewegung ein "... feindliches Verhaltnis" 124) ausaruckt, entspricht ihm in der Ubersetzung 'na' + Akkusativ, das in dieser Funktion auch in den eigenstăndigen altrussischen Denkmălern vorkommt 125):

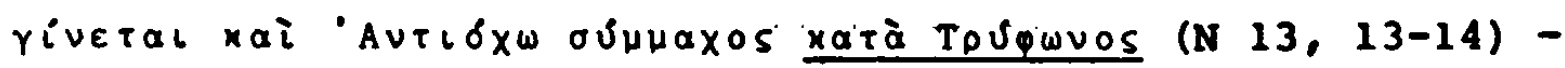
$i$ Antiochovi pomoglb na Trufona (M 169, 25-26):

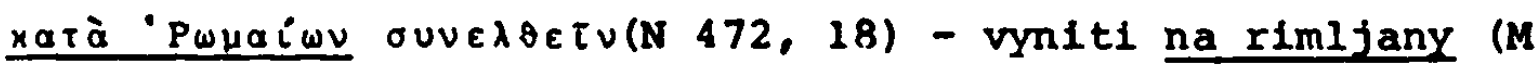
$375,20)$ :

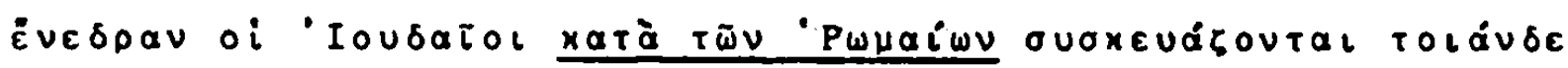
(N 449, 7-8) - ljudéi Ze taku lestb sbtvoriła na rimljany (M 365,22$)$;

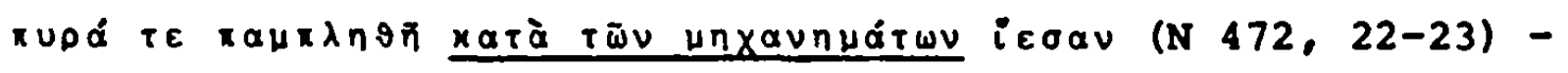
ognb metachu na ovny 1 na poroky (M 375, 25);

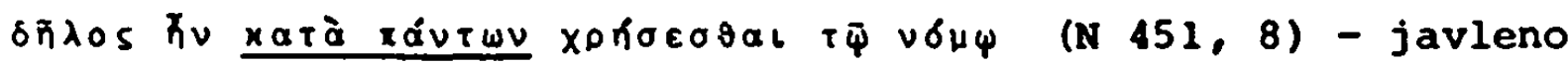
bystb, jako na vsech chožetb vynesti zakonnyi sud (M 366 , $21-22$ ) :

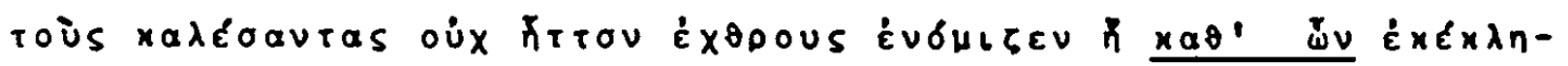
To (N 421, 19-20) - tvorja vragy ravno 1 zvavsich 1 (em.n.Vol.) na ne Ze zvanz bysto (M 352, 27-28).

Mit dem Akkusativ bezeichnet xará ursprünglich die "... Richtung einer Handlung nach einem tiefer liegenden Gegenstande oder uber einen Gegenstand hinab", sodann dient es auch "... zur Angabe eines Erstreckens von oben nach unten hin... auch allgemeiner: in der Gegend von" 126). Diese dynamische Auffassung des Griechischen wird im Altrussischen durch eine statische ersetzt und daher nicht die Richtung, sondern der ort der Handlung betont. Darum finden wir auch in der Ubersetzung als Entsprechung meist ' $v_{b}$ ' + Lokativ: 


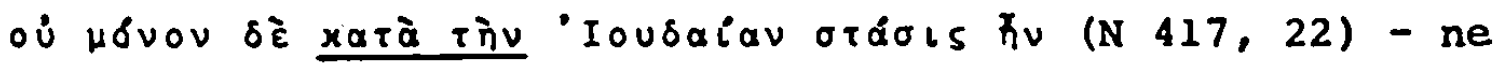

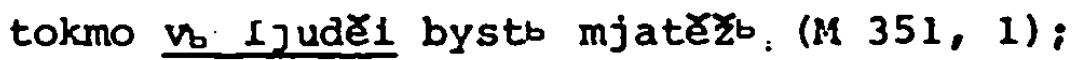

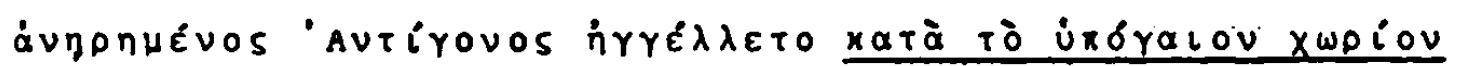
(N 19, 19) - Antigonb ubsen bystb $v$ temne meste (M 172, 3031):

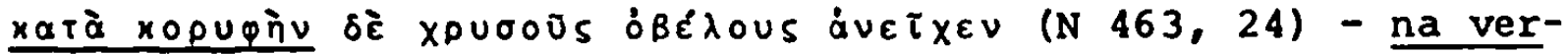
chu Že vsaženy bysa zlaty grozdy ( 1371,17 ).

In einem Fall steht als Entsprechung der bloße Lokativ:

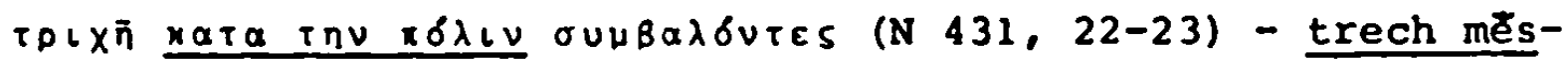
têch snembsesja (M 357, 19).

Wird die Handlung auch im Altrussischen als dynamisch aufgefaBt, so finden wir anstatt ' $v b^{\prime}$ + Lokativ den "tvoritel' nyj mesta", der sowohl im Altkirchenslavischen wie im Altrussischen verbreitet war ${ }^{127}$ ) und auch im modernen Russisch noch als "tvoritel'nyf puti ili prostrantva" 128) weiterbesteht:

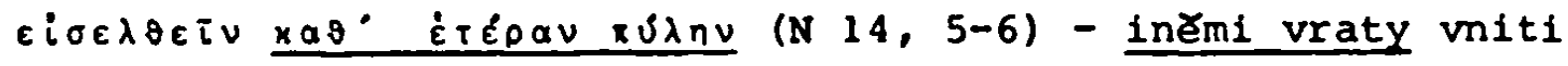
(M 170, 6);

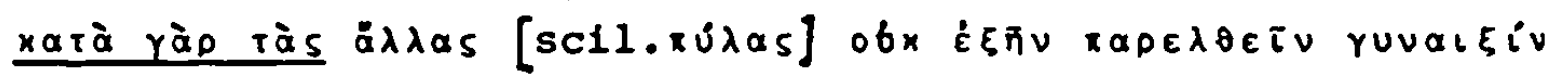
(N 461, 9-10) - inêmi dvêrmi ne dostoino be Zenam vnit1 (M $369,6-7)$ :

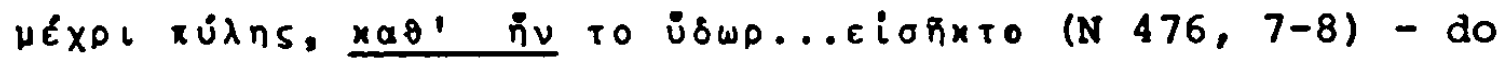
vrat, imi Ze vbvédena bystb voda (M 377,14$)$.

Eine übereinstimmende dynamische Auffassung des Griechischen und Altrussischen liegt vor bei der Angabe des ziels einer feindseligen Handlung, vor allem nach Verben des Schlagens und Schießens. Für $x \alpha r \dot{a}$ erscheint in der Ubersetzung ' $v b$ ' + Akkusativ:

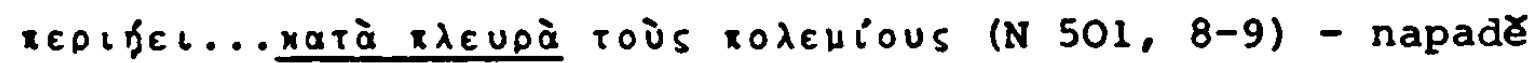
na ratniky $v$ bokb (M 390, 1):

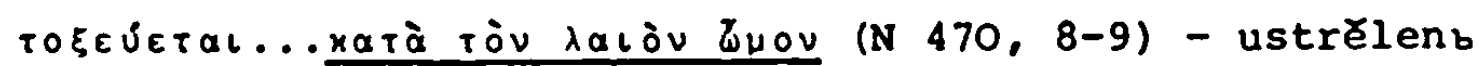
bystb vb levoe ramo (M 374, 10): 
Wird dieses ziel weniger punktuell als flächenhaft verstanden, so tritt in der Ubersetzung 'po' + Dativ für jará ein: $\underline{x a \tau \grave{a} \sigma \tau \delta \mu \alpha}$ xaíuv (N 446, 14-15) - po 1icju sêka (M 364, 17).

Temporal bestimnt $x a \tau \dot{a}+$ Akkusativ eines Substantivs oder Pronomens, vor allem bei Personen-, Herrscher und Dynastiebezeichnungen, die Handlung in ihrer "...Erstreckung in der Zeit" 129). Hier entspricht ihm das altrussische 'pri' + LOkativ:

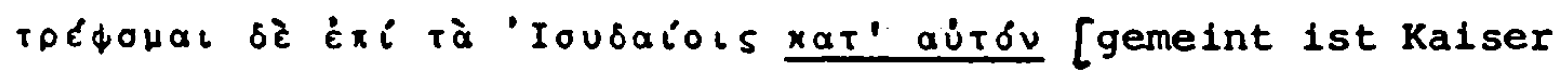
Nero] revठneva (N 202, 11-12) - ispisach Že, jaže byకa sbtvorena pri nem vb Ijudei (M 267, 15).

Ubertragen drückt die griechische Konstruktion $x \alpha \tau \dot{\alpha}+$ Akkusativ die Ursache, den Beweggrund einer Handlung aus 130). In der Ubersetzung steht dafur eine kausale Präpositionalwendung mit 'radi' oder der Instrumentalis causae:

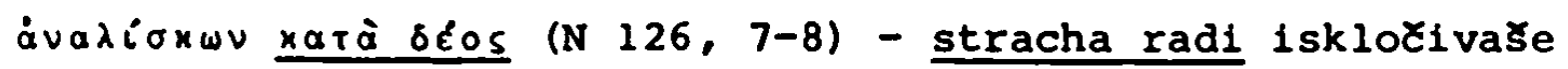
(M 225, 20-21):

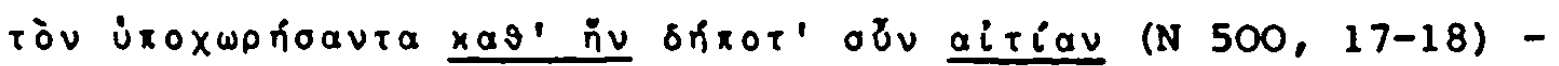
aste kto otstupitb kotoryja viny radi (M 389, 27-28);

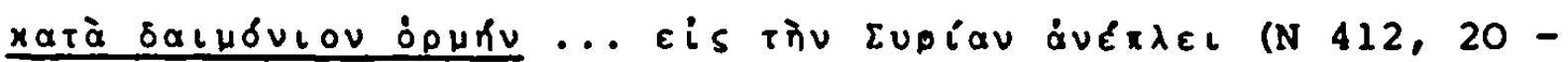
21) bożimb stroeniemb... priplu k Surii (M 348, 12-13);

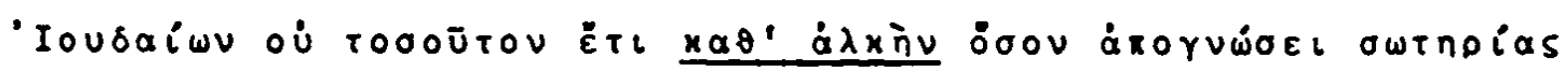

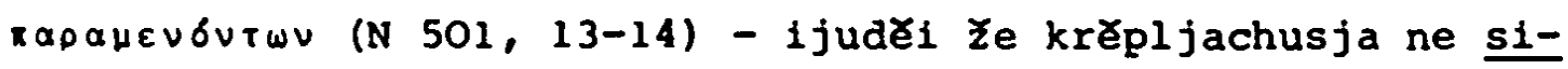
loju, no otCaaniems (M 390, 4-5).

Weiter dient xará + Akkusativ "... uberhaupt zur Angabe einer Rucksicht" 131) und zeigt ebenso wie der Akkusativ und Dativ der Beziehung den Gesichtspunkt an, von dem aus die Aussage des Satzes beurteilt wird. Wiedergegeben wird es hier wie letztere durch den limitativen Instrumental:

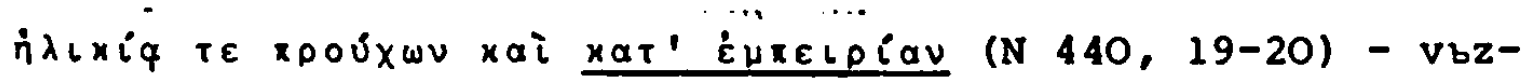


rastom krasenb 1 1skuSeniemb voiskym pređudenb (M 361, 5-6),

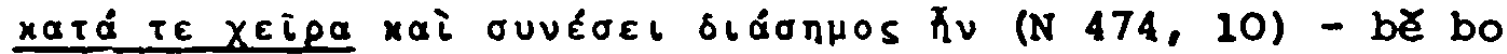
slaven s siloju 1 mudrostiju (M 376, 19):

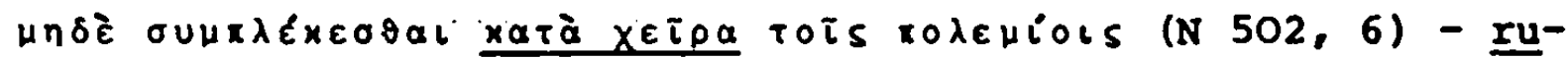
kama ne snimatisja (M 390, 22).

Für die năchste Funktion des xará, die Bezeichnung der Art und Weise, in der eine Handlung vor sich geht ${ }^{132)}$, läBt sich keine einheitliche Ubersetzungsweise feststellen. Sie kann ausgedrulckt werden durch ein Modaladverb, modales Partizip, einen Modảlsatz oder modalen Präpositionalausdruck ('sb' + Instrumental); der Ubersetzer entscheidet hier von Fall zu Fall, labt aber nirgends den modalen Charakter der vorlage verlorengehen:

xaTá TdXos eis Kaloapeiav dQLXVEital (N 412, 21) - skoro priide $k b$ otbcju ( $M 348,13$ );

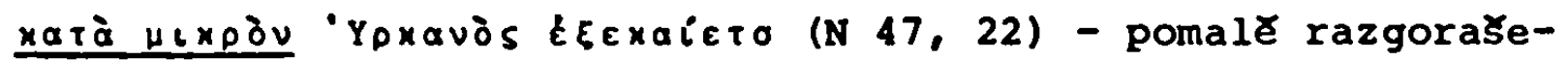
sja sbrdbce Urbkanovo (M 185, 23);

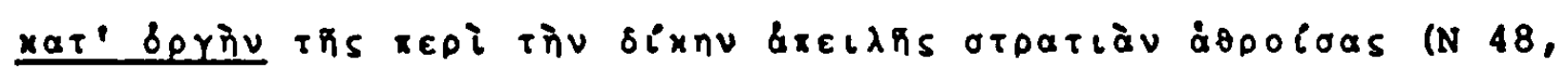
19-20) vbspominaja gnev na Urkana, onoja tjazi radi, 1 sbbra vol mnogy (M 186, 6-7);

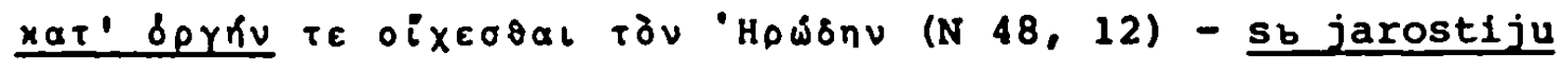
ot1de Irod (M 185, 38).

Dem zur Kennzeichnung eines distributiven Verhaltnisses verwendeten nord 133) entspricht im Altrussischen 'po' + Akkusativ: 134)

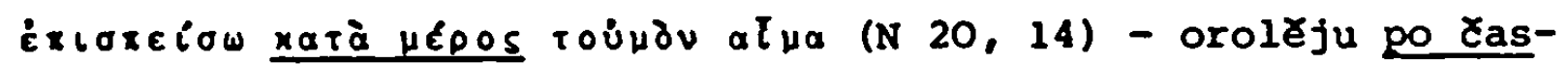
t1 svoju krovb (M 173, 6);

xat' inuépav - po vsja dni (N 126,10/M 225,23: N 67,10/M 192, $19, N 492,18 / \mathrm{M} \mathrm{386,33}$ und passim).

SchlleBlich wird die nach BLASS-DEBRUNNER allgeme in helleni- 
stische Verwendung von $x a \tau \dot{\alpha}+$ Akkusativ als Ersatz für den possessiven und subjektiven Genitiv 135) auch im $\pi$ o$\lambda \varepsilon \mu \circ s$ praktiziert; in der Ubersetzung finden wir, wie bei der Wiedergabe letzterer, ein Possessivadjektiv:

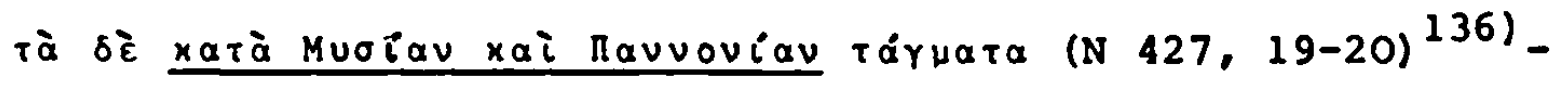
musskyi i pononbskyi polci (M 355, 14).

c) $\mu \in \tau \dot{\alpha}$

Ursprïnglich mit allen drei obliquen Kasus des Griechischen verbunden 137), kommt es mit dem Dativ selbst in der klassischen zeit nur mehr bei Dichtern vor ${ }^{138)}$. BLASS-DEBRUNNER haben es bereits unter die Präpositionen mit nur zwei Kasus eingereint ${ }^{139)}$.

Mit dem Genitiv bezeichnet $\mu \varepsilon \tau \dot{\alpha}$ die Mitbeteiligung an einer Handlung; es hat die Funktionen von ouv + Dativ - das in unserem Denkmal zu selten und vor allem mit zu wenig Entsprechungen in der Ubersetzung vorkommt, als da $B$ man es gesondert behandeln könnte - übernommen und "... dadurch das Gebiet dieser Präposition wesentlich eingeengt" 140). In der Ubersetzung steht ' $s b^{\prime}$ ' Instrumental, mitunter auch ein Participium activi eines transitiven Verbums + Akkusativobjekt ${ }^{141)}$ :

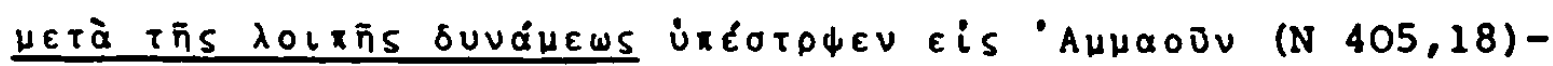
sam Že s proðilimi vbzvrativsja vb Amausb (M 344, 28-29);

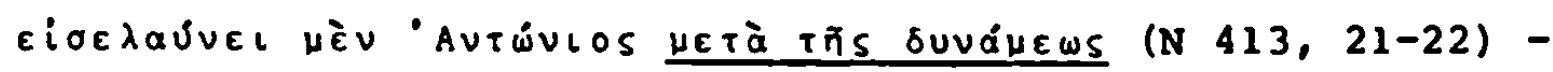
prilde Antonii v Rim s voi (M 357, 17-18);

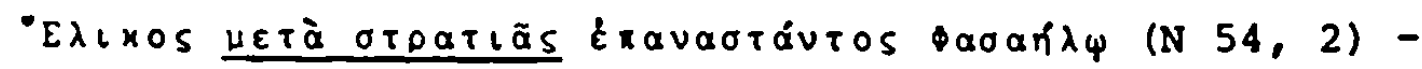
Elegb, poemb voja, prilde... na Fasaila (M 188, 12-13).

Ubertragen drückt $\mu \varepsilon \tau \dot{\alpha} \cdot$ + Genitiv die begleitenden Umstände einer Handlung aus 142). Die altrussische Entsprechung ist wieder ' $s_{b}$ ' + Instrumental, das auch bei der Uberset- 
zung biblischer Texte ins Altkirchenslavische als "modal"nyj sociativ" 143) diese Funktion von uerá vertrat".

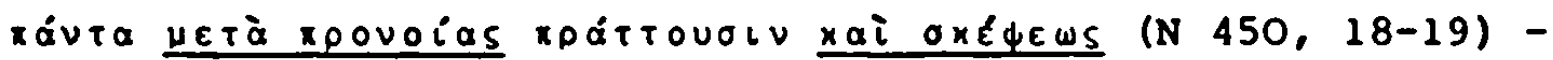
vsja s promyslom, sb smotrenlemb tvorjatb(M 366, 9-10) :

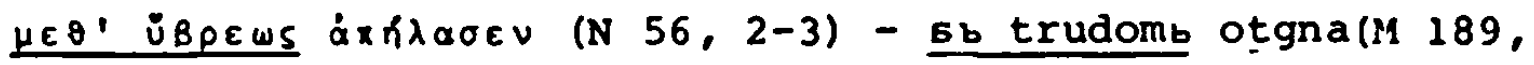
7);

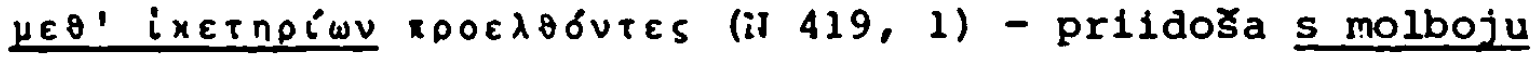
(M 351, 18).

Mit dem Akkusativ gibt $\mu \varepsilon \tau \dot{a}$ den Zeitraum oder Zeitpunkt an, nach dem die Handlung des Satzes vor sich geht 144). Im Altrussischen wird diese Funktion von 'po' + Lokativ wahrgenommen:

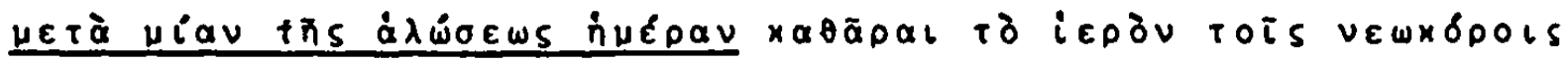
xpooḱtakEv (N 35, 2) - po edinom doni vzjatia povele slugamb cırkbunymb iకtistiti oskvernenija cbrkounaja (M 180, 9-10).

In Verbindung mit Superlativen bezeichnet $\mu \varepsilon \tau \dot{\alpha}$ das erste Glied einer Folge, an dem die ubrigen gemessen werden.

Im einzigen Fall, für den eine vergleichbare Ubersetzung vorliegt, wird es hier wiedergegeben durch 'otb' + Genitiv (comparationis):

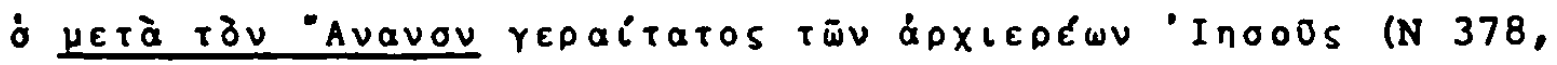
16-17) - Isusb Ze, 1Ze bystb vtory1 ot Ioana (M 334, 12-13).

2) Präpositionen, die mit dem Genitiv und dem Dativ verbunden werden

Hier handelt es sich durchwegs um Präpositionen, die im klassichen Griechisch mit allen drei obliquen Kasus stehen konnten, in der nolvin aber meist nur noch mit zweien verbunden wurden. Bemerkenswert 1st, daB dabei in der Sprache des NT der Dativ im Schwinden begriffen 1st, wăhrend in unserem Denkmal der Akku- 
sativ immer mehr in den Hintergrund tritt.

a) $\pi \varepsilon \rho i$

Ihm entspricht in der Ubersetzung ausnahmslos ' $O$ ' + Lokativ,ganz gleich, ob die griechische Präposition mit dem Genitiv oder dem Dativ steht ${ }^{146)}$. Dabei lassen sich jedocin folgende Funktionen herausstellen:

a) für repi + Genitiv

a) die Bezeichnung eines Grundes:

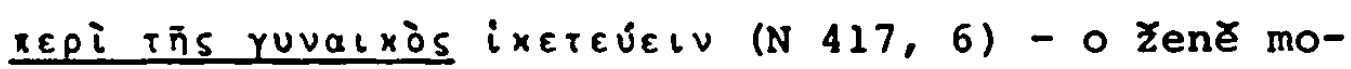
litisja (M 350, 21);

aB) die Angabe eines Zieles:

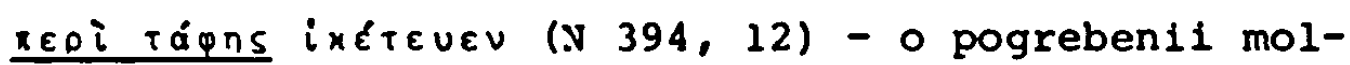
jasesja (M 339, 8-9);

ay) die Bezeichnung einer Rücksicht 147) wie beim 1imitativen Akkusativ und Dativ:

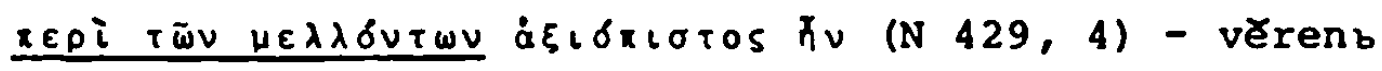
bystb $i$ o buduscich (11 356, 1-2);

as) reine objektfunktionen nach den Verba des Sprechens und der Gemütsbewegung:

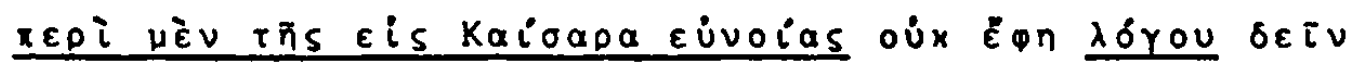
$a \dot{u} \tau \bar{\varphi}(N 45,4)$ - o priaznbstve cesareve ne trebuju svędêteli (M 183, 27-28);

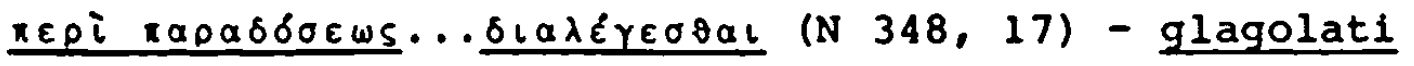
o prexdanii (M 320, 19);

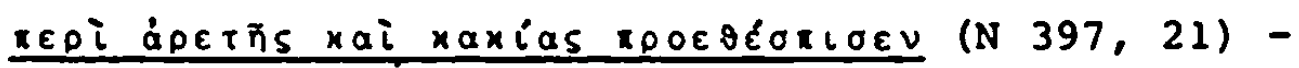
propovedasa o dobrodeteli 1 o zlobe (M 341, 1);

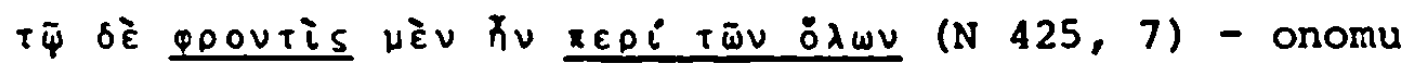
そe peralb bystb... o vsem (11 354, 16). 


\section{B) fủr $x \varepsilon \rho i+\operatorname{Dativ}$}

Mit dem Dativ findet sich $x \varepsilon \rho i$ als Objekt nach den Verba des Fürchtens und Sorgens (für etwas, un etwas). Manchmal steht aber hier auch der Genitiv, so daB sich keine genaue Grenze zwischen dem Gebrauch der beiden Kasus ziehen läBt:

beioas repi Tĩ veaviq (N 48, 5) - ubojavsja o nêmb (M 185 , 29):

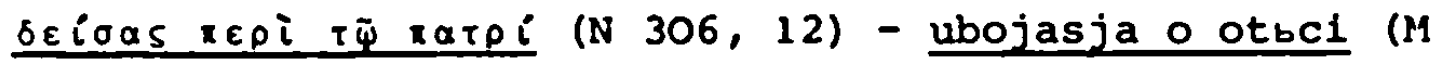
$304,16)$;

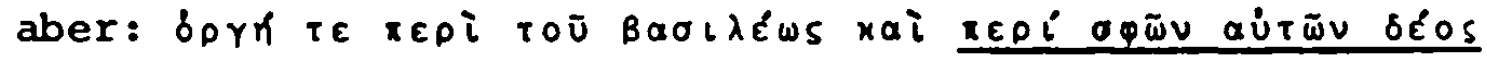
(N 349, 3-4) - 1spolnivకesja jarost1 o cesari 1 o sobę bojaక̌česja (M 320, 22) 148).

b) $\dot{i} \delta$

In Verbindung mit dem Genitiv dient es vor allem zur Bezeichnung des Urhebers, des Agens beim Passiv 149). Im Altrussischen wird es - soweit nicht die Wiedergabe des Agens oder des Passigs uberhaupt vermieden wird 150) - ubersetzt durch den Instrumentalis auctoris oder 'ot' + Genitiv. Dabei lassen sich jedoch im Gegensatz zum Altkirchenslavischen, für das BRAUER die Bevorzugung der Konstruktion mit 'otb' bei reflexiven Verben und die des Instrumentals beim Part. Präs. Pass. nachweist, keinerlei von der Passivform abhängige GesetzmäBigkeiten feststellen, denen zufolge die eine oder andere Möglichkelt gewählt worden wäre. Vielmehr stehen unter schiedslos beide Agensformen sowohl nach den wenigen reflexiven Verben mit Passivfunktion, die als syntaktischer Kirchenslavismus 2 u werten sind 151), wie auch bel den Konstruktionen mit passiven Partizipien. ZahlenmäBig ist der Instrumental stärker vertreten:

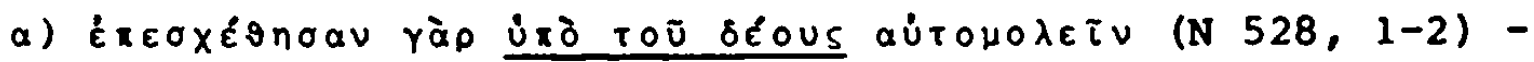
vbzbderžasasja ot vyběrania strachom (M 406, 12); 


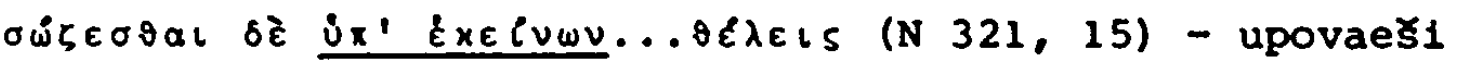
ot nich spastisja (M 308,5 );

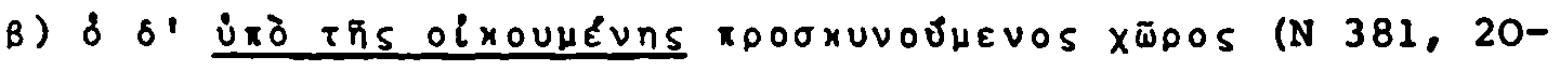
21) - mesto, pokonjaemo (em.n.vol.) vseju vselenoju (M $335,26-27)$;

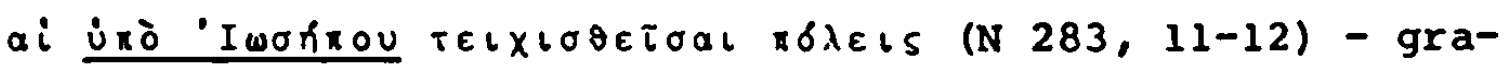
di, sozdanyi Iosifomb (M 295, 29-30).

Jedoch gilt auch für die altrussische Ubersetzung des $\pi \delta \lambda_{\varepsilon}$ wos dieselbe Ausnahme von "... der Promiskuitat der Agenskonstruktionen im Altrussischen", die JANKE für die weltiiche Literatur der altrussischen Epoche registriert und der zufolge "... eine Gruppe von Verben, die Totschlag und andere Gewalttat bezeichnen, ausnahmslos durch otb + Genitiv konstruiert" wird 152). Die Ursache dieser Erscheinung vermutet JANKE in dem Umstand, daB "... die Konstruktion otb + Genitiv die handelnde Person urspringlich eindeutiger zum Ausdruck brachte als der reine Instrumental" 153).

Um aufzuzeigen, daB diese GesetzmäBigkeit, die JANKE bel der Auswertung ausschlieblich eigenständiger altrussischer Literatur konstatieren konnte ${ }^{154)}$, auch in unserem Denkmal nicht durchbrochen wird, seien hier ausnahmsweise alle betreffenden Stellen daraus angeführt; ergibt sich doch dadurch ein weiteres sprachliches Argument für die ostslavischrussische Herkunft der Ubersetzung:

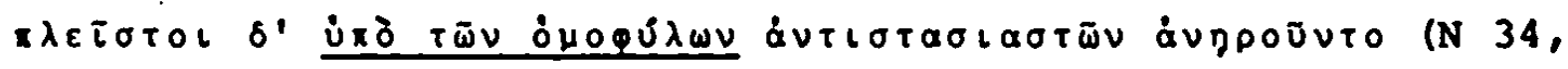
13-14) - mnozi ot srodnikb izbieni bysa (M 179, 36);

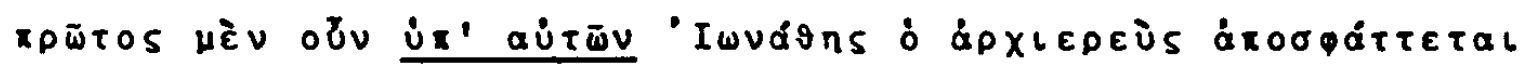
(N 203, 6-7) - pervyi ze ubienb bystb ot nich Ionafan archierri (M 267, 25-26);

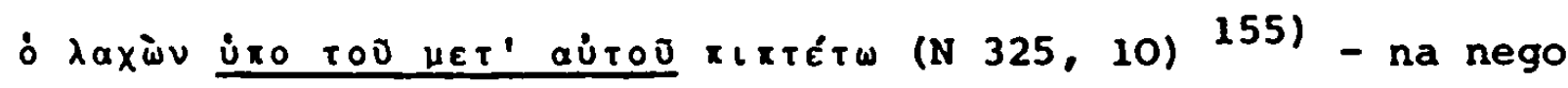
Ze konecb risla budetb, da tot budetb ubienb ot vtorago (M 310, 3-4): 


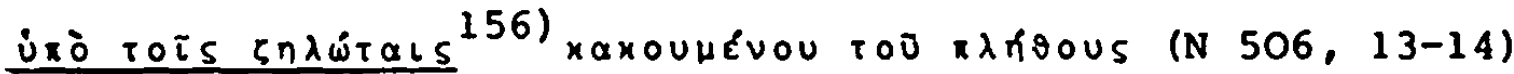
- vidervb drévle ljudi zlobimi ot revnitelo (M 392, 25-26);

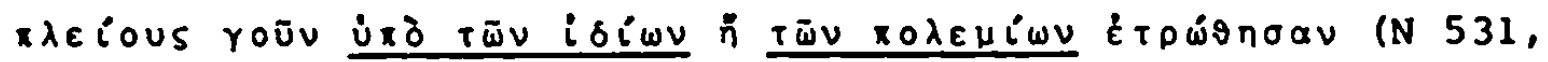
1-2) - 1 bolకa Castb ot svolch jazvleni bysa, negli ot ratnych (M 407, 31-32).

Durch den Instrumental und 'otb' + Genitiv wird der Agens auch bei formal aktiven intransitiven Verba mit passiver Bedeutung wiedergegeben ${ }^{157)}$ :

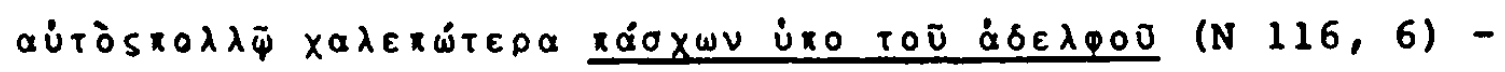
az ljutěisaja straßju ot svoego brata (M 218, 3-4);

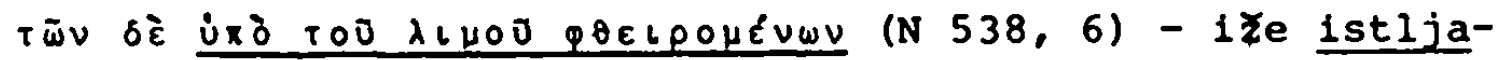
chutb ot glada (M 411, 34);

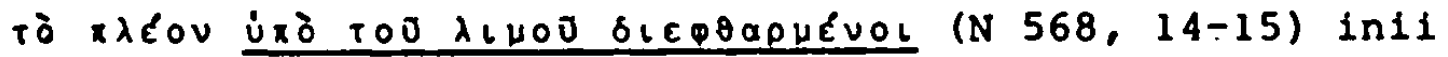
gladom istlexa (M 432, 9).

Das zur Angabe des Grundes einer Handlung verwendete ixó + Genitiv 158) wird ubersetzt durch den Instrumentalis causae oder eine kausale Präpositionalkonstruktion:

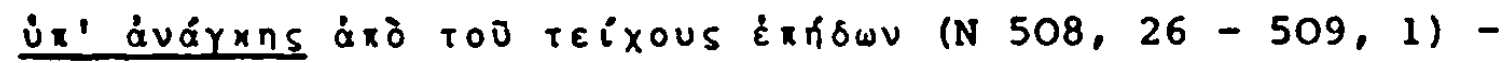
skakachu so zabral nuzeju (M 394, 12);

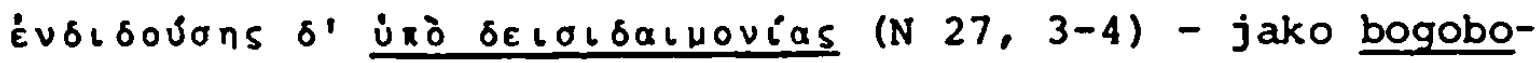
jazniva suši, povele imb (it 176, 2-3).

Mit dem Dativ findet ixó in räumlicher Funktion Verwendung zur Bezeichnung "... des Verwellens unter einem Gegenstand" 159). Die altrussische Entsprechung bildet 'podb' + Instrumental 160):

Ynoüvtes ìnò tois xpáveolv (N 423, 21-22) - pod Selomom sbstarevSesja (M 353, 28).

Auch ubertragen, wo $\dot{x} \times \delta$ + Dativ einen Befehls- oder Machthaber bezeichnet, dem etwas untergeordnet 1st, wird es durch 'podb' w1edergegeben: 


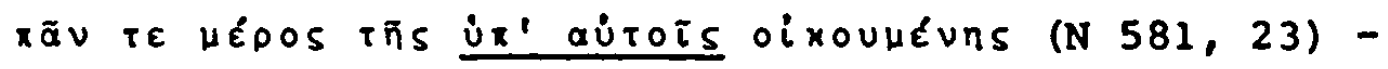
vsja vselěnnaja, pod rimljany susce (M 441, 29-30):

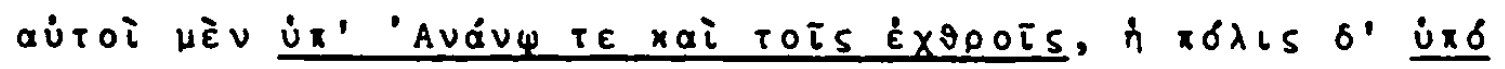
'Pwhaiols (em.n.AMLVRC) oóael revouévn (N 377, 15-17) my skoro budem pod Ananom 1 vragom nasimb, a grad pod rimljany (M 334, 1-2).

II I.Präpositionen mit orei Kasus

1) $\quad x \rho \&$

a) Mit dem Genitiv bezeichnet raoá neben einer "...Entfernung aus der Nähe einer Person" 161) ubertragen auch den Ausgangspunkt und Urheber der Handlung des Satzes 162). In letzterer Funktion entspricht ihm in der Ubersetzung das hier ebenfalls ubertragen gebrauchte 'ot.b' + Genitiv 163):

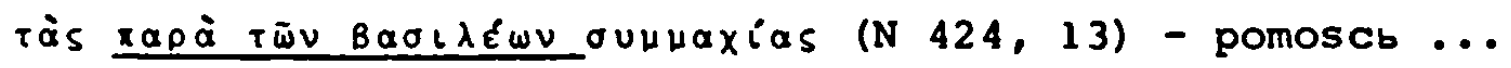
ot okrbstonych cesarevb $(354,7-8)$

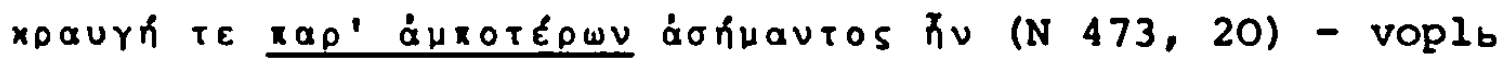
vozvyకaకesja ot obolch neznaem (M 376,6$)$.

Gibt $x a \rho \alpha^{\prime}+$ Genitiv beim Passiv den Agens an 164), so kann es auch durch den Instrumental ubersetzt werden:

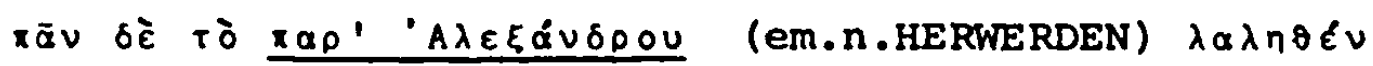
(N 107, 4) - vsja Ze rěb, 1zmolvlena Aleksandrom (M 213, 18).

b) Mit dem (lokativischen) Dativ dient xapá "... zur Angabe eines ruhigen Verweilens in der Nahe einer Person" 165). In unserer Ubersetzung wird es (in Verbindung mit dem Plural eines Nomens) durch ' $v_{b}$ ' + Lokativ wiedergegeben:

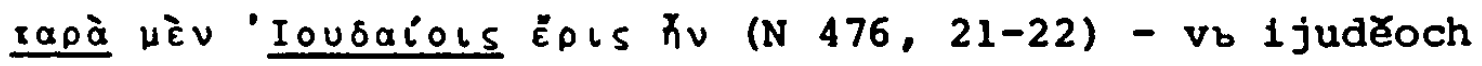
そe revnostb bysto (M 377, 28-29). 
c) Mit dem Akkusativ wird xapá bei den Verba des Schlagens und Treffens gebraucht, um das ziel zu bezeichnen. Wie für $x a \tau \dot{a}+$ Akkusativ steht im Altrussischen hier ' $v_{b}$ ' + Akkusativ:

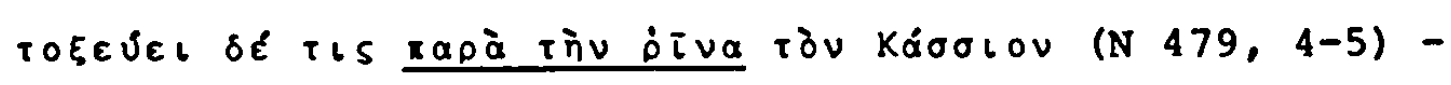
prostrêl1...Kastera v nosb (M 379, 6-7).

Die am häufigsten vorkommende Funktion von raod + Akkusativ ist jedoch die Bezeichnung der Nichtủbereinstimmung, des Zuwiderlaufens der Handlung mit dem Begriff, der durch das Nomen im Akkusativ ausgedruckt ist 166). Der Ubersetzer bringt dafür die Präpositionen 'krome' + Genitiv und 'čeres৮' + Akkusativ, die beide diese Funktion im Altrussischen vertraten 167):

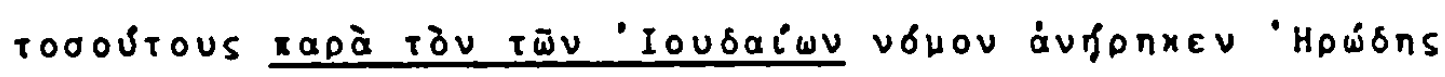
(N 47, 18) - Irod koliko ludii 1zbilb... krome Zidovskago zakona (M 185, 18-19):

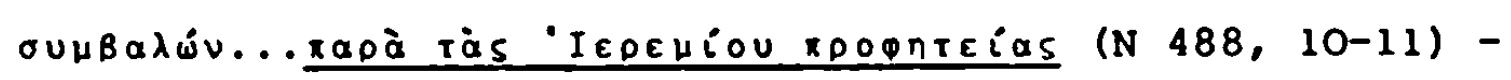
bisja s nimi Erêsb Eremiino prorozbstvo (M 384, 26- 27).

2) $\dot{\varepsilon} \pi \dot{c}$

a) Mit dem Genitiv drückt éxi răumlich ein Verweilen "... auf einem Raume oder Gegenstande" aus 168). Im Altrussischen wird diese Funktion von 'na' + Lokativ wahrgenommen 169), das auch in unserer Ubersetzung die Entsprechung $z u \dot{\varepsilon} \pi i$ bildet:

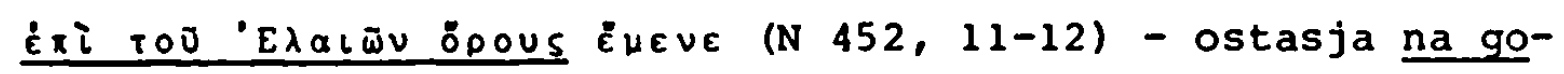
rêleonstêi (M 367, 3-4);

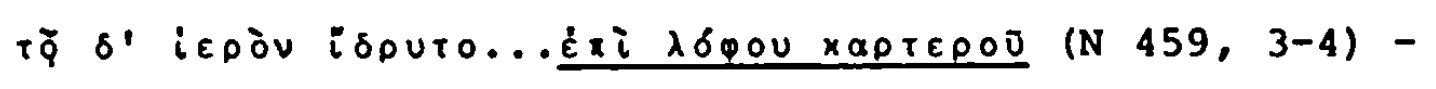
corkbvi Ze sozdana bysto na gore vysoce ( 368,7 ):

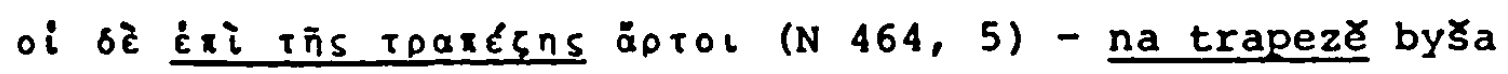
12 chléba (M 370,34-371, 1). 
Steht das zugehörige Nomen im Plural, kann statt 'na' auch 'po' + Dativ gewăhlt werden, wodurch das Fehlen einer engeren räumlichen Begrenzung zum Ausdruck kommt:

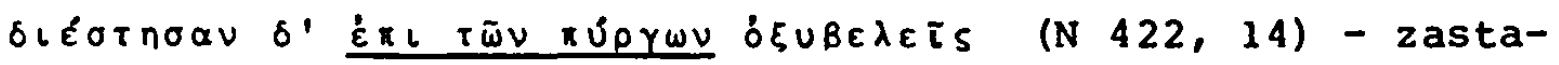
vi๔a そe po synom poroky (M 353,6).

Ebenfalls mit dem Genitiv steht $\dot{\varepsilon} i$, um die "... Richtung auf einen Ort oder Gegenstand" anzugeben; dabei bezeichnet der Genitiv "... nur die Richtung auf das ziel hin; ob das ziel wirklich erreicht wird, bleibt dabei außer Betracht" 170). Im Altrussischen wird hier mehr das $\mathrm{ziel}$ selbst betont; es steht daher ' $\mathrm{vb}^{\prime}$ + Akkusativ bzw. bel Personen 'kb' + Dativ:

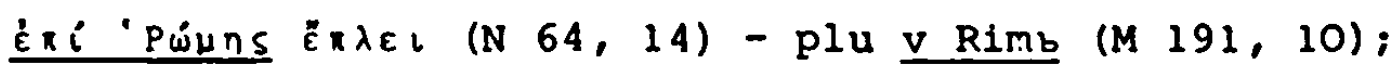

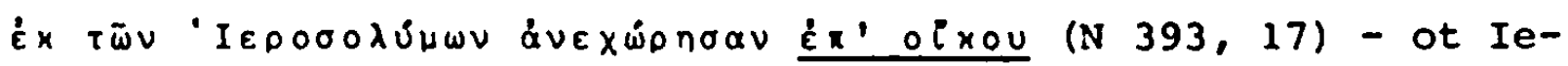
rusalima idoకa $\mathrm{kb}$ svoimb (1! $339,2-3$ ).

b) Mit dem Dativ drückt ériam häufigsten einen zweck, eine Bestimmung oder eine Absicht aus 171). In der Ubersetzung entspricht ihm in dieser Funktion finales 'na' + Akkusativ 172) oder ein finaler Infinitiv:

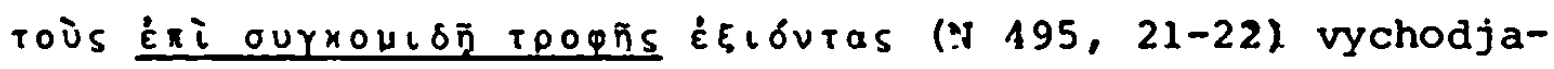
šich na sobrania zëlia (1M 388, 2);

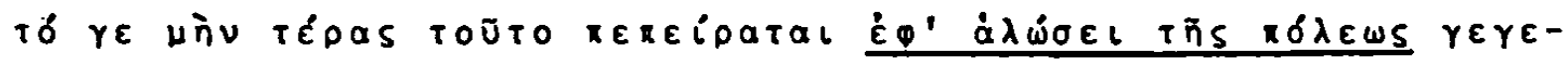
טnuévov (N 491, 2-3) - si znamenia 1 preže była na plênenia grada (M $386,9-10) 172 a)$;

xpolóvies is $\dot{\varepsilon} \pi i \mu a ́ x \eta(N 509,1)$ - vybergachu jako bitisja (em.n.Vol.) (M 394, 14).

Gibt $\dot{\varepsilon} \pi \dot{i}+$ Dativ die begleitenden Umstände einer Handlung an 173), so wird es' durch ein modales Partizip übersetzt:

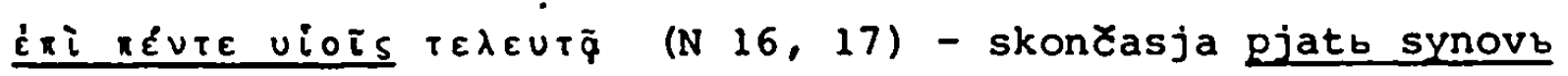
ostavivb (M 171, 9). 
c) $\varepsilon \times i+$ Akkusativ bezeichnet ein räumliches ziel, eine Richtung. 174 vor allem nach Verba der Bewegung oder der Veranlassung einer Bewegung:

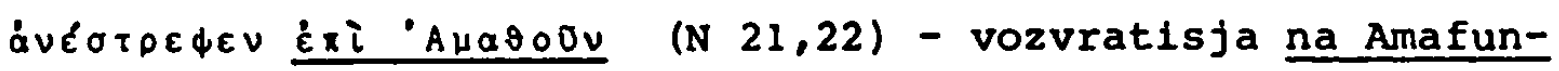
ta $(M 173,26)$;

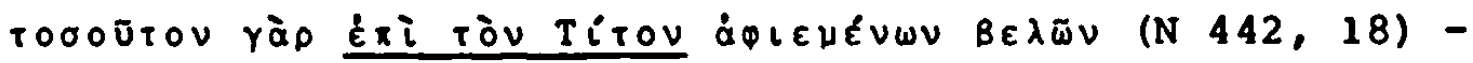
toliko bo strêlb 1 kopil pušaemy na Tita (M $362,11-12$; em. n.Vol.).

Auch ubertragen, wo es zur "...Angabe des Zweckes, der Absicht" dient 175), wird $\dot{\varepsilon} x i+$ Akkusativ durch 'na' wiedergegeben:

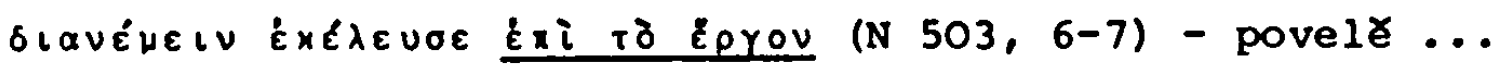
lziti na dêlanie (M.391, 6-7).

Ebenfalls durch ' $n a$ ' ubersetzt wird es schlieblich in Objektsfunktion nach Verben der Gemutsbewegung:

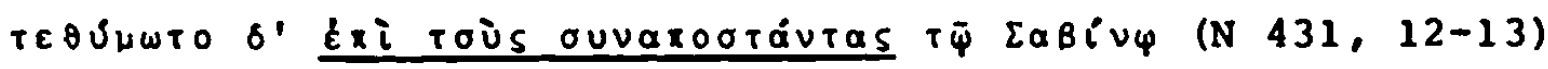

- jari Ze sja na otstuplbsich sb Savinom (M 357, 9).

$\xi \times i$ hat also in allen Kasus und fast allen Funktionen eine direkte Entsprechung in 'na', sei es mit dem Akkusativ oder dem Lokativ. Dabei handelt es sich aber nicht um eine "automatische" Wiedergabe durch den Ubersetzer - wir haben ja gesehen, daB er gegebenenfalls auch andere Konstruktionen ( $z$. B. Partizip) dafür verwendet - , sondern es liegt eine weitgehende echte Ubereinstimmung der Funktionen beider Präpositionen vor. 


\section{Bypotaxe}

Die zusammengehörigkeit von Sätzen, die dem Inhalt nach eine Einheit bilden, läßt sich in der Sprache am besten ausdrulcken durch die Hypotaxe, die Unterordnung eines Satzes unter den anderen, wobei "... der Satz; welcher seinem Inhalte nach eine bloBe nähere Bestimmung oder eine Ergänzung des andern enthält, auch auBerlich, in Ansehung der Form, als ein unselbständiges, abhängiges, $b l O B$ bestimmendes oder ergänzendes Glied des andern" deutlich hervortritt ${ }^{176)}$. Der Hauptsatz seinerseits gibt einen Teil seiner Funktionen an den untergeordneten Satz ab und kann für sich allein nicht mehr als vollständiger Satz gelten, ebensowenig wie der Nebensatz ohne Hauptsatz denkbar ist. Es liegt also nicht eine bloBe Abhangigkeit des Nebensatzes vom Hauptsatz vor, sondern es entsteht eine neue Einheit, der zusammengesetzte Satz, bei dem die enge Verbundenheit von Haupt- und Nebensatz oft durch Korrelativa demonstriert wird.

Ihrer Funktion nach lassen sich die Nebensätze in zwe1 Gruppen einteilen 177). Die erste wird von den Nebensätzen gebildet, die sich auf ein bestimmtes Glied des Hauptsatzes beziehen und dieses näher bestimmen und weiter ausbauen; hierzu gehören die Relativ-, Vergleichs- und objektsătze. Die zweite Gruppe wird gestellt von all denjenigen, bei denen eine "funktionelle Korrelation" zwischen Haupt- und Nebensatz als Ganzem vorliegt, also den Adverbialsätzen.

1. Relativsatze

Die Relativsătze, die der năheren Bestimmung eines Substantivs (oder Pronomens) dienen, nehmen die Funktion eines Adjektivs oder attributiven Partizips im einfachen Hauptsatz wahr. Von der griechischen Schulgrammatik werden sie daher auch als Adjektivsätze oder Attributivsätze bezeichnet ${ }^{178)}$. Die hăufigste Einleitung im Griechischen ist das Relativpronomen is, in, $\therefore ;$ in der Ubersetzung entspricht $1 \mathrm{hm}$ das ebenfalls aus anaphorischem Pronomen enstandene 179) 'ize, jaže, ež'; Satzmodus ist im Griechischen der Indikativ bzw. der oblique Optativ, im Altrussischen der Indikativ: 


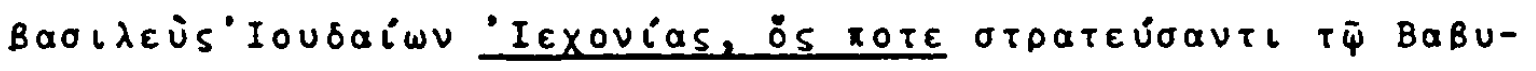

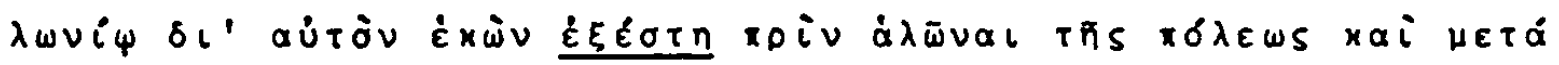

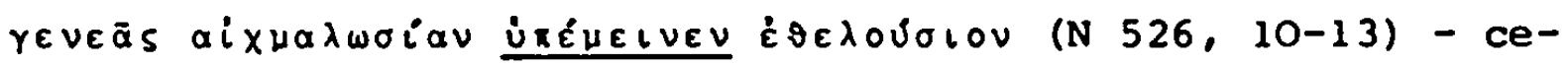
sarb ijuděeskb Iochonia, ǐ̌e drěvle prisedకim na no vavilonjanom voleju vystupil pred pleneniems $1 \mathrm{sb}$ svoim rodom (M 405, 14-16; erg.n.I);

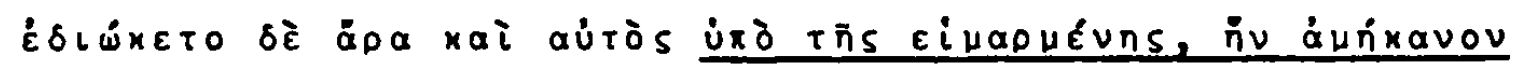
slaquyeiv ountou outa (II 52.3, 22-23) - sudom postizenb bystb, ego Ze nikto ne moZetb uběati, smertenb syi (M 403, 29-30). Weitere Beispiele siehe $N 26,14 / M 175,14 ; N 453,6-7 / M 367$, 18 ; $N 475,19-20 / M 377,8-9 ; N 517,1 / M 399,11 ; N 526,2-4 /$ M 405, 7-9 und passim.

Der Gebrauch altrussischer Interrogativa zur Einleitung eines Relativsatzes ist äuBerst selten, z.B.:

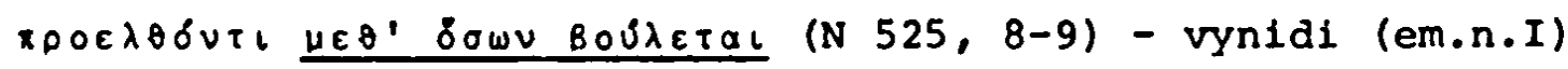
s kollkom chošesi (M 404, 27-28).

Gewöhnlich wird stattdessen zur Wiedergabe von ooos das verallgemeinernde Relativum 'eliko' verwendet:

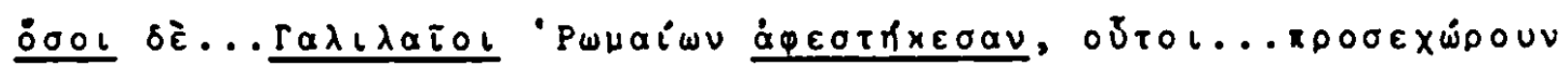
(N 346, 1-2) - eliko Galilexi utekoła ot rimskb ruk, dajachutsja im (M 319, 2-3);

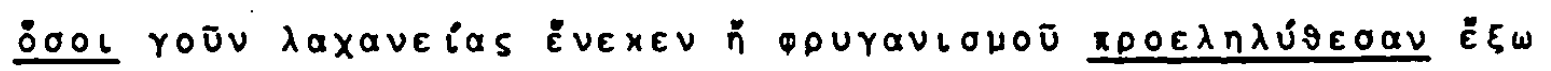

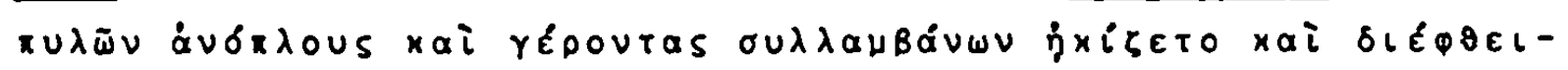
pev (N 417, 9-11) - na obrêtajusłichsja pusti gnêvb, eliko vynidosa lachans sobrati ili arevrb, starii, ili Zeny, ili nemoక̌nii (M 350, 23-25).

Eine Besonderhe1t des Griechischen ist das "...gelegentliche Hineinziehen des Bezugswortes in den Relativsatz" 180). Im Altrussischen wird diese konstruktion dann nachvollzogen, falls bei unverkürter Konstruktion Bezugswort und Relativum in der Ubersetzung im gleichen Kasus stehen müBten (die Kasusverhältnisse der Vorlage sind dabei ohne Bedeutung): 


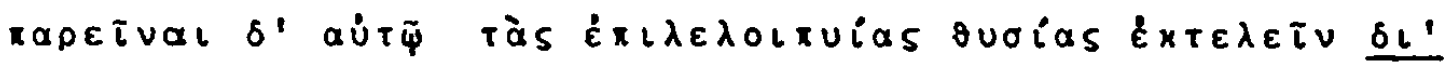

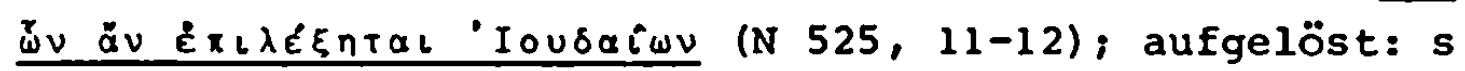
Ijudei. s nimiže izvolǐ̌i).

Immer vermieden wird diese konstruktion, die nach RUZICKA im Slavischen einen Gräzismus darstellt 181), wenn sich für Bezugswort und Relativum verschiedene Kasus ergeben. In diesem Falle erscheint ersteres stets im Hauptsatz und steht in dem Kasus, den dessen regierendes verbum erfordert; im Relativsatz wird es wiederaufgenommen durch das Pronomen, welches sich in seinem Kasus nach dem Prädikat des Nebensatzes richtet:

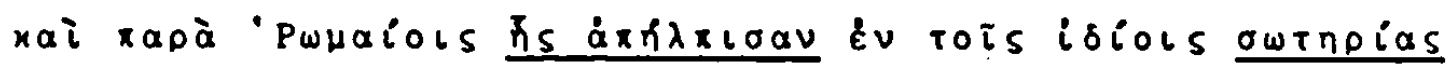

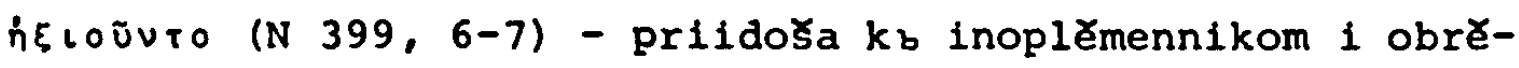
toła $v$ nich spasenie, ego Ze ot svoich ne ulucisa (M 341 , 19-21):

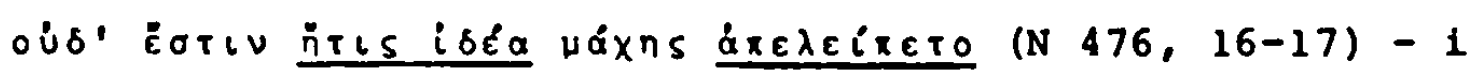
néstb obraza ratnago, iže ne javisja tu (M 377, 23-24).

Auch der griechischen Konstruktion, bei der das Bezugs wort ganz weggelassen und "... durch verbale Determinierung, die seinen $\mathrm{Zweck}$ oder seine gerade wesentliche Eigenschaft angibt, umschrieben" wird, wobei "... der Kasus, in dem der umschriebene Gegenstand stehen müte, ... aus dem zusammenhang hervorgeht" 162), folgt das Altrussische nur, wenn das $z u$ ergänzende Bezugswort ein objekt des Hauptsatzes darstellt und im selben Kasus stehen müBte wie das Relativpronomen :

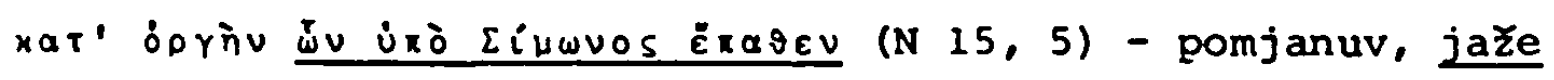
emu sotvori Simonb $(M 170,24 ;$ zu ergänzen wäre im Hauptsatz ein Akkusativobjekt).

Aber bereits wenn es sich bei dem Bezugswort un ein anderes Satzglied handelt, wird es ergänzt, selbst wenn die Rektion in Haupt- und Nebensatz dieselbe ist: 


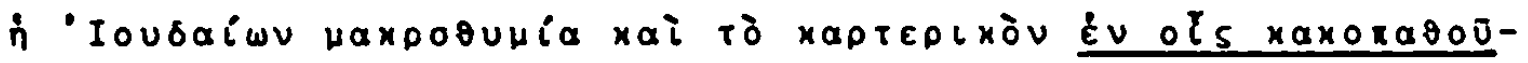
olv (N 518, 4-5) - ijuděisko dblgotrbpenie 1 kréposto vb strastech, $v$ nich Ze strazjut (M 399, 31-32).

Griechische Relativsätze mit stark kausalem oder konsekutivem Nebensinn werden im Altrussischen durch die entsprechenden Adverbialsätze wiedergegeben:

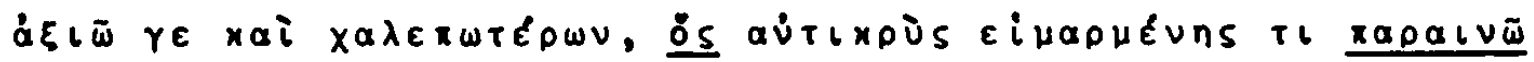
(N 526, 22-23) em.n.Pa ${ }^{1}$ LVR) - dostoin esmb puSCe sich slySat1 ot tebe, pone Ze glagolju protivu sudu (M 405, 25-26);

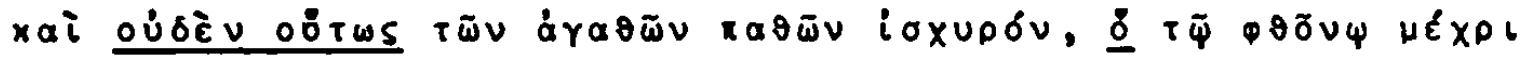
xavios ávikxet (N 19, 5-7) - 1 ne estb krepko tako blagoe, jako možtb protivitisja zavistiju do konca (M 172, 19-21).

Neben den oben behandelten unterscheidet POSPELOV noch die Gruppe der sog. weiterfuhrenden Relativsatze (povestvovatel' no-rasprostranitel'nye), die nicht der Erläuterung eines Substantivs des Hauptsatzes dienen, sondern den ganzen Satz un einen neuen Prădikatsinhalt erweitern 183). Diese Art von Relativsätzen, die im griechischen Original unseres Denkmals ziemlich stark verbreltet ist - in der Regel handelt es sich hier un Nebensätze, deren Subjekt das Relativum ist wird in der Ubersetzung auch anders behandelt als die ubrigen. Da diese Nebensätze in ihrer Handlung eine Weiterfuhrung, oft auch eine zeitliche Fortsetzung der Hauptsatzhandlung darstellen, werden sie meist - in ein paar Fällen finden wir hier auch eine genaue Ubertragung - als selbstăndige Aussagesătze wiedergegeben:

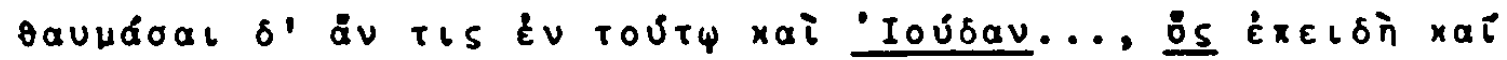

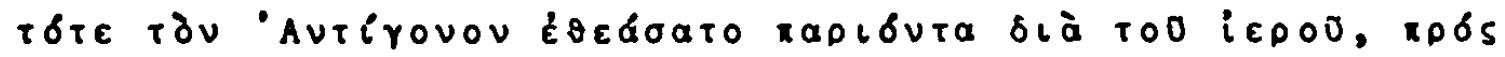
roos ruwpinous duexpayev (N 19, 8-11) - Ijuda osejaninb,

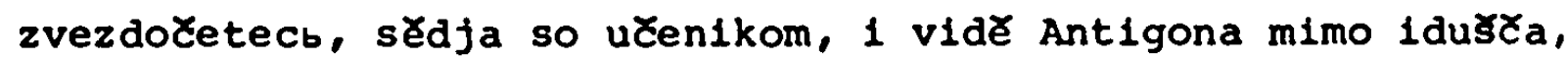
vozp1 (M 172, 22-23);

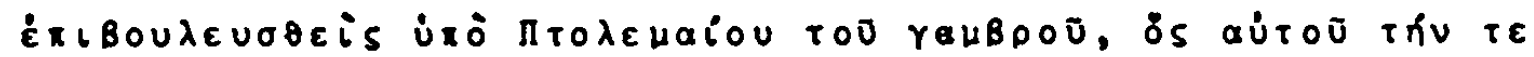

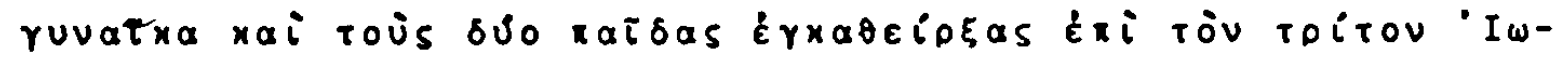

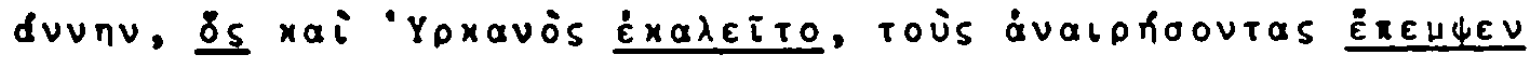


(N 13, 24 - 14, 2) - Potolomeri...umori i, a Zenu ego i dva syna dẹržałe okovavb, a na tretıego poslav ubiti ego, narečmago Arkama (M 170, 1-3);

Das letztere Beispiel, in dem der weiterführende Relativsatz durch einen Hauptsatz, der zweite, sein Beziehungswort näher bestimmende aber durch ein Partizip, also ebenfalls eine Bestimmung, übersetzt ist, zeigt deutlich die differenzierte Auffassung beider Typen durch den Ubersetzer.

11. Objektsätze

Die Objektsätze vertreten als Nebensätze "... die Stelle eines im Akkusative stehenden [,] das Prädikat des Hauptsatzes ergänzenden Objekts" 184). Das stützwort im übergeordneten Satz, auf das sie sich beziehen, ist also dessen regierendes Verbum. Dabei ist der Kreis derjenigen Verba, die einen Objektsatz bedingen können, semantisch ziemlich eng begrenzt.

\section{1) Die Deklarativsătze}

Sie sind im Griechischen abhängig von den Verba dicendi, declarandi und sentiendi. Eingeleitet werden sie durch ór $t$ und ws; als Modus finden wir in der Regel den Indikativ 185). Der altrussische Deklarativsatz hat als Modus ebenfalls den Indikativ, die Konjunktion ist 'jako':

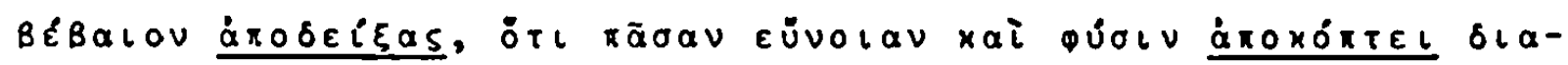

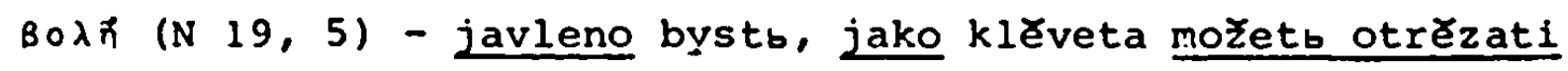
vsjaku ljubovb $i$ pravdu (M 172, 18-19).

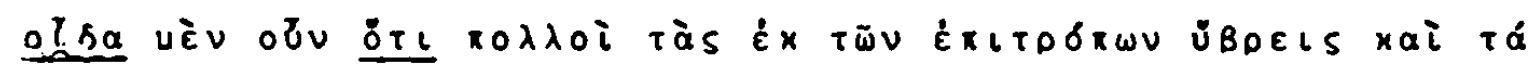

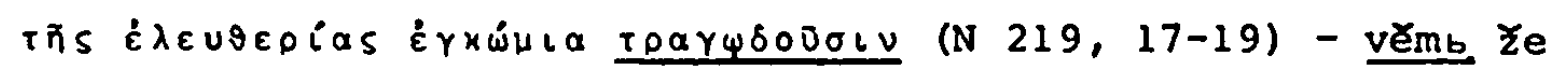
jako mnozi $\mathrm{vb}$ ustech nesutb nepravdy gemonbsky i pochvalu svobode ( $11274,31-32$ );

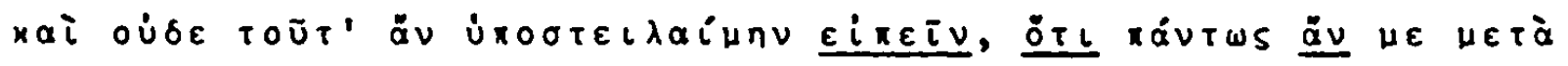

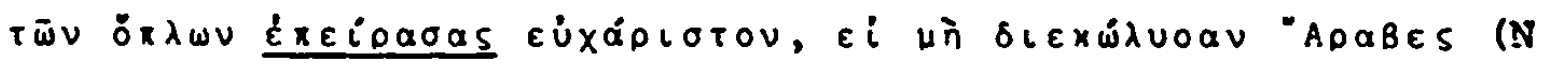


89, 7-9) - 1 ne bojasb tebe, povědaju ti, jako Ze so oruZiem iskułal by mene, asce by ne voeval na aravy (M 203, 8-9) 185a):

Weitere Beispiele finden sich in großer Anzahl über den ganzen Text hin.

\section{2) Indirekte Fragesätze}

Wie die Deklarativsätze geben sie das objekt des Hauptsatzprädikats an, und zwar nach den Verben des Fragens und der UngewiBheit im weitesten Sinne ${ }^{186)}$. Sie werden eingeteilt in Wort- und Satzfragen.

a) Wortfragen

Im Griechischen werden sie eingeleitet durch indirekte

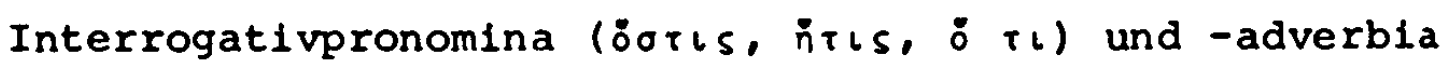
(z.B. ( $\left.\dot{0}^{\text {) }} \mathrm{xws}\right)$. Daneben finden auch die direkten Interrogativa Verwendung 187 ). In der Ubersetzung finden wir als Konjunktionen vor allem die Pronomina ' $k b t o$ ' und ' cto' und die Adverbla 'kako' und 'otkudu'. Modus ist der Indikativ, bei lodalbedeutung kann auch der Infinitiv stehen:

Épls hu jotls xpoxtvouvejoas xapioalto tois nirenóolv (N 476,22 ) - revnostb bystb, kto prež ubienb budetb pred gemonom $M 377,29)$;

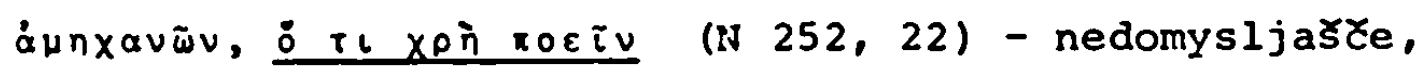
Eto sbtvoriti (M 285, 33):

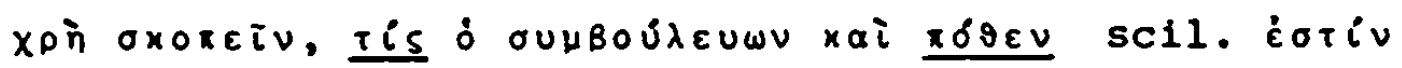
(N 526, 19) - podobno $t i$ smotréti, kto s toboju beseduetb 1 otkudu estb (M 405, 21-22):

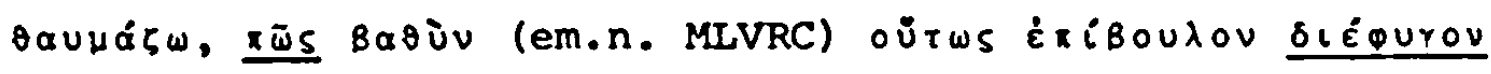
(N 143, 8-9) - divljusja, kako ubězach takago gluboka zla stroitelja (M 236, 35-36); 


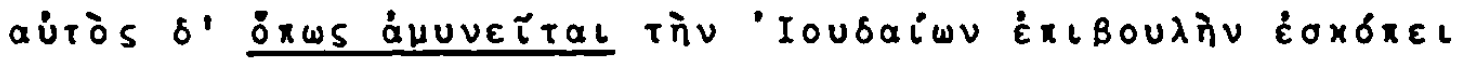
(N 451, 17-18) - i smotrjaకe, kako mbstiti ijudeiskuju lestb (I1 366, 30-31).

\section{b) Satzfragen}

Im Griechischen werden sie konstruiert mit Hilfe der Konjunktion $\varepsilon i$, die ursprünglich eigentlich Doppelfragen einleitete 188), und dem Indikativ bzw. obliquen Optativ als Modus. In der Ubersetzung werden sie eingeleitet durch 'asCe', was RUzICKA als "klaren Gräzismus' bezeichnet, der dadurch begünstigt worden sei, "... daß ein semantischer und syntaktischer Spielraum des ASTE es erleichterte, dem Druck des griechischen Vorbildes nachzugeben, außerdem wohl ein gewisser Bedarf nach einer Konjunktion des indirekten Fragesatzes bestand und schlieblich der klare syntaktische Zusammenhang das richtige Verständnis des ÃSTE an dieser Stelle sicherte" 189). Als Modus finden wir im Altrussischen den Indikativ:

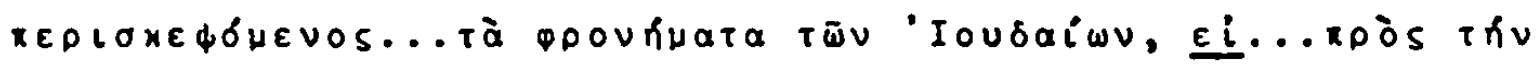

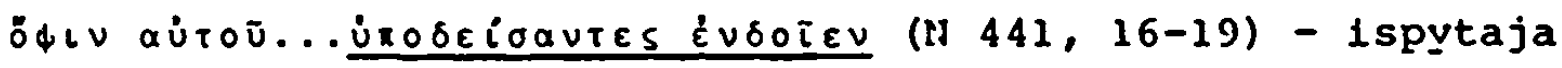
umb ijudereskb, ašče nžasnutsja ot vifěnija ego 1 predadjatsja (M 361, 23-24);

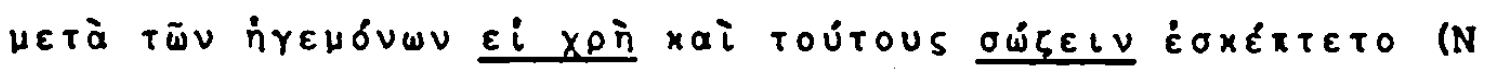
$344,8-9)$ - 1 sıprasa 3 ja (cm.n.Vol.) s voevodami, asce dostoino [scil. estb] priselbca pustiti (M 317, 25-26).

\section{3) Zielsätze}

Sie bezeichnen "... eine Wirkung (ein zu Bewirkendes, ein Erstrebtes, ein $\underline{\text { iel) " }}$ " und stehen "... nach den Verben der Sorge, Uberlegung, Verhütung, Bemühung, Bestrebung, des Bewirkens, Veranstaltens und der Aufforderung, des Befehlens. Untergegliedert werden sie in die abhängigen Heischesätze und die "ursprünglichen Abwehrsätze" 191). 
a) Heischesätze

Im klassischen Griechisch werden sie eingeleitet durch is, orws: Modus ist der Konjunktiv. Bei Josephus finden wir häufiger iva, das in klassischer zeit in dieser Funktion "... nur ausnahmsweise erscheint" 1921. Eigentliche Heischesätze treten jedoch im $\pi \delta \lambda \varepsilon \mu \circ$ nur selten auf, meist steht nach den betreffenden Verben dafür der objektsinfinitiv. In der Ubersetzung werden beide Konstruktionen gleich behandelt und als objektsätze, eingeleitet durch 'da' (in einem Falle durch 'aby'), wiedergegeben. Modus ist in der Regel der Indikativ, wobei als Entsprechung für eine griechische Aoristform ein perfektives, für eine Präsens- oder Imperfektform ein imperfektives Verbum gewählt wird:

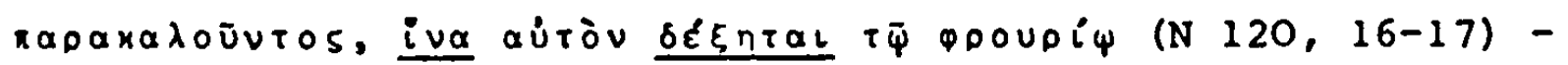
moljascusja, da priimetb $1 \mathrm{v} \operatorname{grad}(M 221,20)$;

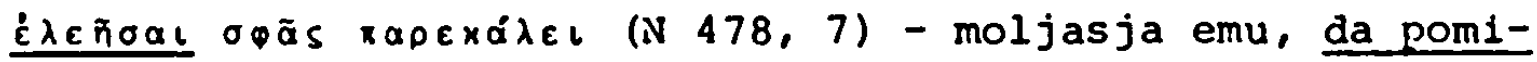
lueto ja (M 378, 20-21):

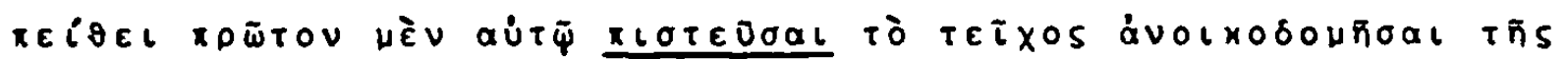
ratpioos (N 261, 6-7) - pomolisja, da porulitb emu sbzdanie stêny gradnyja (M 288, 1-2);

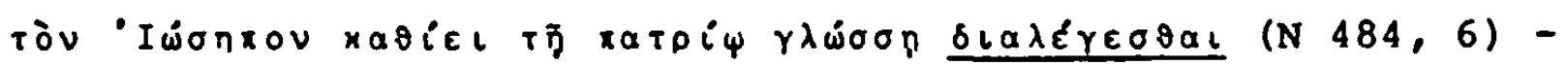
posla Iosifa, da beseduetb otbČskym jazykom (M 382, 2-3).

Von den Heischesätzen mit dem Verbum im Konditional vertreten nur 4 eine entsprechende Konstruktion des Originals, davon 3 einen Infinitiv und nur ein einziger einen Heischesatz. Modus des letzteren ist der bei oxws sonst nur nach Präterita im Hauptsatz auftretende Optativ 193). Seine Wiedergabe durch den Konditional spricht für BRÄUERs Hypothese, der zufolge dieser im Altrussischen einen wunsch bezeichnet 194); doch läbt sich mangels weiterer Entsprechungen kein allgemeiner Schluß ziehen, da ja bei den griechischen Infinitivbeispielen kein Modusvergleich möglich ist: 


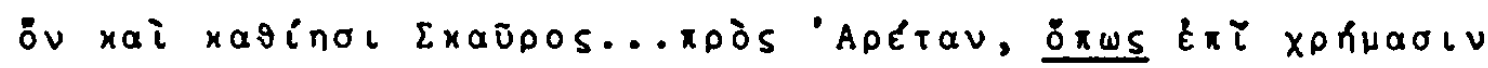

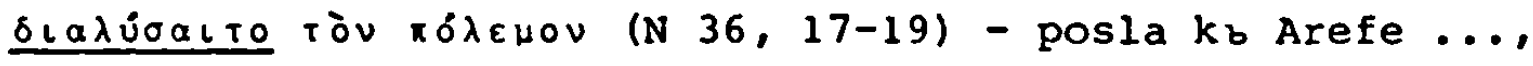
da by svobodilb ot rati svoju zemlju darmi (M 181, 2-4);

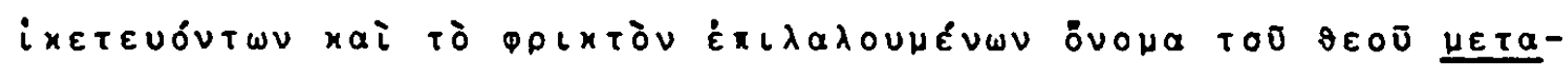

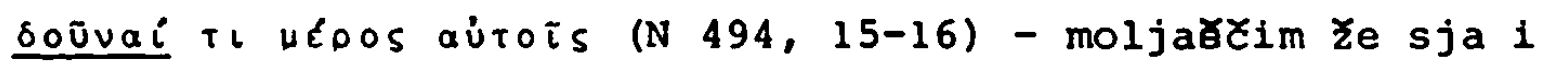
strašnoe imja božie prizyvajušim, da byక̧a podali imb Zastb zelia (M 387, 18-19);

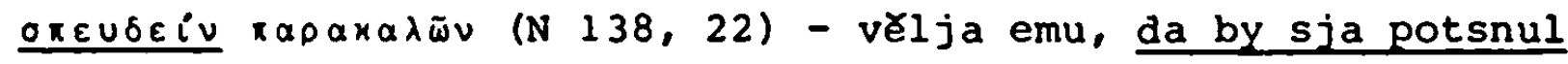
borzo (M 233, 31-32):

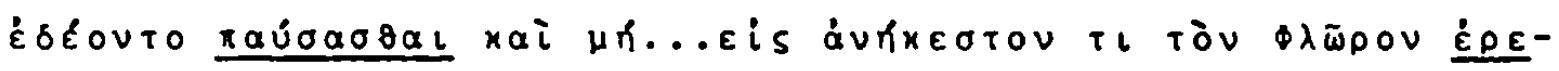
OicElv (N 214, 4-5) - moljachusja, da byక̧a prestali ot voplja, da ne vozvratjatb Flora na bezlepienuju jarostb (M 271,25-26).

Der Moduswechsel im letzten Beispiel düfte darauf zurückzuführen sein, daß der Ubersetzer das zweite Glied des griechischen Heischesatzes als eigenen Adverbialsatz, abhängig vom ersten Heischesatz, betrachtet hat; ein Bindewort ist jedenfalls in keiner der zugänglichen Handschriften $z u$ finden und bei asyndetischer Reihung würde man die Beibehaltung des Konditionals erwarten.

b) Abwehrsätze

Sie stehen hauptsächlich nach den Verba timendi und cavendi und heiBen daher in der griechischen Schulgrammatik "Substantivsätze der Befürchtung" 195). Doch ist dieser Begriff etwas zu eng gefaBt und daher BRÄUERs Benennung vorzuziehen. Eingeleitet werden sie im Griechischen durch die ursprüngliche Prohibitivpartikel $\mu n$, die erst im Laufe der Sprachentwicklung zur Konjunktion wurde 196), seltener durch $\mu$ f xore. $\delta \times w s \mu h, \dot{w} s \omega r$. Modus ist der Konjunktiv, nach einem historischen Tempus im Hauptsatz kann auch der (oblique) Optativ stehen. Im Altrussischen werden die Abwehrsätze eingeleitet durch 'da ne' und (seltener) 'egda kogda' 197). Als Modus steht bei 'egda kogda' immer und bei 'da ne' in der überwiegenden Mehrzahl der Fälle der Indikativ, wobei wiederum die 
bei den indikativischen Heischesätzen beobachtete Ubereinstimmung zwischen griechischem Tempus und slavischem Aspekt auftritt:

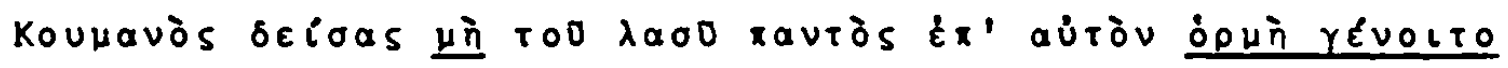
(N 198, 5-6) - Kumanb ubojasja, da ne vsi ljudi ustremjatsja na no (M 265, 18);

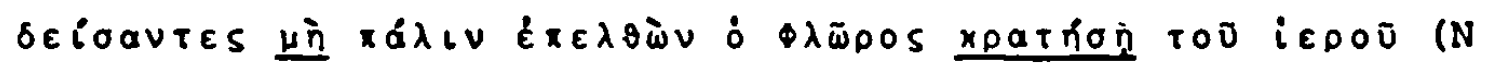
216, 13-14) - bojastesja, da ne, paky priłed, Flor prilmetb corkbvb (M 272, 32-33);

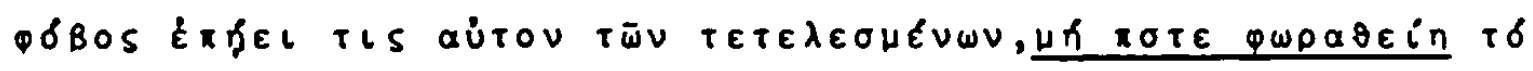
- dopaxov (N 139, 6-7) - 1 strach napade na nb, egda kogda 1spytano bystb (budet Vol.) zelie (II 234, 1-2);

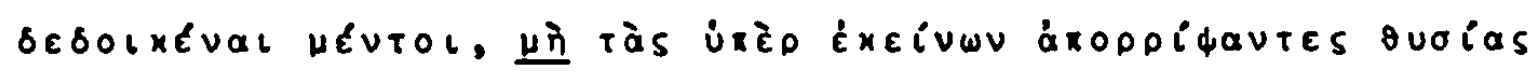

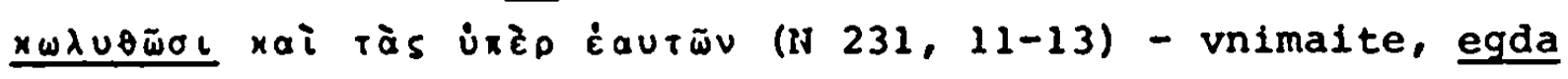
kogda otvergbse rimskia zertvy, 1 vbzbraneni budete 0 sobe Zreti (M 279, 31-280, 1; bei MESCERSIJs Interpunktion ist das Komma nach 'Zertvy' kaum gerechtfertigt);

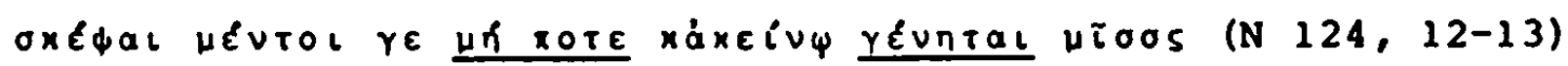
- smotri Ze, eda kogda 1 tomu budetb nenavistb (M 224, 1112).

Von den obigen Belspielen mit 'egda kogda' registriert BRÄUER nur das erste 198 ).

Mit dem Konditional stehen 2 Abwehrsätze, von denen BRÄUER wiederum nur einen anführt 199).

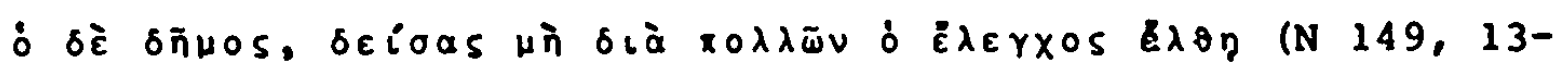
14) - narod Ze, ubojavsja, daby ne na vsja nasel cesarev gnêvb (M 240,7);

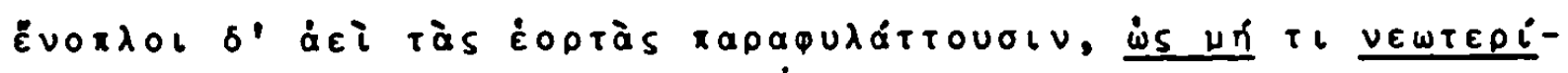

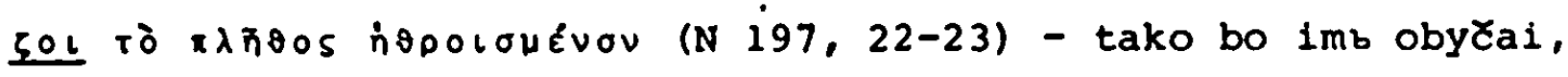
vborużesja, bijusti na prazdnikb, da by ne smeli ljudi Zidovstil smjastisja (M 265, 9-11). 
Auch hier läBt die geringe Anzahl der Belege keine Schlubfolgerung daruber $z u$, wodurch der altrussische Konditional bedingt ist. Wenn man sich BRAUER anschlieBen will, der den Indikativ als eine dem Altkirchenslavischen, den Konditional dagegen als eine dem Altrussischen entsprechende Konstruktion auffaBt 200) , könnte man annehmen, daB zunächst der griechische Optativ des einen Beispiels den Ubersetzer zur Wahl des Konditionals ermutigte, der ihm ja von der Imgangssprache her geläufig sein mußte - zudem ist gerade an dieser stelle die Nuance eines wunsches sehr stark vertreten - ; sodann wandte er die Konstruktion mit dem Konditional auch da an, wo in der Vorlage diese "Brücke" fehlte.

1II. Finale Adverbialsatze

Sie sind mit den Heische- und Abwehrsätzen "... hinsichtlich der Bedeutung sowohl als der Konstruktion, sowie der einleitenden Konjunktionen nahe verwandt" 201). Der Unterschied gegenüber diesen Objektsätzen liegt darin, daB sich die Adverbialsätze nicht $b l O B$ auf das Prädikat des Hauptsatzes, sondern auf dessen gesamten Inhalt beziehen und ihn năher bestimmen, indem sie das $\mathrm{ziel}$ angeben, um dessentwillen die Handlung unternommen wird.

Die griechischen Konjunktionen sind dieselben wie bei den Heischesätzen: im positiven Satz iva, oxws, is, im verneinten

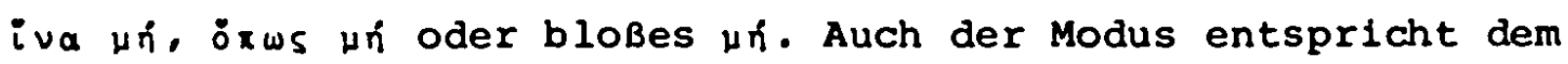
des Heischesatzes, doch fällt in unserem Denkmal auf, daB der sonst fakultativ verwendete oblique Optativ nach historischem Tempus im Hauptsatz hier in den verneinten Finalsätzen kategorische Verwendung findet. In der Ubersetzung steht als Konjunktion 'da', Im verneinten Satz 'da ne' und (seltener) 'egda kogda'. Der Modus ist in der Regel der Indikativi in fünf Fällen steht der Konditional, wobel die Vorlage in dreien den optativ, in den beiden andern den Konjunktiv zeigt. Die Ubereinstimmung zwischen griechischem Tempus und slavischem Aspekt ist bis auf einige Ausnahmen gewahrt: 
1) Sätze mit altrussischem Indikativ

a) positiv:

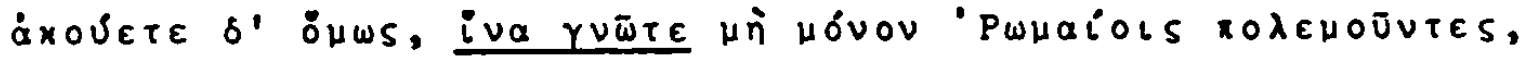
$\dot{\alpha} \lambda \lambda \dot{\alpha} x \alpha i \tau \tilde{\varphi} \vartheta \in \tilde{\varphi}$ (N 486, 16-17) - no obace vnuSite, da razumete, ne tokmo $\mathrm{kb}$ rimljanom ratni susce, no $1 \mathrm{~kb}$ bogovi (M 383, 14-15):

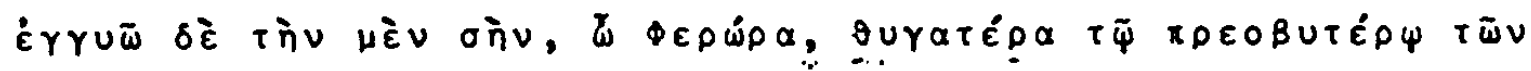

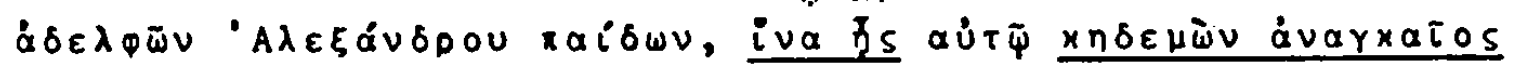
(N 126, 20 - 127, 2) - daju Ferorinu dకterb za Aleksandrova syna starł̌ Łago, da budetb emu Feror testb 1 stroitelb nužnyi (M 225, 33-226, 1):

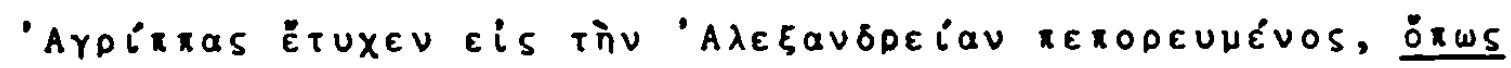

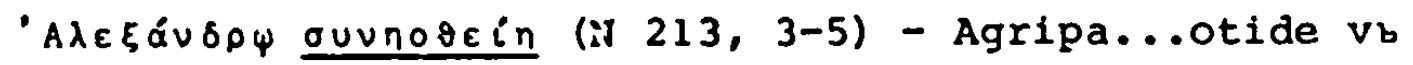
Aleksandriju, da vbzveselitsja sb Aleksandrom (M 271, 4-6);

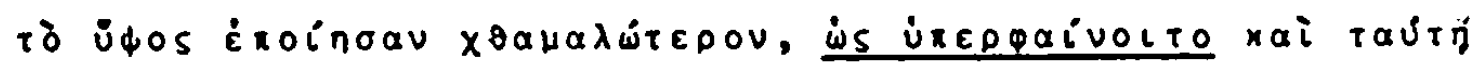
ró $i \varepsilon \rho \delta v(N 453,4-5)$ - Zelezy...sbtvoriła niže, da javitsja corkovnyi verb [sicl] (M 367, 16-17):

b) verneint:

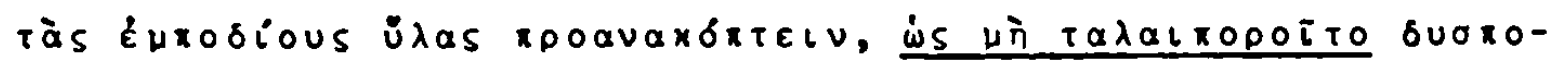
poov tó oтpáteuna (N 290, 24-25) - sekuకCe 1 ravnjajusరe, da ne trudjatsja ljutym putem (M 299, 24):

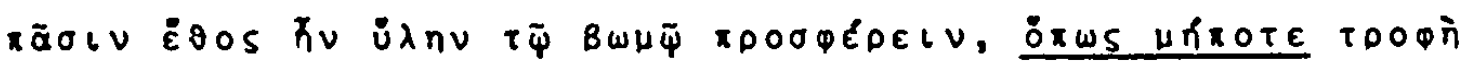
$\tau \tilde{\psi}$ xupi $\lambda \in i$ inol (N 233, 3-5) - obycai bystb vsemb nositi dreva kb Zertovniku, egda kogda oskudęetb piša ognevi (M $280,16-17)$;

2) Sătze mit altrussischem Konditional

a) fur griechischen Optativ:

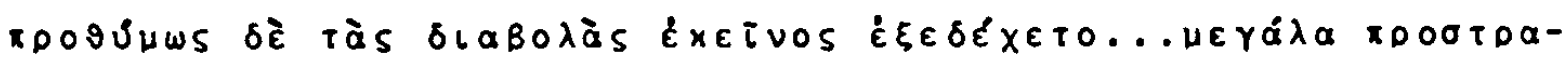

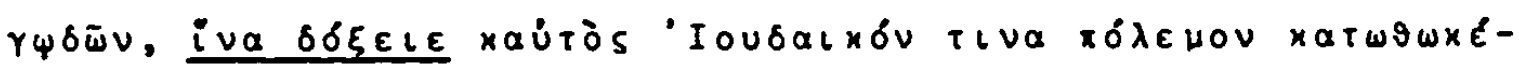
val (N 626, 14-17) - veliŁałe zêlo pregresenia si i prilygaše, da byక̌a mněli, slyక̌aše, jako se někotoruju veliku 
brano ijudeisku ispravilb (M 467, 13-15);

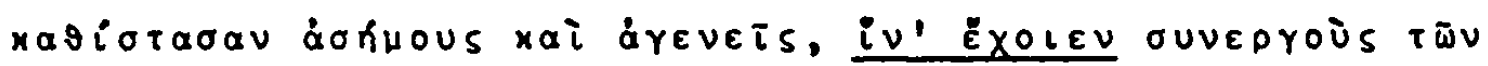

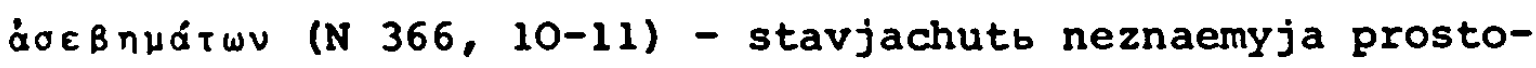
rodnyja, da bysa imeli 1ch na svoja bezakonia poborniky (M 329, 1-3);

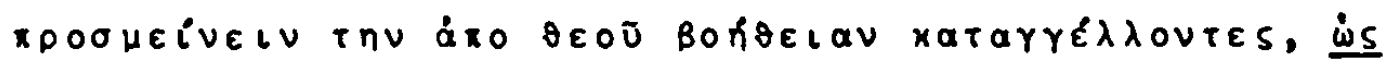

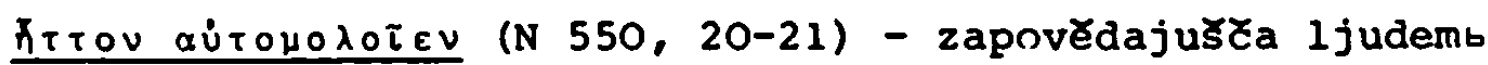
zdati bozia pomosti, ca bysa ne bezali kb rimljanom (M $419,29-30)$;

b) fur griechischen Konjunktiv:

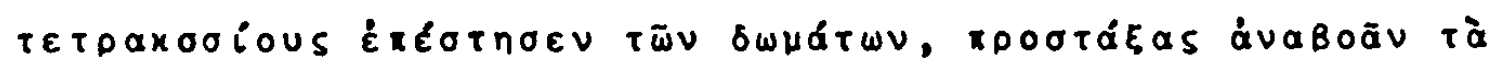

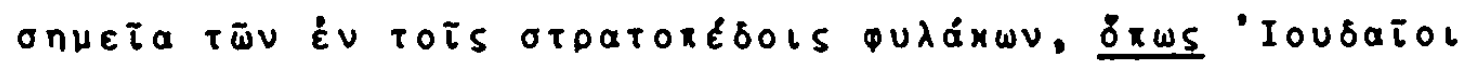

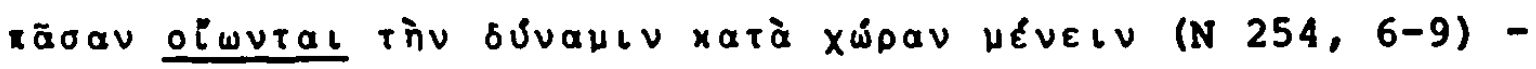
postavi 400 chrabrych s chorugvam1, da bysa mnell Zidove vsju silu tu suscu (M 286, 10-11);

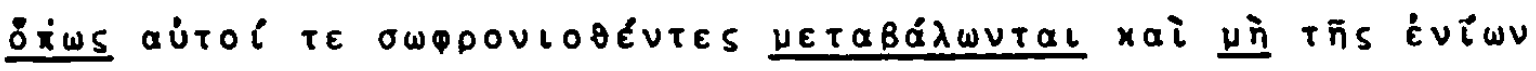

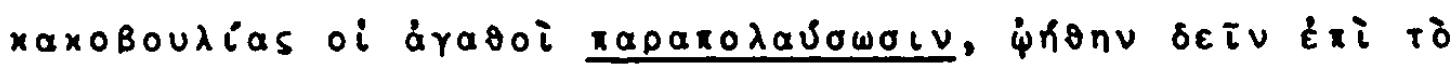

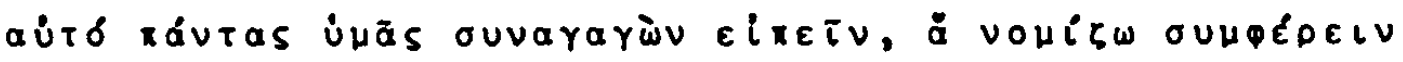
(N 219, 11-13) - da byకa sja izmenili na cerlomudrie 1 da byȘa blazii ne priali zlo za zlo, jaže mnju na polzu [ ] ] vsemb povedaju vam (M 274, 24-26).

\section{Konsekutivsätze}

Sie gehören zu den "...Adverbialsätzen der Art und Weise oder der Vergleichung", drücken "... eine aus dem Prădikate des Hauptsatzes hervorgehende wirkung oder Folge" aus 202) und bezeichnen "... das Verhältnis .... ... wie die im Nebensatze ausgedrulckte Wirkung oder Folge $\mathrm{zu}$ der im Hauptsatze ausgedrickten Ursache stehen" ${ }^{\text {203) }}$. Eingeleitet werden sie im Griechischen durch die Konjunktionen $\dot{\omega} \sigma \varepsilon$, is, wobel im ubergeordneten Satz als Stutzwort das Demonstrativadverb oنंtws oder ein Demonstrativadjektiv wie roloũros, rooouros stehen kann (Gradsätze) 204). Im klassischen Griechisch wird unterschieden 
zwischen dem Gebrauch von $\dot{\omega} \sigma \varepsilon$, is mit dem Infinitiv zur Bezeichnung einer Folge, die "... eine bloB ideelle, bloB in der Vorstellung befindliche, nicht objektiv in der Wirklichkeit gegebene und darum auch keiner bestimnten zeitspäre angehörige" ist 205), und ihrer Verbindung mit einem Verbum finitum "... bei Angabe von wirklichen, in einer bestimmten zeit stattfindenden Ereignissen" 206).

In der Sprache des NT ist aber bereits der Indikativ weitgehend vom Infinitiv verdrängt 207), und im $\Pi \delta \lambda \in \mu \circ s$ hat er diesem gănzlich das Feld überlassen. Streng genommen haben wir es also zumindest formal gar nicht mehr mit einem Nebensatz zu :un, weil das diesen charakterisierende Verbum finitum fehlt. Die Behandlung der Konsekutivkonstruktionen an dieser stelle scheint jedoch gerechtfertigt durch die Tatsache, daB sie auch die griechische Schulgrammatik unter die Adverbialsätze einreiht 208), sowie durch ihre tellweise wiedergabe als vollwertige vebensatze in der Ubersetzung.

Die im griechischen original bereits verlorengegangene Unterscheldung zwischen tatsächlicher und nur möglicher Folge wird nămlich vom Ubersetzer konsequent durchgeführt. Bei der Bezeichnung der möglichen Folge, inshesondere, wenn in der Vorlage der Infinitiv durch (potentiales) äv verstärkt ist, wird die griechische Konstruktion nachvollzogen 209). Dagegen wird die tatsăchliche Folge durch einen Nebensatz mit dem Indikativ als Modus angegeben. Als Konjunktion entspricht in beiden Fällen dem griechischen $\dot{\omega} \sigma \tau \varepsilon$, is das polysemantische slavische 'jako'.

\section{1) Infinitivkonstruktionen}

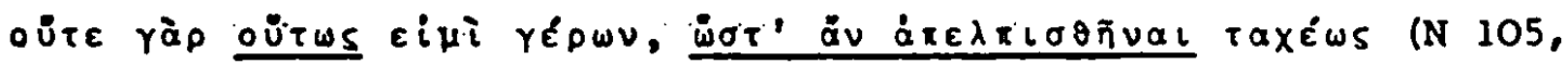
23-24) - ni bo esmb velmi star, jako vskoré (erg.n.A) otčajatisja (M 212, 25):

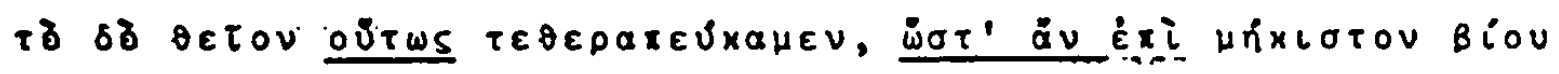

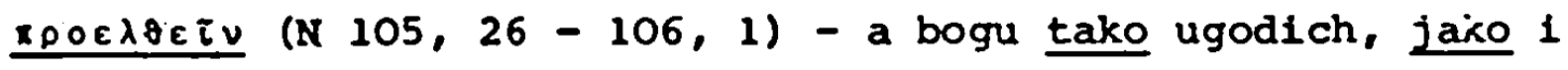


na mnoga lexta Żti (I 37, 9-10; die entsprechende Stelle $M$ 212, 27-28 liefert hier die wenig sinnvolle Lesart:̈ jako 1 na mnogach leta);

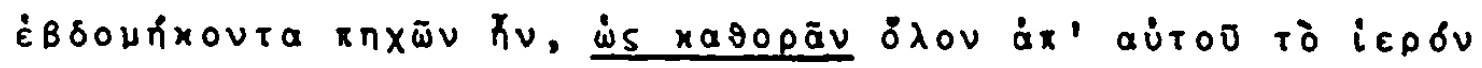
(N 467, 20-21) - 70 lakot, jako videt1 ot nego cbrkbvb (M $373,8)$.

2) Nebensătze

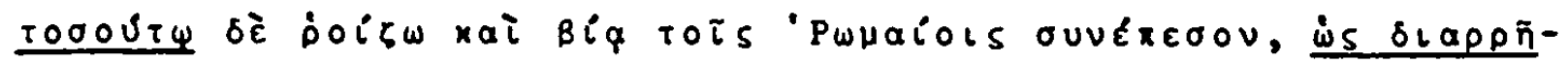

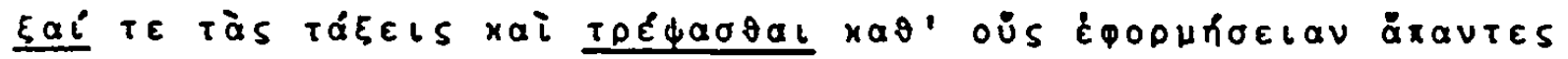
(N 305, 19-21) - napadosta bo... s takoju krépostiju 1 skorostiju, jako razdrusista polkb velmi (M 303, 31-304, 1):

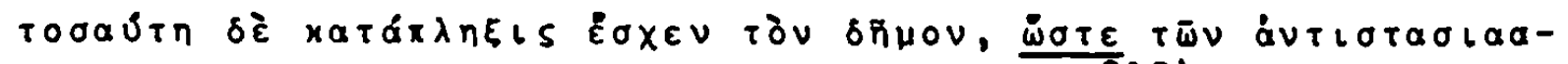

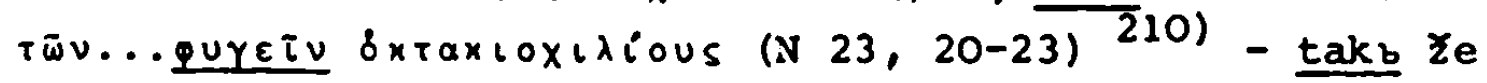
strachb 1 užastb oderżăe ljudi, jako...bęzasa ot mjateżnikb 80 tysjastb (M 174, 24-26).

Schlieblich seien noch zwel Falle angefuhrt, wo der griechischen Konsekutivkonstruktion ein altrussischer Finalsatz entspricht. Diese "...Möglichkeit einer rein finalen Auffassung" răumen BLASS-DEBRUNNER bereits für einige stellen des NT ein und erklären sie dadurch, daB "... überhaupt die jüdische Teleologie bei der Verwischung des Unterschiedes zwischen Absicht und Folge mitgewirkt haben wird" 211):

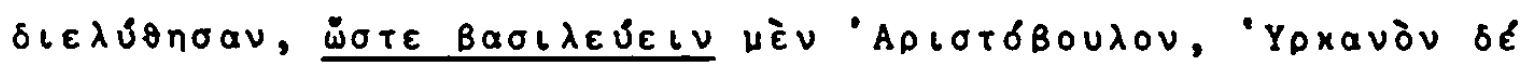

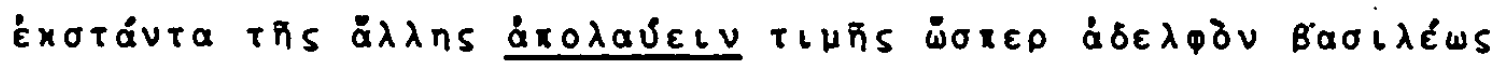
(N 28,10-12) - urjadistasja, da Irkanb archlerêistvuetb 1 Cestb vsjakuju prinimaetb, a Aristovulb da cesarbstvuetb (M 176, 24-26) 212),

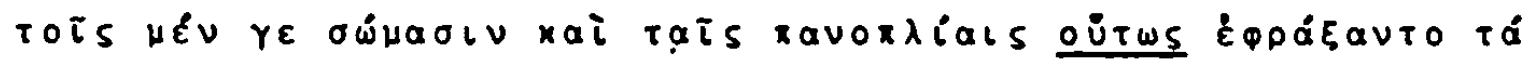

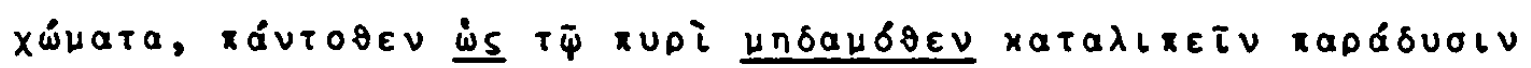
(N 515, 14-16) - obıgraže prispy vsjuda têlom 1 orużemb, da ne budetb loze ognevi polezti (em.n.BARSOV) na nb (M 398, 23-24). 
v. Konditionalsatze

Die konditionalen Adverbialsätze bezeichnen "... das Verhăltnis einer Bedingung zu einem Bedingten" , wobel der Hauptsatz "... das vom Nebensatze Bedingte oder das aus dem Nebensatze Gefolgerte oder Bewirkte" ausdruckt 213). Die Benennung des Nebensatzes als Vordersatz (Protasis) und des Hauptsatzes als Nachsatz (Apodosis) geht vom logischen Ablauf der in beiden enthaltenen Handlungen aus und besagt nichts uber ihre Position zueinander bezulglich der Satzstellung. Das Verhältnis von haupt- und Nebensatz ist kausal, die Bedingung "... wird als ein angenommener, als ein möglicher Grund, als eine mögliche voraussetzung gedacht" $2 \frac{14}{14}$. Das Verhältnis dieser Voraussetzung zur Wirklichkeit, wie es subjektiv vom Sprechenden betrachtet wird, findet seinen Ausdruck in der Aussageform des Verbums. Abgesehen vom irrealen Verhältnis, das an anderer stelle gesondert behandelt wird 215), finden wir in unserem Denkmal drei verschledene Typen konditionaler Nebensatze:

1) Die im Nebensatz enthaltene Bedingung oder Voraussetzung wird als wirklich, als real empfunden. In diesem Fall wird er eingeleitet durch $\varepsilon i$, mit dem Indikativ als Modus; im übergeordneten Satz steht ebenfalls der Indikativ oder, bei einer abgeschwächten Behauptung, der potentiale Optativ. In der Ubersetzung finden wir als Entsprechung einen durch 'aste', selten 'oze' 216), eingeleiteten, indikativischen Nebensatz:

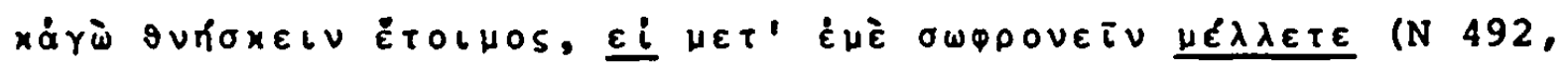
2-3) - aక̧e bo po mne crlomudrit1 chošete, 1 azb umru za vy (M 386, 24):

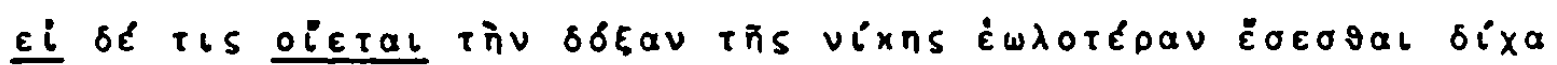

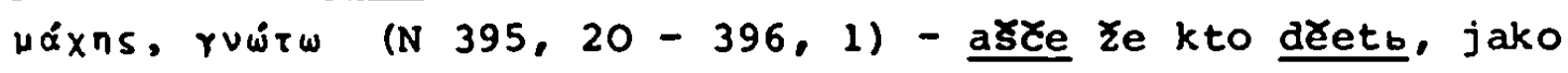
pobeda ne slavna budetb, azb tomu vbzvešaju (M 340, 2-3);

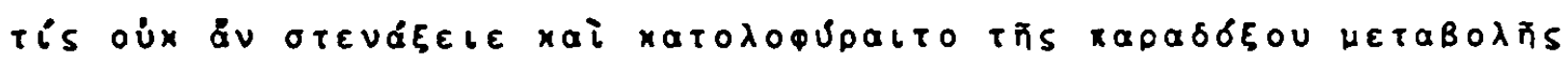

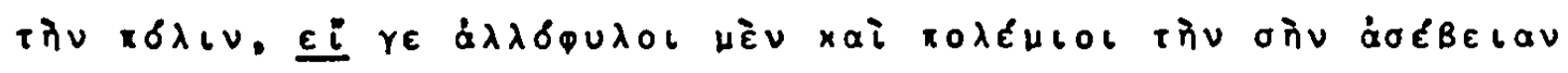

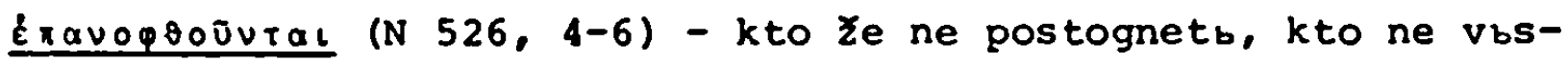


placeto, zrja preménenie preslatmago grada sego, ože (em.n. Vol.) inoplemennici ratnii tvoe bezakonie ispravlajuto (M 405, 10-13; Interpunk.n.I).

2) Die durch den $\varepsilon i$-Satz ausgedrückte Bedingung wird als unsicher, als nur möglich aufgefaßt, die im Hauptsatz stehende Folge jedoch als kategorisch für den Fall der Erfüllung dieser Bedingung angesehen (meist ist dabei das Prädikat des Hauptsatzes ein Verbum der Ankündigung oder Androhung): als Modus hat hier das Griechische den Optativ. Im Altrussischen entspricht dieser Konstruktion ein Konditionalsatz mit 'asce' und dem Indikativ eines perfektiven Verbums, da die Handlung des Nebensatzes in ihrer Abgeschlossenheit betrachtet wird:

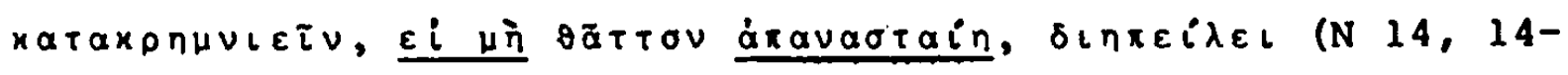
15) - posð̌eniemb pretjałe, ał̌e ne otstupitb $(M 170,15)$ :

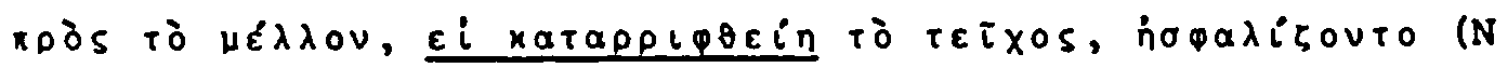
$515,4-5)$ - dumachu.... kako mogutb izbyt1, aste razbbjutb stêny (M 398, 14-15);

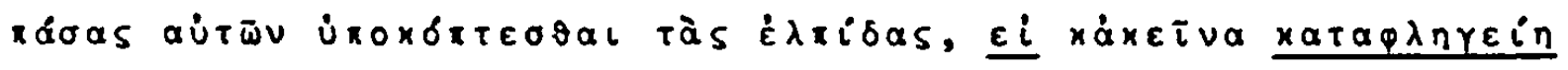
$\tau \grave{\alpha}$ हिүa (N 515, 17-18) - vse bo upovanie otrezasja ot nich, ał̌e 1 si dêla pož̃ena budutb (M 398, 25-26).

3) Die Bedingung wird als eine solche hingestellt, "...deren Verwirklichung je nach Lage der Umstände $z u$ erwarten steht" 217). Da diese Verwirklichung erst in der zukunft eintreten kann, steht im Griechischen als llodus der Konjunktiv, der "...überhaupt in Nebensätzen... futurische... Bedeutung hat" 218). Eingeleitet wird der Nebensatz im Griechischen durch $\varepsilon a ́ v$. In der Ubersetzung steht ebenso wie bei 2) 'aše' mit dem Indikativ eines perfektiven Verbums:

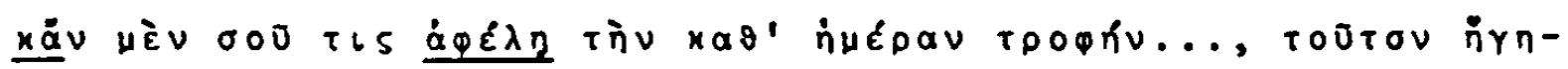

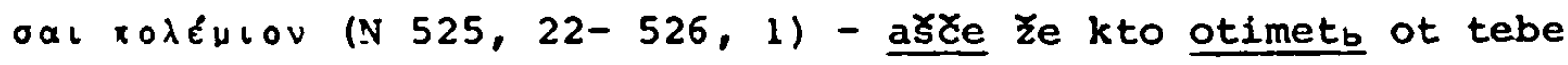
piscu.... to ne vrag $1 i$ ti budetb (M 405, 4-5), 


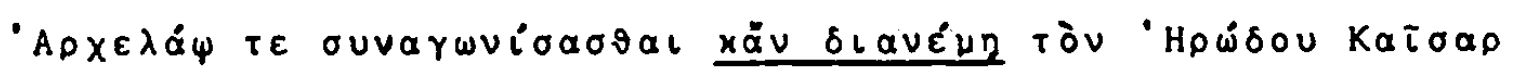

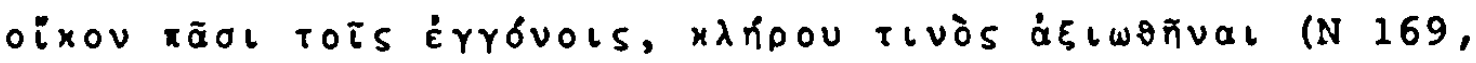
23-24) - ili Archelaevi pomagati i Cbstb ot nego priati ili, aše cesarb razdelitb vsemu rodu dom Irodovb, da $i$ sego pricastitb ko imeniju ego (M 247, 28-31).

Außer diesen adäquaten Entsprechungen gibt es noch einige Fälle, wo für einen griechischen Konditionalsatz, der Nuancen einer finalen, kausalen oder temporalen Bedeutung enthălt, eben die entsprechenden Adverbialsätze erscheinen:

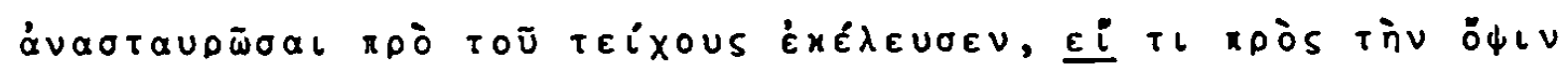

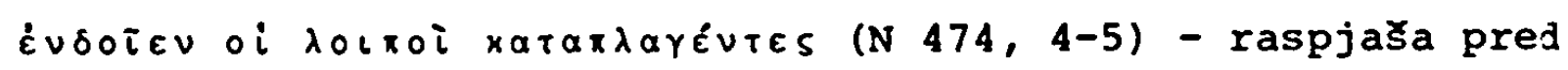
stĕnami, da simb vidĕniemb užasnutsja gražane 1 osklabjatsja (M 376, 15-16).

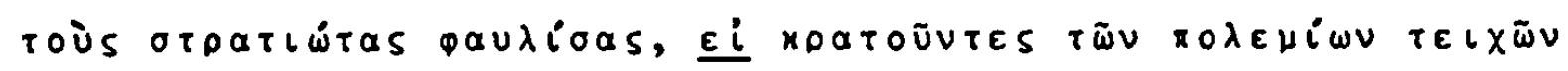

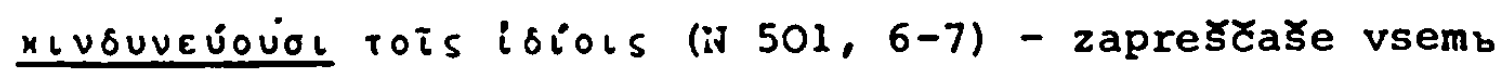
svoim, zane rasplênivకe inoplĕmennila stĕny, a svoim ne promysljaete (M 389, 33-34);

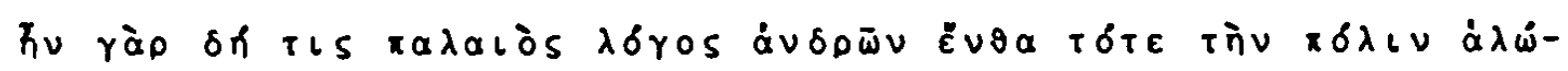

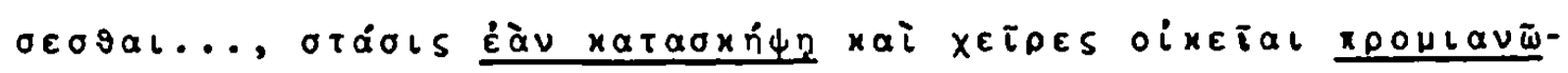

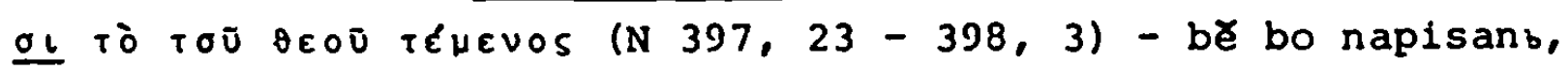
jako togda budetb vzjatb Ierusalimb grad... eg egda usobica budetb na grader i svoima rukama oskvernjat oltarb bozii (M $341,3-5)$.

\section{Konzessivsätze}

Der Form nach den Konditionalsätzen nahe verwandt sind die adverbialen Konzessivsätze, die eine Einräumung, ein zugeständnis ausdrücken 219). Eingeleitet werden sie im Griechischen durch $\varepsilon i$ oder $\dot{\varepsilon} a \dot{v}, z u$ welchen $x \alpha i$ in der Bedeutung "arch" hinzutritt; der Hauptsatz drúckt statt der Folge einen Gegersatz aus, was meist durch stutzwörter wie $\dot{\alpha} \lambda \lambda \alpha^{\prime}$, ơuws angezeigt wird. Im Altrussischen werden die Konzessivsätze eingeleitet durch 'aste $i$ ', Modus ist wie im Griechischen der 
Indikativ; im Hauptsatz erscheint häufig ein adversatives Bindewort ('no', 'obace'):

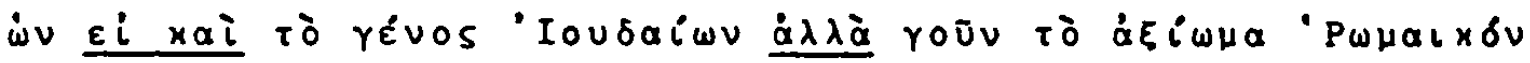

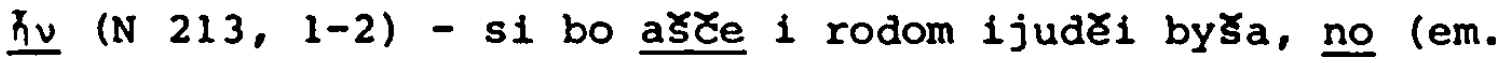
n.I) sanb rimskyi vdasja ot cesarja imb (M 271, 3-4).

Im übrigen werden konzessive Beziehungen im Griechischen "... weit häufiger" durch Partizipialkonstruktionen ausgedrückt 220).

VII. Kausalsătze

Kausale Nebensätze sind im $\Pi \delta \lambda \varepsilon \mu \circ$ s relativ selten; kausale Bedziehungen werden meist durch Hauptsätze mit ráp oder durch Partizipialkonstruktionen ausgedrückt. Bei den wenigen vorhandenen Nebensätzen findet vor allem $\dot{k} \varepsilon \dot{i}$ + Indikativ Verwendung, ferner treten Verbindungen Präposition + Relativum, die bereits zu Konjunktionen verschmolzen sind 221), auf. Die Entsprechungen in der Ubersetzung sind 'poneze' und 'zane' :

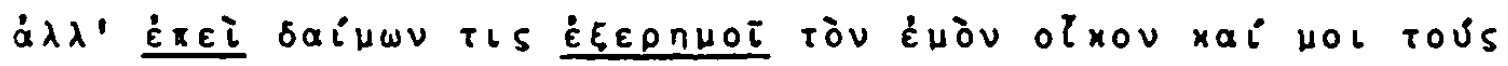

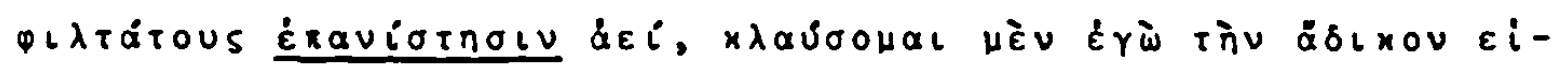

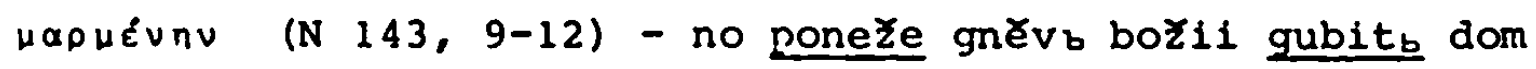
moi i na mja vbstanetb ljubovnikb moi, i poplarju azb nepravednago suda (M 236; $36-237$, 2; Interp.em.n.I):

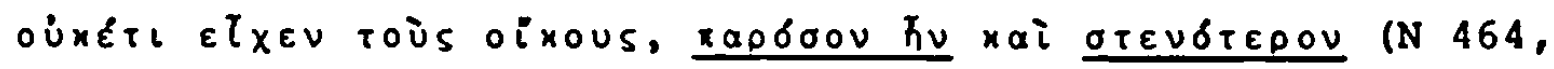
15) - ne...byకa chrami, zane be tesno (M 371, 9);

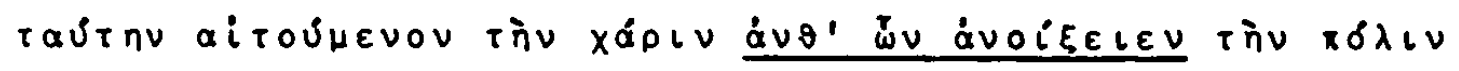
(N 506, 22-23) - vozdastb emu se za blagodatb, zane otvrbze emu vrata gradnaa (M 392, 33).

VIII. Temporalsat?

1) Temporalsätze mit dem husdruck eines allgemeinen Zeitverhältnisses

Sie werden im Griechischen eingeleitet durch die Konjunktio- 


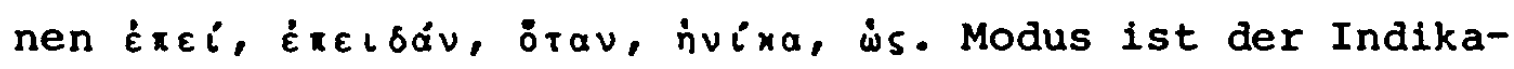
tiv, bei den mit àv zusammengesetzten Konjunktionen der Konjunktiv. Alle diese Konjunktionen können eine Gleichoder Vorzeitigkeit gegenüber der Handlung des Hauptsatzes ausdrücken. In der Ubersetzung entsprechen ihnen 'egda' ('vnegda') und 'imže' (beide mit Indikativ), wobei letzteres oft furr is steht und vor allem zum Ausdruck der Vorzeitigkeit dient.

a) Nebensätze mit dem Ausdruck der Gleichzeitigkeit:

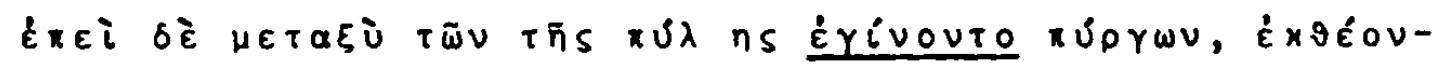

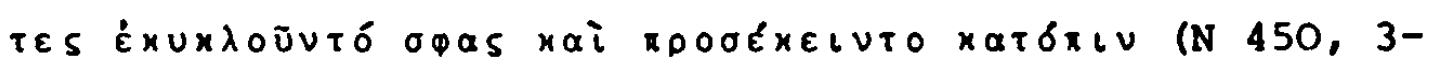
4) - im ̌e voiny byకa mezi stěnami, vytekకe, obistupiకa 1 sěachutb ja (M $366,1-2)$;

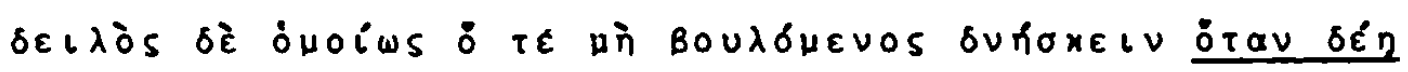

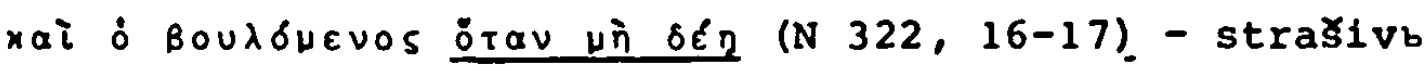
Że estb vkupe, 1Ze ne umiraetb, egda dostoino [scil. estb], 1Ze umiraetb, egda nedostoino (M 308, 22-24).

b) Nebensätze mit dem Ausaruck der Vorzeitigkeit:

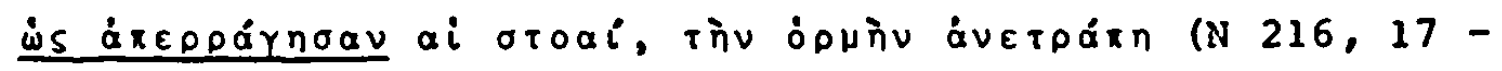
18) - im Ze otš̌koక̌asja komary, vbzbranisja (em.n.Vol.) ot strĕmlenia svoego (M 273, 2-3);

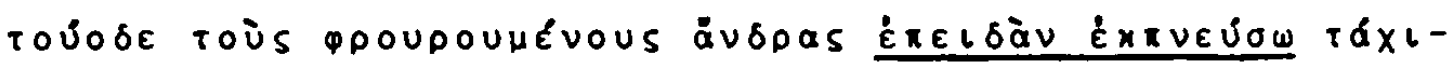

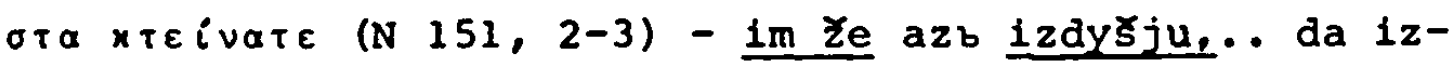
bbjut ja (M 241, 1-2).

In einigen Fällen erscheint infolge verschiedener Auffassung der Handlung ein griechisches gleichzeitiges Satzverhältnis in der Ubersetzung als vorzeitig und umgekehrt:

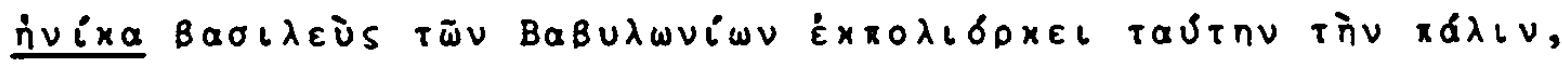
... $\varepsilon \varepsilon \delta \varepsilon \times i a s \ldots \varepsilon \dot{\alpha} \lambda \omega$ (N 488, 9-11) - egda obbsta sb grad cesarb vavilonskyi,... tb samb sedekija ... jatb bystb (M $384,25-27$ ): 


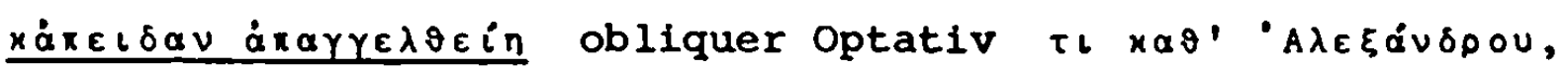

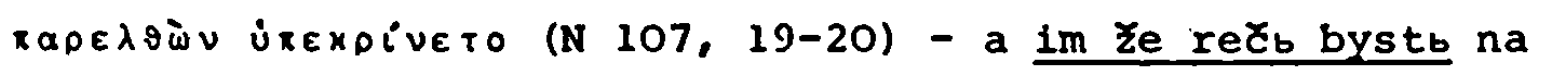
Aleksandra, tal (em.n.I) pristupasetb, tvorjasja po nem molvja (M 213, 32-34).

\section{2) Temporalsätze mit speziellem Zeitverhältnis}

Diese Art der Temporalsätze gibt eine Dauer oder Begrenzung der sich im Hauptsatz vollziehenden Handlung an. Die häufig-

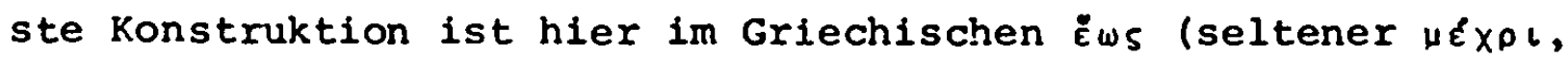
ảxo ا) mit dem Indikativ des Präsens oder Imperfekts (Dauer der Handlung) bzw. des Aorists (Begrenzung); tritt åv als Verstärkung zur Konjunktion, erscheint der Konjunktiv 222). In der Ubersetzung steht 'dondež' mit dem Indikativ eines imperfektiven (Dauer) bzw. perfektiven Verbums (Begrenzung)222a). Im Gegensatz zum heutigen Sprachgebrauch des Russischen, wo "...v pridatoxnych predloženijach s sojuzom poka k skazuemomu pribavljaetsja otricatel naja Castica ne", wenn "...dejstviem, o kotorom govoritsja $v$ pridatoßnom predlozenii, priostanavlivaetsja...dejstvie, o kotorom govoritsja v glavnom" 223), wird hier der Unterschied zwischen Zeitdauer und Begrenzung ebenso wie in den eigenständigen altrussischen Denkmälern 224) nur durch den Verbalaspekt zum Ausdruck gebracht.

\section{a) Handlungsdauer:}

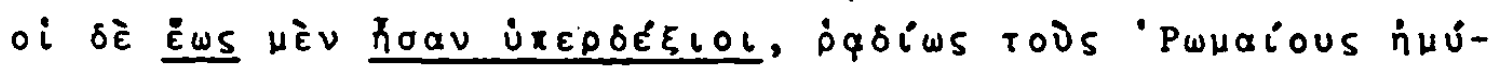
vavio (N 247, 15-1E) - oni Ze, dondeže byకa na gornich méstech, odolevachu rimljanom (M 283, 35-36);

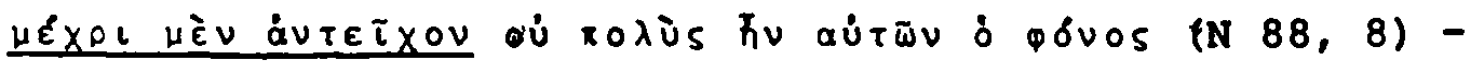
dondeže protivljachutsja, ne mnogo ich pade (M 202, 21-22).

b) Handlungsbegrenzung:

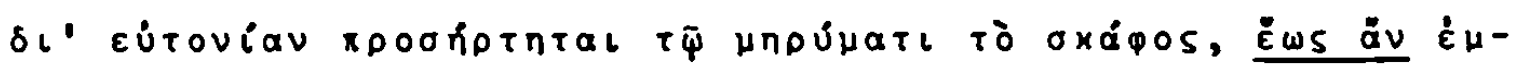
unviq ruvaıx mogutb otrðzati ni ̌elezom.... donde Ze oblejutb krovbju, byvajuక̌eju ot ženy (M 347, 7-8): 


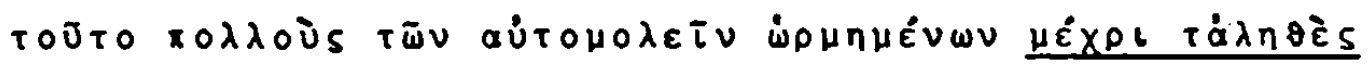

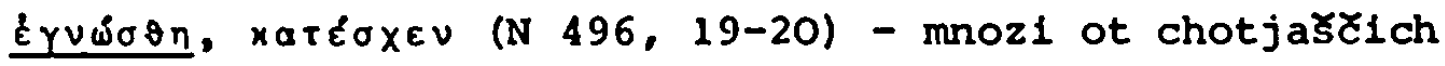
prebégnut1 vbzderzachusja, dondeže razuměsa pravau ( $M$ $388,10-11$ ) 225).

Die Beendigung der Hauptsatzhandlung vor dem Eintritt der Nebensatzhandlung, wobel letztere oft uberhaupt nicht mehr verwirklicht wird, findet im Griechischen ihren Ausdruck durch xoiv mit dem Indikativ bzw. Konjunktiv oder mit dem Infinitiv. Letzere, in unserem Denkmal allein vertretene Konstruktion "... stellt die Handlung schlechtweg ohne alle Nebenbeziehung des zeit- und Modalverhältnisses ...als temporale năhere Bestimmung dar. Daher kann diese Verbindung nicht allein in allen vorher angeführten Fällen = Verwendungsradius von $x \rho i v$ + Verbum finitum stehen, sondern auch da, wo ein Modus des Verbi finiti nicht geeignet sein wlirde. Ganz naturlich und notwendig ist demnach die Verbindung von xoiv mit dem Infinitive, wenn von einer Handlung die Rede ist, welche gar nicht eingetreten ist oder nicht eintreten kann " 226). In der Ubersetzung steht in der Regel ein durch 'preže daže ne' eingeleiteter Nebensatz mit dem Indikativ 227) eines perfektiven Verbums, da die Nebensatzhandlung vom Hauptsatz aus in ihrer Abgeschlossenheit (sei es auch manchmal nur einer gedachten, falls die Handlung nicht wirklich vollzogen werden kann) betrachtet wird:

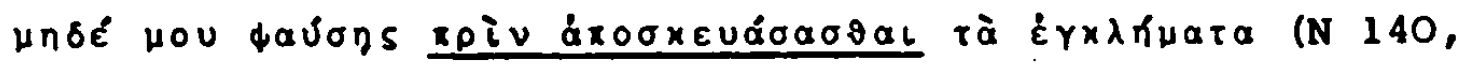
20) - ne prikasaisja mex, prezde daže ne olistisisja ot viny (M 235, 19);

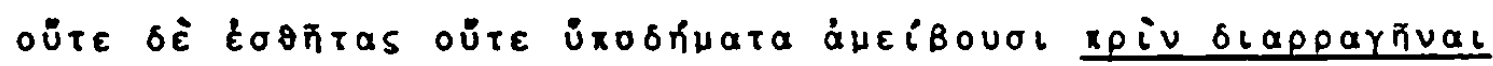

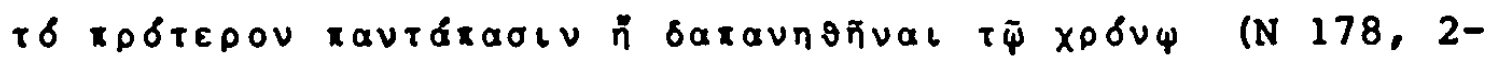
3) - riz że 1 spog ne izmenjajut, preže daže ne izderutsja otinud (M 253, 2-3);

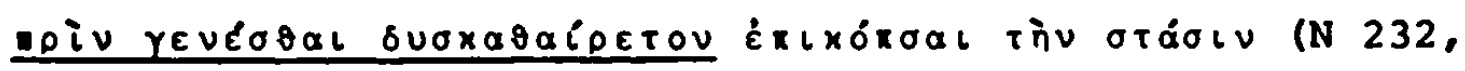
5-6) - da prildetb kb gradu sb siloju, preže daže ne vbzgoritsja plamenb (M 280, 5-7). 
Ebenso wie für temporales xpo in der Ubersetzung ein abhăngiger Temporalsatz auftreten konnte 228), wird andererseits die xoiv-Konstruktion auch durch eine altrussiche Präpositionalwendung mit 'peredb' (preže) + Instrumental wiedergegeben; es liegt also eine Vertauschbarkeit beider Konstruktionen vor:

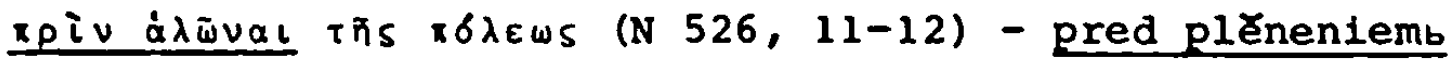
(M 405, 15-16);

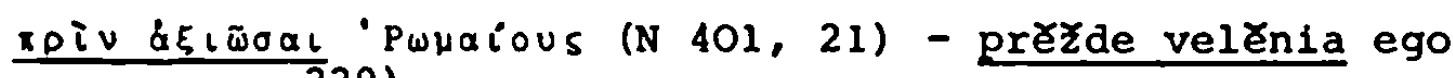
(M 343,7) 229). 
D. Modi im unabhangigen Satz

Durch die Modi wird im Griechischen das subjektive Verhältnis zum Ausdruck gebracht, "... in welchem ein ausgesprochener Gedanke $z u$ der geistigen Auffassung oder dem Willen des Redenden steht" 230). Aus der Vielfalt der Funktionen der griechischen Modi seien hier nur diejenigen herausgegriffen, die in der Ubersetzung eine konstante Entsprechung gefunden haben. 231)

\section{Realis}

Durch den "... Indikativ des Imperfekts (höchst selten des Aorists)" nach den Ausdrilcken "...der unerfülten Forderung" wird im Griechischen bezeichnet, daß eine "... Notwendigkeit, Pflicht, Möglichkeit usw. als wirklich, als thatsächlich vorhanden hervorgehoben wird, während die als notwendig usw. bezeichnete Handlung selbst nicht wirklich eingetreten ist" 232). Im Gegensatz zum Deutschen, das hier den Konjunktiv verwendet,schlieBt sich das Altrussische eng an die griechische Konstruktion an und gebraucht $z$ um Ausdruck des Realis des Imperfekt (bei der Kopula 'byti' auch das 1-Partizip) unvollendeter verba:

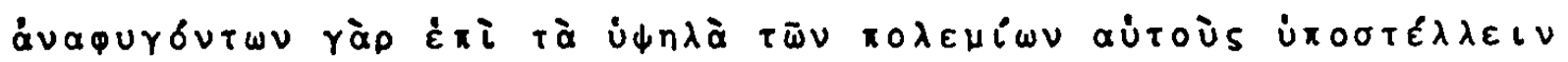

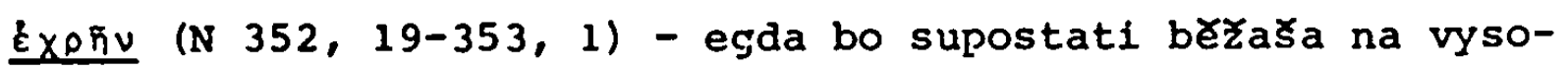
kaa města, togda nam bljust1 podobaše (M 323, 4-5):

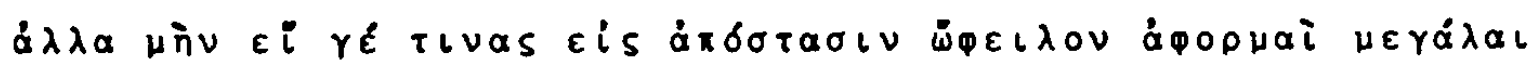

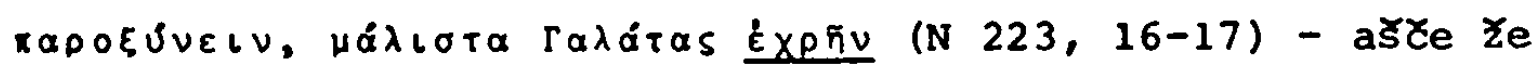
i komu ratitisja ot nich, dostoino bylo Galatom (M 277, 1).

Trotz der genauen Ubereinstimmung mit der Vorlage scheint jedoch hier kein EinfluB der griechischen Konstruktion vorzuliegen, da der altrussische Realis auch in eigenständigen Denkmälern, wie etwa im Igorlied 233), dieselbe Form zeigt. 
11. Irrealis

Er bezeichnet eine "... Handlung, die unter gewissen (entweder ausdrücklich ausgesprochenen oder wenigstens angedeuteten) Bedingungen geschehen konnte, aber nicht verwirklicht wurde, weil die Bedingungen nicht exfuiltt wurden" 234) . Sprachlich ausgearückt wird im Griechischen die unerfüllte Handlung (im Hauptsatz) durch den Indikativ mit äv, die Bedingung durch einen mit $\varepsilon i$ eingeleiteten indikativischen ivebensatz. Dabei steht "... meist... der Aorist, als das Tempus der abgeschlossenen Handlung, mit Bezlehung auf die Vergangenheit, das Imperfekt hingegen, als Tempus der sich entwickelnden Handlung, auf die Gegenwart" 235). Im Altrussischen steht ein Hauptsatz + konditionalem Nebensatz, letzerer eingeleitet durch 'ašč'. Modus ist in beiden der Konditional perfektiver bzw. imperfektiver Verba. Dabei wird in der Wahl des Aspekts nicht das Zeitverhăltnis, sondern die Abgeschlossenheit bzw. Fortdauer der Handlung berücksichtigt. Die Verwendung des perfektiven Aspekts fallt also nicht mit dem "Irrealis der Vergangenheit", die des imperfektiven nicht mit dem "Irrealis der Gegenwart" 236) automatisch zusammen 237):

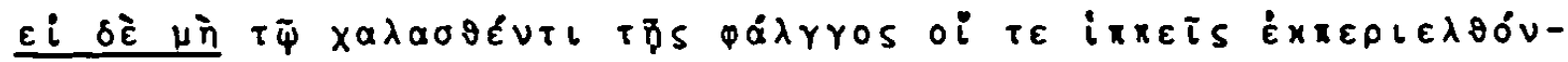

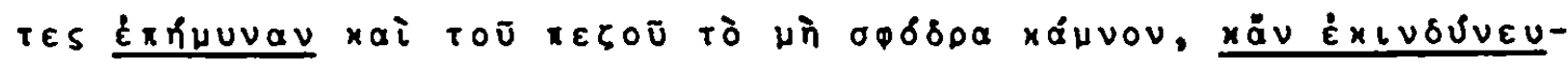

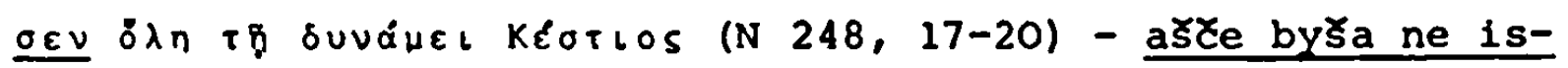
polnill razdrusenago polka skoro $i$ inil konnici, 1 pésci poKivajuske, to otinud bystb poběenb bylb Kestii (M 284, 19-21);

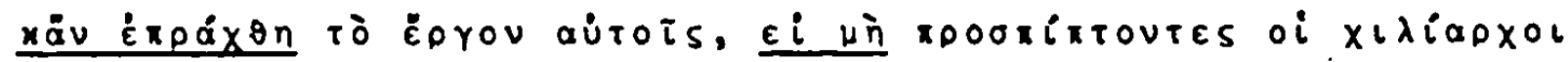

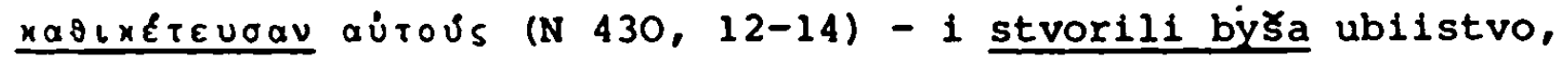
ałte byకa sja ne molili imb sotnici (M 356, 23-24):

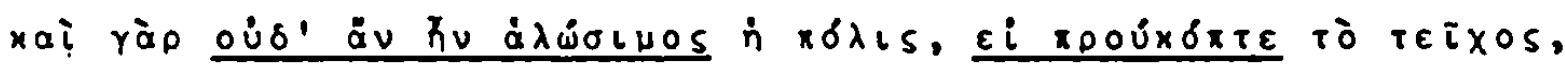

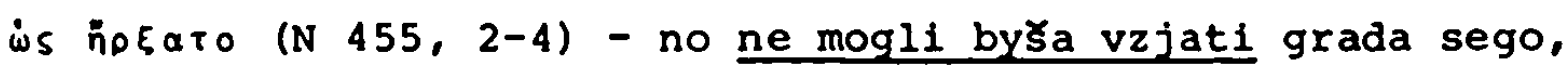
aste by Agrippa skontalb. stêny, aky pocalb (M 367, 32 - 368,1).

\section{Potentialis}

Der Optativus potentialis, verbunden mit åv, wird im Griechi- 
schen gebraucht, "...wenn der Redende eine Handlung als eventuell möglich hinstellt" oder "... wenn er seine subjektive Ungewissheit über die Wirklichkeit einer Handlung zum Ausdruck bringen will... (Optativ der gemilderten Behauptung)" 238). Sehr oft wird er als stilmittel verwendet, "... zu dem Zwecke.... dem Vortrage fest begründeter und bestimnter Urteile oder sicherer Tatsachen die Farbe des Zweifels und der Unentschiedenheit zu geben" 239). In der Ubersetzung steht dafür der Indikativ, wodurch die Behauptung erheblich kategorischer als im Original zum Ausdruck kommt. Da hier auch im Griechischen der Optativ des Aorists (im Gegensatz zum Indikativ) kein temporales Verhältnis bezeichnet, sondern in bloBer Aspektfunktion steht, entspricht ihm im Altrussischen ein Verbum perfectivum und umgekehrt dem Optativ des Präsens ein Verbum imperfectivum:

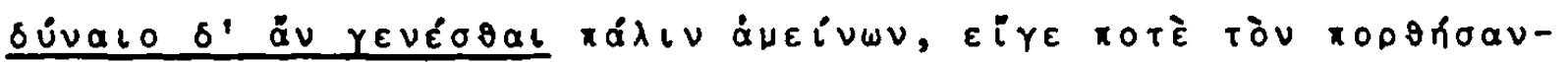

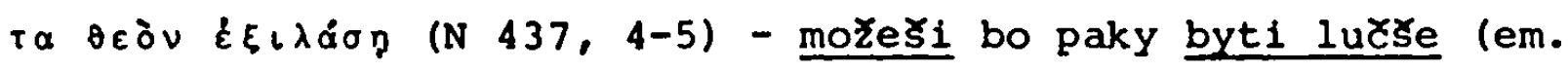
n.Vol.), ałŁe bo sja pomoliłi bogu (11 360, 4-5);

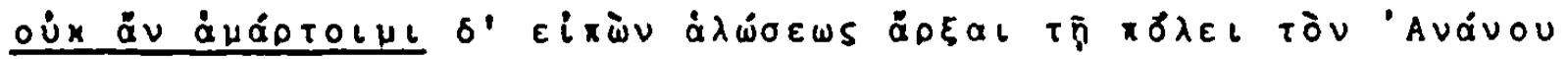
od́varov (N 388, 19-20) - ał̌e Ž reku, jako Ananova smbrtb naxatokb bysto plexnenia $i$ razbienia stenamb, to ne sıgrexu (M 337, 12-13);

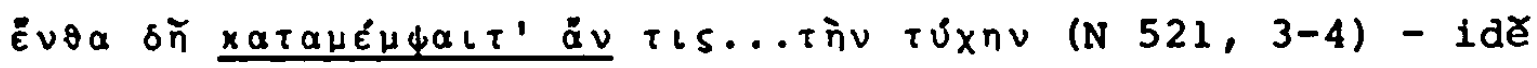
そe vbsponosito kto sud (M 402, 3).

Interessant ist ein Fall, wo der Ubersetzer das allerdings getrennt vom Verbum stehende åv des Potentialis mit der Konjunktion $\dot{c} \alpha \dot{v}$ verwechselt und den griechischen Hauptsatz als abhängigen Konditionalsatz wiedergibt; selbstverständlich wird dadurch der sinn erheblich entstellt 240):

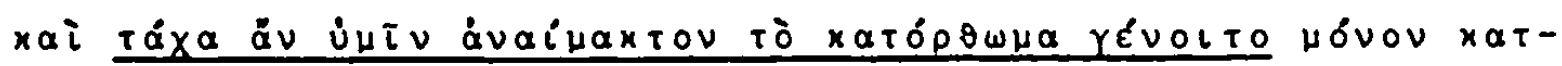

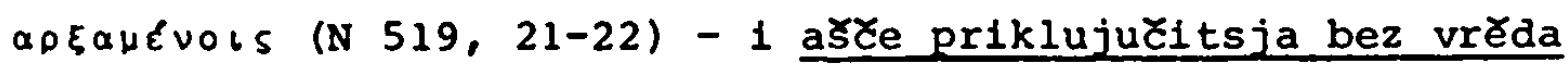
1 bez krove pobediti, tokmo postupite (M 401, 7-8). 
IV. Imperativ

Dem griechischen Imperativ entspricht im allgemeinen der aus indogermanischem Optativ entstandene slavisch-altrussische. Der Imperativ der 3.Person wird umschrieben durch 'da' + Indikativ, wobei das BewuBtsein, daß es sich hier ursprïngltch um einen Heischesatz handelt, noch so wach ist, daB mitunter sogar ein Verbum imperandi eingefügt wird, z.B.:

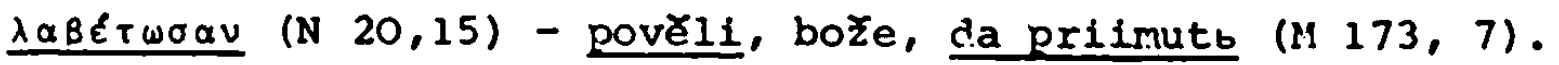

Der Imperativ des Passivs wird wiedergegeben durch den ieines Reflexivums :

$\dot{\alpha} \lambda \lambda \alpha$ ớcou $\gamma \in(N 89,21)$ - spasisja (M 203, 7).

Auch der griechische Prohibitiv, ausgedrückt durch $\mu n$ mit dem Konjunktiv des Aorists 241), wird als (verneinter) Imperativ behandelt und durch diesen bzw. die Umschreibung mit 'da' übersetzt:

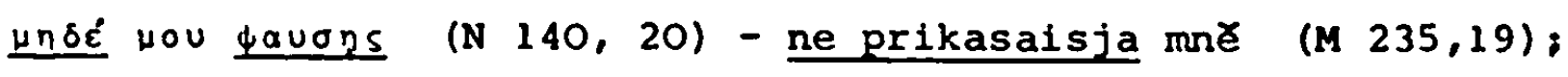
פopUBRon $\delta \varepsilon$ Hol $\mu n \delta \varepsilon i s ~(N ~ 219,13-14)$ - da ne poropšcuto nikto Ze na mja (M 274, 26). 
E. Partizipialkonstruktionen

Das Partizip ist formal ein Verbaladjektiv. Es "...sovmeకtaet $v$ sebe..priznaki glagola $i$ priznaki imeni prilagatel nogo, no vvidu nalicija $v$ nem osnovnych kategorij glagola - zaloga, vida 1 vremeni - ono tesnee svjazano $s$ glagolom 1 vchodit $v$ sistemu glagol 'nych obrazovanij. Krome togo, pricastie sochranjaet glagol 'noe upravlenie, i k nemu (kak 1 k drugim glagol-nym formam) mogut primykat' narecija. iNo kak nesprjagaemaja forma pricastie ne imeet kategorij naklonenija 1 lica" 242). In einer hochentwickelten und grammatisch ausgefeilten sprache wie dem klassischen und nachklassischen Griechisch hatte "... bel dem großen Reichtume ... an Partizipformen der Gebrauch derselben ... einen Umfang gewonnen, wie nicht leicht in 1rgend einer anderen Sprache" 243). So treffen wir denn auch Im $\pi \delta \lambda \varepsilon \mu \circ s$ auf eine Vielzahl von Partizipien und Partizipialkonstruktionen, deren Mannigfaltigkeit den Ubersetzer vor erhebliche Anforderungen stellte.

1. Das Partizip als Ergänung eines Verbalbegriffes

GemăB seiner Eigenschaft als Attributiv kann das Partizip als Ergănzung nur zu denjenigen Verba treten, "... welche als Ergänzung eine Thätigkeit verlangen, die an einem Gegenstande wie ein Attribut haftet, so dab derselbe in irgend einer Thätigkeit oder in irgend einem zustande begriffen scheint" 244). Dabei kann das substantiv, mit dem das Partizip kongruiert, im Satz als objekt oder als subjekt fungieren.

\section{1) Kongruenz mit dem Satzobjekt}

Hier hăngt das Partizip hauptsächlich ab von den Verba sentiendi und putandi 245). Dabei tritt das vom Partizip näher $\mathrm{zu}$ bestimmende objekt in den vom regierenden Verbum geforderten Kasus (normalerweise den Akkusativ), das mit ihm kongruierende Partizip nimmt denselben Kasus an. Diese Konstruktion des Accusativus cum participio wird in der Ubersetzung nach- 
vollzogen. Im Gegensatz zur altkirchenslavischen Ubersetzungsliteratur, für die RUZICKA den AcP nur nach 'vidêti', 'uzbręti', 'slyšati' und 'obrěsti' konstatiert 246), tritt er in der 'Iudejskaja vojna' auch nach Verba putandi auf. LOMTEV betrachtet diese Konstruktion als die für das Altrussische ubliche 247 ):

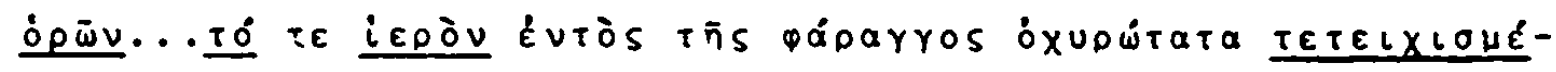
vou (N 32, 10-12) - viděvb ... cbrkbvb vnutroudu zagraženu velikoju tværdostiju (M 178, 29-30; Interpunkt.em.n.I):

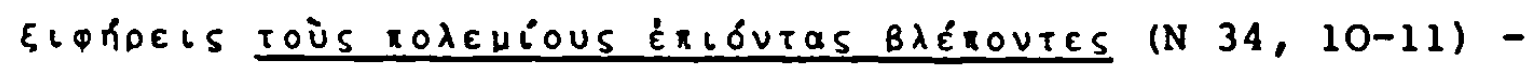
vidjaste ratnych iduste na nja s mexi (M 179, 33; Interp. em.n.I) 248);

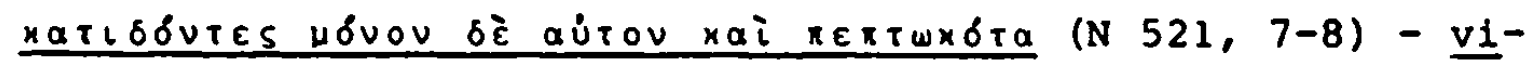
děve edinago suša i padకasja (M 402, 8);

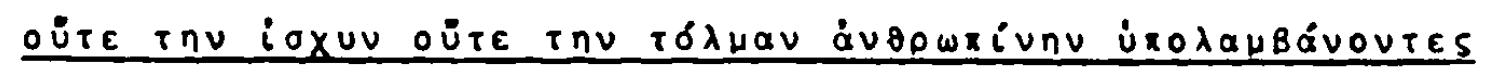
N 523, 18-19) - mnjaše silu ego netelovębskuju (M 403, 26-27) 249).

2) Kongruenz mit dem Satzsubjekt

Als năhere Bestimmung des Satzsubjekts kommt das Partizip (des Präsens) vor nach den Verba des Anfangens, Aufhörens oder der Fortsetzung einer Tätigkeit 250). Die von VAILLANT als Imitation des Griechischen betrachtete Nachvollziehung dieser Konstruktion, wie sie auch in unserem Denkmal auftritt, sieht RUZICKA nur bedingt von der Vorlage beeinfluBt 251). Nach LOMTEV wechselt hier im Altrussischen das Partizip mit dem Infinitiv ab 252), doch lassen die von ihm angeführten Beispiele (u.a. aus dem Ostromir-Evangelium, wo sich der Einfluß des griechischen Originals nicht ganz ausschließen läBt) keinen Schluß über die Eigenständigkeit der Partizipialkonstruktion zu:

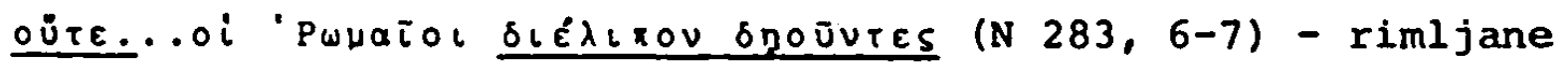

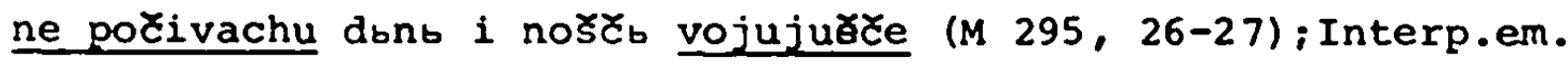
n. I) ; 


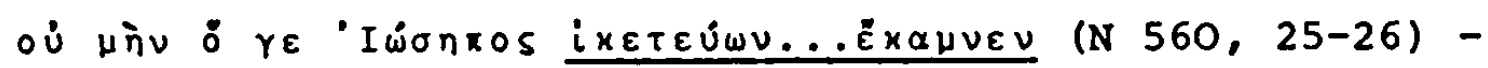
Iosifb Ze ni...prèsta moljasja imb (M 426, 25-26; Interp. em.n.I);

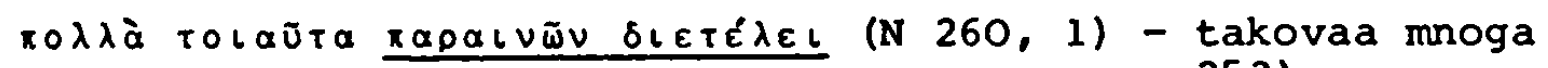
nakazaa prebyvase (M 287, 21; Interp.em.n.I) 253).

11. Das Partizip als nähere Bestimmung eines Substantivs

Das zur "...Bezeichnung einer unmittelbaren attributiven Bestimmung eines Substantivbegriffs" ${ }^{254)}$ dienende, oft mit dem Artikel gebrauchte Partizip wird in unserer Ubersetzung durch einen Relativsatz wiedergegeben 255):

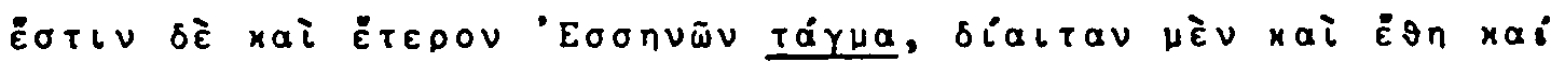

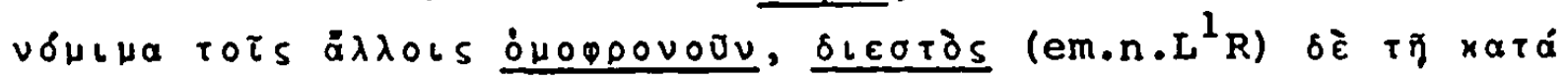
ráuov $\delta 6 \xi \eta$ (N 185, 5-7) - estb Ze 1 drugyi Zinb osiiskyi, ize Zitie, nravy 1 zakonb odinbglasiem derzatb, no raskotarajutsja brat bnymi myslomi (M 256, 21-22);

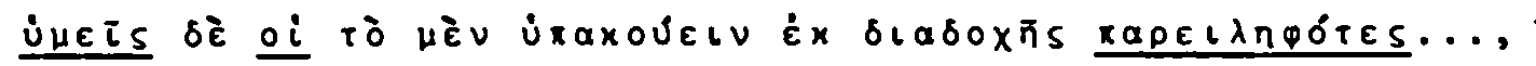

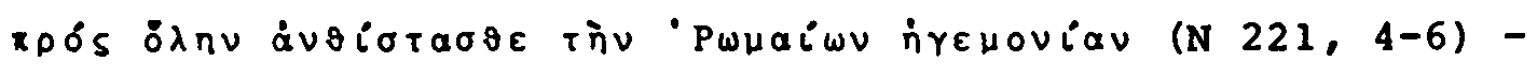
a vy, iže priali este, aky otıとьskoe (em.n.vol.) naslędovanie rabotu, nyne protivljaetesja vsei vlasti rimstei (M 275, 22-24).

111. Das Partizip zum Ausdruck adverbialer Beziehungen

1) Participium coniunctum

Bei dieser Konstruktion, die sich als verkürzter Nebensatz betrachten läBt, ist das Subjekt dieses postulierten Nebensatzes zugleich ein Glied des Hauptsatzes. Es hat also in letzterem ein Beziehungswort, welches allerdings nicht immer verbal ausgedrulckt sein muB, sondern auch implicite (z. B. in der Prädikatsform) enthalten sein kann. Mit diesem Be- 
ziehungswort kongruiert das Partizip in Genus, Kasus und Numerus. In der Ubersetzung finden wir eine genaue Entsprechung zum Original, da diese Konstruktion auch dem Slavischen geläufig ist:

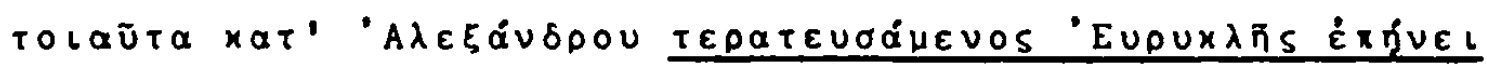

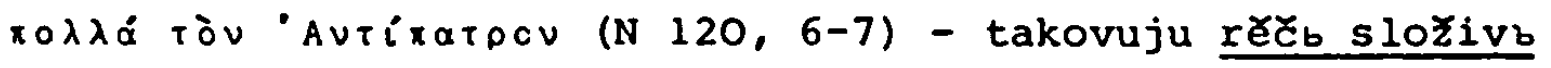
Evruklii na Aleksandra, chvaljaకetb Antipatra (11 221, 11-12);

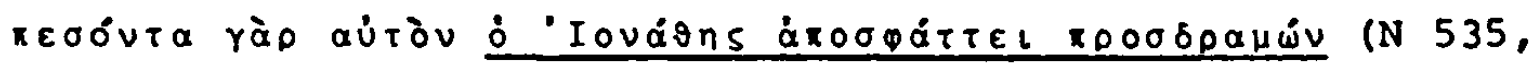
17-18) - i, pritekb, ijudejaninb vbgruzi vo nb me 18).

Etwa in einem Viertel der Fälle, wo sich diese Konstruktion gegenüber dem Verbum des Hauptsatzes in präpositiver Position befindet, wird der altrussische Hauptsatz durch das Bindewort ' $i$ ' angeschlossen. RUZICKA deutet diese sowohl im Altkirchenslavischen wie auch in den ältesten Denkmälern anderer Slavinen auftretende Erscheinung 256) als eine Art Ubergangsform zwischen Para- und Hypotaxe: "...Das Partizip ist noch "fast gleichstark', aber nicht mehr 'gleichstark'. Es ist bereits untergeordnet, aber noch fast gleichgeordnet. Hypotaxe und Parataxe beginnen sich erst abzuzeichnen. Die Konstruktion mit Konjunktion neben der konjunktionslosen ist ein symptom der sich wandelnden syntaktischen wertigkeit des nominalen partizips, das an dem allgemeinen EntstehungsprozeB der Hypotaxe in der slavischen Literatursprache teilnimmt. Im altslavischen Satzbau, der am griechischen Modell gewachsen ist, besteht ein ad hoc errichtetes hypotaktisches system. Die Konstruktionen mit Konjunktion sind deshalb selten. Das literarisch ausgeformtere Griechisch mit seinen syntaktisch klar eingeordneten Partizipien drängt die slavischen Partizipien zur Einfügung und Unterordnung im einfachen Satz. Eine gewisse vorgegebene strukturelle Homogenität erleichterte diesen EinfluB. Manchmal allerdings widerstrebt ihm das slavische in besonders augenfälliger weise und läßt die relative Selbständigkeit des Partizips eigenwillig her- 
vortreten, wo seine Einfügung durch die Gesamtstruktur des Satzes gerade erleichtert scheint" 257). Die relative Häufigkeit der Konstruktionen mit ' $i$ ' in unserem Denkmal weist also auf eine gewisse Eigenständigkeit und Unabhängigkeit vom syntaktischen Modell der Vorlage hin. Besonders gerne tritt hier das ' $i$ ' auf in Perioden, wo es bereits mehrfach berechtigterweise (d.i. im Sinne der festgefügten Regeln des Griechischen, z.B. bei Aufzählungen und Satzreihen) vorkommt:

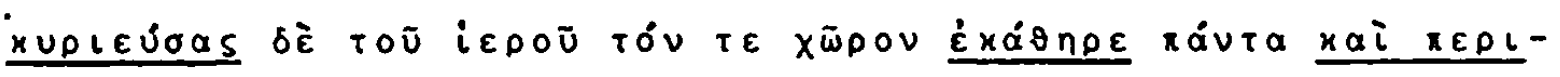

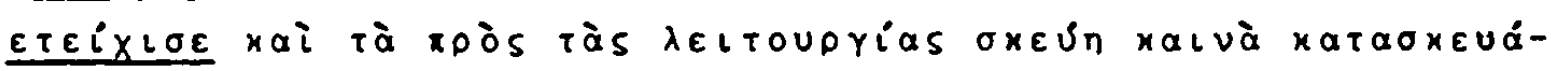
aas eis tòv vaòv eiofuerxev (N 11, 12-15) - i obuemb cbrkbvb, $i$ vse mésto osvjativ i zazda (em.n.I) i sosudy corkbvnyja stvori novy $i$ polożi vb cbrkbvi (M 168, 12-13; Interp.em.n.I);

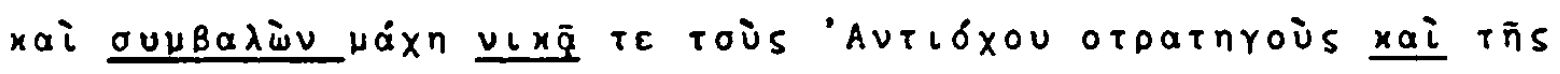

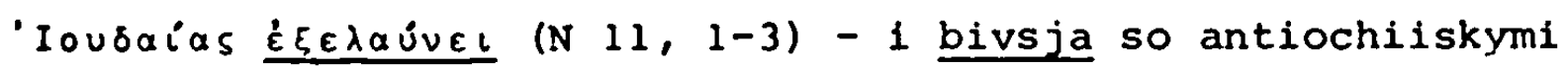
voevodami, i odole imb, i vygna ot Ijuderi (M 168, 2-3);

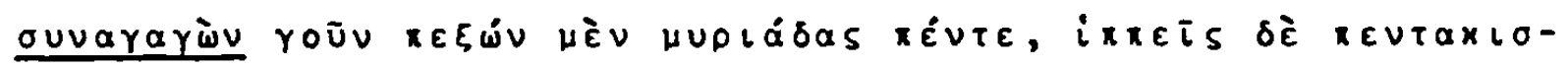

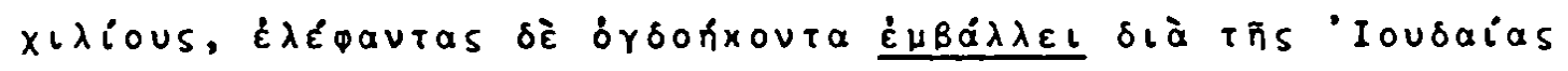

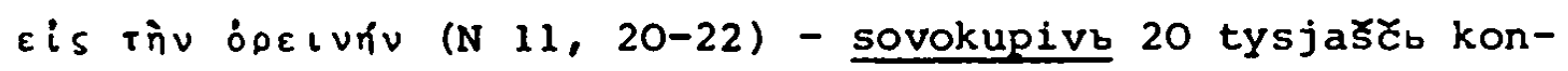
nikb, i peకca 100 tysjaక̌b, i kolesnicb 300, a slonov 50 i 5, i ide skvoze Ijudéju i vza grad vifısurb (M 168, 17-19).

\section{2) Genitivus absolutus}

Im Gegensatz zum Participium coniunctum hat hier das subjekt der Partizipialkonstruktion im Hauptsatz kein Beziehungswort, so daß diese vom Hauptsatz vollkommen unabhängig ist. Die Entsprechung im Altrussischen (wie im Altkirchenslavischen) bildet der absolute Dativ:

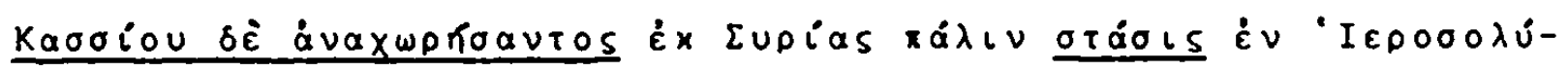
Hols yiveral (N 54, 1-2) - Kasiju Ze ot Xedకju ot Suria, paky mjateź estb $\tilde{z}_{b}$ Ierusalime (M 188, 11-12).

Weitere Beispiele siehe $N 53,17 / M 188,5 ; N 55,20 / M 189,1 ; N$ $56,12 / \mathrm{M} \mathrm{189,16;N} 57,6 / \mathrm{M} 189,28 ; \mathrm{N} 57,19 / \mathrm{M} 189,35$ und passim. 
Besondere Erwähnung verdienen die Fälle, wo einem griechischen Participium coniunctum in der Ubersetzung bei wörtlicher wiedergabe ein absoluter Dativ entspricht, obwohl das Subjekt der Partizipialkonstruktion ein Beziehungswort im Hauptsatz aufweist. Wahrscheinlich sind hierfür zwei Ursachen verantwortlich, nämlich einmal die noch wenig festen Regeln der altrussischen Syntax und andererseits der Einfluß der altkirchenslavischen Evangelienübersetzungen, die diese Konstruktionen als Lehnübersetzungen aus dem neutestamentlichen Griechisch übernommen hatten ${ }^{258)}$. Im $\pi \delta \lambda \varepsilon \mu o s$ selbst finden wir jedoch keine Abweichungen von der Norm der klassischen Sprache, so daß man nur von einem "mittelbaren Gräzismus" sprechen kann:

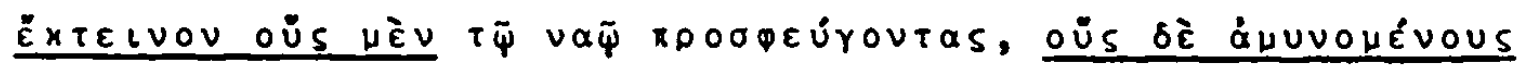
(N 34, 8-9) - izbivachu židy, ovĕmb kb corkbvi pribęgajuకðimb, ovemb protivjašimsja (M 189, 31-32):

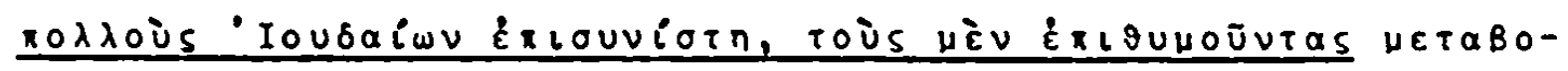

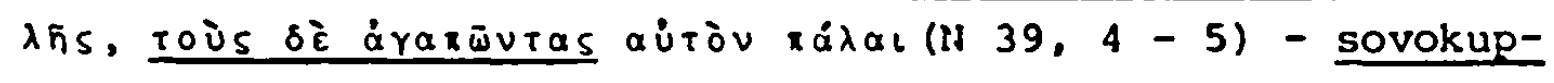
ljaja voja mnogy, drugymb chotjascimb izmenenija, overmb そ̌e 1jubjascimb i (M 181, 31-32):

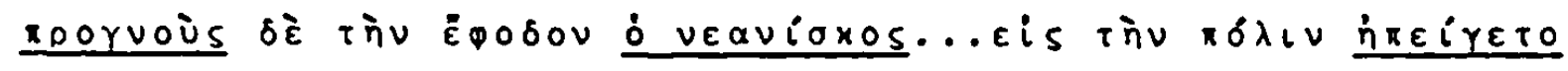

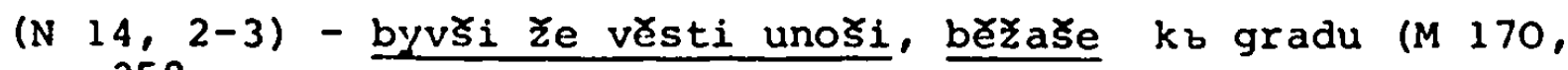
$3-4)^{258 a}$.

Die wörtliche Ubersetzung eines durch is oder xaixep (xaitoi) näher bestimmten adverbialen Participium coniunctum oder Genitivus absolutus (mit dem Ausdruck einer subjektiven Wertung bzw. einer Einräumung) dürfte dem syntaktischen Einfluß der Vorlage zuzuschreiben sein:

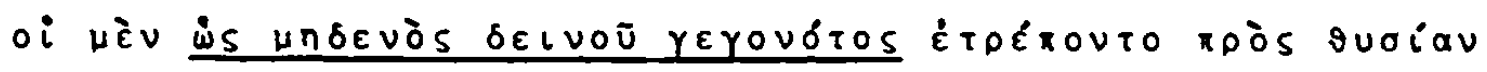
(N 157, 13-14) - po tom, aky ne sbtvorకe nicto ž zla, idosa na Zertvu (M 244, 27-28);

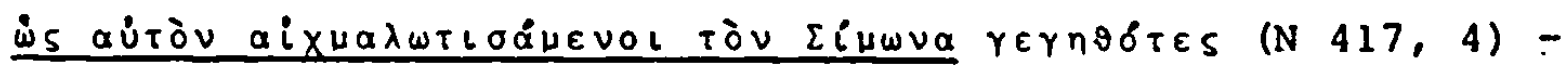
radujuకtesja.... jako samogo simona plenivకe (M 350, 19-20): 


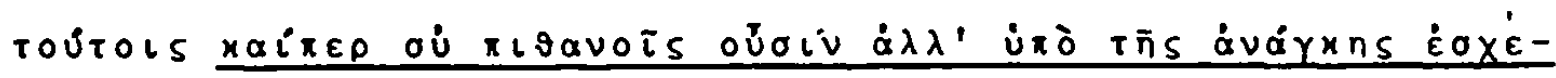

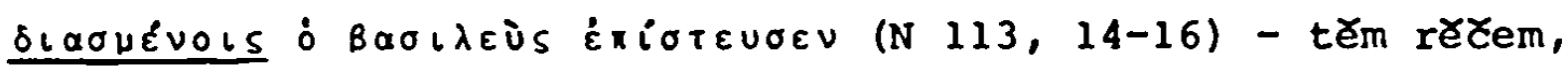
aక̌e 1 nepravym suక̌em, no nužeju stroenom, věru jatb cesarı (M 216, 22-24);

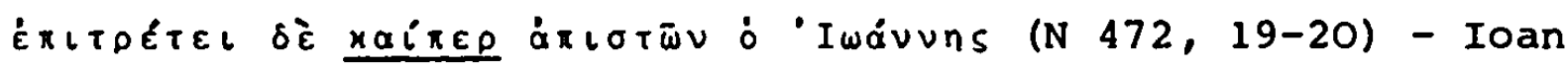
そe, aకŁe $i$ ne velmi veruja, no obač povele (M 375, 22-23).

Die Regel ist nämlich sonst hier die Wiedergabe durch einen entsprechenden adverbialen Nebensatz, wie auch die nicht näher bestimmten Partizipialkonstruktionen häufig durch einen solchen übersetzt werden. Da das Altrussische aufgrund seines ebenfalls reichen Inventars an Partizipialformen die griechischen Konstruktionen ohne besondere Schwierigkeiten nachvollziehen konnte, dürften stilistische Gründe und die Neigung des Ubersetzers zu einer präziseren, konkreteren Darstellung, wie sie der Nebensatz mit seiner Konjunktion und seinem Verbum finitum bietet, für die Wahl dieser Ubersetzungsweise ausschlaggebend gewesen sein. Ubersetzungstechnisch ist sie zweifellos höher $z u$ werten, da sie ein genaues Verständnis, manchmal sogar eine Interpretation der Vorlage verlangt. Besonders häufig kommen als Entsprechungen griechischer Partizipialkonstruktionen Kausal- und Konzessivsätze vor, da das Griechische diese Beziehungen fast durchwegs durch Partizipia ausdrückt.

\section{a) Kausalsätze}

Sie stehen sowohl für nicht näher bestimte Partizipia wie auch für solche, die durch $\dot{\alpha} \tau \varepsilon$ oder $\dot{\omega} s$ gekennzeichnet sind. Bei letzteren gehen allerdings die Nebenbedeutungen des selbstverständlichen bzw. subjektiven Grundes, die durch die griechischen Bestimmungen zum Ausdruck kommen, in der Ubersetzung verloren:

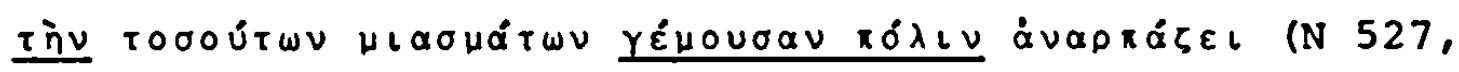
3-4) - v schiకCen b budeto Ierusalim, zane ispolnisja skvernosti neizrecenny ( $M$ 405, 33-34); 


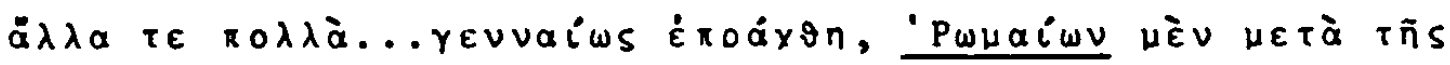

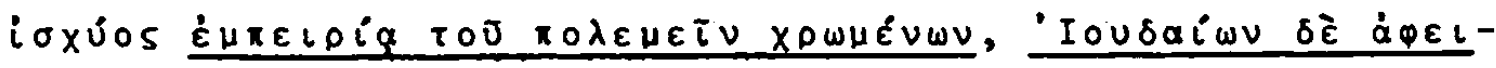

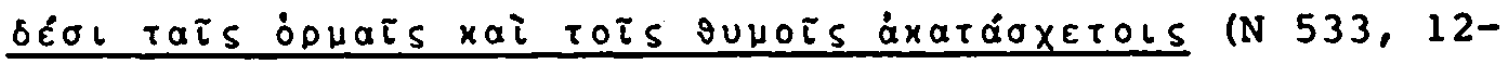
14) - mnogo chrabrbstvo pokazasa.... zane rimljane silnęi-

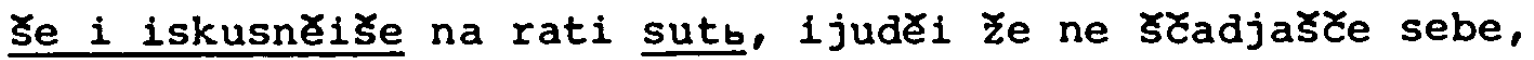
prejarivsesja, aky slëpii, skakachu (M 409, 3-6; Interp.

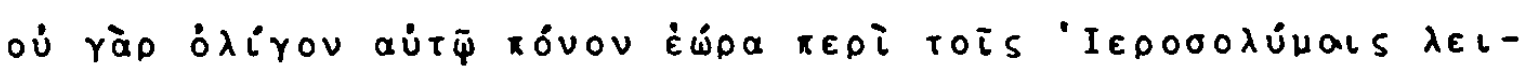

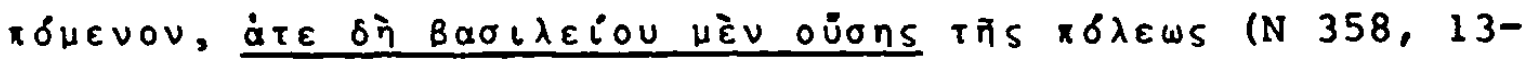
15) - Zujałe bo jako trudu byti, zane cesarbstvo Żidovsko to estb (M 325, 8);

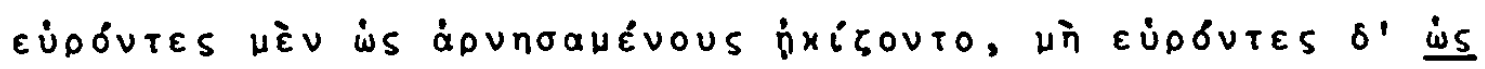

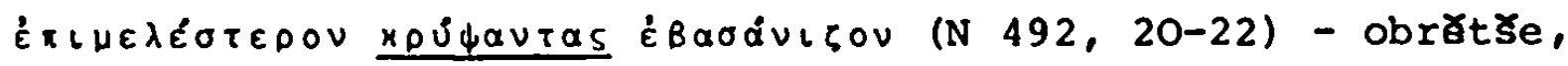
bьjachu domovitych, zane zapirachusja, i ne obretłe, bole bbjachu rekuకte, jako potaiste (M 385, $36-386,1)$ 259a);

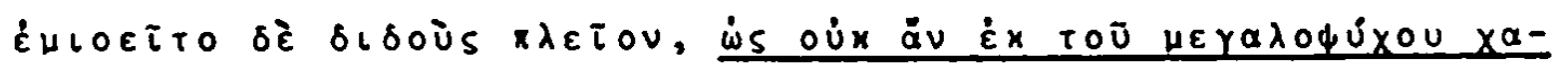

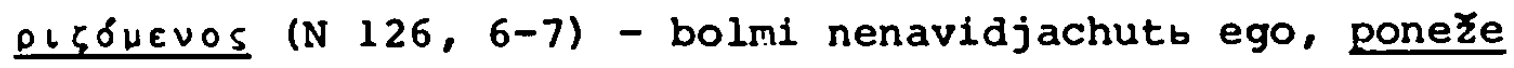
ne ot veledusia daase (M 225, 19-20).

b) Konzessivsätze

Auch sie entsprechen sowohl nicht näher bestimmten griechischen Partizipien als auch solchen, die schon formal (durch $x a i, x a i \pi \in p)$ als konzessiv gekennzeichnet sind:

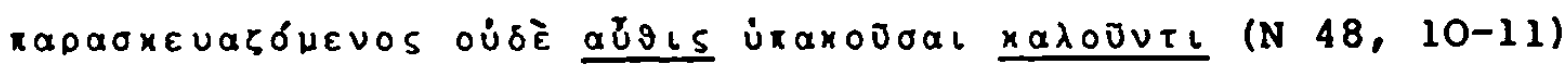
- pristroilb na sja ne poslusati emu, aste i vtoroe vzovetb ego (M 185, 35-36):

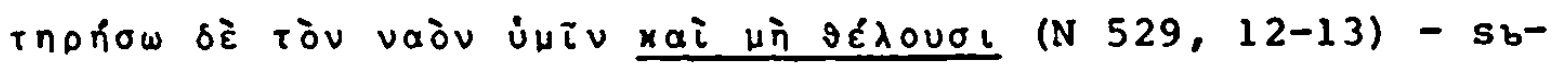
chranju Ze corkbvb bez skvernosti, aకte $i$ vy ne chošete (I1 407, 5-6);

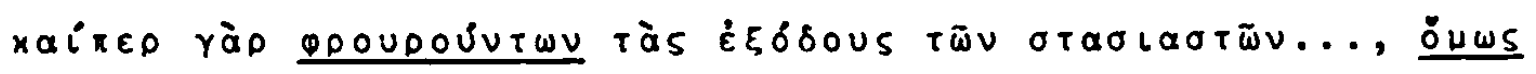

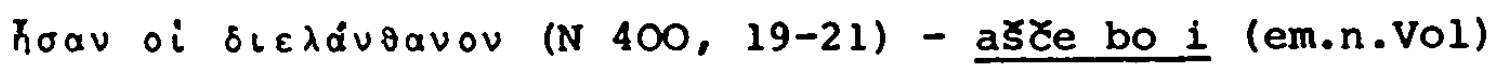
putii strazachuto revniteli.... no obace mnozi, tajascesja, pribęachu (!1 342, 18-20). 
c) Konditionalsätze:

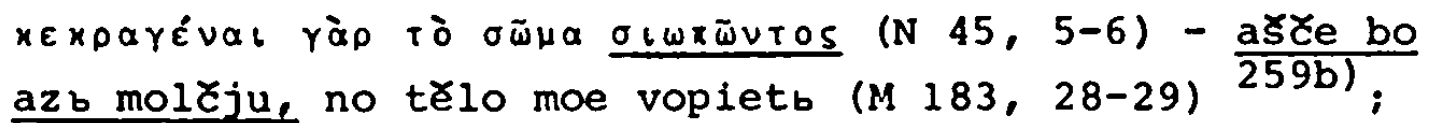

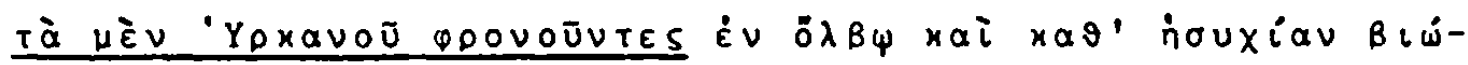
oovial (N 45,24-46,1) - ałce Urkanovi...pokoreni este, to $\mathrm{vb}$ obilii $i$ vb tisine poživete (M 184, 20-22).

Ist dabei der dem Partizip übergeordnete Hauptsatz irreal, so wird diese Irrealität in der Ubersetzung auch im Nebensatz zum Ausdruck gebracht:

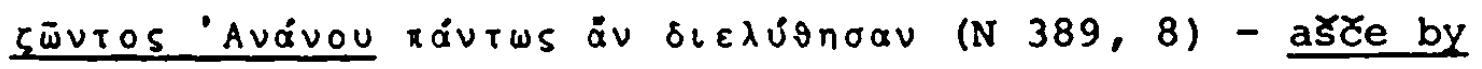
Zivb bylb Ananb, to umirilb by rimskuju vlastb ( $M 337$, 16-17):

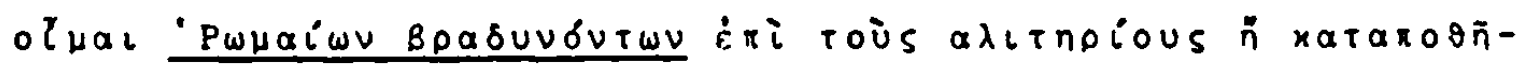

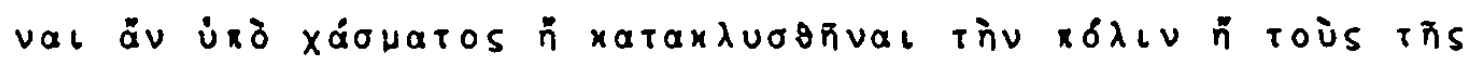

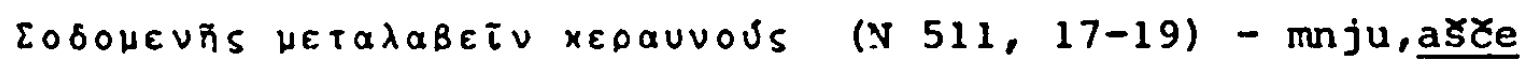
bysa umedlili rimljane na okanbnych (em.n.BARSOV), to ili zemlja by zinuši ja požerla, ili potopb by potopil grad, ili sodomskyi ognb nebesnyi požerlb by sьi bezbožnyi grad (M 395, 13-16).

d) Temporalsätze:

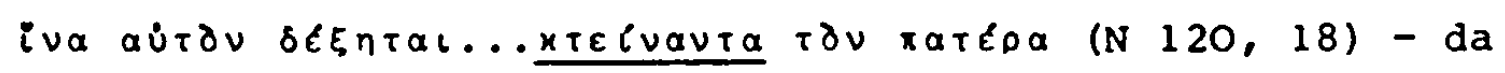
priimetь i.... im Že ubievê otbca (M 221, 20-21);

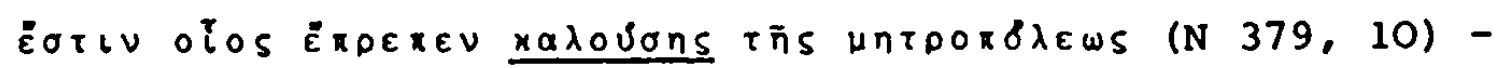
moguకとe pomoకとi (em.n.Vol.) mitropolii, egda vremja nužno vbzovetb (M 334, 25-26).

Kurze Partizipialkonstruktionen können durch einfache Adverbialbestimungen wiedergegeben werden. Dabei entspricht in der Regel dem modalen und kausalen partizip der Instrumental, dem temporalen oder einen zeitlichen Hintergrund angebenden eine Präpositionalwendung mit 'pri': 


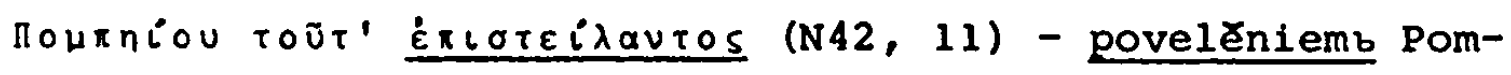
pievymb (M 183, 7-8);

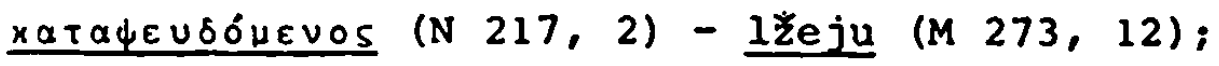

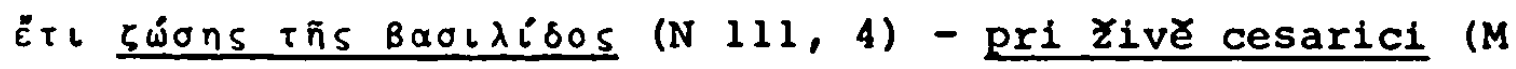
215, 14):

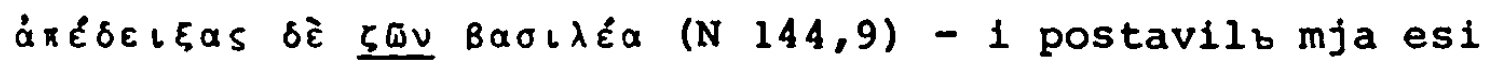
cesarems pri svoem Zivote (M 237, 25-26).

Da, wie oben gezeigt 260), ungekehrt dem Aufbau nach komplizierteren griechischen Präpositionalwendungen in der Ubersetzung Partizipialkonstruktionen entsprechen, scheint es die Tendenz des Ubersetzers zu sein, kurze und einfache Adverbialverhăltnisse durch Prăpositionen, kompliziertere durch Nebensätze und Partizipien auszudrücken.

1v. Das Partizip des Futurs zum Ausdruck finaler Beziehungen

Im Griechischen bezeichnet das Partizip des Futurs (häufig in Verbindung mit $\dot{\omega} s$ ) ebenso wie der Finalsatz ein ziel oder eine Absicht 261). Die Behandlung dieser Konstruktion auBerhalb des Rahmons der ubrigen Adverbialpartizipien erscheint deshalb zweckmäßig, weil sie die Verkürzung nicht nur eines Finalsatzes, sondern auch eines objekt- bzw. Heischesatzes darstellt. Im Gegensatz zur altkirchenslavischen (sakralen) Ubersetzungsliteratur, wo nach ANGELOVA das Partizip des Futurs "... am allerseltensten" vorkommt 262), - dementsprechend wird es von ihr auch kaum untersucht -, finden sich in unserem Denkmal uber 20 Stellen, wo es eine vergleichbare Ubersetzung besitzt. Dabei kommt bis auf eine einzige fusnahme 263) die Finalität im Altrussischen eindeutig zum Ausdruck, und zwar werden alle ihre Bezeichnungsmöglichkeiten erschöpft:

1) Für ein griechisches Partizip, das die Verkürzung eines Heischesatzes darstellt und demgemäß als objekt im Akkusativ steht, steht in der Ubersetzung entweder ein durch 'da' eingeleiteter Nebensatz oder ein finaler objektsinfinitiv: 


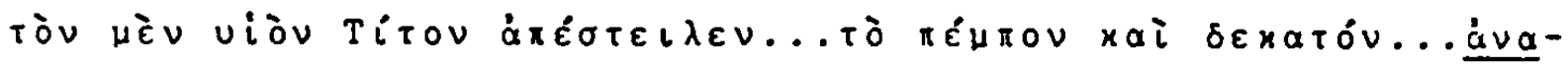
otroovia Tárua (N 274, 12-13) - posla syna svoego Tita,...da poimetb polkb (M 292, 18-19);

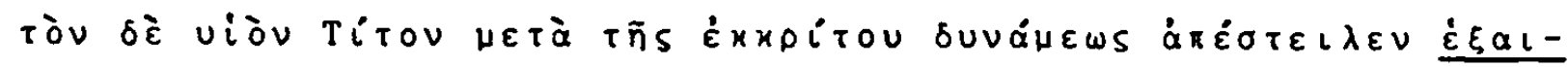

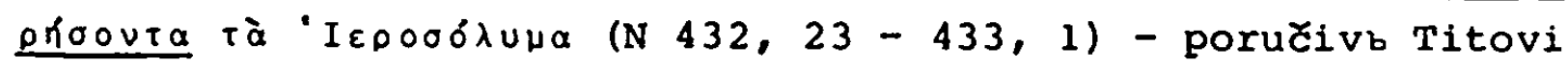
izbrannyja voi, da vozmetb Ierusalimb (M 357, 32);

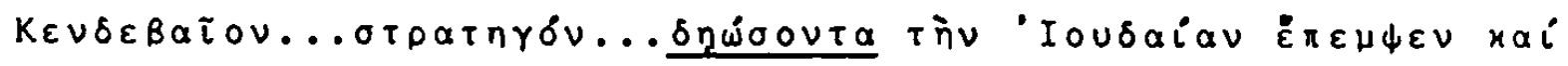

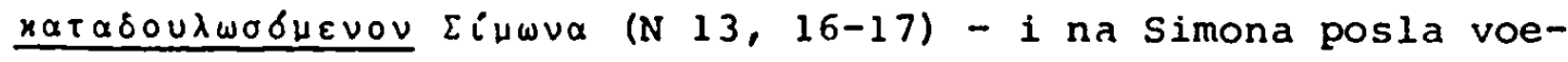
vodu Konderveja i pogubiti i porabotiti (M 169, 27-28);

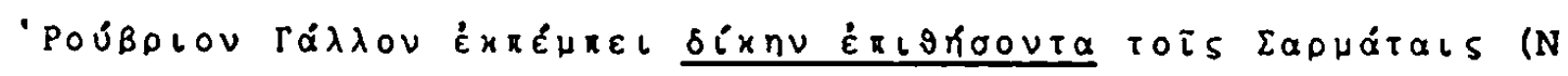
583, 14-15) - ustroi voevodu Oluvri Gala vbzloziti mestb na sovramantiy (M 442, 25-26).

2) Auf dieselbe Weise werden Partizipien übersetzt, die die Stelle eines finalen Adverbialsatzes vertreten, und bei denen das Subjekt des Partizips identisch mit dem des Hauptsatzes ist 264):

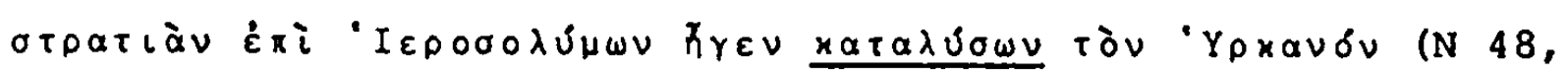
20-21) - ide vb Ierusalimb, da vyženetb Urkana (M 186, 7);

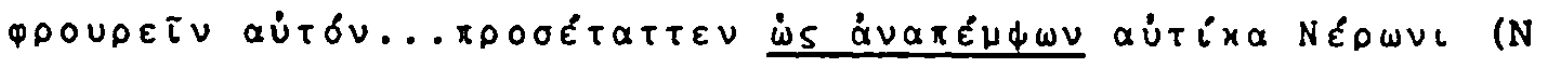
$326,14-15)$ - povele tverditi ego, da posletb $i k$ Neronu (M $310,12-13$ ) 264a);

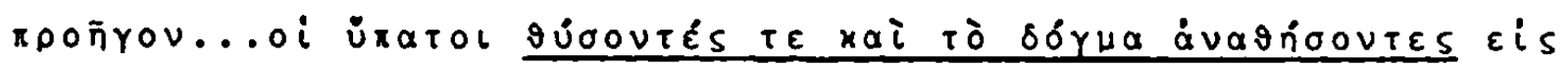

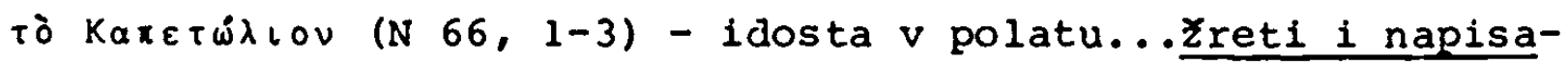
ti o Irodove cesarbstve (M 191, 32-32);

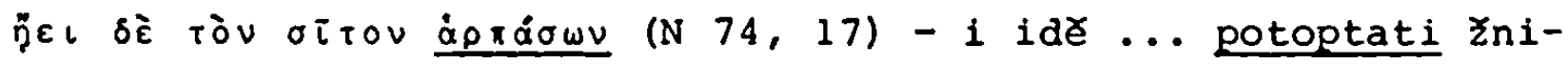
ta ich (M 195, 18-19).

3) Daneben steht, ebenfalls bei gleichem Subjekt von Partizip und Hauptsatz, die Ubersetzung des Partizips des Futurs durch das Partizip Präsens, von 'chotěti' + Infinitiv des betreffenden Verbums: 


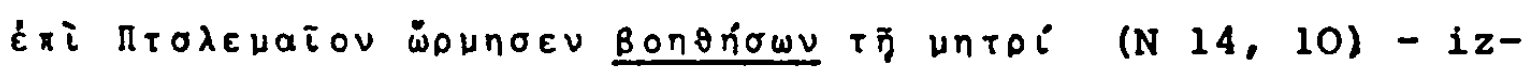
ide na ptolomeja mbstiti chotja materb (11 170, 9-10);

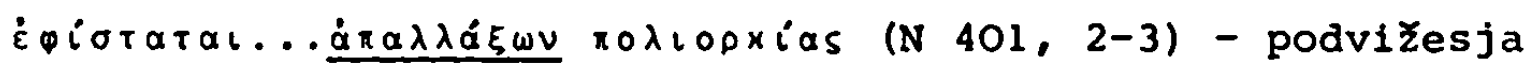
.... chotja izbaviti ich (11 342, 25-27);

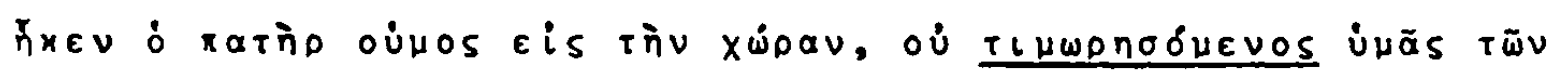

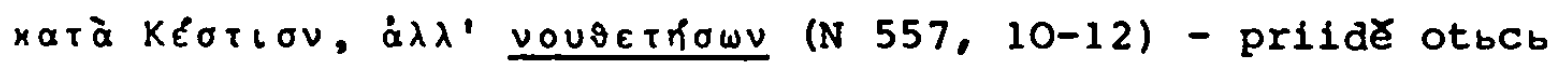
moi $v$ zemlju vałju, ne mbstiti chotja nad vami, no nakazati vy (I1 424, 4-6).

Man wäre versucht, diese Stellen als wörtliche Ubersetzung der Vorlage $z u$ werten, da 'choteti' + Infinitiv im Altrussischen auch zur Bildung des zusammengesetzten Futurs verwendet wurde 265). Es tritt aber auch ein Beispiel auf, wo das griechische Partizip des Futurs durch dieselbe Konstruktion wie oben wiedergegeben wird, jedoch mit dem Partizip von 'zadati', das nie zur bloBen zukunftsumschreibung benutzt und dadurch entsemantisiert wurde. Analog dazu durfte auch 'choteti' in den o.a. Stellen seine lexikalische Bedeutung voll besitzen und daher klar eine Finalität zum Ausdruck bringen:

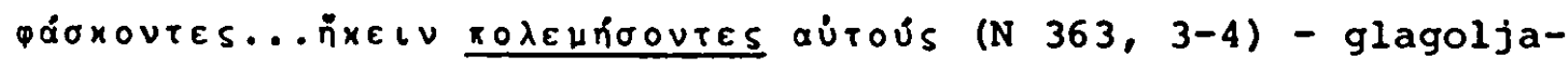
కte, jako... pridochnm... zazjuste s nimi bitisja (I1 327,5-6).

4) Schlieblich wird das tinale Partizip des Futurs noch ubersetzt durch einen Präpositionalausdruck mit 'na' + Akkusativ:

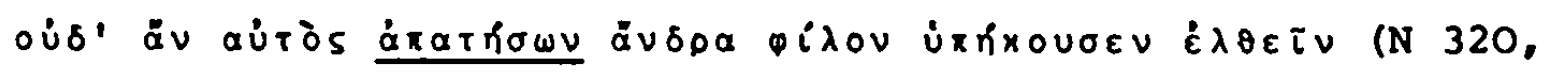
10-11) - ni azb bych poslusal ego na prelestb tobe (11 307. 12);

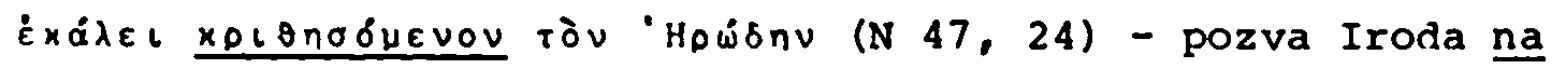
sudiše (I1 185,24$)$;

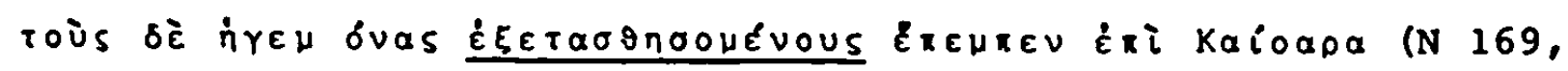
3-4) - a igemony ich posla $k$ cesarevi na ispytanie viny (II $247,10-11)$.

Auch hier haben wir bereits bei den präpositionen die umgekehrte Entsprechung festgestellt, als robs + Akkusativ zur 
Angabe eines $\mathrm{zieles}$ durch einen finalen Adverbialsatz übersetzt wurde 266). Die Verwendurig des Präpositionalausdrucks mit 'na' als Entsprechung für einen einfachen, die des Nebensatzes bzw. Infinitivs für einen komplizierteren griechischen Ausdruck, hält sich ebenfalls an die sonst geübte Ubersetzungspraxis 267). Allerdings dürfte bei den letzten beiden 0.a. Beispielen für die Wahl der Präpositionalwendung mitbestimmend gewesen sein, daß sich auf diese Weise eine Wiedergabe der Passivform des griechischen Partizips erübrigte.

\section{v. Das absolute Partizip (Accusativus absolutus)}

Diese spezielle Konstruktion des Griechischen unterscheidet sich vom Genitivus absolutus hauptsächlich dadurch, daß es fast nur von unpersönlichen Verben gebildet wird und einen eingliedrigen, (zumindest formal) subjektlosen Ausdruck darstellt 268), während die Genitivkonstruktion durch die Zweiheit von subjekt und Partizip gekennzeichnet ist. Da dieses absolute Partizip im Akkusativ verschiedene Adverbialfunktionen bezeichnen kann, die jeweils nur aufgrund des Kontexts bestimmt werden können, erscheinen die von KUHNER-GERTH angeführten deutschen "Entsprechungen" wie 'vorausgesetzt', 'angenommen', 'keinen Mann ausgenommen' 269), die durchwegs nur in einer Funktion erscheinen (hier: konditional bzw. modal), recht fragwïrdig. Auch das Altrussische wie das Slavische überhaupt besitzt keine genaue Entsprechung dieser Konstruktion 270), so daß sich der Ubersetzer des $\pi \delta \delta^{2} \mu \circ \mathrm{s}_{\text {auf }}$ verschiedene Weise helfen muB 271).

So wird denn das Participium absolutum in zwei fällen durch einen Adverbialsatz (kausal und temporal mit adversativem Nebensinn), in einem durch eine Kausalwendung (Präposition 'po' + Dativ) ersetzt! alle übrigen Stellen weisen statt des Partizips einen selbständigen Hauptsatz auf 272) :

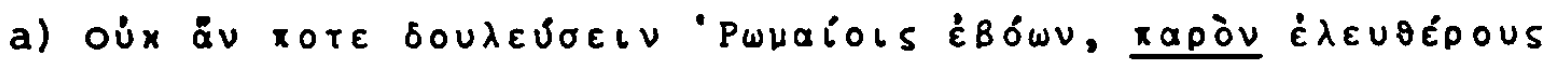
árovaveiv (N 478, 14-15) - vopijachu: nikoli Ze ne pora- 
botimsja rimljanom, zane možem vb (em.n.Vol.) svobode umrêti (M 378, 30-31):

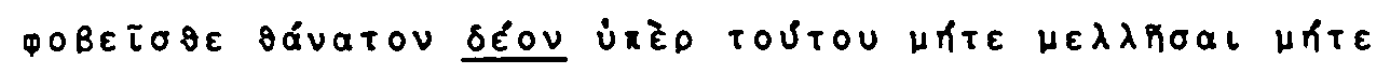
ounboudov ávaneival (N 614, 6-7) - 1 ubojalisja este.... im Ze dostoino bysto ne medilti na to $i$ zatat sovetniky (M 460, 15-17);

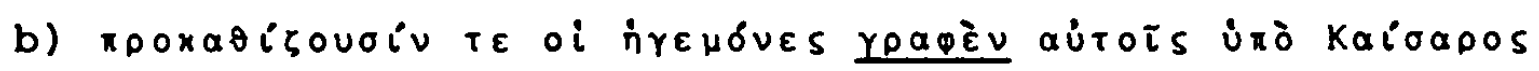
(N 122, 19-20) - sě̉కim Ze gemonom po veleñiju cesarevu (M 223, 2-3);

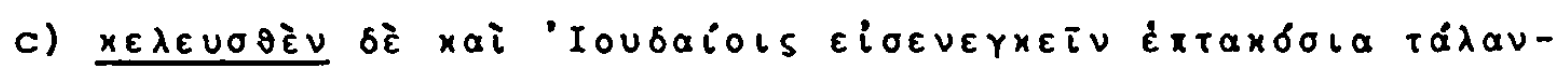

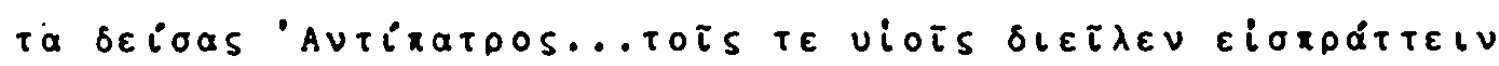
Tá xphuara (N 50, 11-13) - povele [scil.Kassi1] i Ant1patrovi vydati ot 1 juder 7 sot talantb zlata. I se, ubojavsja,... razsla syny svoja... sbbrati zlata (M 186, 3436):

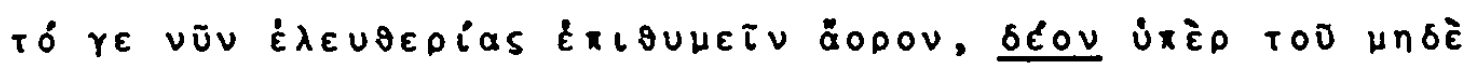

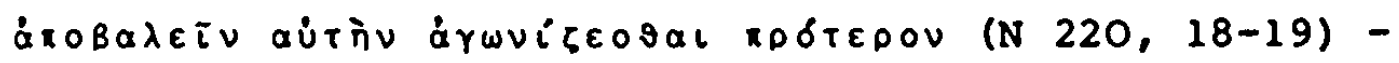
aకそe Ze nyne svobodu ožidaete, to bezvrémenno délo tvorite. Podobase preze vsjak trud 1 potb prilmati 1 krovb prolivat1 za svobodu (M 327, 13-14):

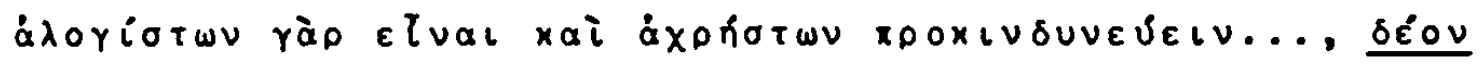

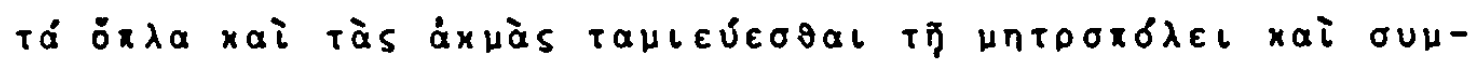

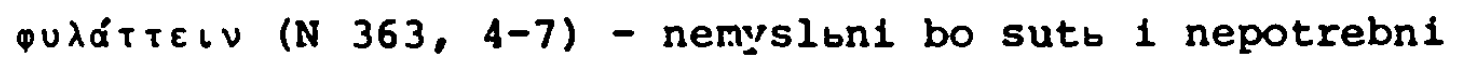
(em.n.Vol.), 1Ze Zresb silu strazjutb... Podobaet Ze namb vopruzii vaju pristroju chraniti na sobljudenie mitropo111 (M 327, 6-9).

Besonders die letztere tbersetzungsweise zeigt wieder das Bemühen um die Wiedergabe der Aussage des Originals durch die gebräuchlichsten Sprachmittel der Ubbersetzungssprache. 


\section{F. Verbaladjektive}

Das Griechische besitzt zwei verschiedene Verbaladjektive, die durch Anfügung von - Téos bzw. - Tos an den Verbalstamm gebildet werden.

1. Verbaladjektiv auf - téos

Die Verbaladjektive auf - $\tau \dot{\varepsilon} \circ s^{\prime . . . ~ b e z e i c h n e n ~ d e n ~ B e g r i f f ~}$ der Notwendigkeit und entsprechen dem lat. Gerundive" 273). Während dabei das Verbaladjektiv eines intransitiven Verbums immer in der Neutrumform erscheint, kann das eines transitiven auch persönlich konstruiert werden, d.h. das 10gische Objekt steht wie beim Passiv im Nominativ und das Verbaladjektiv kongruiert damit in Genus, Kasus und Numerus. Bei beiden Konstruktionen tritt der Agens im Dativ auf 274). In der Ubersetzung wird das verbaladjektiv auf - Téos fast regelmäßig durch einen unpersönlichen Ausdruck der Verpflichtung (z.B. 'podobaetb') + Infinitiv des betreffenden Verbums wiedergegeben. Diese konstruktion wird wohl deshalb bevorzugt, weil hier der Agens ebenfalls im Dativ erscheinen kann, was einerseits dem Vorbild des Originals entgegenkommt, andrerseits voll den Regeln der altrussischen syntax entspricht 275):

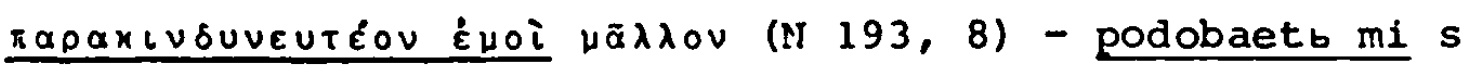
vami postradati (M 262, 14);

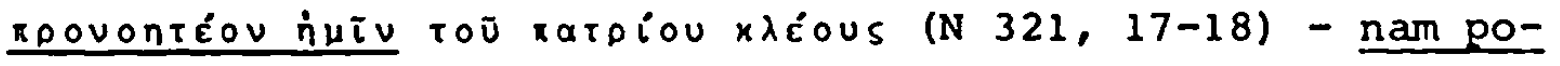

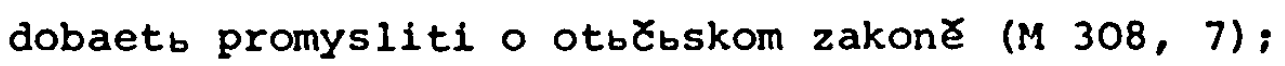

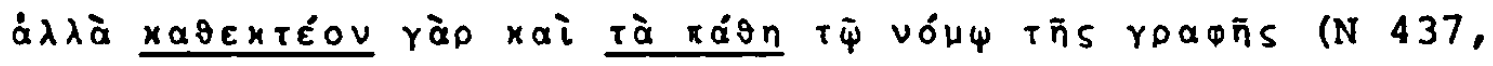
5-6) - no dostoiro vbzderzati placb po zakonu pisanija (M $360,6-7)$;

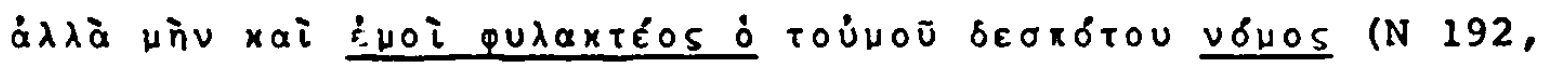
10-11) - mnx (ostoitb chraniti svoego vladyki obrazb (11 261, 28-29).

Nur mit je eincm einzigen Beispiel ist dagegen die Uberset- 
zung dieses Verbaladjektivs durch den Imperativ (2.Person) und den Indikativ des Präsens in Hortativfunktion (1.Pers.Dual.) vertreten, die ein erheblich freieres Umgehen mit der Vorlage zeigt:-

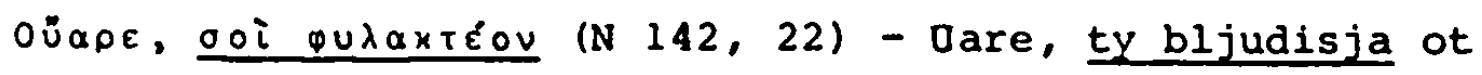
nego (M 236, 28);

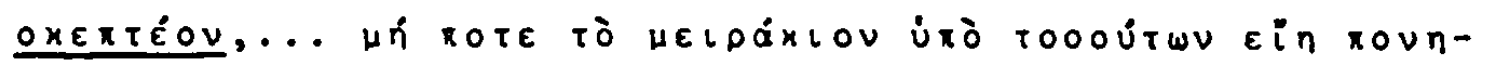

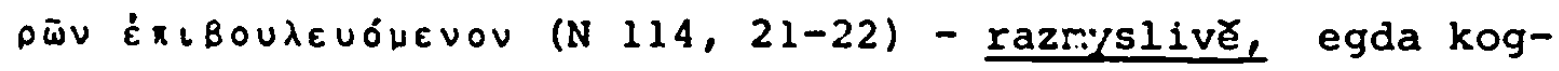

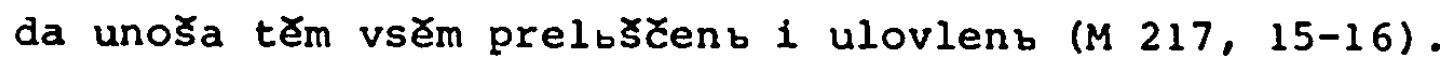

I1. Verbaladjektiv auf-tos

Es bezeichnet einmal "... den Begriff einer Möglichkeit, wie die lat. Adj. auf bilis und wie die deutschen auf lich und bar" 276). Bei negativem Sinn erfolgt die Bildung vor allem mittels des a privativum. Im Altrussischen entspricht ihm hier ein Partizip Präsens Passiv, das im Altrussischen dieselbe Funktion vertrat 277):

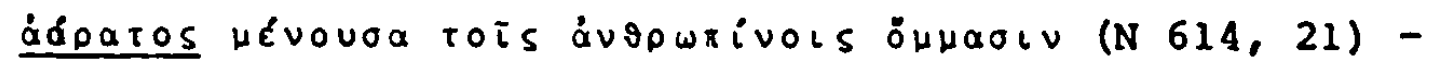
nevidima Celověrskyma orima (M 460, 27-28);

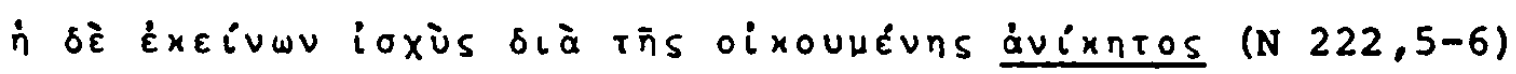
- onych Ze sila po vsei vselenei ne pobedima esto (11 276. 9-10):

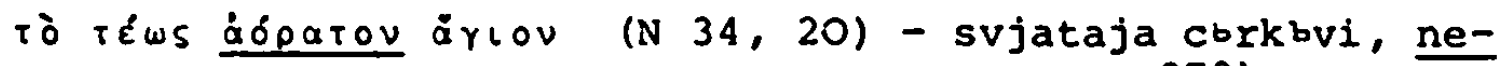
vidima suకti inoplexmenniky preže (M 180, 2) 278).

Das letzte Beispiel bildet eine Uberleitung zur zweiten Funktion des Verbaladjektivs auf -ros, in der es "...eine abgeschlossene Thätigkeit wie das Partic. Perf.Pass." ausdrückt 279). Eine genaue Entsprechung durch die Wiedergabe mit dem Part. Prät. I eiries reflexiven Verbums ist nur in einem einzigen Beispiel gegeben:

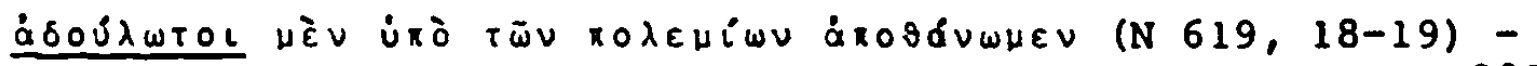
da umremb, ne porabotivłesja inoplemennikomb $(M 463,2) 280)$. 
Ansonsten sind hier die Grenzen zum Adjektiv recht flieBend. Wird das Verbaladjektiv prädikativ gebraucht, so empfindet es der Ubersetzer sogar als adverbiell und gibt es durch ein Adverbiale der Art und Weise (ausgedrückt durch eine Präpositionalwendung) wieder:

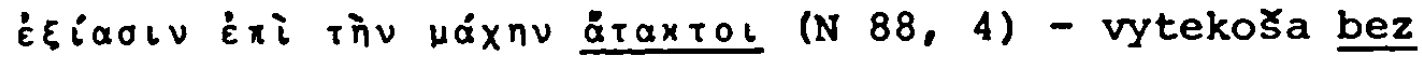
narjada (M 202, 19-20). 


\section{G. Infinitivkonstruktionen}

Im $\Pi \delta \delta \varepsilon \mu \mathrm{os}$ treten vor allem drei Infinitivkonstruktionc. auf, mit denen sich der Ubersetzer aufgrund ihres häufigen Vorkommens auseinandersetzen muBte.

1. Der finale objektsinfinitiv

Er steht nach den Verben des Bittens und des Befehlens, des Schickens und der Bewegung 281) und wird, wie bereits oben angeführt 282), ebenso wie die Final- und Heischesätze durch einen mit 'jako' eingeleiteten altrussischen Nebensatz wiedergegeben. AuBer den schon oben angeführten Beispielen siëhe noch N 31,11/M 178,11! N 269,7-8/M 290,36; N 294,9-10/M 300, 18-19; N 298, 17-18/M 301,28 und passim.

11. Der Akkusativ mit dem Infinitiv (Acl)

Nach den Verben des Denkens, Glaubens, Sagens und der sinnlichen Wahrnehmung sowie den unpersönlichen Ausdrücken des Sollens und Dürfens und des Sichereignens 283) wird im Griechischen die den Inhalt der Prädikatsaussage bildende Handlung durch den Infinitiv ausgedruckt, ihr subjekt steht im Akkusativ. Diese Konstruktion des Akkusativs mit dem Infinitiv wird in unserem Denkmal auf zwei verschiedene Arten ubersetzt.

1) Nach den Verba putandi und sentiendi 284) erscheint für den AcI ein abhängiger Objektsatz (Konjunktion 'jako') mit dem Akkusativ des AcI als subjekt:

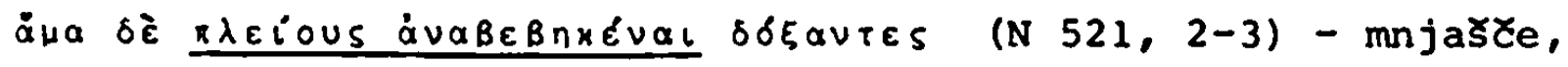
jako mnozi vbzlezosa (M 402, 2-3):

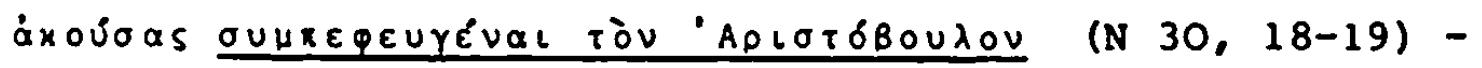
slysavb, jako Aristoulb pobere (M 177, 34). 
2) Nach den unpersönlichen Ausdrücken des Sollens und Sichereignens wird der griechische Acr durch den Dativ mit dem Infinitiv ersetzt, wie ja im slavischen und besonders im Russischen bei unpersönlichen Ausdrücken das logische Subjekt uberhaupt im Dativ zu stehen pflegt 285) :

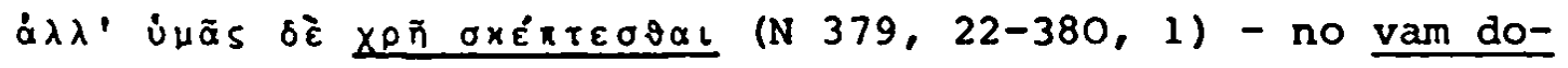
stoit razumet 1 ( $M 334,32-335,1)$;

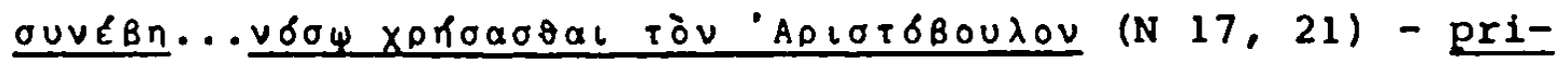
klukisja...Aristoulu razboletisja (M 171, 29-30).

111. Der substantivierte oder artikulierte Infinitiv

Diese typische Konstruktion des Griechischen, die auch in dieser sprache erst in nachhomerischer zeit, als die syntax bereits voll ausgefeilt war, entwickelt wurde 286), bietet zusätzliche Möglichkeiten eines Ausdrucks syntaktischer Beziehungen, denn "... der $z u$ dem Infinitive hinzutretende Artikel ro ...erhebt diesen allgemeinen Begriff zu einem bestimmteren und begrenzteren und nähert ihn den eigentlichen abstrakten Substantiven. Mittels des Artikels kann er, wie die Substantive, dekliniert werden und wird fähig, Beziehungsverhältnisse, welche durch die Kasus des substantivs bezeichnet werden, auszudrücken. Die deutsche sprache macht den Infinitiv durch den Artikel zu einem vollständigen Substantive; in der griechischen sprache aber gibt der artikulierte Infinitiv seine verbale Natur nicht auf, sondern behält, wie der Infinitiv ohne Artikel, die Konstruktion und Rektion des Verbs bei, wie er auch unterschiedene Formen für die unterschiedenen Genera des Verbs und für die unterschiedene Beschaffenheit des verbalen Thätigkeitsbegriffes hat." 287) Bei der Ubertragung in eine relativ junge und noch ungeformte Sprache wie das Altrussische durfte der deklinierte Infinitiv besondere Schwierigkeiten bereitet haben. Daher ist es auch verständlich, wenn in unserem Denkmal der Ubersetzer durch freiere wiedergabe eines Abschnittes versucht, die Ubersetzung eines deklinierten Infinitiv (besonders, wenn 
es sich um eine passive Form handelt) zu umgehen. Allerdings läßt sich im einzelnen nicht entscheiden, ob es sich bei allzu frei wiedergegebenen Stellen un Ausweichmanöver des Ubersetzer handelt oder um eine beabsichtigte Paraphrasierung der Vorlage (sei es um zu kürzen oder die Darstellung zu straffen usw.). Ganz offensichtlich ist das Bemuhen, eine genaue Wiedergabe der Infinitivkonstruktion $z u$ vermeiden, in den beiden folgenden Beispielen:

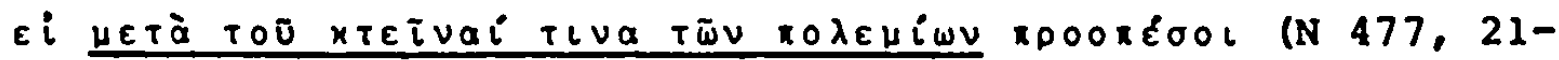
22 ) - aste protivna ubijutb 1 sami padutb sb nimb (M 378 , $12-13)$;

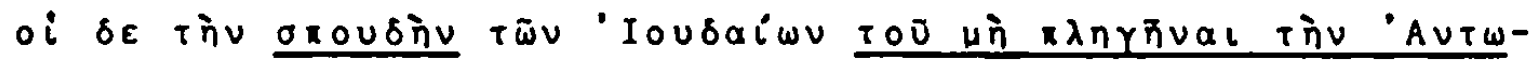

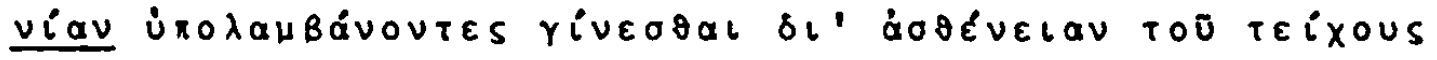
(N 516, 11-13) - oni そ̌e mnȩa tక̌anie ijuderisko, jako Antoniiskia (em.n.Vol.) slabosti branjatb (M 398, 36-37).

Im ersten Beispiel wurde die Infinitivhandlung der des $\varepsilon_{i}-$ Satzes beigeordnet, im zweiten die im Griechischen durch die Infinitivkonstruktion ausgedrückte năhere Bestimmung zu orouó - 'ţ̧anie' einfach unterschlagen.

Andererseits finden wir an uber hundert stellen eine genaue Entsprechung der griechischen konstruktion und zwar auch dann, wenn diese noch kompliziert wird durch den Einschub näherer Bestimmungen zwischen Artikel und Infinitiv. Dabei lassen sich drei Ubersetzungsweisen herauskristallisieren.

1) Wiedergabe des artikulierten Infinitivs durch den altrussischen Infinitiv

Diese Lösung ist die am seltensten gebrauchte (in etwa 15 \& der Fälle). Erklären läßt sich diese Einschränkung dadurch, daß der altrussische Infinitiv als Indeklinabile nur in Nominativ- oder Akkusativfunktion vorkommt. Seine Verwendung ist also auf die Fälle begrenzt, wo er als subjekts-oder Objektsinfinitiv stehen kann. Bestimnt wird diese Anwendungsmöglichkeit durch die eigensprachlichen Gesetze des Altrus- 
sischen, so daß ohne weiteres ein griechischer Genitivus obiectivus durch einen Infinitiv in Akkusativfunktion wiedergegeben wird.

a) Subjektsinfinitiv:

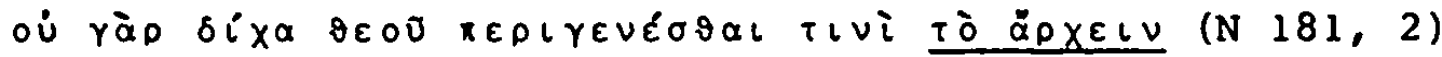

- bez božia bo povelénia nikomu že vdaetbsja vladð̌ti

(M 254, 21-22);

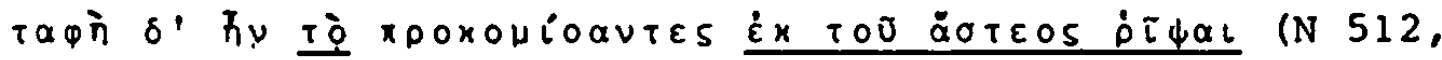

8-9) - pogrebanie そe se bystb: vynesకe iz grada, vbvreక̌̌i vo propastb (M 395, 26-27);

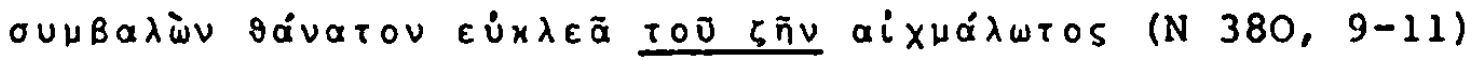

- léple smertb slavnu vzjati negli żiti pléneni (M 355, $5-6)$.

b) Objektsinfinitiv

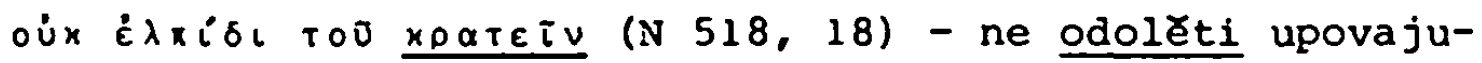
కとe (M 400, 13):

TOTS ठ' $\underline{\nu \varepsilon \imath \nu} \dot{\alpha} v \alpha \dot{\gamma} x n \pi \alpha p \tilde{n} \nu$ (N 523, 2-3) - prednim Že nuža (em.n. Vol.) ests ili ubiti, ili ubsenu byti 288 ) ( 1403,11 ).

2. Wiedergabe durch ein Substantiv

Diese Ubersetzung, die in etwa 40 \& der Fälle gewählt wurde, ist in ihrer Anwendungsmöglichkeit ebenfalls begrenzt, da sie nur die griechischen Infinitive erfassen kann, die keine nähere Bestimung bei sich haben, es sei denn eine solche, die durch ein Adjektiv oder ein anderes, mit dem Substantiv kongruierendes Attribut. Dafür können bei dieser Ubersetzungsweise syntaktische Beziehungen durch sämtliche obliquen Kasusfunktionen ausgedrückt werden. Auffallend ist, daß in unserem Denkmal nicht einmal die Hälfte der anstelle des substantivierten Infinitivs verwendeten substantiva von Verbalsubstantiva gestellt wird, die dem Infinitiv noch am 
nächsten verwandt sind. Bei den ubrigen handelt es sich um normale abstrakte substantiva, die der Wortbildung nach keinen Bezug zum Infinitiv aufweisen. Teilweise stehen Substantiva als Entsprechung für den deklinierten Infinitiv auch in syntaktischen Beziehungen, die ebensogut durch einen subjekts- oder objektsinfinitiv hätten ausgedrückt werden können.

a) Verbalsubstantiva:

$\delta \varepsilon i \sigma a s$ Io $\pi \lambda \varepsilon i v(N$ 429, 11-12) - ustrasivsja préplutbja (M 356, 5-6);

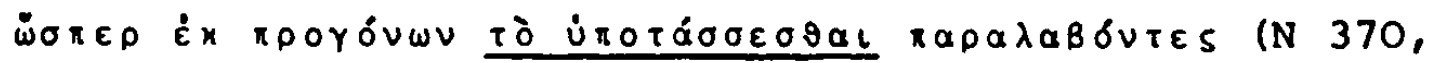
14-15) - aky ot praded (em.n.Vol.) nasledovavse pokorenbe (14 331, 18);

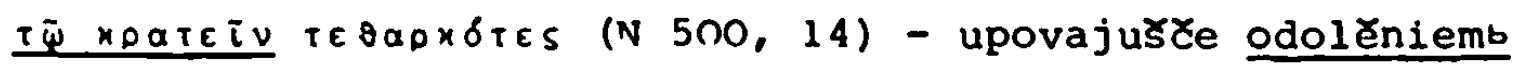
(M 389, 24-25) 289):

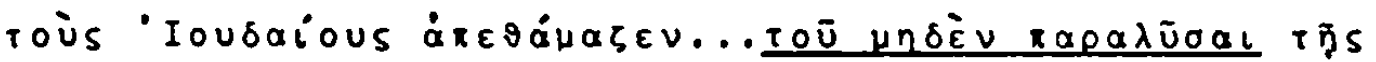
Opnoxeias (N 33, 19-20) - divjaకtetsja そidomb... radi... zakona chranenija (M. 179, 23-24):

Mittels des Ersatzes des doppelt negativen griechischen Infinitivausdrucks ( $\mu n \delta \varepsilon^{\circ} v$ und $\pi \alpha \rho \alpha \lambda \sigma \sigma \alpha \iota$ ) durch einen positiven Ausdruck ('chranenie') kann im letzten Beispiel auch das Akkusativobjekt des griechischen Infinitivs (un-

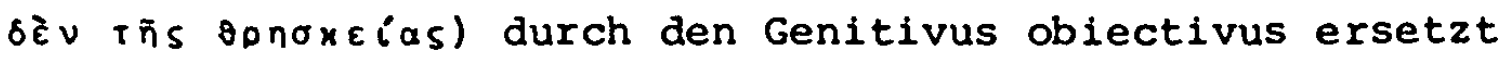
werden.

b) Neutrale Substantiva:

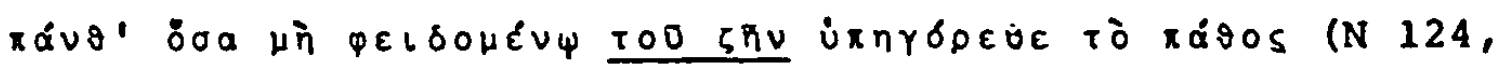

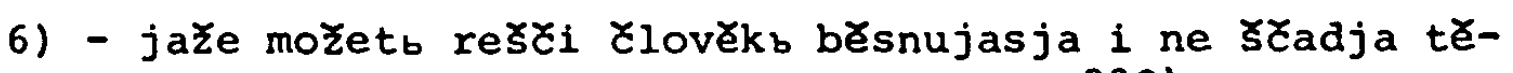
la svoego, ni pomnja zivota (M $224,1-3)^{290)}$;

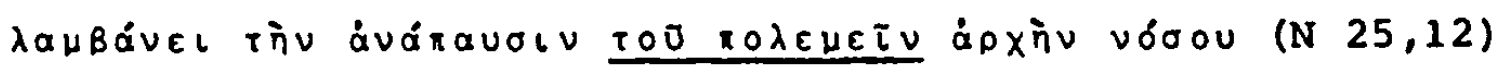

- porivb ot rati, naca boleti (M 175, 14); 


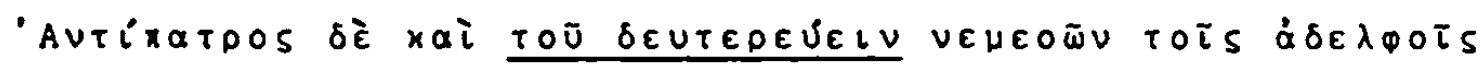

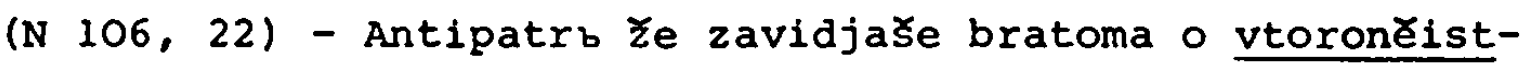
vu $(M 213,12-13)$;

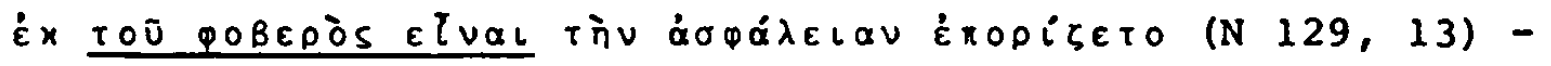
grbdostiju 1 grozoju promyకljase sobe utverzenie (M 227, 1415):

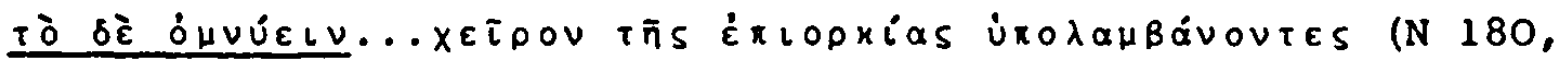
1-2) - rnta ̌e mnitsja im puకðe vsjakago grěcha (11 253, 3334);

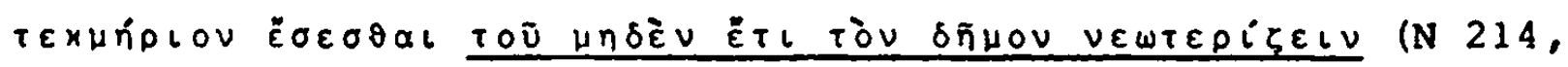
10-11) - se budetb znamenie bezzlobia ljudskago (M 271, 31) 291):

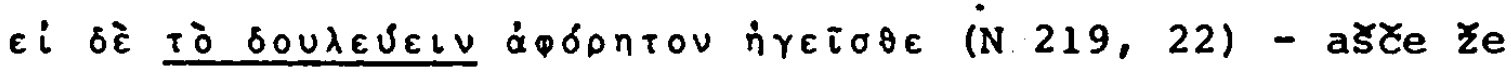
rabota nesterpima mitsja (M 274, 33);

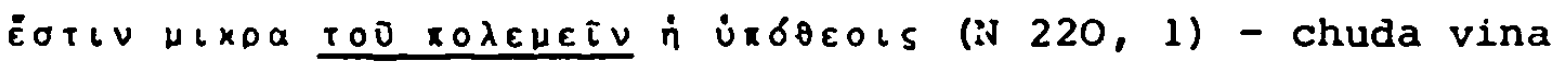
vam na branb (M 274, 35);

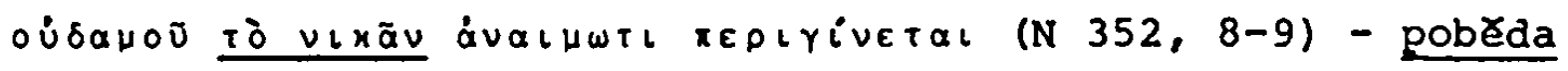
Ze bez krovi ne věncaetb muža (M 322, 24-25).

3. Wiedergabe durch einen Nebensatz

Diese dritte Möglichkeit ist eigentlich immer anwendbar, da der dem Infinitiv entsprechende Nebensatz alle Bestimmungen eines solchen (Objekt, Adverbiale) enthalten kann und so auf keine zusätzliche Aussage des artikulierten Infinitivs verzichtet werden muß. Vor allem kann das logische subjekt des (zum AcI gewordenen) Infinitivs durch das grammatische des Nebensatzes ausgedrulckt werden. Die syntaktische Abhängigkeit des Infinitivs wird durch die Art des Nebensatzes bzw. die Wahl der Konjunktion berücksichtigt. Der Ubersetzer entscheidet sich für die Wiedergabe des artikulierten Infinitivs durch einen Nebensatz (insgesamt kanpp die Hälfte aller Fälle) vor allem bei einer Abhängigkeit des Infinitivs von Präpositionen, sodann, wenn dieser in einem Casus obliquus steht; schlieblich 
werden in einigen Fällen sogar subjekts- und objektsinfinitive auf diese Weise wiedergegeben, wenn sie eine nähere Bestimmung bei sich haben.

a) Kausalsätze

Mit 50 \& aller Nebensätze stehen die Kausalsätze als Entsprechung für den artikulierten Infinitiv zahlenmäBig an erster Stelle. Das ist verständlich, wenn man sich die vielfältigen Möglichkeiten des Ausdrucks kausaler Beziehungen im Griechischen vor Augen hält. So finden wir in der Vorlage als Beziehungswort des Infinitivs den Dativus causae, eigentlich kausale Präpositionen und solche, bei denen die Kausalität nur mittelbar ausgedrückt ist:

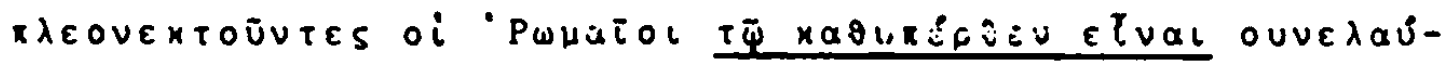
vovalv áuias eis tñu ópayra (N 447, 10-11) - rimljane Ze, premogse, zane s visoty bbjachut, Zidy prignasa vsech na propastb ( $M 364,27-28$; Interp.em.n.I);

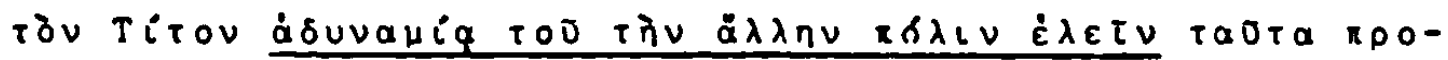

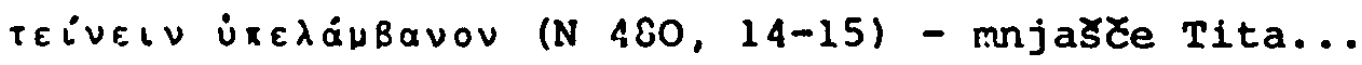
rě si smireny glagoljuక̌a, zane ne možtb grada vnutranjago vzjati (M 380, 6-8);

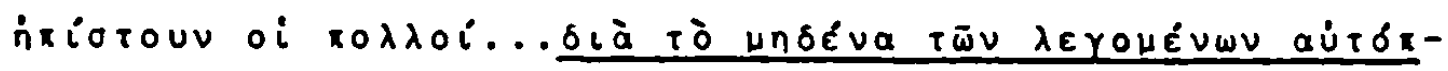
Inv rapeival (N 331, 8-9) - ne jasa verry,.... zane ne bystb Celověka, iŽe by orima svoima vidð̌lb (11 312, 11-12);

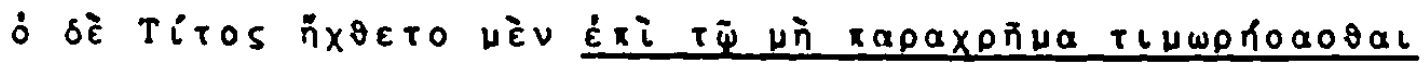
róv 'Iwáuvnv iñs áxátns (N 362, 4-5) - Titb Ze pexalbnb bystb, zane ne skoro mbsti nad Ioannom prelbsti ego radi (M 326, 24-25);

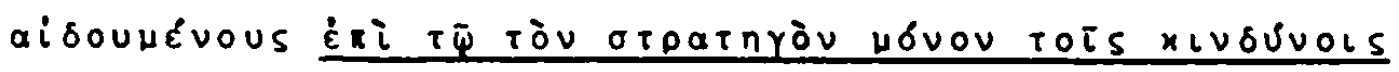

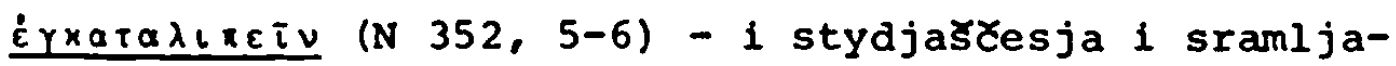
juకXesja, zane ostaviకa gëmona svoego vb ustęch brani (M 322, 20-21) 292); 


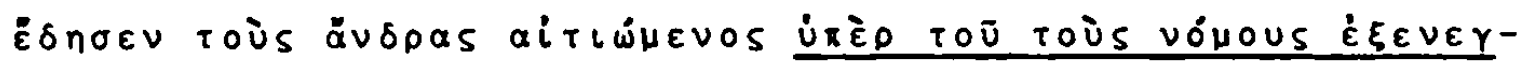
xeiv iñs Kaloapias (N 210, 7-8) - onb Ze, emb ich, svjaza, priloživb na nja vinu, zane vynesosa zakonnyja knigy ot Kesaria (M 269, 25-26);

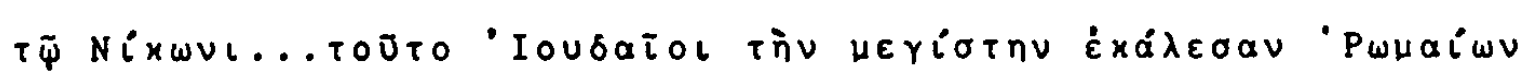

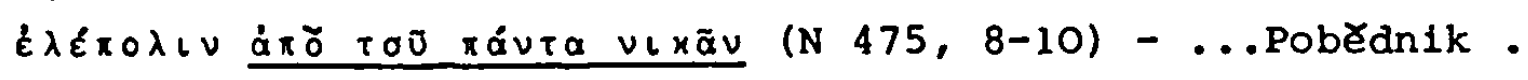
Tako bo naricachu velikago ovna, zane vsja pobezałe (M 377 , 3-4).

b) Finalsätze

War bei den durch Kausalsätze wiedergegebenen Infinitivkonstruktionen die syntaktische Funktion im Griechischen stets klar zu erkennen gewesen, so ist das bei denen, die durch einen Finalsatz ersetzt werden (etwa 25 \& der Nebensatzentsprechungen), keineswegs immer der Fall. AuBer dem eigentlichen konkreten $z i e l$ wird oft ein im Griechischen nur unterschwellig angedeuteter Wunsch durch den altrussischen Finalsatz ausgedrückt. In diesem Fall steht zur Bezeichnung der schwächeren Realität als Modus der Konditional. Schließlich findet sich sogar ein Finalsatz als Entsprechung für ein Adverbiale der Art und Weise:

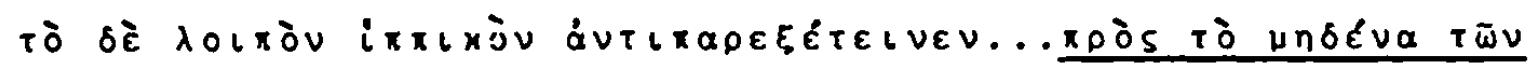

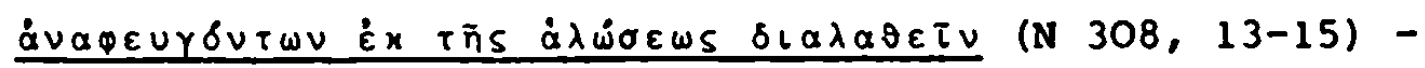
prokb konnikb postavi po prigoriju, da ne utęetb (em.n.Vol.) iz grada nikto Ze gražanı (M 305, 9-10);

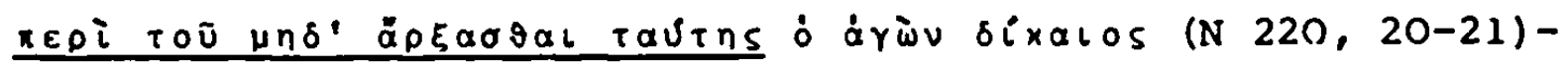

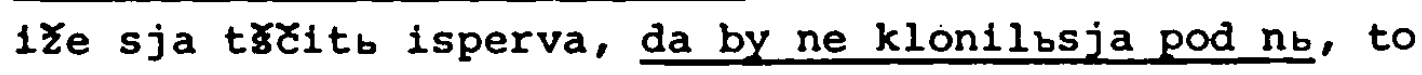
pravb estb 1 chvalenb (M 275, 15-16).

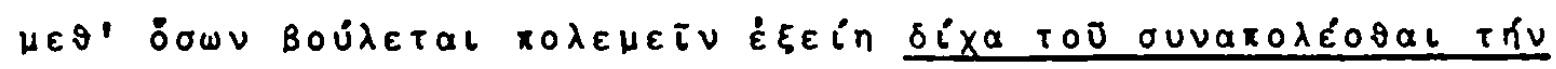
TE $x \delta \lambda_{l v} \times a i$ Tòv vaòv $\alpha u T \bar{\varphi}$ (N 525, 8-10) - vnide s kolikom choł̌esi, da ne pogibnetb grad moi 1 cbrkbvi (M 404, 27-28) 293).

Die übrigen Nebensatzarten sind als Entsprechung für den artikulierten Infinitiv nur vereinzelt vertreten. Es kommen noch folgende Typen vor: 
c) Temporalsätze:

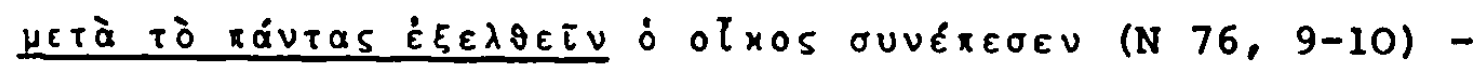
inb Ze razidołasja vsi s veXerja, 1 padesja vnezapnu chramina (M 196, 16-17):

d) deklarative Objektsätze:

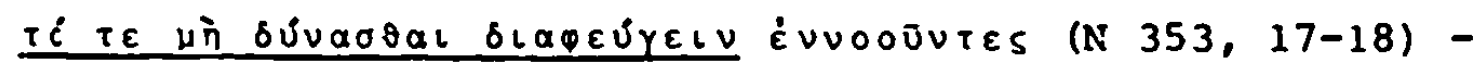
pominajuste, jako...utę̧ఁi nelbze (M 323, 18-19);

e) ir.direkte Fragesätze:

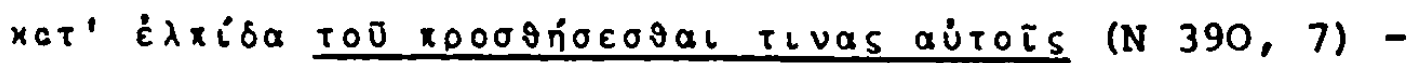
lovjaకte, aše kto prilozitsja k nim (M 337, 27). 


\section{H. Artikel}

AuBer mit dem Infinitiv wird der Artikel im Griechischen noch mit einer Reihe anderer Wort- und Satzteile verbunden. Meist handelt es sich (abgesehen von den eigentlichen substantiva und substantivierten Adjektivä und Pronomina) um Adverbia und Präpositionalausdrücke, die dadurch eine Substantiv- bzw. Adjektivfunktion erhalten 294). Der von BLASSDEBRUNNER vermerkte Gebrauch des Artikels als "Regens eines Genitivs" 295) fehlt im $\Pi \delta \lambda \varepsilon \mu o s$.

In unserem Denkmal werden für diese Fälle, für die KURZ dem Ubersetzer der altkirchenslavischen Evangelien bescheinigt, daß er "... obtižný úkol musil łesiti" 296), vier Möglichkeiten der Wiedergabe angewandt:

\section{1) Die bestimmte Form des Adjektivs}

Diese Lösung ist die am weitesten verbreitete (mit nahezu $50 \&$ der Fälle). Sie wird sowohl angewandt, wenn die Artikelverbindung in substantivischer Funktion steht, als auch für einen Ausdruck in attributiver Funktion. Im ersteren Fall richtet sich das altrussische zusammengesetzte Adjektiv in Genus und Numerus nach dem griechischen Artikel, im letzteren kongruiert es mit dem von ihm zu bestimmenden Substantiv:

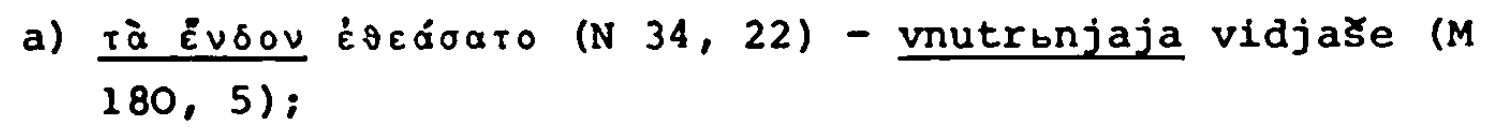

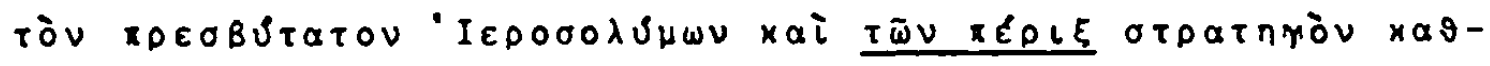
írnolv (N 46, 9-10) - postavi stareiłago syna vladéti na Ierusalim i na okrbstnaja(M 184, 27-29).

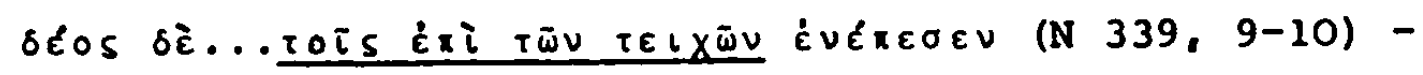
napade strach na vsja stojastaja na zabraléch (M 316, 3);

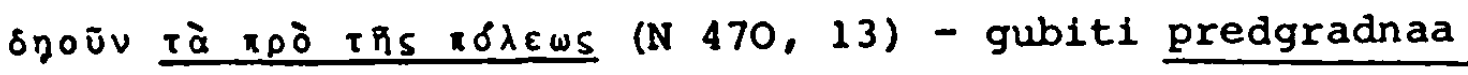
(M 374, 12-13); 


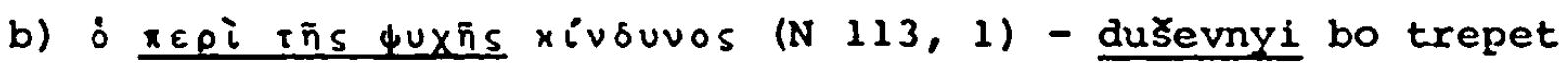
(M 216, 10-11);

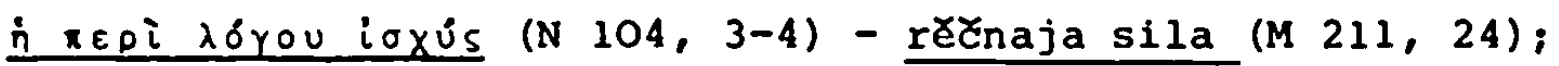

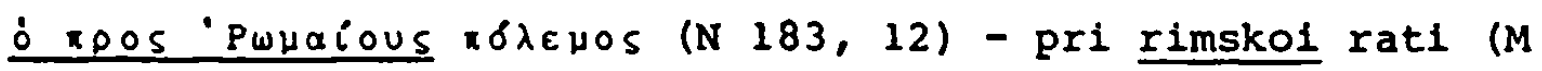
255, 19);

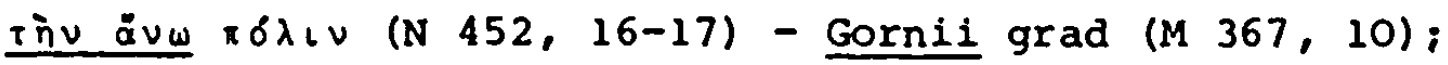

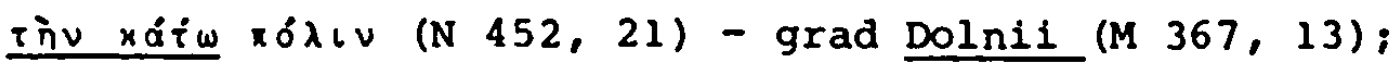

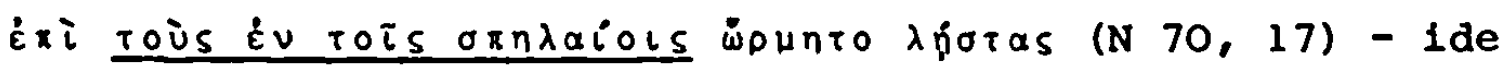
na pererskia razboiniky (1! 192, 31).

\section{2) Substantiva}

Diese Ubersetzungsweise, die in etwa einem Viertel der Fälle gewăhlt wurde, findet naturgemäB nur dann Anwendung, wenn die griechische Artikelverbindung in reiner substantivfunktion steht :

Ià xaià iñv $\dot{\alpha} \rho x \hat{v} v(N 16,15)$ - vlastb (M 171, 8);

ToUs Év ToIs IEpooodunoLs (N 410, 19-20) - ierusalimljany (M $347,18)$;

ánúveoval toùs ádo too teixous (N 68, 15) - streljati na zabralniky (M 192, $36-193,1)$.

3) Das Partizip Präsens Aktiv von 'byti' + Substantiv bzw. Adjektiv.

Diese in unserem Denkmal nur selten vorkommende Entsprechung war vor allem in der altkirchenslavischen Ubersetzungsliteratur im Gebrauch gewesen. KURZ wendet sich gegen die Auffassung von GRUNENTHAL, der zufolge die Partizipform eine genaue Entsprechung des Artikels an sich darstellt 297), und betont die Geschlossenheit des ganzen Ausdrucks 298): 


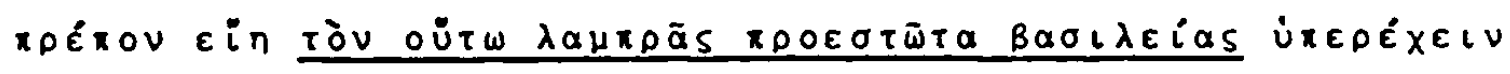

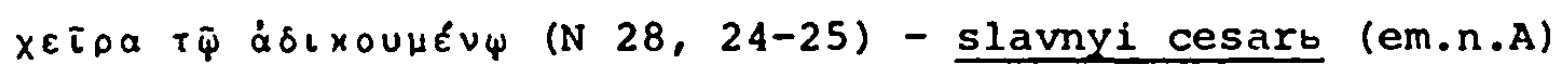
syi podoben esi obidimymb ruku podavati (M 176, 36-37).

\section{4) Relativpronomen + Adverbiale}

Wenn von den bisherigen Entsprechungen der Artikelkonstruktion KURZ feststellen konnte, daß "...překladatel postupoval zcela samostatné" 299), so lehnt sich diese letzte eng an die Vorlage an. Es ist dies die einzige tbersetzungsweise, wo der griechische Artikel an sich und nicht der ganze Ausdruck ein Aquivalent findet 300 ). Sie besteht darin, daB an das Relativum 'iZe', häufig ohne Rücksicht auf Genus und Numerus in der erstarrten Form 'ež' 301), der Ausdruck (meist mit Präposition), der der näheren Bestimmung des Artikels im Griechischen entspricht, angeschlossen wird. Dabei steht diese Verbindung 'iže' + Präpositionalausdruck im Satz immer hinter dem Glied, von dem sie grammatisch abhängt:

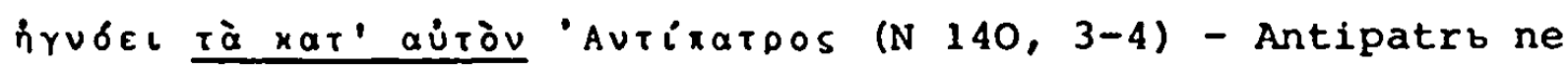
vedase, jaže na nb (M 234, $36-235,1$ ):

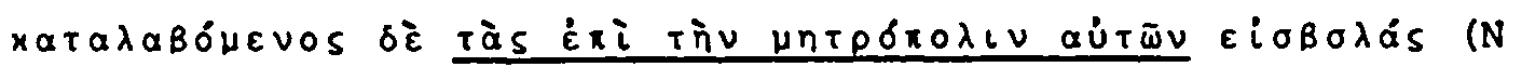
405, 8-9) - préja vsja puti, jaže kb Erusalimu (M 344, 20-21);

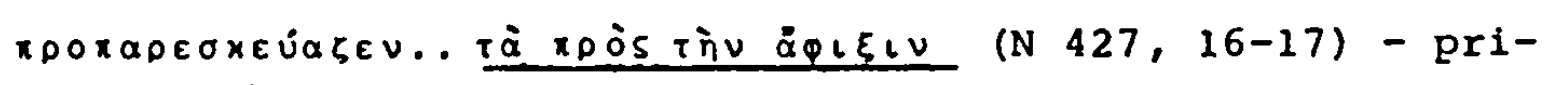
straevaకe, jaže na potrebu prisestvia ego (M 355, 11).

Da der Ausdruck mit ' $1 Z \mathrm{Z}^{\prime}$ ' in allen Fällen entweder als subjekt oder objekt fungiert, also unmittelbarer Bestandteil des Hauptsatzes ist, erscheint die Interpunktation MESCERSKIJs, der ihn durch Komma abtrennt, irreführend 302)! auf diese Weise ließe sich nämlich die Artikelkonstruktion als verkürzter Relativsatz deuten, in dem das Prädikat (meist 'byti') zu ergänzen wäre und ebenso das Bezugswort im übergeordneten Satz. Tatsächlich gab es unter den Forschern, die sich mit derHerkunft und Einordnung dieser Konstruktion befaBten, die 
Tendenz, sie als ursprünglichen Relativsatz aufzufassen. Der Hauptvertreter dieser Richtung war MARGULIES. Dagegen nahmen PASTRNEK, GRUNENTHAL und auch WEINGART den EinfluB des griechischen Artikels als bestimmend an 303). Wenn man die Fixierung des altrussischen Ausdrucks bezüglich der Wortstellung in Betracht zieht, erscheint die letzte Deutung wahrscheinlicher, da ein Relativsatz in der Regel sowohl vor als auch nach seinem llauptsatz stehen kann 304). Mehr Klarheit in diese Frage könnte eine vergleichende Untersuchung der Relativsätze mit dem Prädikat 'byti' einerseits und der obigen Konstruktion auf der anderen Seite bringen, da man aufgrund einer statistischen Aufstellung darüber, inwieweit bei ersteren eine Ellipse des prädikats gebräuchlich ist, uber eine Identität bzw. Divergenz beider Konstruktionen entscheiden könnte.

Wie in der altkirchenslavischen Ubersetzungsliteratur bestimen auch in der 'Iudeiskaja vojna' die freieren Entsprechungen für die griechische Artikelkonstruktion die Mehrzahl der Fälle. Doch erweist sich die altrussische Ubersetzung noch erheblich selbständiger als die altbulgarischen Texte: Während in diesen das $Z$ ahlenverhältnis von adjektivischer wiedergabe und Nachvollziehung der griechischen Konstruktion ('iže' + Präpositionalwendung) $5: 4$ betrug, ist es in der 'Iudeiskaja vojna' auf 5 : 1 zusammengeschrumpft. Diese Tatsache zeigt, wie wenig sich der Ubersetzer in seiner Arbeit von den traditionellen Entsprechungsschabïonen beeinflussen lieB. 


\section{ZUSAMMENFASSUNG}

Aufgrund der obigen Beobachtungen lassen sich für die slavische Ubersetzung des "Jüdischen Krieges" folgende Feststellungen treffen:

1) Als Quelle muB eine griechische Fassung angenommen werden, die nur unwesentlich von der allgemein bekannten, der Edition NIESE's zugrundeliegenden abweicht. Die zahlreichen Kürzungen bzw. Zufügungen sind, von wenigen Ausnahmen abgesehen, dem Ubersetzer zuzuschreiben (vgl. S. $20 \mathrm{ff.}$ ).

2) Die Ubersetzung ist nicht im südslavischen Raum, sondern in der Kiever Ruś entstanden und in deren altrussisch-kirchenslavischer Schriftsprache abgefaßt. Die altrussische Provenienz wird neben der Verwendung phonetischer Besonderheiten des Ostslavischen und speziell altrussischer Lexik (insbesondere auf dem Gebiet der Kriegsterminologie, vgl. S. $31 \mathrm{ff}$ ) vor allem durch die Bezeichnung des Agens beim Passiv (vgl. S. $94 \mathrm{ff.)}$ unterstrichen.

3) Bei der Ubertragung der griechischen Konstruktionen wurde nur in wenigen Fällen die wörtliche Entsprechung oder eine Nachvollziehung gewählt. In der Regel wurden dem syntaktischen System des Slavisch-Altrussischen fremde Konstruktionen nach ihrem jeweiligen Funktionsgchalt analysiert und demzufolge durch in der Ubersetzungssprache übliche wiedergegeben. Diese Ubersetzungsweise - besonders klar herauskristallisiert bei der Behandlung der griechischen Infinitiv- und Artikelkonstruktionen (vgl. S. 145 - 157) und der einzelnen Präpositionen (vgl. S. $71 \mathrm{ff}$ ) - läßt den Schluß zu, daß der Ubersetzer einerseits die Sprache des griechischen Originals vorzüglich kennt und imstande ist, sie einwandfrei $z u$ analysieren, andererseits die volle skala des syntaktischen Inventars der Ubersetzungssprache $z u$ nützen weiB. Die Möglichkeit eines zusammenwirkens von griechischen und russischen Gelehrten bei der Ubersetzung läßt sich dabei nicht ausschlieben. 


\section{ANMERKUNGEN}

1. Anmerkungen zur Einleitung

1) Siehe Literaturverzeichnis.

2) Ebenda.

3) Ebenda.

4) Vgl. NIESE S.IV-X.

5) Vgl. MESCERSKIJ Istorija, S.15-20.

6) Anmerkungen und wissenschaftliche Redaktion von ANDRE VAILLANT, Ubersetzung in das Französische von PIERRE PASCAL.

7) Vgl. Istorija, S. 166 .

8) Einen ausführlichen und vollständigen Uberblick über die bisherige Literatur bringen MESCERSKIJ (Istorija, S. 5-15) und KRULL (zur Bildsprache, S. 8-33).

9) Siehe Literaturverzeichnis.

10) Ebenda.

11) Ebenda.

12) Vgl. Issledovanie. Vvedenie, S. 3: "... Ot nekotorych predpolozenij...v nastojał̌ee vremja prichoditsja...otkazyvat sjan.

13) Siehe Literaturverzeichnis.

14) IнгоYL. Band 1, S. 9-10.

15) Issledovanie. Vvedenie, S. 8-9.

16) Vgl. ebenda, S. 9-10.

17) Vgl. ebenda. Vyvody, s. 3.

18) Ebenda, S. 4.

19) Vgl. Istorija, S. 64-65.

20) Vgl. ebenda, S. 107.

21) Issledovanie. Vyvody, S. 2.

22) Vgl. S. 87.

23) Griechische Lehnsyntax, S. 177.

24) Istorija, S. 51-64.

25) Vgl. oben, Einleitung S. 19.

26) MESCERSKIJ Istorija, S. 56-57.

27) Vgl. ebenda, S. 47-50.

28) Ebenda, S.50. 
11. Anmerkungen zum 1. Kapitel:

1) Vgl. oben S. 20 .

2) Sur la version, S. 56.

3) Vgl. SREZnEVSkIJ Materialy. Tom I, Sp. 373.

4) Vgl. K voprosu, S. 252.

5) Vgl. dazu die deutsche Ubersetzung des griechischen Textes: "und starb...Er war in der Tat sehr glücklich zu preisen, und in keiner Weise ließ er es $z u$, das Geschick seinetwegen $z u$ tadeln" (BAUERNFEIND-MICHEL Flavius Josephus. Band 1, S. 18) . - PASCAL (ISTRIN Tome 1, S. 9) übersetzt das altrussische 'bezb ponosa' durch 'sans reproche'.

6) Der entgegengesetzte sinn beider Fassungen ist textkritisch nicht aus anderen Lesarten zu erklären.

7) Nur an einer einzigen stelle findet sich auch im Altrussischen eine Nachvollziehung der Oratio obliqua.

8) Vgl. Im Griechischen 'Otน, is in derselben Funktion (KUHNER-GERTH Teil 2. Band 2, S. 555-556).

9) Hier ist sich der Ubersetzer anscheinend nicht klar uber das objekt der Rede. Erst im zweiten Satzglied schwenkt er auf die logisch richtige zweite Person (der Redner spricht zu Antipater selbst) ein.

10) Griechische Lehnsyntax, S. 180.

11) KOTLJAREVS'KYJ, IVAN Eneida. KYiv 1968, S. 12.

12) Vgl. AN SSSR Grammatika russkogo jazyka. Tom 2. Kniga 2, S. 5: "Neopredelenno-liCnymi nazyvajutsja odnosostavnye predložnija, $v$ kotorych glavnyj દlen vyražen glagolom $v$ forme 3-go lica množestvennogo tisla ... i oboznałaet dejstvie, soverకaemoe neopredelennymi licami".

13) Vgl. unten S. 94 . 
111. Anmerkungen zum 2. Kapitel:

1) ISTRIN La prise. Tome 2, S. 255-278; MESCERSKIJ Istorija, S. 532-565.

2) Das von ISTRIN erstellte und nach mündlicher Auskunft MESCERSKIJs den vollständigen Wortschatz der 'Iudejskaja vojna' umfassende Wörterverzeichnis, das sich im Leningrader Archiv der Akademie der Wissenschaften der UdSSR (fond 332, opiś 1, Nr. 7) befindet, konnte ich trotz meiner Bemühungen an Ort und stelle aus archivtechnischen Gründen nicht einsehen.

3) Nach SCHUMANN (Die griechischen Lehnbildungen, S.1) liegt bei einem Wort eine Lehnbedeutung dann vor, "... wenn es nach fremdsprachlichem Vorbild eine zusätzliche Bedeutung annimmt".

4) Vgl. Materialy. Tom 3, Sp. 188-192 und 428-431.

5) Vgl. ebenda. Tom 2, Sp. 596.

6) Vgl. Drevne-greCesko-russkij slovar. Tom 1, S. 984.

7) Jie Verwendung von 'ovbnb' bereits an früherer stelle im rext $(M 179,20)$ dürfte eine spätere Korrektur des Ubersetzers sein.

8) Lehnbildungen, S. 1 .

9) An späterer Stelle wird dieser Terminus bereits durch 'chorjugvi' wiedergegeben (N 441,5/M 361, 15).

10) Jgl. Materialy. Tom 2, Sp. 1146; LICHACEV Slovo, S. 44: -... oba poly sego vremeni".

11) SREZNEVSKIJ (Materialy. Tom 1, Sp. 331) bringt hierfür ein Beispiel aus der Povest' vremennych let.

12) Jgl. Grečeskie paralleli, S. 157.

13) Alle drei in den Wörterbüchern von SREZNEVSKIJ und MIKLOsICH nicht verzeichnet.

14) Igl. etwa 'Sbsudo-chranilbnica' (SREZNEVSKIJ Materialy. Iom 3, Sp. 833). 
15) Bei diesem Wort handelt es sich nach SCHUMANNs Terminologie (Vgl. Lehnbildungen, s. 3) in der Ubersetzung um einen Lehngliedzusatz, da das altrussische 'torpenie' allein das griechische Kompositum bereits vollständig ersetzen würde, während es nun "... gewissermassen anderthalbnal wiedergegeben" wird.

16) GreČeskie paralleli. S. 163.

17) Ebenda, S. 162. 
1V. Anmerkungen zum 3. Kapitel:

1) Vgl. KUHNER-GERTH Teil 2. Band 1, S. 290-291.

2) Vgl. ebenda, S. 291.

3) Ebenda, S. 293. - Vgl. Schwyzer S. 70.

4) Vgl. SREZNEVSKIJ TOM 1, Sp. 269-270, 291; - Siehe auch M 184, 28-29: vladet1 na Ierusalimb 1 na okrbstnaja (ohne genaue Entsprechung im Original).

5) Vgl. KUHNER-GERTH Teil 2. Band 1, S. 293; BLASS-DEBRUNNER S. 99 .

6) Vgl. VONDRAK S. 245-246.

7) $\mathrm{Zu}$ 'iže utekకe' vgl. unten, "H. Artikel".

8) Vgl. Materialy. Tom 1, Sp. 885-886.

9) Siehe unten, S. 64-65.

10) BERNSTEJN S. 86 .

11) Iz zapisok po russkoj grammatike. Tom 1-2. Charkov 1888, S. 457 (hier zit. nach BERNSTEJN S. 86 .

12) Vgl. Materialy. Tom 1, Sp. 1032.

13) Vgl. ebenda. Tom 2, Sp. 762 .

14) Vgl. BLASS-DEBPUNNER S. 102: SCHWYZER S. 82-82.

15) KUHNER-GERTH Teil 2. Band 1, S. 318.

16) Oðerki, S. 213 .

17) Vgl. KOPYLENKO o jazyke, S. 175 ff.

18) Vgl. KUHNER-GERTH Teil 2. Band 1, S. 43.

19) Siehe unten, S. 60.

20) Vgl. FRUCHTEL S. 130. - Vgl. auch SCHWYZER S. 84-86.

21) Vgl. AN SSSR Grammatika russkogo jazyka. Tom 1, S. 126127; TAUSCHER-KIRSCHBAUM Grammatik der russischen Sprache, S. 69.

22) S. 53 .

23) BLASS-DEBRUNNER S. 105. 
24) FRANZ KREBS Die Präpositionsadverbien in der späteren historischen Gräcität. Teil 1, S. 7. (Mứnchen 1884).

25) Siehe unten, S. 59.

26) Vgl. Istorija, S. 75 .

27) Siehe diesen, unten S. 68-69.

28) Vgl. den Ablativus limitationis im Lateinischen.

29) KUHNER-GERTH Teil 2. Band 1, S. 404-405.

30) Ebenda, S. 405

31) Ebenda, S. 430 .

32) Ebenda.

33) Ebenda, S. 432.

34) Vgl. SREZNEVSKIJ TOM 2, Sp. 1591-1592.

35) ISTRIN (La prise de Jérusaleme. Tome 1, S. 10, Anm. 4) hält 'zavistiju' für eine falsche Lesart von 'zavisti' und beruft sich dabei auf den griechischen Text. VAILLANT (ebenda, S. 11, Anm. 2) erklärt es als Dativform eines Nominativs 'zavistie' und belegt das mit analogen Beispielen aus dem Codex Suprasliensis.

36) Vgl. BLASS-DEBRUNNER S. 124.

37) KUHNER-GERTH Teil 2. Band 1, S. 435.

38) Ebenda, S. 438; vgl. FRUCHTEL S. 138.

39) LOMTEV S. 247. - Vgl. BERNSTEJN S. 159-160.

40) Vgl. FRUCHTEL S. 138.

41) Vgl. die lateinische Wendung 'tecto recipere'.

42) Siehe S. 54.

43) KUHNER-GERTH Teil 2. Band 1, S. 417.

44) Vgl. OCerki, S. 254

45) Vgl. ebenda, S. 337.

46) KUHNER-GERTH Teil 2. Band 1, S. 331.

47) Ebenda, S. 332. 
48) Ebenda.

49) In Anlehnung an dieses Modell durfte auch die Ubersetzung eines zusammengesetzten Wortes durch den Objekts-

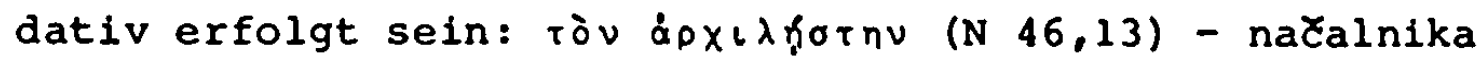
razboinikomb (M 184, 31-32).

50) Bei den Ausdrücken des Herrschens steht im Altrussischen der Objektsdativ auch dann, wenn das Griechische als Objekt der Nominalform eines tränsitiven Verbums den Akkusativ hat. In diesem Falle wird letztere durch ein vollwertiges Nomen wiedergegeben; z.B.:

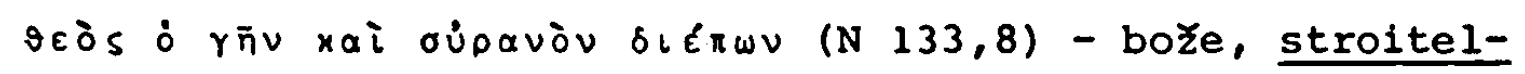
ju nebu $i$ zemli (M 230, 6-7).

51) KUHNER-GERTH Teil 2. Band 1, S. 332.

52) An einer stelle steht hier auch der possessive Dativ in der Ubersetzung: 'Yoxavoũ ourátno $(N 60,5)$ - Urkanu dకCi (11 190, 24-25).

52a)Vgl. SCHWYZER S. 122.

53) Vgl. KUIINER-GERTH Teil 2. Band 1, S. 354; FRUCHTEL S.142.

54) Mitunter steht auch im Griechischen statt des Genitivs der Dativ (vgl. KUHNER-GERTH Ausf. Grammatik. Teil 2. Band 1. S. 355); er wird dann konsequent durch den Instrumen-

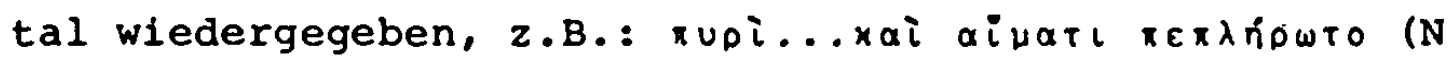
283, 9-10) - i ispolnisja... ognemb i kroviju (M 295, 28).

55) Vgl. FRUCHTEL S. 143.

56) Vgl. ebenda, S. 145

56a)Vgl. AN SSSR Grammatika russkogo jazyka. Tom 2. Kniga I, S. 147 .

57) Vgl. OzEgov slovaŕ russkogo jazyka, S. 583 und 593.

58) Vgl. Materialy. Tom 2, Sp. 1492-1493.

59) Vgl. ebenda, Sp. $1411^{\circ}$ und 1416.

60) KUHNER-GERTH Teil 2. Band 1, S. 391.

60a) VONDRAK Vergleichende slavische Grammatik. Band 2, S.251. 
60b) In der Ubersetzung ist hier ein echter Komparativ ('preze', 'paðe') eingetreten, wodurch die Verwendung des Gen. comp. noch berechtigter erscheint.

60c) Im Altrussischen ist hier sinngemäß ein Komparativ im Sinne von "eher" (etwa 'bole') zu ergänzen.

61) KUHNER-GERTH Teil 2. Band 1, S. 394.

62) Ebenda.

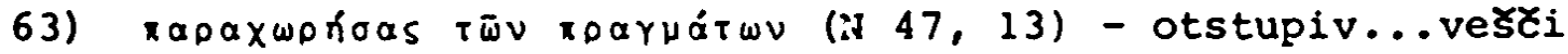
(M 185, 16-17).

63a) Vgl. den Ausdruck des Genitivus separationis in der Sprache des NT mit Hilfe dieser Präposition (BLASS-DEBRUNNER S. 116$)$.

64) FRUCHTEL S. 151.

65) KUHNER-GERTH Teil 2. Band 1, S. 385.

66) Der Instrumental steht im Altrussischen auch dann, wenn das Griechische statt des Genitivs ein Temporaladverb hat: z.B.: vuxtós (N 60, 11) - nostiju (M 190, 29).

67) KUHNER-GERTH Teil 2. Band 1, S. 385.

68) Der bloße Lokativ zur Ortsbezeichnung erscheint $M$ 176,15: zatvori Antoniiskêmb synu (ohne genaue griechische Entsprechung).

69) Vgl. LOMTEV OCerki, S. 315.

70) KUHNER-GERTH Teil 2. Band 1, S. 448.

71) Vgl. die deutsche Präposition "vor" in räumlicher und zeitlicher Funktion sowie ihre Entsprechungen im Griechischen $(x \circ \delta)$, Lateinischen (ante) und in den einzelnen Slavinen. Im Französischen ist bereits eine Differenzierung eingetreten in "avant" (zeitlich) und "devant" (rüumlich).

72) Vgl. GERKULES Staroslavjanskie predlogi, S. 650.

73) Vgl. ebenda. 
74) Vgl. KUHNER-GERTH Teil 2. Band 1, S. 450; GERKULES S. 314: "...teper soðetanie predloga s imenem javljaetsja ustojとivym sozetaniem obeich morfem, mezdu nimi net upravlenija.

75) KUHNER-GERTH Teil 2. Band 1, S. 456.

76) Vgl. BLASS-DEBRUNNER S. 132.

77) Ebenda.

78) KUHNER-GERTH Teil 2. Band 1, S. 456.

79) Vgl. GERKULES S. 336.

80) Vgl. LOMTEV S. 324.

80a) Vgl. ebenda, S. 327: "...Konstrukcija 's pljus roditel' nyj padež upotrebljalas ... v znađenii vozvyకennogo mesta, otkuda osuకčestvljaetsja dejstvie".

81) KUHNER-GERTH Teil 2. Band 1, S. 457.

82) GERKULES S. 337.

83) LOMTEV S. 343.

84) Vgl. KUHNER-GERTH Teil 2. Band 1, S. 459; SREZNEVSKIJ Tom 1, Sp.

85) KUHNER-GERTH Teil 2. Band 1, S. 456.

86) Vgl. ebenda.

87) $\dot{x}$ wurde im Griechischen ursprünglich nur mit den Verba der Bewegung verbunden (vgl. ebenda, S. 456).

88) Vgl. Drevnegreそesko-russkij slovar. Moskva 1958, Tom I, S. 476 .

89) Ebenda.

90) LOMTEV S. 303.

91) Materialy. Tom 2, Sp. 1646.

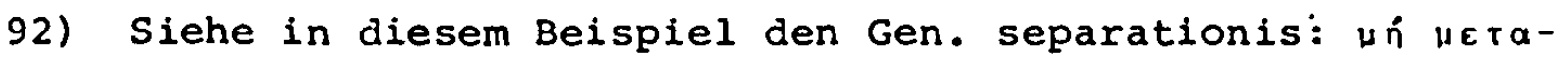

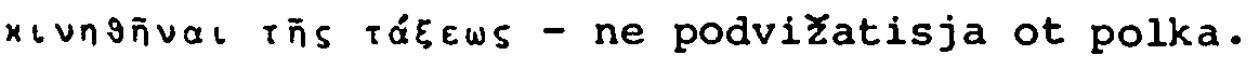

93) Vgil. KƯHNER-GERTH Teil 2. Band 1, S. 456. 
94) Vgl. ebenda, S. 453.

94a) Vgl. KtHNER-GERTH Teil 2. Band 1, S. 353.

94b) Vgl. BLASS-DEBRUNNER S. 137.

94c) ołerki, S. 305.

95) Vgl. KUHNER-GERTH Teil 2. Band 1, S. 402.

96) Vgl. LOMTEV S. 420.

97) Vgl. KUHNER-GERTH Teil 2, Band 1, S. 402.

98) Wenn $\delta$ ixa in der Bedeutung 'abgesehen von, außer' steht, gibt es der Ubersetzer auch durch 'krome' m. Genitiv

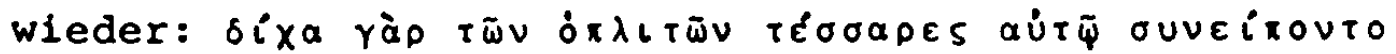
uUpıács (N 416, 14-15) - idjachu bo po nemb, kromer oružnikb, 4 tomy (N 350,11$)$.

99) KUHNER-GERTH Teil 2. Band 1, S. 462.

100) Vgl. LOMTEV S. 373.

101) Vgl. KUHNER-GERTH Teil 2. Band 1, S. 462.

102) Vgl. LOMTEV S. 373.

103) Vgl. ebenda, S. 309.

104) Vgl. Staroslavjanskie predlogi, S. 323 - es kann hier aber im Altrussischen auch eine andere präposition gewählt werden, die die Art der Abhängigkeit genauer bezeichnet: Év doxarais övta xai póvols (N 470, 22-23) ZivuకCei pod voschyకCeniemb i pod krovoprolitiemb (M $374,19-20)$.

105) Vgl. ebenda, S. 324.

106) KUHNER-GERTH Teil 2. Band 1, S. 468.

107) Vgl. GERKULES S. 318; LOMTEV S. 321.

108) Stellt das durch $\varepsilon i$ s ausgedrückte räumliche $z i e l$ einen nicht näher umgrenzten Raum dar, kann dafür in der Ubersetzung auch po $\mathrm{m}$. Dativ eintreten, das nach LOMTEV ( $S$. 309) ein "...neopredelennoe napravlenie $v$ predelach ukazannogo imenem sußCestvitel'nym prostranstva" anzeigt. 


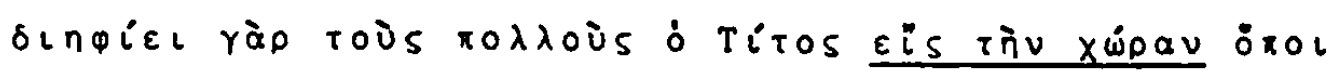

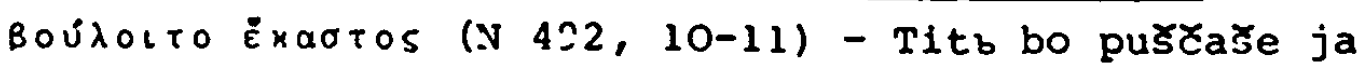
po zemljam, idě̃e kto chotjase (11 386, 30-31).

109) GERKULES S. 319.

110) Vgl. ebenda.

111) Vgl. Materialy. Tom 1, Sp. 1386.

112) Vgl. GERKULES S. 322 .

113) KUHNER-GERTH Teil 2. Band 1, S. 470.

114) Vgl. ebenda, S. 488 .

115) BLASS-DEBRUNNER, S. 150.

116) Diese Entsprechungsregel wird jedoch durchbrochen, wenn einerseits bei Sachobjekten die Richtung betont wird, andererseits beim persönlichen objekt die Feindseligkeit der Handlung ausgedrilkt werden soll (vgl. S. 87).

117) KUHNER-GERTH Teil 2, Band 1, S. 481.

118) LOMTEV S. 315.

119) KUHENER-GERTH Teil 2, Band 1, S. 481.

120) Ebenda, S. 482 .

121) Vgl. oben Seite 79.

122) MESCERSKIJ trennt grundlos den Nebensatz durch Punkt $\mathrm{ab}$.

123) Vgl. KUHNER-GERTH Teil 2. Band 1, S. 475.

124) Ebenda, S. 476.

125) Vgl. aus der Nestorchronik: "...ide oleg na greky" (GUDZIJ S.7).

126) KUHNER-GERTH Teil 2. Band 1, S. 477.

127) Vgl. GERKULES S. 290; LOMTEV S. 239-240.

128) Vgl. AN SSSR Grammatika russkogo jazyka. Tom 1, S.125.

129) KUHNER-GERTH Teil 2, Band 1, S. 478.

130) Vgl. ebenda.

131) Ebenda, S. 479. 
132) Vgl. ebenda, S. 480.

133) Vgl. ebenda.

134) Vgl. SREZNEVSKIJ Tom 2, Sp. 982; - im Altkirchenslavischen war 'po' distributiv nur mit dem Dativ verbunden worden (vgl. GERKULES S. 335).

135) Grammatik, S. 145.

136) In der Vorlage ist hier $x \alpha$ rá zweifellos räumlich verwendet, doch ist auch die zugehörigkeit zumindest unterschwellig ausgedrickt; der Ubersetzer betont mehr die letztere.

137) Vgl. KUHNER-GERTH Teil 2. Band 1, S. 505.

138) Vgl. ebenda, S. 507.

139) Vgl. Grammatik, S. 144-145.

140) KUHNER-GERTH Teil 2. Band 1, S. 505.

141) Vor allem bei den Verba des Gebens, Nehmens und Habens: - vgl. die im Deutschen durch "mit" übersetzten griechischen Partizipia $\bar{x} x \omega \nu$, ar $\omega \nu, \phi \varepsilon \rho \omega \nu, \lambda \alpha \beta \dot{\omega} \nu$ (vgl. KUHNER-GERTH Teil 2. Band 2, S. 87).

142) Vgl. ebenda. Teil 2. Band 1, S. 506.

143) Vgl. GERKULES S. 342-343.

144) Vgl. KUHNER-GERTH Teil 2. Band 1, S. 508.

145) Vgl. ebenda.

146) Vgl. ebenda, S. 492-493.

147) Vgl. ebenda, S. 492.

148) Vielleicht hat in diesem Beispiel der erste Teil des Ausdrucks, wo $\pi \varepsilon \rho i$ in Objektsfunktion mit dem Genitiv steht, den Kasus des zweiten Gliedes beeinflußt.

149) Vgl. KUHNER-GERTH Teil 2. Band 1, S. 522.

150) Vgl. Seite 29 .

151) Vgl. Der persönliche Agens beim Passiv, S. 89.

152) Der Ausdruck des Passivs im Altrussischen, S.66. 
153) Ebenda.

154) Vgl. ebenda. Quellenverzeichnis, S. IV.

155) $\Pi i \pi \tau \varepsilon \iota \nu$ wird im Griechischen hier als Passivum $z u$ einem Aktivum "fallen" verstanden.

156) Zur Verwendung des Dativs anstelle des Genitivs bei der Bezeichnung des Agens vgl. KUHNER-GERTH Teil 2 , Band 1, S. 524 .

157) Vgl. ebenda, S. 522.

158) Vgl. ebenda, S. 523.

159) Ebenda, S. 524.

160) Vgl. LOMTEV S. 306.

161) KUHNER-GERTH Teil 2. Band 1, S. 509.

162) Vgl. ebenda, S. 509-510.

163) Vgl. LOMTEV S. 324.

164) Vgl. KUHNER-GERTH Teil 2. Band 1, S. 510.

165) Ebenda.

166) Vgl. ebenda, S. 512.

167) Vgl. SREZnEVSKIJ Tom 1, Sp. 1329, und Tom 2, Sp. 1502.

168) KUHNER-GERTH Teil 2, Band 1, S. 495.

169) Vgl. LOMTEV S. 309.

170) KUHNER-GERTH Teil 2. Band 1, S. 496.

171) Vgl. ebenda, S. 503.

172) Vgl. LOMTEV S. 315.

172a) 'plenenia' ist hier Plural.

173) Vgl. KUHNER-GERTH Teil 2. Bard 1, S. 502.

174) Vgl. ebenda, S. 503.

175) Vgl. ebenda, S. 504.

176) Vgl. ebenda, Teil 2 Band 2, S. 347.

177) Vgl. POSPELOV Izmenenija, S. 7-8. 
178) Vgl. KUHNER-GERTH Teil 2. Band 2, S. 399; SCHWYZER S. 639 .

179) Vgl. FASMER / VASMER / ÉtimologiCeskij slovaŕ. Tom 2, S. $118-119$.

180) SŁONSKI Die Ubertragung der griechischen Nebensatzkonstruktionen, S. 7 .

181) Vgl. Griech. Lehnsyntax, S. 180.

182) Ebenda, S. 182.

183) Izmenenija, S. 20.

184) KUHNER-GERTH Teil 2. Band 2, S. 354.

185) Vgl. ebenda, S. 355 und 358.

185a) Der altrussische Konditional ist hier durch den Irrealis bedingt.

186) Vgl. ebenda, S. 349.

187) Vgl. ebenda, S. 516.

188) Vgl. ebenda, S. 533.

189) Griechische Lehnsyntax, S. 157; - vgl. hierzu J. U. M. BAUEROVI: "..Konstantín a pruni prekladatele zvolili vhodne slovanské slovo jako staly ekvivalent reckých spojek $\varepsilon i, \dot{\varepsilon} a \dot{v}(\alpha \tilde{v})$, totiz ASTE, a uživali ho k jejIch tlumoðeni i $v$ takových (méne Castých) funkcich, do kterých by se vlastnim vyvojem jister nebylo dostalo (Staroslovernske ASTE, S. 157).

190) KUHNER-GERTH Teil 2. Band 2, S. 372.

191) Vgl. BRÄUER zur Entwicklung der ursprünglichen Abwehrsätze, S. 79 .

192) Vgl. KUHHER-GERTH Teil 2. Band 2, S. 377.

193) Vgl. ebenda, S. 372.

194) Untersuchungen zum Konjunktiv, S. 22.

195) Vgl. KUHNER-GERTH Teil 2. Band 2. S. 390.

196) Vgl. ebenda, S. 391. 
197) In einem einzigen Fall steht auch bloßes 'da':

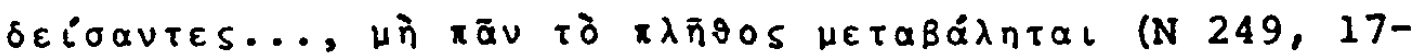
19) - ubojałasja, da preložitsja narod kb Agripe (M 284, 27).

198) Vgl. Zur Entwicklung der ursprünglichen Abwehrsätze, S. 79; - das von ihm noch angeführte zweite Beispiel (M 356, 21-22) hat im Original als Entsprechung keinen Abwehr-, sondern einen indirekten Fragesatz.

199) Vgl. ebenda.

200) Vgl. ebenda, S. 66-67.

201) KUHNER-GERTH Teil 2. Band 2, S. 377.

202) Ebenda, S. 499.

203) Ebenda, S. 499.

204) Vgl. ebenda.

205) Ebenda, S. 501 .

206) Ebenda, S. 512 .

207) Vgl. BLASS-DEBRUNNER S. 238 .

208) Vgl. KUHNER-GERTH Teil 2. Band 2, S. 501-511.-

Siehe auch KURZOVÁ Zur syntaktischen Struktur, S. 88 : "Der Infinitiv mit $\ddot{w} \tau \tau$ schließt sich nach seiner Funktion und inneren Struktur eindeutig an den Nebensatz an: Eine konjunktionale Partikel verbindet sich mit einer Verbalform mit Prädikatsfunktion, die manchmal sogar explizit ausgedrückt ist."

209) Doch dürte es sich hierbei nicht um einen syntaktischen Gräzismus handeln, da nach LOMTEV (S. 532) diese Konstruktion auch in der Chronikliteratur bezeugt ist. - Vgl. den Gebrauch des Infinitivs zum husdruck modaler Beziehungen im modernen Russisch.

210) Wenn dabei im Griechischen das logische Subjekt ausgedrückt wird, steht es im Akkusativ, so daß der Infinitiv zum AcI wird.

211) Grammatik, S. 239. 
212) Vgl. die deutsche Ubersetzung dieser Stelle durch BAUERNFEIND-MICHEL, die das konsekutive Element mit dem finalen verbinden will: "... und versöhnten sie sich in dem Sinne, daß Aristobulos König sei, Hyrkanos aber die Ehrenstellung, wie sie einem Bruder des Königs zusteht, unter Verzicht auf sonstige Ehren genieBen solle (Flavius Josephus De bello Iudaico. Band I, S. 33).

213) KUHNER -GERTH Teil 2. Band 2, S. 463.

214) Ebenda, S. 464

215) Vgl. S. 125

216) Nach LAVROV (Uslovnye i ustupitel 'nye predloženija, $s$. 81) findet sich 'ože' vor allem in frühen, von der kirchenslavischen Schriftsprache wenig beeinflußten Denkmälern.

217) KUHNER-GERTH Teil 2. Band 2, S. 473.

218) Ebenda.

219) Vgl. ebenda, S. 488 .

220) Ebenda, S. 490; - ebenfalls konzessiv und auch in der Ubersetzung so behandelt ist folgende Konstruktion mit

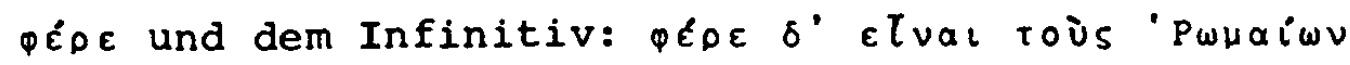

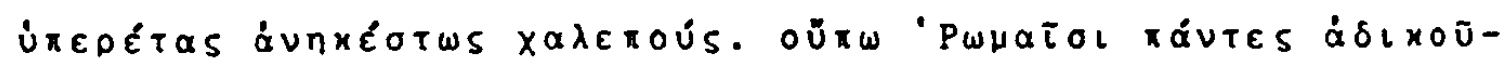
$\sigma เ v$ inās (N 220, 7-8) - aక̌e i rimskyja slugy ljuty sutb, no ne vsi rimljane nasilia vam tvorjat (M 275, 4-5).

221) Vgl. SEONSKI S. 4 .

222) Vgl. KUHINER-GERTH Teil 2. Band 2, S. 445.

222a) Zweifellos vom Griechischen beeinfluBt ist die Verwen-

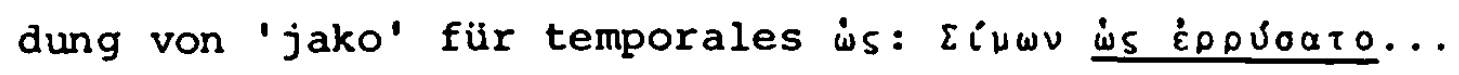

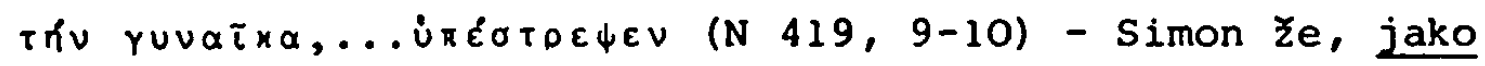
izbavi ženu, sta okolo Ierusalima (M 351, 22).

223) AN SSSR Grammatika russkogo jazyka. Tom 1, Kniga 2, S. 307 .

224) Vgl. LOMTEV S. 505 
225) UÉxol m. Infinitiv (mit konsekutivem Nebensinn) wird auf dieselbe Weise ubersetzt: $\dot{\mu} \mu \alpha \tau i \gamma \omega \sigma \varepsilon \nu, \mu \varepsilon \times \circ \iota . . \tau a$

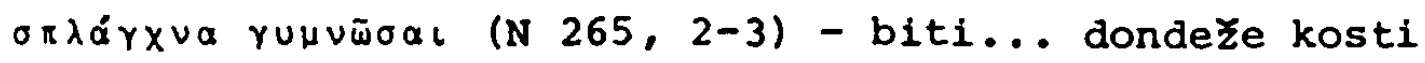
javiకasja (M 289, 36-37).

226) KÜHNER-GERTH Teil 2. Band 2, S. 457. - Vgl. KURZOVA zur syntaktischen struktur, S. 51-52.

227) Steht ausnahmsweise auch im Altrussischen der Infinitiv, so wäre ein Modalverb zu ergänzen: $x a \lambda \delta v \gamma \varepsilon \ldots h v \dot{\varepsilon} \mu \circ i$

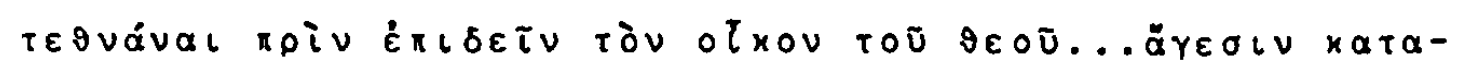
réuovia (N 386, 16-17) - dobre mi esto umrěti, preže daže ne vidřti chrama božia oskvernena (M 330, 4-5); - vgl. BAUERNFEIND-MICHEL (Band 2, s. 27):"...bevor ich... sehen muB".

228) Vgl. oben,s. 76 .

229) Zum Genitiv bei 'preżde' vgl. oben, S. 76.

230) KUHNER-GERTH Teil 2. Band 1, S. 200-201.

231) Den vier griechischen Modi Indikativ, Konjunktiv, Optativ und Imperativ entsprechen im Slavischen die drei: Indikativ, Konditional und Imperativ.

232) KUHNER-GERTH Teil 2. Band 1, S. 204.

233) Vgl. LICHACEV slovo (S.43): "ne lepo li ny bjaset": vgl. dazu die Ubersetzung von RZIGA und SAMBINAGO (Slovo S. 21): "... ne sledovalo 11 by nam".

234) KUHNER-GERTH Teil 2. Band 1, S. 214.

235) Ebenda.

236) Vgl. FRUCHTEL S. 176 .

237) Vgl. im heutigen Russisch die Bildung des Irrealis der Gegenwart (bzw. der zukunft) durch perfektive Verba: "...eta propoved ljubvi radi ljubvi.... esli by mogla imet silu, $v$ konce koncov privela by そelovečestvo $k$ polnomu vymiraniju" (CECHOV Duél 'XVI, zit. n. AN SSSR Gramm. russk. jaz. II, 2, S. 326) und des der vergangenheit durch imperfektive: "...Esli by Marijka ne portila nastroenie, vse bylo by choroso (PANOVA Kruzilicha, Kap. 7: zit. ebenda). 
238) KUHNER-GERTH Teil 2. Band 1, S. 231.

239) Ebenda, S. 233.

240) Ein durch die Textüberlieferung bedingter Fehler ist hier wohl ausgeschlossen, da weder ISTRIN noch MESCERSKIJ eine variierende Lesart anführen.

241) Vgl. KUHNER-GERTH Teil 2. Band 1, S. 237.

242) AN SSSR Grammatika russkogo jazyka. Tom 1, S. 504.

243) KUHNER-GERTH Teil 2. Band 2, S. 98.

244) Ebenda, S. 48 .

245) Vgl. ebenda, S. 50.

246) Vgl. Das syntaktische System, S. 240.

247) "Infinitivu drevne-grełesłogo i latinskogo jazykov pri étich glagolach / = sentiendi / sootvetstvovalo pricastie nastojašego vremeni" (OCerki, S. 72).

248) MESCERSKIJS Interpunktion (Komma nach'ratnych') verstärkt noch die ohnehin durch die Verwendung der Nominativform des Partizips für den Akkusativ gegebene Möglichkeit einer MiBdeutung der Stelle, da man auf diese Weise die beiden Partizipien 'vidjaste' und 'iduste' als gleichberechtigt ansehen könnte, wodurch beim zweiten ein falsches Subjekt unterstellt wïrde. Vgl. dagegen die Ubersetzung PASCALs: "...voyant les guerriers marcher sur eux (ISTRIN Tome 1 , S. 23).

249) Die Weglassung des Partizips ' $\dot{\omega} v$ ' bei Adjektiva in der Funktion einer Kopula ist im Griechischen eine häufige Erscheinung (vgl. KUHNER-GERTH Teil 2. Band 2, S. 101102), deren Nachahmung durch den Ubersetzer nicht verwundert.

250) Vgl. KUHNER-GERTH Teil 2. Band 2, S. 57.

251) "... Als Gräzismus wäre es allenfalls eine analogische Ubertragung der so überaus häufigen Gleichung zwischen dem griechischen und altslavischen Partizip auf diese idiomatische Konstruktion, die im Griechischen ausgeprägter ist" (Griechische Lehnsyntax, S. 183). 
252) Vgl. Ołerki, S. 67 .

253) Hier wird die Unhaltbarkeit der Interpunktion MESCERSKIJS, der Partizip und Verbum durch Komma voneinander trennt, besonders deutlich. Ihm zufolge würden zwei verschiedene Handlungen vorliegen, während es sich in wirklichkeit nur um eine einzige handelt. Vgl. die tbersetzung von PASCAL "...Tel etaient les nombreux conseils qu' il ne cessait de leur donner (ISTRIN Tome 2, S. 197).

254) KUHNER-GERTH Teil 2. Band 2, S. 46.

255) Vgl. die analoge Ubersetzung ins Altkirchenslavische bei KURZ K otáce. Band 7, S. $310 \mathrm{f}$.

256) Vgl. Das syntaktische System, S. 107.

257) Ebenda, S. 109

258) Vgl. BLASS-DEBRUNNER S. 263. - Siehe auch L. NECASEK: "...na rozdil od doby klasické, celkem peそlive se vyhybajlcr tomu, aby podmet vazby genitivu absolutn tho mel nejjaký vztah k jinému elenu vêty, v niż stojr, užrá se genitivu absolutn tho hojne i misto participialnich vazeb spojitých $v$ akusativu nebo dativu, nł̌kdy se objevI i tehdy kdyz vêta uz obsahuje substantivum nebo zájmeno $v$ genitivu, $k$ nemuz by se pak celá vazba spojita mela odnáset"" (Starosolvênské dativnf vazby, S. 14) und "..máme $v$ rectine stejne jako $v$ staroslovĕnకtine absolutnI vazbu participiálni pripojenou $k$ slovesu přisudkovêmu akusativem, jez se souCasne vztahuje $k$ podmetu vazby" (Ebenda, s.19).

258a) Bei diesem Beispiel ist in der tbersetzung eine subjektsverschiebung der Partizipialkonstruktion eingetreten, doch wenn 'unosa' auch nicht mehr das grammatische subjekt ist, so ist doch noch eine starke Verbindung zum Hauptsatz erkennbar, weshalb auch in letzterem ein verbal ausgedrücktes subjekt fehlt.

259) Ebenfalls durch einen Kausalsatz wiedergegeben ist ein finales Part. coni.; der finale Sinn wird dabei gewahrt durch den Einschub des Modalverbs 'choteti' in den Neben-

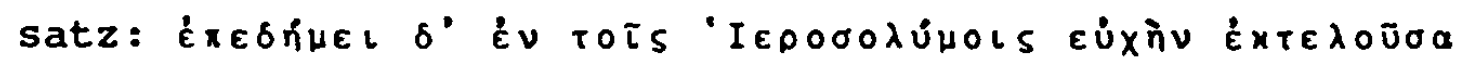


$\tau \bar{\psi} \vartheta \varepsilon \tilde{\varphi}(\mathrm{N} 213,16-17)$ - priłestvie (em.n.Vol.) ei bjaక̌ $\checkmark$ Ierusalimb, pone そ̌e chotjaకe otdati molitvu bogovi (M 231, 14-16).

259a) Im zweiten Glied der Konstruktion wurde dem Ubersetzer die subjektivität des Grundes anscheinend bewuBt und er gibt es deshalb durch wörtliche Rede wieder.

259b) In diesem Beispiel ist auch eine konzessive Bedeutungsnuance enthalten.

260) Vgl. S. 85 .

261) Vgl. KUHNER-GERTH Teil 2. Band 1, S. 185; FRUCHTEL S. 189.

262) Die Partizipialkonstruktionen, S. 17.

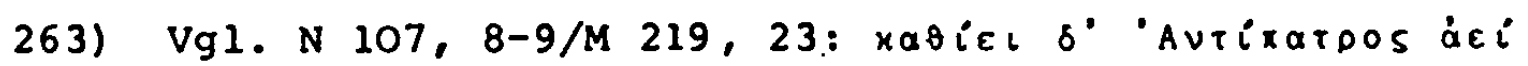

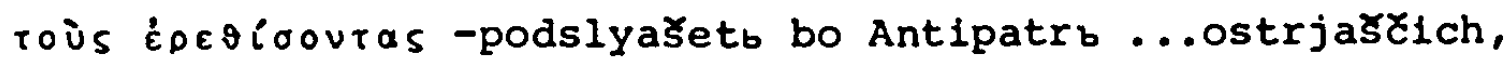
wo im Altrussischen ein nicht näher bestimmtes part.Präs. steht.

264) Hierher würde auch $M 285,5$ gehören: prizyvachu Kestija, da otvorjatb, emu (erg.n.A) vrata, doch handelt es sich bei dieser stelle um eine Fehlinterpretation eines durch is näher bestimmten Partizips zum Ausdruck eines nur scheinbaren Sachverhalts; die Futurform bezeichnet hier im griechischen Text einzig die Handlungszeit (zukunft):

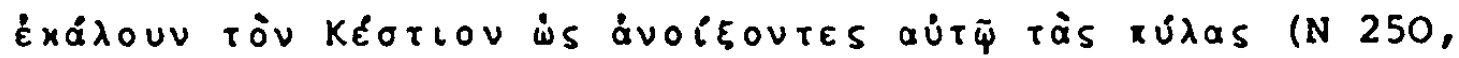
22-251, 1; die Tore werden in Wirklichkeit nicht geöffnet). Die Partizipform des Futurs scheint also vom Ubersetzer automatisch (in diesem Beispiel fälschlicherweise) mit dem Begriff einer Finalität gleichgesetzt worden $z u$ sein.

264a) Subjekt des altrussischen Haupt- und Nebensatzes ist in diesem Beispiel Vespasian, Objekt ('i') der gefangene Josephus.

265) Vgl. LOMTEV S. 64; BIRNBAUM Die Zukunftsumschreibungen, passim.

266) Vgl. oben S. 82. 
267) Vgl. S. 85 .

268) Vgl. KUHNER-GERTH Teil 2. Band 2, S. 87-88.

269) Vgl, ebenda.

270) Die von LESKIEN (Handbuch, S. 364, Nachtrag) als Nachbildung der griechischen Konstruktion bezeichnete verabsolutierte Akkusativform des Partizips kommt in unserem Denkmal (insgesamt 2 Beispiele) nur als Entsprechung für griech. Part. coni. bzw. Gen. abs. vor: tñs xatpíoos

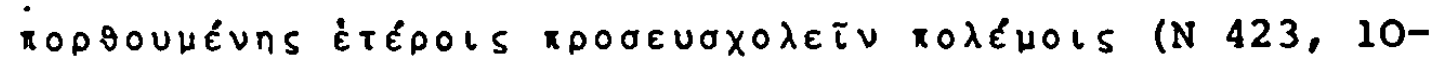

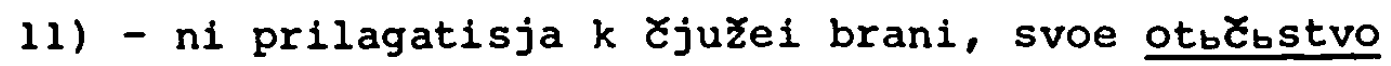
razvoevano suక̌e (M 353, 17-18) und:

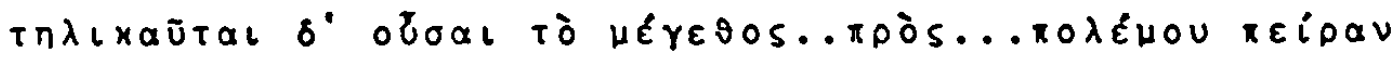

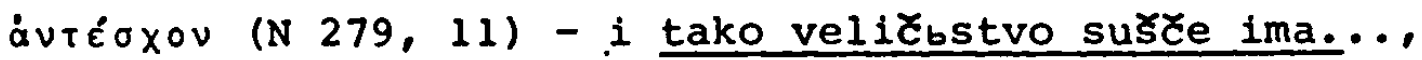
ni v edino vremja oslaběsa protivu brani (M 294, 25-27).

271) In einer Anzahl von Fällen ist die stelle mit dem Acc. abs. einfach weggelassen, wie in folgendem (konzessiven,

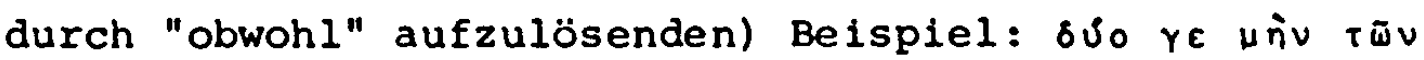

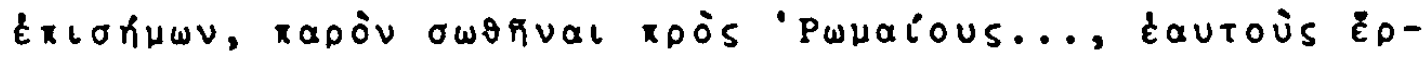

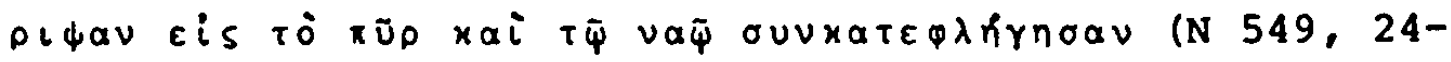
$550,1)$ - dva $₹$ ot marocitych vbvergosasja vo ognb $i$ sъžžena bysta sı corkbvbju (M 419, 10-11).

272) Bei der Ubersetzung eines Acc. abs., der die nicht erfullte Pflicht ausdrückt, steht wie bei der eines einfachen Realis das Imperfekt.

273) KUHNER-GERTH Teil 1, Band 2, S. 290.

274) Vgl. ebenda, Teil 2. Band 1, S. 447.

275) Vgl. die Bezeichnung des Agens bei unpersönlichen Ausdrücken durch den Dativ im modernen Russisch und anderen Slavinen (z.B. dem Polnischen).

276) Vgl. KUHNER-GERTH Teil 1. Band 2, S. 288.

277) Vgl. die Entsprechung von dópatos und 'nevidimb' bei SRESNEVSKIJ (Materialy. Tom 2, Sp. 360).

278) DaB 'nevidimb' hier wirklich noch als Partizip aufgefaßt wird, zeigt die Angabe des Agens im Instrumental. 
279) Vgl. KUHNER-GERTH Teil 1. Band 2, S. 288.

280) Der Unterschied zu einem wirklichen Passiv ist in der Form 'inoplemennikomb' ausgedrückt, das in objektfunktion steht, während beim eigentlichen Passiv zur Agensbezeichnung der Instrumental oder 'ot' stehen müBte.

281) Vgl. KUHNER-GERTH Teil 2. Band 2, S. 6; BLASS-DEBRUNNER S. 237 .

282) Vgl. S. 108 .

283) Vgl. KUHNER-GERTH Teil 2. Band 2, S. 28.

284) Bei den Verba dicendi steht im Griechischen gewöhnlich die Oratio obliqua, die im Altrussischen durch die Oratio recta ersetzt wird (vgl. oben, S. 28).

285) Vgl. oben, Anm. 275; AN SSSR Grammatika russkogo jazyka. Tom 2. Kniga 2, S. 33: "... BezliCnoe predloženie, glavnyj Zlen kotorogo vyražen predikativnym narexiem lodnim ili $v$ sołetanii s infinitivom), možet byt' rasprostraneno dopolneniem $v$ forme datel rogo padeza imeni sustestvitel nogo ili mestoimenija."

286) Vgl. KUHNER-GERTH Teil 2. Band 2, S. 2.

287) Ebenda, S. 37.

288) Den Gebrauch des Dativs beim Prädikatsnomen als sog."vtoroj datel'nyj" bezeichnet LOMTEV (S. 74) als ursprüngliche Norm, die später durch den prädikativen Instrumental verdrängt worden sei.

289) 'odolenniemb' dürfte hier Objektsinstrumental sein.

290) Mit über 10 Beispielen als Entsprechung für einen griechischen Infinitiv ( $\tau$ ò $\xi \tilde{n} v$ ) bildet 'Zivotb! eine Ausnahme, da sonst keine festen Entsprechungen festzustellen sind, sondern der Ubersetzer fallweise ein passendes Substantiv wählt.

291) Hier hat der Ubersetzer auch bei dieser etwas komplizierten griechischen Konstruktion die logischen $\mathrm{Z}$ usammenhänge genau eingehalcen $u$ ù čs às logiscire subjekt behinhaltenden 
Akkusativ des AcI wie einen Subjektsgenitiv durch ein Adjektiv wiedergegeben; auf diese Weise wurden sowohl der sinn der Vorlage wie auch die begrenzten syntaktischen Verbindungsmöglichkeiten des den Infinitiv ersetzenden Substantivs (das nur eine kongruierende Bestimmung $z u$ sich nehmen kann) voll berücksichtigt.

292) Die im klassischen Griechisch durchaus übliche Verwendung von $\dot{\varepsilon} x i$ mit dem Dativ zur Bezeichnung kausaler Verhältnisse (vgl. KUHNER-GERTH Teil 2. Band 1, S.500) kommt sonst im Text kaum vor.

293) Bei diesem Beispiel düfte es sich um eine Verlegenheitslösung handeln, da im Altrussischen ein negativer Nebensatz der Art und Weise vom Ty'P unserer deutschen Wendung "ohne daß" nicht existiert. Vgl. auch die moderne russische Wendung 'bez togo, 'toby', die auch formal einem Finalsatz entspricht.

294) Vgl. KUHNER-GERTH Teil 2. Band 1, S. 594-595; KURZOVA zum Charakter, S. 201.

295) Grammatik, S. 166.

296) K otázce. BS Band 7, S. 323.

297) Vgl. Die Ubersetzungstəchnik. AfslPh Band 31, S. 343.

298) "Nelze vకak souhlasiti s formulácl O. GRthrinthaL, který ...pravr, Že se Ělen překládá participiem syj.... tu jde přece o smysl celého místa (K otázce. BS Band 7, S. 331332).

299) K otázce, BS Band 7, S.333.

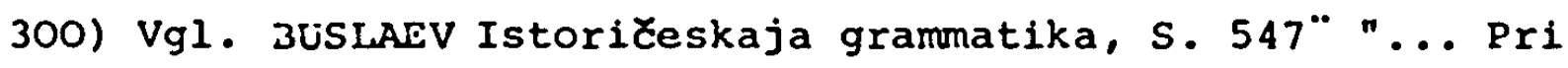
neopredelennom naklonenii 'eze' upotrebljaetsja...v smysle greðeskogo člena".

301) Vgl ebenda; BORKOVSKIJ-KUZNECOV IstoriCeskaja grammatika, S. 474 .

302) ISTRIN faBt den Ausdruck als zum Hauptsatz gehörig auf und setzt keine Satzzeichen. 
303) Vgl. KURZ K otázce. BS Band 7, S. 338.

304) Vgl. oben, S.102. - Vgl. auch N 339, 10-11/M 315, 2627 ( s. oben S. 47), wo dem 'iZe' ein Partizip folgt

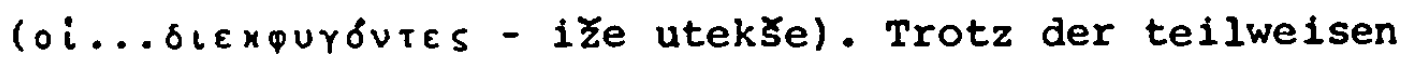
formellen Ubereinstimmung mit den 0.a. "iže"-Konstruktionen durfte es sich hier inhaltlich um eine wiedergabe der Artikelkonstruktion la) handeln, da "iž" hier zweifellos als Nom.plur. aufzufassen ist und somit eine nähere Bestimmung der einfachen Partizipform 'utekłe' darstellt. 


\section{NACHWORT}

Die vorliegende Untersuchung wurde im Juli 1969 von der Philosophischen Fakultät der Universität München als Dissertation angenommen.

Die Anregung $z u$ dieser Arbeit erhielt ich im Sommersemester 1966 von Herrn Professor Dr. Alois Schmaus, der mir jederzeit mit seinem kostbaren Rat zur seite stand und sich liebenswürdigerweise bereit erklärte, die Arbeit in die "Slavistischen Beitrăge" aufzunehmen. Herrn Professor Dr. Alois Schmaus bringe ich hiermit meinen herzlichsten Dank zum Ausdruck.

Besonderen Dank schulde ich ferner den Herren Professoren R.I. Avanesov, Moskau und N.A. MeకCerskij, Leningrad, für ihre Hilfsbereitschaft bei der Beschaffung schwer zugänglicher Literatur und ihren wertvollen wissenschaftlichen Rat, sowie dem Sekretăr des "Institut d' Etudes Slaves", M-r Aslanoff, Paris, für die bereitwillige Uberlassung seltenen Archivmaterials.

Der Großzügigkeit der Studienstiftung des Deutschen Volkes verdanke ich einen vierwöchigen Forschungsaufenthalt in Moskau und Leningrad, der das Voranschreiten meiner Arbeit entscheidend beeinflubte.

Dem Verlag Otto Sagner und dem Redaktor der "Slavistischen Beiträge", Herrn Dr. P. Rehder, München, sei an dieser Stelle für die Veröffentlichung der Arbeit gedankt. 